UNIVERSIDADE DE BRASÍLIA - UnB

INSTITUTO DE GEOCIÊNCIAS - IG

PÓS-GRADUAÇÃO EM GEOCIÊNCIAS APLICADAS

ANÁLISE DO POTENCIAL DE SÉRIES TEMPORAIS DE ÍNDICES DE VEGETAÇÃO (NDVI E EVI) DO SENSOR MODIS PARA DETECÇÃO DE DESMATAMENTOS NO BIOMA CERRADO

Adriana Panhol Bayma

Dissertação de Mestrado № 079

Brasília - DF

Março de 2015 
UNIVERSIDADE DE BRASÍLIA - UnB INSTITUTO DE GEOCIÊNCIAS - IG

PÓS-GRADUAÇÃO EM GEOCIÊNCIAS APLICADAS

\section{Análise do potencial de séries temporais de índices de vegetação (NDVI e EVI) do sensor MODIS para detecção de desmatamentos no bioma Cerrado}

Dissertação de Mestrado apresentada ao Programa de Pós-Graduação em Geociências Aplicadas da Universidade de Brasília, como requisito parcial para obtenção do título de Mestre. Área de concentração: Geoprocessamento Aplicado à Análise Ambiental

Adriana Panhol Bayma

Orientador: Edson Eyji Sano

Brasília - DF

Março de 2015 


\section{BANCA EXAMINADORA}

Edson Eyji Sano - Orientador

Embrapa Cerrados

Adriana Chatack Carmelo

Universidade de Brasília - Examinador Interno

Roberto Rosa

Universidade Federal de Uberlândia - Examinador Externo

Brasília - DF

Março de 2015 


\section{FICHA CATALOGRÁFICA}

Bayma, Adriana P.

Análise do potencial de séries temporais de índices de vegetação (NDVI e EVI) do sensor MODIS para detecção de desmatamentos no bioma Cerrado / Adriana Panhol Bayma; orientação de Edson Eyji Sano. Brasília, 2015

99p.

Dissertação de Mestrado (M) - Universidade de Brasília / Instituto de Geociências, 2015.

1. Sensoriamento remoto; 2. Assinaturas temporais; 3. Savana tropical; 4. Imagens de satélite.

Bayma, Adriana Panhol. Análise do potencial de séries temporais de índices de vegetação (NDVI e EVI) do sensor MODIS para detecção de desmatamentos no bioma Cerrado. Brasília, Instituto de Geociências, Universidade de Brasília, 2015, 99p. Dissertação de Mestrado.

\section{CESSÃO DE DIREITOS}

NOME DO AUTOR: Adriana Panhol Bayma

TÍTULO DA DISSERTAÇÃO DE MESTRADO: Análise do potencial de séries temporais de índices de vegetação (NDVI e EVI) do sensor MODIS para detecção de desmatamentos no bioma Cerrado.

\section{GRAU: Mestre ANO: 2015}

É concedida à Universidade de Brasília permissão para reproduzir cópias desta tese de doutorado e para emprestar ou vender tais cópias somente para propósitos acadêmicos e científicos. Esse direito poderá ocorrer somente após a publicação dos artigos contidos no documento. $O$ autor reserva-se a outros direitos de publicação e nenhuma parte desta dissertação de mestrado pode ser reproduzida sem a autorização por escrito do autor. 
Uma mente que se abre a uma nova ideia jamais voltará ao seu tamanho original.

- Albert Einstein-

As dificuldades são como as montanhas.

Elas só se aplainam quando avançamos sobre elas.

-Provérbio japonês- 
Aos meus pais Nilson e Aparecida (em memória), muito do que sou devo a vocês; ao meu irmão Anderson que acompanha toda minha trajetória; Ao Marcelo, meu companheiro de longa data, sempre me apoiando em minhas escolhas com sua amizade e amor; Às nossas filhas Amanda e Melissa, por serem o que são: tudo o que faço é inspirado na existência de vocês. 


\section{AGRADECIMENTOS}

A Deus, que me permitiu chegar até aqui, com capacidade de trabalho para dar prosseguimento aos estudos num período da vida em que não é tão fácil retomá-los.

Ao meu orientador, Prof. Edson Sano, pela paciência, dedicação, empenho e tempo dispensados, nas viagens de campo, nas horas de orientação, nas revisões, nos ensinamentos dados. Apesar de conhecê-lo há alguns anos por força do trabalho, após o privilégio dessa breve convivência passei a respeitá-lo e admirá-lo ainda mais, não só por poder ter podido aprender um pouquinho de seu conhecimento e de sua sabedoria, como também por ter conhecido o tamanho de sua capacidade de trabalho, da grandiosidade e da generosidade de sua pessoa. Muito grata pela parceria!

Aos Professores Dra. Adriana Chatack e Dr. Roberto Rosa por aceitarem o convite de participarem da banca e a quem agradeço as contribuições efetuadas.

Ao Marcelo por entender minhas ausências e pelo incentivo para continuar os estudos desde sempre e pelo apoio em casa para suprir minha falta. Às minhas filhas, por também compreenderem minhas ausências e me apoiarem na minha escolha.

Aos professores do programa de Pós-Graduação em Geociências Aplicadas da UnB, especialmente aos Professores Paulo Meneses, Tati e Roig, pelas oportunidades de convivência acadêmica e pelos ensinamentos que foram dados com um idealismo que somente os professores podem ter.

Ao meu amigo que fiz há alguns anos durante a especialização na UnB, Gervásio (Gegê) que sempre foi um incentivador para que eu continuasse o que começamos lá trás. Obrigada por me convidar para "andar contigo".

Aos colegas do Programa de Pós-Graduação em Geociências Aplicadas da UnB, que dividiram alegrias, angústias, além de bons momentos e boas ideias durante o curso, Hiago, Felipe, Pereira, Simone. Às novas amigas Karen, Lílian e Omolabake, que foram pontos de apoio fundamentais durante o período da escrita da dissertação. Com certeza as coisas foram menos penosas com a disponibilidade de vocês em ajudar e na troca de experiências. 
Ao Serjão, que mantém a "casa" em ordem, o Laboratório de Sensoriamento Remoto e Análise Espacial - que foi minha casa nos últimos meses - pela disponibilidade e pela dedicação.

À Elane Borges, que me ajudou a vencer os primeiros obstáculos, que por vezes pareciam intransponíveis, do programa TIMESAT.

Aos companheiros das viagens a campo, Raquel Trevizam e Daniel Freitas (que por coincidência foram meus colegas de especialização também), especialmente pelos bons momentos vivenciados nas viagens de campo (alguns deles um pouco tensos). Ao Gustavo Bediaga, pela disposição em viajar para LEM, dirigindo por horas a fio, passando aperto nas estradas em condições tão precárias.

À Thaise e ao Heleno (Embrapa Cerrados), pela companhia na viagem de campo a Mateiros-TO e também pelo apoio na Embrapa Cerrados.

À lona'i Moura, colega de trabalho no MMA, que sempre me incentivou a fazer um mestrado.

Às minhas amigas de décadas, Andréa, Kátia e Meumã (minha paciente e inspirada revisora!), por vibrarem com minhas escolhas (e participarem delas, inclusive esta) e por todo esse tempo de amizade.

Ao Projeto Cerrado Jalapão (MMA/GIZ), que proporcionou a realização das viagens de campo;

Ao CSR/IBAMA, na pessoa do Daniel (o mesmo lá de cima!) e do Rodrigo, que sempre deram uma mão quando era preciso e também pela disponibilização de bases de dados.

À Universidade de Brasília, que me proporcionou uma graduação, uma especialização e, agora, o mestrado. Orgulho de ser sua aluna! 


\section{RESUMO}

O Cerrado é reconhecido como a savana mais biodiversa do mundo e localiza-se na porção central do país, onde se encontram as principais nascentes de importantes bacias hidrográficas brasileiras. É um bioma caracterizado por uma ampla variedade de formações fisionômicas, determinadas por fatores como solos, disponibilidade hídrica e pela forte sazonalidade climática. Apesar de sua importância ambiental, o Cerrado vem sofrendo rápidas alterações de origens antrópicas, devido à crescente pressão para a abertura de novas áreas produtivas, sendo que aproximadamente $50 \%$ de sua área já foram desmatadas. A utilização de índices de vegetação de imagens de satélite proporciona obtenção de informações sobre mudanças no uso e cobertura da terra ao estimar parâmetros biofísicos relacionados ao estado da vegetação, entre eles, padrões sazonais. Este estudo teve por objetivo avaliar o uso de séries temporais do índice de vegetação normalizada pela diferença (NDVI) e do índice de vegetação realçado (EVI) do sensor Moderate Resolution Imaging Spectroradiometer (MODIS) para detecção de desmatamentos no bioma Cerrado. Esses dois índices estão disponíveis no produto MOD13Q1, com resolução espacial de $250 \mathrm{~m}$. O período considerado foi de 2000 a 2013. A área de estudo foi composta por quatro municípios: Jataí/GO, Luís Eduardo Magalhães/BA, Mateiros/TO e São Miguel do Araguaia/GO. As séries temporais foram suavizadas pelo filtro de logística dupla, disponível no programa TIMESAT. Em seguida, foram extraídas as assinaturas temporais representativas das formações vegetacionais encontradas em cada município nos trabalhos de campo realizados em 2013 e 2014 (formações florestais nos municípios de Jataí e São Miguel do Araguaia; formações savânicas nos quatro municípios; e formações campestres em Mateiros). Testes estatísticos de Kruskal-Wallis indicaram que não é possível definir assinaturas temporais únicas para cada formação vegetacional e para todo o Cerrado. Dessa forma, foram definidas duas assinaturas temporais para as formações florestais, duas assinaturas temporais para as formações savânicas (uma para Jataí e São Miguel do Araguaia e outra para Luís Eduardo Magalhães e Mateiros) e uma assinatura temporal para as formações campestres. Em cada uma dessas assinaturas, foram delimitados os limiares de desmatamento, que são os valores mínimos de EVI e NDVI abaixo dos quais podem ser considerados como desmatamento (por exemplo, os limiares de desmatamento do EVI para formações florestais de Jataí e São Miguel do Araguaia foram, respectivamente, 0,38 e 0,64). Em seguida, foram selecionados alguns pixels do MODIS que apresentaram, em algum ponto das séries temporais, índices abaixo dos limiares preestabelecidos. Validação com imagens dos satélites Landsat e ResourceSat (resoluções espaciais de $30 \mathrm{~m}$ e $24 \mathrm{~m}$, respectivamente) indicaram que é possível detectar desmatamento em séries temporais de formações florestais e savânicas. O NDVI mostrou 
maior sensibilidade que o EVI para detectar desmatamento (magnitude da queda dos valores de NDVI nos pontos de desmatamento foi maior do que a de EVI).

Palavras-Chave: Sensoriamento remoto, assinaturas temporais, savana tropical, imagens de satélite. 


\begin{abstract}
The Cerrado is recognized as the most biodiverse savanna in the world and is located in the central portion of the country, where we find most of the sources of water springs of major Brazilian river basins. Cerrado is characterized by a wide variety of vegetation formations, determined by factors such as soil variety, water availability and strong climatic seasonality. Despite its environmental importance, the Cerrado is experiencing rapid land conver changes due to increasing pressure for new areas for food and energy production, with $50 \%$ of its area already deforested. Satellite-based vegetation indices can provide information about land use and land cover changes or estimates about biophysical parameters related to the state of the vegetation, including seasonal patterns. This study aimed to evaluate the use of time series of Normalized Difference Vegetation Index (NDVI) and Enhanced Vegetation Index (EVI) from the Moderate Resolution Imaging Spectroradiometer (MODIS) sensor for deforestation detection in the Cerrado biome. These two indices are available in the MOD13Q1 product, with spatial resolution of $250 \mathrm{~m}$. The time period considered was from 2000 to 2013. The study area consisted of four municipalities: Jataí/GO, Luís Eduardo Magalhães/BA, Mateiros/TO and São Miguel do Araguaia/GO. The time series were smoothed by the double logistic filter available in the TIMESAT program. Then, we extracted representative temporal signatures of vegetation formations found in each municipality during the field work conducted in 2013 and 2014 (forestlands in the municipalities of Jataí and São Miguel do Araguaia; shrublands in the four municipalities and grasslands in Mateiros). Kruskal-Wallis statistical tests indicated that it is not possible to obtain unique temporal signatures for each vegetation formation and for the entire Cerrado. Accordingly, we defined two temporal signatures for forestlands, two temporal signatures for shrublands (one for Jataí and São Miguel do Araguaia and another for Luis Eduardo Magalhães and Mateiros) and one temporal signature for grasslands. In each of these signatures, deforestation thresholds were defined, which correspond to the minimum values of EVI and NDVI below of which can be considered as deforestation (for example, the deforestation thresholds of EVI and for forestlands of Jataí and São Miguel do Araguaia were, respectively, 0.38 and 0.64 ). Then we selected some MODIS pixels showing, at some point in the time series, values lower than the predetermined thresholds. Validation with Landsat and Resourcesat satellite images (spatial resolution of $30 \mathrm{~m}$ and $24 \mathrm{~m}$, respectively) indicated that it is possible to detect deforestation in time series of forestlands and shrublands. NDVI showed higher sensitivity than EVI to detect deforestation (magnitude of the decrease in NDVI values at the points of deforestation was higher than that from EVI).
\end{abstract}

Keywords: Remote sensing, temporal signatures, tropical savanna, satellite images. 


\section{LISTA DE FIGURAS}

Figura 2.1 - Sistema de referência de cenas do sensor MODIS, com a localização do tile h10v13. Fonte: NSIDC (2013)............................................ 25

Figura 2.2 - Produto MOD 13: NDVI (à esquerda) e EVI, abrangendo a América do Sul. Fonte: Soares et al. (2007) ................................................... 31

Figura 3.1 - Fluxograma metodológico das principais etapas de trabalho ............. 35

Figura 3.2 - Mapa de localização das áreas de estudo no bioma Cerrado (municípios de Jataí/GO, Luís Eduardo Magalhães/BA, Mateiros/TO e São Miguel do Araguaia/GO) e localização do tile h13......................... 36

Figura 3.3 - Cubo temporal 3D das imagens MODIS ……………………....... 38

Figura 3.4 - Localização dos pontos de visita de campo nos municípios de Jataí/GO, Luís Eduardo Magalhães/BA, Mateiros/TO e São Miguel do Araguaia/GO

Figura 3.5 - Fotografias panorâmicas de campo ilustrando plantio de milho em Jataí (a), formação savânica em Luís Eduardo Magalhães (b), formação campestre em Mateiros (c) e pastagem cultivada com Brachiaria em São Miguel do Araguaia (d)

Figura 3.6 - Recorte de imagem Landsat-8 de Jataí/GO (composição colorida RGB/564) mostrando uma coordenada GPS de campo correspondente à formação florestal (Cerradão).

Figura 4.1 - Dados originais e filtrados de séries temporais de EVI de formações florestais de São Miguel do Araguaia (a), formações savânicas de Luís Eduardo Magalhães (b) e formações campestres de Mateiros (c)

Figura 4.2 - Dados originais e filtrados de séries temporais de NDVI de formações florestais de São Miguel do Araguaia (a), formações savânicas de Luís Eduardo Magalhães (b) e formações campestres de Mateiros (c)

Figura 4.3 - Precipitação total anual dos municípios estudados. Fonte: INMET (2015)

Figura 4.4 - Séries temporais de EVI para as formações florestais (a), savânicas (b) e campestres (c), encontrados nos municípios de Jataí/GO, Luís Eduardo Magalhães/BA, Mateiros/TO e São Miguel do Araguaia/GO, filtrados pelo método de logística dupla, disponível no programa TIMESAT

Figura 4.5 - Séries temporais de NDVI para as formações florestais (a), savânicas (b) e campestres (c), encontrados nos municípios de Jataí/GO, Luís Eduardo Magalhães/BA, Mateiros/TO e São Miguel do Araguaia/GO, filtrados pelo método de logística dupla, disponível no programa TIMESAT. 
Figura 4.6 - Relação entre NDVI e EVI referente às séries temporais (período: 2000-2013) das formações vegetacionais naturais dos municípios de Jataí (JAT), Luís Eduardo Magalhães (LEM), Mateiros (MAT) e São Miguel do Araguaia (SMA)

Figura 4.7 - Teste de Shapiro-Wilk para verificação da normalidade dos valores de EVI das formações florestais dos municípios de Jataí (a) e São Miguel do Araguaia (b), das formações savânicas dos municípios de Jataí (c), Luís Eduardo Magalhães (d), Mateiros (e) e São Miguel do Araguaia (f) e das formações campestres de Mateiros $(\mathrm{g})$.

Figura 4.8 - Teste de Shapiro-Wilk para verificação da normalidade dos valores de NDVI das formações florestais dos municípios de Jataí (a) e São Miguel do Araguaia (b), das formações savânicas dos municípios de Jataí (c), Luís Eduardo Magalhães (d), Mateiros (e) e São Miguel do Araguaia ( $f$ ) e das formações campestres de Mateiros (g).

Figura 4.9 - Séries temporais de EVI e de NDVI de um ponto em Jataí (latitude: S 1758 54,79; longitude: W 5141 37,54) com correspondentes limiares de desmatamento de uma formação florestal.

Figura 4.10 -Séries temporais de EVI e de NDVI de um ponto em São Miguel do Araguaia (latitude: S 1320 42,46; longitude: W 4958 52,29) com correspondentes limiares de desmatamento de uma formação florestal.

Figura 4.11 -Séries temporais de EVI e de NDVI de um ponto em Luís Eduardo Magalhães (latitude: S 1159 27,50; longitude: W 4558 48,16) com correspondentes limiares de desmatamento de uma formação savânica.

Figura 4.12 - Séries temporais de EVI e de NDVI de um ponto em Jataí (latitude: S 1759 7,84; longitude: W 5142 39,07) com correspondentes limiares de desmatamento de uma formação savânica.

Figura 4.13 - Séries temporais de EVI e de NDVI de um ponto em São Miguel do Araguaia (latitude: S 139 15,89; longitude: W 502 8,34) com correspondentes limiares de desmatamento de uma formação savânica

Figura 4.14 - Séries temporais de EVI e de NDVI de um ponto em Mateiros (latitude: S 1027 21,11; longitude: W 462 47,75) com correspondentes limiares de desmatamento de uma formação savânica.

Figura 4.15 - Séries temporais de EVI e de NDVI de um ponto em Mateiros (latitude: S 1019 41,44; longitude: W 470 59,99) com correspondentes limiares de desmatamento de uma formação campestre. 


\section{LISTA DE TABELAS}

Tabela 2.1 - Especificações do sensor MODIS ........................................... 25

Tabela 2.2 - Bandas do sensor MODIS e suas aplicações ............................ 26

Tabela 2.3 - Produtos MODIS e potenciais de uso ....................................... 28

Tabela 3.1 - Dados referentes às campanhas de campo realizadas nos quatro municípios considerados nesse estudo (total de pontos visitados no campo: 126). FLO = Formação florestal; SAV = Formação savânica; $\mathrm{CAM}=$ Formação campestre CA = Cultura agrícola; e PC = Pastagem cultivada

Tabela 3.2 - Datas das imagens dos satélites Landsat e ResourceSat utilizadas para analisar o desempenho dos limiares de desmatamento relativos a séries temporais do MODIS EVI e NDVI

Tabela 4.1 - Avaliação da qualidade dos pixels utilizados na composição das médias representativas das formações fisionômicas por município. $0=$ dado bom; 1 = dado marginal; 3 = dado com influência de cobertura de nuvens. A categoria 2 (neve/gelo) não ocorre nos quatro municípios em questão

Tabela 4.2 - Estatística básica das séries temporais representativas dos municípios estudados. JAT = Jataí; LEM = Luís Eduardo Magalhães; MAT = Mateiros; SMA = São Miguel do Araguaia; FLO = formações florestais; $\mathrm{SAV}=$ formações savânicas; $\mathrm{CAM}=$ formações campestres.....

Tabela 4.3 - Teste Kruskal-Wallis de igualdade de médias de valores de EVI (série temporal de 2000 a 2013) para a mesma formação vegetacional e diferentes municípios. JAT = Jataí; LEM = Luís Eduardo Magalhães; MAT = Mateiros; e SMA = São Miguel do Araguaia. Ho = séries temporais são estatisticamente iguais

Tabela 4.4 - Teste Kruskal-Wallis de igualdade de médias de valores de NDVI (série temporal de 2000 a 2013) para a mesma formação vegetacional e diferentes municípios. JAT = Jataí; LEM = Luís Eduardo Magalhães; MAT = Mateiros; e SMA = São Miguel do Araguaia. Ho = séries temporais são estatisticamente iguais.

Tabela 4.5 - Valores mínimos de EVI e de NDVI para as formações fisionômicas das áreas estudadas 


\section{LISTA DE SIGLAS}

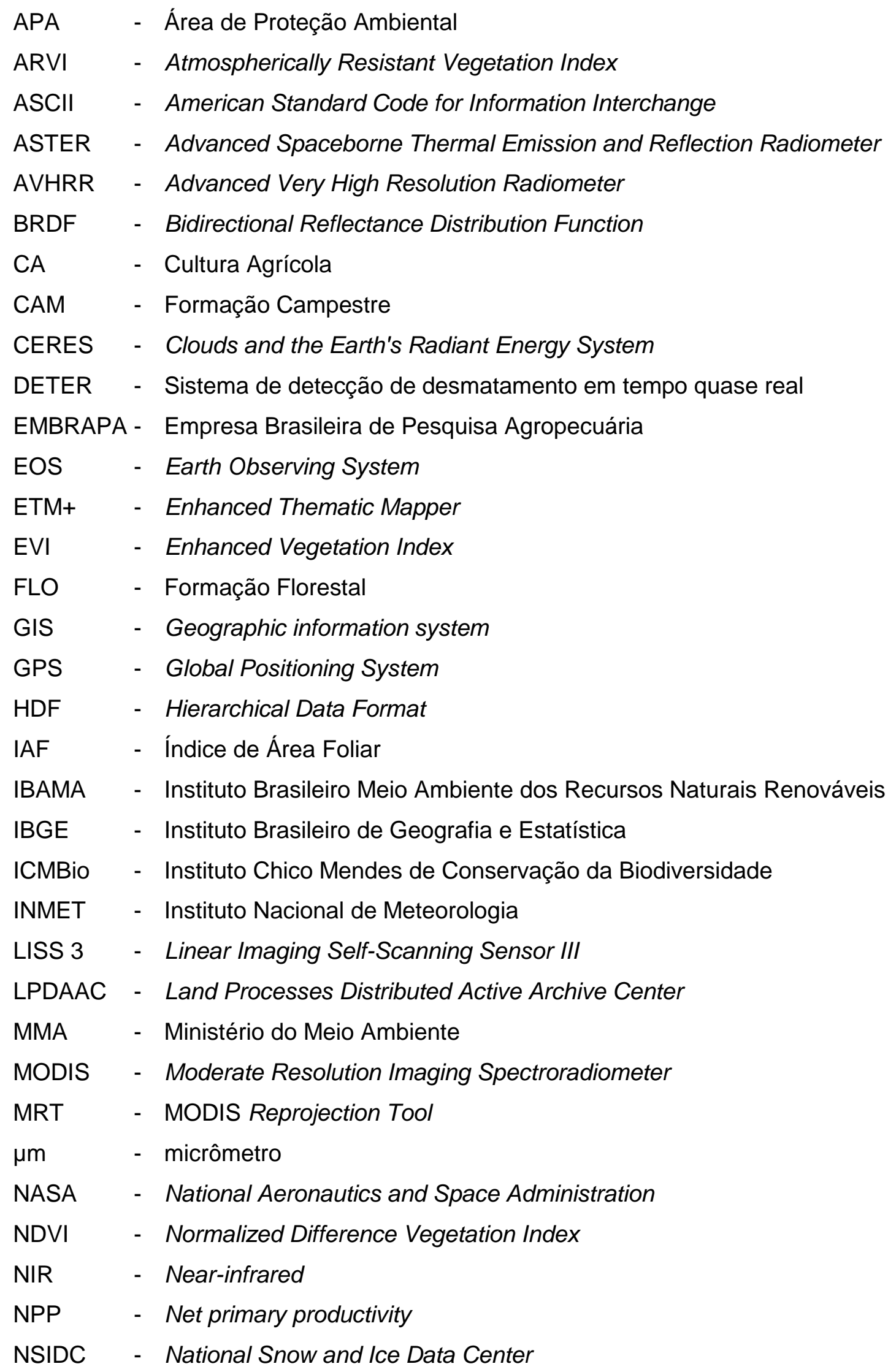


OLI - Landsat 8 Operational Land Imager

PVI - Perpendicular Vegetation Index

QA - Quality Assessement

SAV - Formação Savânica

SAVI - Soil Adjusted Vegetation Index

SEGPLAN - Secretaria de Estado de Gestão e Planejamento do Estado de Goiás TIFF - Tagged Image File Format

TM - Thematic Mapper

UTM - Universal Transversa de Mercator

WGS - World Geodetic System 


\section{SUMÁRIO}

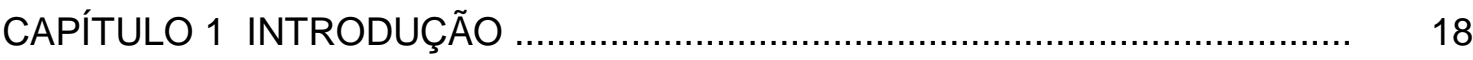

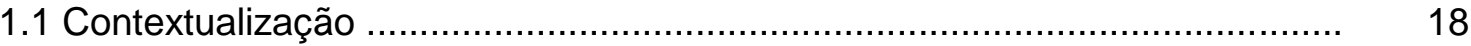

1.2 Objetivos ..................................................................................... 21

CAPÍTULO 2 FUNDAMENTAÇÃO TEÓRICA ……………….......................... 22

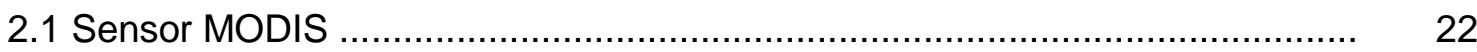

2.2 Índices de vegetação .............................................................................. 29

2.3 Séries temporais ............................................................................ 32

CAPÍTULO 3 MATERIAIS E MÉTODOS …………………............................

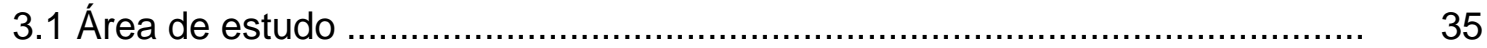

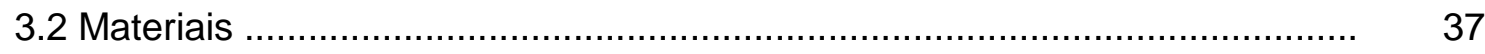

3.3 Campanhas de campo .................................................................. 38

3.4 Assinaturas temporais do MODIS EVI e NDVI

representativas de cada formação vegetacional ......................................... 41

3.5 Limiares de desmatamento ..........................................................................

CAPÍTULO 4 RESULTADOS E DISCUSSÃO ……............................................ 46

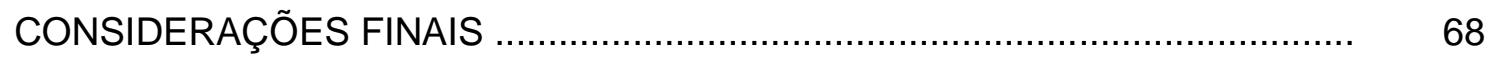

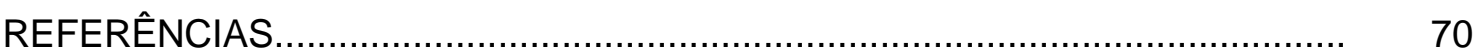

ANEXO - Relatório fotográfico das expedições de campo, realizadas nos municípios Jataí/GO, Luís Eduardo Magalhães/BA, Mateiros/TO e São Miguel do Araguaia/GO..78 


\section{CAPÍTULO 1}

\section{INTRODUÇÃO}

\subsection{CONTEXTUALIZAÇÃO}

O Brasil é apontado como um dos 17 países considerados megabiodiversos, ou seja, que reúnem mais de $70 \%$ de toda a biodiversidade do planeta (MITTERMEIER et al., 1999) e onde habita mais da metade da população mundial (BUREAU, 2014). Especificamente, o País abriga $13 \%$ de todas as espécies do mundo, equivalente a 1,8 milhão de espécies (LEWINSOHN et al., 2005). Parte desse percentual encontra-se no bioma Cerrado, que responde por $5 \%$ da diversidade global (DIAS, 1992) e por aproximadamente 20 a $50 \%$ do número total de espécies brasileiras, dependendo do grupo taxonômico considerado (MACHADO et al., 2004).

Com sua área core situada na porção central do País, em uma região de ocorrência de planaltos e chapadas, cujas altitudes variam de 300 a 1700 m (AB' SÁBER, 2003), o bioma Cerrado desempenha papel importante como fonte de recursos hídricos superficiais do Brasil e de parte da América do Sul. Assim ocorre exatamente por ocupar as partes mais altas das bacias hidrográficas que compõem essas regiões (LIMA e SILVA, 2007), onde nascem os rios que formam seis das principais bacias brasileiras: Paraná, Atlântico - Trecho Leste, Atlântico-Trecho Norte/Nordeste, Tocantins, São Francisco e Amazonas.

Com uma área de 203,6 milhões de hectares (IBGE, 2004), o bioma Cerrado é um ecossistema complexo, com mosaicos de formações campestres, arbustivas e arbóreas e com flora e fauna bem adaptadas à acentuada sazonalidade climática - seis meses de estação seca e seis meses de estação chuvosa (EITEN, 1993). Essa ampla variedade de fatores bióticos, além de outros abióticos como solo, relevo e topografia, conferem, ao bioma, elevada biodiversidade. De acordo com Mendonça et al. (1998), o número de plantas vasculares existente no Cerrado é superior ao encontrado na maioria das regiões do mundo, sendo aqui encontradas mais de 7.000 espécies de plantas herbáceas, arbustivas, arbóreas e cipós, das quais quarenta e quatro por cento é endêmica, elevando o Bioma ao patamar de savana mais rica do mundo (KLINK e MACHADO, 2005). Também por sua alta riqueza, alto endemismo e atual estado de conservação, Myers et al. (2000) incluíram o Cerrado entre os 25 hotspots para conservação no mundo, pois, além de apresentar extrema abundância de espécies endêmicas, tem sofrido enormes perdas de habitat.

Em magnitude, o Cerrado é o bioma brasileiro que mais sofreu alterações com a ocupação humana nas últimas três décadas, devido principalmente à crescente pressão para a abertura de novas áreas para a produção de carne, grãos e etanol para exportação, o 
que coloca em risco a sobrevivência de muitas espécies e a integridade de seus habitat (DIAS, 1994; MACHADO et al., 2004).

Outros fatores que têm contribuído de forma expressiva para a ocupação agrícola do Cerrado são a facilidade no emprego de mecanização, propiciada pelo relevo predominantemente plano da região (com declives suaves, geralmente menores do que $3 \%$ ) e pela boa estabilidade de agregados do solo, como também a existência de boas condições de profundidade e a boa oferta de água (precipitação média anual superior a $1.000 \mathrm{~mm}$ por ano), possibilitando a prática de agricultura de sequeiro (LOPES e GUILHERME, 1994). Dados derivados de imagens do satélite Landsat de 2009-2010 mostraram que aproximadamente $49 \%$ da cobertura vegetal original do Cerrado foram suprimidas (IBAMA, 2010). A despeito da forte ameaça de desmatamento e de iniciativas de monitoramento anual do desmatamento no Cerrado por parte do Ministério do Meio Ambiente (MMA) e do Instituto Brasileiro do Meio Ambiente e dos Recursos Naturais Renováveis (IBAMA), não existe ainda, para o Cerrado, um sistema operacional de monitoramento do desmatamento em tempo quase real que permita subsidiar as atividades de fiscalização no campo de desmatamentos ilegais (FERREIRA et al., 2007).

Devido a características como alta periodicidade na aquisição de imagens e possibilidade de imageamento de grandes áreas, as imagens de satélite permitem monitorar alterações na vegetação de forma contínua no tempo e no espaço. Nesse sentido, a utilização de dados de sensoriamento remoto é marcadamente útil no monitoramento em larga escala das alterações que têm ocorrido nos diversos ecossistemas que compõem o bioma Cerrado. Os mapeamentos temáticos derivados de imagens de satélite fornecem informações espaciais e quantitativas sobre dinâmicas de ocupação e transformações ambientais, permitindo a definição mais precisa de ações e políticas públicas para conservação e recuperação do referido bioma.

Muitas iniciativas de mapeamento da cobertura vegetal do bioma Cerrado têm sido realizadas por instituições governamentais federais e estaduais, por institutos de pesquisa e por organizações não-governamentais e em diferentes escalas (MANTOVANI e PEREIRA 1998; EVA et al., 2004; MACHADO et al., 2004; KRONKA et al., 2005; SANO et al., 2008, 2010; SCOLFORO e CARVALHO, 2006; FERREIRA et al., 2007), a maior parte delas com a utilização de dados provenientes de sensores remotos orbitais. No entanto, essas iniciativas, que em sua maioria estão baseadas em análises de imagens de satélite de uma única data, não permitem uma análise mais apurada da dinâmica das mudanças ocorridas na cobertura e no uso da terra.

O fato de essas iniciativas não terem se tornado um sistema que monitore o bioma de forma repetitiva se deve, em grande parte, à dificuldade em monitorar um bioma de mais de 2 milhões de $\mathrm{km}^{2}$, com alta heterogeneidade de fitofisionomias e com marcada 
sazonalidade climática, aspectos que influenciam sobremaneira nas respostas espectrais dessas fitofisionomias, as quais são influenciadas também pela precipitação (FERREIRA et al., 2003; LIESENBERG et al., 2007). Outro fator que tem dificultado a implementação de um sistema de monitoramento para o Bioma, e que tem sido evidenciado em inúmeros estudos, está a dificuldade em discriminar áreas que apresentam comportamento espectral semelhante - como é o caso das tipologias campestres (Campo Limpo e Campo Sujo) com as pastagens (SANO et al., 2007), o que acaba por dificultar sobremaneira a identificação de desmatamentos.

Nessa perspectiva, o uso de séries temporais do sensor Moderate Resolution Imaging Spectroradiometer (MODIS) pode ser considerado de grande valia para a detecção de desmatamentos recentes no Cerrado, em razão de suas características de resolução espacial (250 metros), espectral (36 bandas) e temporal (1-2 dias) (JUSTICE e TOWNSHEND, 2002). Ademais, os produtos do sensor MODIS, especialmente aqueles cujos potenciais de utilização são voltados a estudos relativos a ecossistemas terrestres, são extremamente úteis, pois têm propiciado a análise das transformações e perturbações ocorridas na cobertura vegetal ao longo de mais de 10 anos (VERBESSELT et al., 2012). Nesse aspecto, o desenvolvimento de índices de vegetação, elaborados com o propósito de explorar as propriedades espectrais da vegetação, possibilitou a inferência de parâmetros biofísicos referentes à vegetação de extensas áreas da superfície da Terra, bem como de suas respostas frente à ação de fenômenos geofísicos e à influência antrópica (GINCIENE e BITENCOURT, 2011).

Desta forma, para estudos em escala regional - especialmente os realizados por meio de composições multitemporais -, é possível realizar as análises das mudanças no uso e cobertura da terra por meio de índices de vegetação NDVI (sigla em inglês do termo Normalized Difference Vegetation Index) e EVI (sigla em inglês do termo Enhanced Vegetation Index) do sensor MODIS, os quais são capazes de evidenciar variações sazonais, interanuais e de longo termo de parâmetros estruturais, fenológicos e biofísicos da vegetação (HUETE et al., 2002; CORREIA et al., 2006).

A proposta deste estudo é aportar subsídios para a elaboração de um sistema de detecção de desmatamento em tempo quase real (DETER) para o Cerrado, desenvolvido atualmente por meio de um projeto de cooperação internacional entre os governos do Brasil e da Alemanha (Projeto Cerrado Jalapão), o qual tem proporcionado a realização de parte das atividades para a definição dessa metodologia.

Com base em uma análise multitemporal, as séries temporais do NDVI e EVI poderão evidenciar se as mudanças ocorridas são devidas à sazonalidade climática ocasionada pela alteração no regime de chuvas ou se ocorrem por mudanças no uso da terra de causa (p. ex. desmatamentos) ou, ainda, se são causadas por queimadas. Para 
tanto, torna-se importante avaliar a capacidade de as séries temporais de índices de vegetação NDVI e EVI propiciarem informação suficiente para possibilitar a diferenciação na mudança de comportamento espectral da vegetação, de modo a predizer se houve ou não desmatamento ou alteração nas classes de vegetação nativa e de uso da terra.

Neste trabalho, a análise das séries temporais teve a finalidade de estimar 0 momento em que houve mudança nas assinaturas temporais de fitofisionomias de quatro áreas do Cerrado, as quais poderiam estar associadas a atividades de desmatamento. As alterações detectadas foram confirmadas por meio de análise visual de imagens dos satélites Landsat e ResourceSat, as quais foram conferidas por meio de polígonos de desmatamentos detectados recentemente.

\subsection{OBJETIVOS}

O objetivo geral deste estudo é avaliar o uso de séries temporais dos índices de vegetação NDVI e EVI do sensor MODIS para detecção de desmatamentos no bioma Cerrado.

Como objetivos específicos, têm-se:

- Estruturação de um banco de dados contendo séries temporais (período 2000-2013) do MODIS EVI e NDVI de quatro municípios do Cerrado.

- Definição de assinaturas temporais representativas de classes de cobertura vegetal natural encontradas nos quatro municípios.

- Definição de limiares de desmatamento por formação vegetacional. 


\section{CAPÍTULO 2}

\section{FUNDAMENTAÇÃO TEÓRICA}

Nesta seção, serão abordados os principais aspectos relativos a características do sensor MODIS, índices de vegetação e séries temporais.

\subsection{Sensor MODIS}

O sensoriamento remoto é uma tecnologia largamente utilizada atualmente para levantamentos da superfície terrestre em escala global e periódica, auxiliando efetivamente o monitoramento das mudanças das feições terrestres (MENESES e ALMEIDA, 2012). No entanto, a modelagem das dinâmicas globais necessita de uma grande gama de informações, e, por esse motivo, devem ser coletadas sistematicamente durante um longo período de tempo, de maneira a representar apropriadamente cada região da superfície terrestre, oceanos e atmosfera (LATORRE et al., 2003). Assim, o uso de sensores de alta resolução temporal propicia a observação de fenômenos terrestres de forma contínua, permitindo o monitoramento, modelagem e avaliação das informações coletadas (JUSTICE et al., 1998).

Os métodos utilizados em sensoriamento remoto possibilitam a realização de medições dos estados dos alvos terrestres por meio de suas características espectrais, ao integrarem as informações sobre os processos físicos e biológicos em diferentes escalas, temporal e espacial. O sensor MODIS possui características que permitem acompanhar as mudanças nos alvos terrestres em alta escala temporal, tendo em vista a disponibilidade de produtos gerados pelo sensor. Apresenta-se, assim, uma oportunidade única de caracterizar as condições da superfície terrestre e a dinâmica da cobertura vegetal de várias regiões do planeta, dada sua repetitividade (JUSTICE e TOWNSHEND, 2002). A aplicação dos produtos MODIS é ampla, tendo sido bastante utilizados em vários estudos para detecção de mudança de comportamento espectral da vegetação, i. e., quando a alteração ocorre seja ela por causas naturais (mudanças devido a fenologia ou sazonalidade) ou antrópicas (desmatamento, fogo, conversão para outros usos), como também em estudos sobre produtividade primária e a respeito de processos biofísicos (ANDERSON et al., 2005; SAKAMOTO et al., 2005; CORREIA et al., 2006; FERREIRA et al., 2007; GALFORD et al., 2008; JACQUIN et al., 2010; COUTO JÚNIOR et al., 2012; ANJOS et al., 2013).

O sensor MODIS é uma dos principais sensores do sistema de observação da Terra de longa duração (EOS - Earth Observing System) da NASA (National Aeronautics and Space Administration), com a finalidade de apoiar pesquisas sobre a dinâmica global e os processos que ocorrem na superfície, por meio de diversos levantamentos da terra, dos 
oceanos e da atmosfera (SOARES et al., 2007). O sensor está a bordo dos satélites TERRA (primeira plataforma EOS, lançada em 1999) e AQUA (lançada em 2002). A plataforma TERRA (EOS AM) realiza observações matutinas, e seus principais objetivos de monitoramento são os estudos de nuvens, aerossóis, balanço de radiação, ciclo de carbono, entre outros. De forma complementar, a plataforma AQUA (EOS PM) observa a superfície terrestre no período da tarde e se destina a estudos sobre o ciclo da água na Terra, coletando informações sobre evaporação dos oceanos, vapor d'água na atmosfera, nuvens, precipitação, umidade na superfície da Terra, gelo, neve, além de outros parâmetros (SOARES et al., 2007). Outros sensores também se encontram a bordo dessas duas plataformas - os mais conhecidos são o ASTER e o CERES.

Além de outros produtos já pré-processados, o MODIS disponibiliza o índice de vegetação normalizado pela diferença (NDVI) e o índice de vegetação realçado (EVI), a cada 16 dias e com resolução espacial de 250 m (HUETE et al., 2002).A alta resolução temporal do MODIS é um aspecto determinante em estudos fenológicos e na discriminação espectral, podendo ser utilizada para obter conhecimento aprofundado a respeito dos ciclos sazonais da vegetação em biomas com forte contraste sazonal, como o Cerrado (LIESENBERG et al., 2007).

As imagens MODIS apresentam resolução espacial de 250, 500 e 1.000 metros e uma resolução espectral que varia de 620 a 14.385 nanometros, num total de 36 bandas. As imagens podem ser geradas com uma frequência quase que diária e cobrem uma vasta área geográfica, o que o torna uma fonte de informações espaciais atrativa e adequada para o monitoramento de grandes regiões (MACHADO et al., 2004). Esse sensor foi idealizado para auxiliar o estudo integrado do funcionamento da terra, oceanos e atmosfera, considerando o planeta como um ecossistema único e inter-relacionado, integrando os seus diversos biomas e ambientes na superfície terrestre.

Uma característica importante do MODIS é a disponibilização dos produtos com correção dos efeitos atmosféricos (nuvens, aerossóis, etc.) e com georreferenciamento (CARVALHO JÚNIOR. et al., 2008). Sua utilidade se mostra mais evidente se levarmos em consideração que, nos levantamentos realizados em escala regional, a ocorrência de nuvens é um fator limitante. Sano et al. (2007) concluíram que, no Cerrado, a possibilidade de obtenção de imagens ópticas na estação chuvosa em que haja menos de $10 \%$ de cobertura por nuvens é inferior a $20 \%$.

Um diferencial desse sensor está em seus produtos que apresentam alta qualidade geométrica das imagens, permitindo o acompanhamento e monitoramento precisos de alterações ocorridas na superfície terrestre (SOARES et al., 2007). Outra característica que confere destaque a esse sensor é sua alta resolução temporal: a disponibilização de informações a cada 1-2 dias permite a realização de estudos em escalas regional e global, 
de maneira mais repetitiva acerca de mudanças ocorridas na superfície terrestre e que requeiram constante monitoramento (por exemplo, desastres ambientais, ocorrências de desmatamento, etc.). Além disso, os dados do MODIS se encontram em um formato readyto-use, ou seja, prontos para o uso, com correção atmosférica, desprovidos de nuvens e georreferenciados (FERREIRA et al., 2007).

Em ambas as plataformas, a aquisição de dados brutos se dá em 12 bits; somente após seu processamento são disponibilizadas aos usuários, em 16 bits. Esses conjuntos de dados são divididos em cinco níveis hierárquicos de processamento (JUSTICE et al., 2002):

- nível 0: equivalem aos dados brutos, sem nenhum tipo de tratamento, não disponíveis aos usuários;

- nível 1A: produtos que contém as 36 bandas utilizadas para dados de entrada de calibração, com inclusão de indicadores de qualidade relacionados à perda de pixel ou existência de pixels de baixa qualidade;

- nível 1B: produtos que apresentam os dados de calibração e geolocalização para as 36 bandas geradas pelo nível 1 ;

- nível 2: produtos que são gerados a partir das radiâncias calibradas dos produtos de nível $2 \mathrm{G}$;

- nível 3: produtos reamostrados que produzem estimativas das variáveis geofísicas para cada grade de localização; e

- nível 4: produtos gerados pela incorporação dos dados MODIS em modelos para se estimarem variáveis geofísicas.

De acordo com Soares et al. (2007), a menor unidade de processamento referente aos níveis $2 \mathrm{G}$, 3 e 4 se configura em um tile, correspondente a uma área geocodificada de $1.200 \mathrm{~km} \times 1.200 \mathrm{~km}$, na projeção senoidal. Na Figura 2.1, são mostrados o sistema de referência das cenas do MODIS e a localização do tile utilizado neste trabalho. 


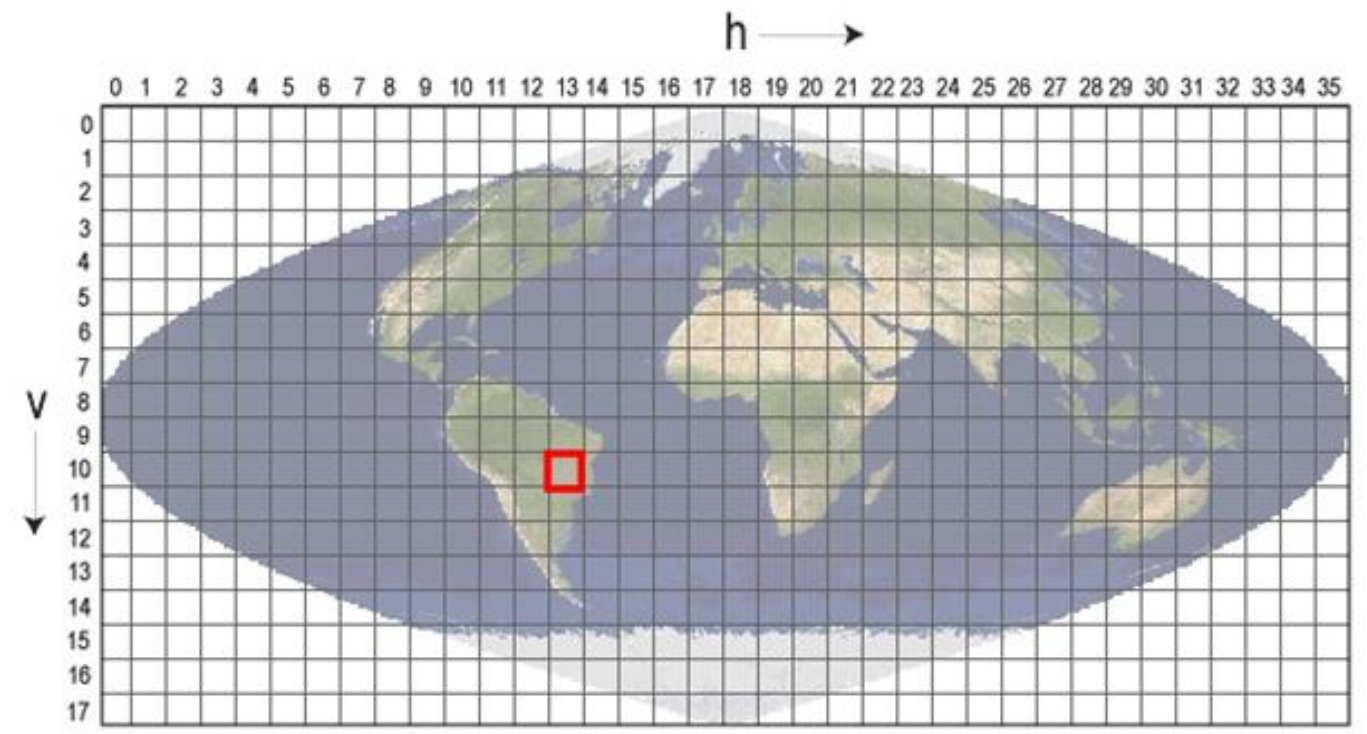

Figura 2.1 - Sistema de referência de cenas do sensor MODIS, com a localização do tile h10v13. Fonte: NSIDC (2013).

As principais informações relativas às plataformas TERRA e AQUA estão sintetizadas na Tabela 2.1.

Tabela 2.1 - Especificações do sensor MODIS.

\begin{tabular}{|c|c|}
\hline Parâmetro & Especificações \\
\hline Órbita & $\begin{array}{l}705 \mathrm{~km} \text {, solssíncrona, polar; cruzamento } \\
\text { equatorial às 10:30 A.M descendente } \\
\text { (TERRA); cruzamento equatorial à 1:30 } \\
\text { P.M ascendente (AQUA) }\end{array}$ \\
\hline Resolução Espectral & $0,4-14,4 \mu \mathrm{m}$ \\
\hline Resolução Espacial & $\begin{array}{l}250 \mathrm{~m} \text { ( } 2 \text { bandas), } 500 \mathrm{~m} \text { ( } 5 \text { bandas), } \\
1000 \mathrm{~m} \text { ( } 29 \text { bandas), a nadir }\end{array}$ \\
\hline Precisão Radiométrica & $\begin{array}{l}5 \% \text { Absoluto, }<3 \mu \mathrm{m} ; 1 \% \text { Absoluto, }>3 \\
\mu \mathrm{m} ; 2 \% \text { de reflectância }\end{array}$ \\
\hline Cobertura de repetição & $\begin{array}{l}\text { Diária, para latitudes }>30^{\circ} \text { e a cada dois } \\
\text { dias, para latitudes }<30^{\circ}\end{array}$ \\
\hline Quantização & 12 bits \\
\hline
\end{tabular}

Fonte: Adaptado de Anderson et al. (2003).

Conforme os dados da Tabela 2.1, é possível observar que o sensor MODIS opera em um largo espectro eletromagnético, em 36 bandas, que varia de 0,4 a 14,4 $\mu \mathrm{m}$. Destaca- 
se que as duas primeiras possuem resolução de $250 \mathrm{~m}$, outras cinco têm $500 \mathrm{~m}$ e as restantes detêm $1 \mathrm{~km}$ de resolução espacial. As bandas 1 a 7, que operam entre 0,405 $\mu \mathrm{m}$ e 2,155 $\mu \mathrm{m}$, têm, como uso principal, as observações da Terra, nuvens, aerossóis, oceanos e vapor d'água atmosférico. As demais bandas se situam na porção do termal, à exceção da banda 26, a qual se localiza na região do infravermelho médio. A Tabela 2.2 apresenta as bandas do sensor MODIS, a largura das bandas e seus principais usos.

Tabela 2.2 - Bandas do sensor MODIS e suas aplicações.

\begin{tabular}{|c|c|c|c|}
\hline Uso Principal & Banda & $\begin{array}{l}\text { Largura da Banda } \\
\qquad(\mu \mathrm{m})\end{array}$ & $\begin{array}{c}\text { Resolução } \\
\text { espacial } \\
\text { (m) }\end{array}$ \\
\hline \multirow{2}{*}{ Terra/nuvens/ aerossóis (limite) } & 1 & $0,62-0,67$ & \multirow{2}{*}{250} \\
\hline & 2 & $0,841-0,876$ & \\
\hline \multirow{5}{*}{$\begin{array}{l}\text { Terra/nuvens/aerossóis } \\
\text { (propriedades) }\end{array}$} & 3 & $0,459-0,479$ & \multirow{5}{*}{500} \\
\hline & 4 & $0,545-0,565$ & \\
\hline & 5 & $1.230-1.250$ & \\
\hline & 6 & $1.628-1.652$ & \\
\hline & 7 & $2.105-2.155$ & \\
\hline \multirow{9}{*}{$\begin{array}{l}\text { Cor do } \\
\text { oceano/fitoplâncton/biogeoquímica }\end{array}$} & 8 & $0,405-0,420$ & \multirow{9}{*}{1.000} \\
\hline & 9 & $0,438-0,448$ & \\
\hline & 10 & $0,483-0,493$ & \\
\hline & 11 & $0,483-0,493$ & \\
\hline & 12 & $0,546-0,556$ & \\
\hline & 13 & $0,662-0,672$ & \\
\hline & 14 & $0,673-0,683$ & \\
\hline & 15 & $0,743-0,753$ & \\
\hline & 16 & $0,862-0,877$ & \\
\hline \multirow{3}{*}{ Vapor d'água atmosférico } & 17 & $0,890-0,920$ & \multirow{3}{*}{1.000} \\
\hline & 18 & $0,931-0,941$ & \\
\hline & 19 & $0,915-0,965$ & \\
\hline \multirow{4}{*}{$\begin{array}{l}\text { Temperatura da superfície / } \\
\text { nuvens }\end{array}$} & 20 & $3.600-3.840$ & \multirow{4}{*}{1.000} \\
\hline & 21 & $3.929-3.989$ & \\
\hline & 22 & $3.929-3.989$ & \\
\hline & 23 & $4.020-4.080$ & \\
\hline \multirow{2}{*}{ Temperatura atmosférica } & 24 & $4.433-4.498$ & \multirow{2}{*}{1.000} \\
\hline & 25 & $4.482-4.549$ & \\
\hline
\end{tabular}




\begin{tabular}{llll}
\hline \multirow{2}{*}{ Vapor d'água de nuvens Cirrus } & 26 & $1.360-1.390$ & \\
\cline { 2 - 3 } & 27 & $6.535-6.895$ & \multirow{2}{*}{1.000} \\
\cline { 2 - 3 } & 28 & $7.175-7.475$ & \\
\hline Propriedade de nuvens & 29 & $8.400-8.700$ & 1.000 \\
\hline Ozônio & 30 & $9.580-9.880$ & 1.000 \\
\hline Temperatura de superfície / & 31 & $10.780-11.280$ & \multirow{2}{*}{1.000} \\
\cline { 2 - 3 } nuvens & 32 & $11.770-12.270$ & \\
\hline \multirow{2}{*}{ Altitude de topo de nuvens } & 33 & $13.185-13.485$ & \\
\cline { 2 - 3 } & 34 & $13.485-13.785$ & \multirow{2}{*}{1.000} \\
\cline { 2 - 3 } & 35 & $13.785-14.085$ & \\
\cline { 2 - 3 } & 36 & $14.085-14.385$ & \\
\hline
\end{tabular}

Fonte: Adaptado de Latorre et al. (2007).

Como mencionado anteriormente, os dados do sensor são apresentados em formato de produtos, divididos de acordo com sua aplicação. No caso dos produtos para ecossistemas terrestres (MODLAND), a Tabela 2.3 apresenta os nomes dos 36 produtos da plataforma TERRA, conforme uma estrutura fornecida no seguinte formato: MOD (referente à plataforma TERRA), seguido de dois algarismos relacionados a uma finalidade, cuja descrição também se encontra na Tabela 2.3. 
Tabela 2.3 - Produtos MODIS e potenciais de uso.

\begin{tabular}{|c|c|}
\hline Produto & Descrição \\
\hline \multicolumn{2}{|c|}{ Relativos à calibração dos dados } \\
\hline MOD01 & Valores de radiância nível 1A \\
\hline MOD02 & $\begin{array}{l}\text { Valores de radiância calibrada e georreferenciada } \\
\text { nível 1B }\end{array}$ \\
\hline \multicolumn{2}{|r|}{ Relativos à atmosfera } \\
\hline MOD04 & Produto de aerossol \\
\hline MOD05 & Total de água precipitável \\
\hline MOD06 & Produto de nuvem \\
\hline MOD07 & Perfil atmosférico \\
\hline MOD08 & Grades de produtos atmosféricos \\
\hline MOD35 & Máscara de nuvens \\
\hline \multicolumn{2}{|r|}{ Relativos ao continente } \\
\hline MOD09 & Reflectância de superfície \\
\hline MOD11 & Temperatura de superfície e emissividade \\
\hline MOD12 & Cobertura da terra/ mudança da cobertura da Terra \\
\hline MOD13 & $\begin{array}{l}\text { Grades de índice de vegetação - máximo NDVI e MVI } \\
\text { integrado }\end{array}$ \\
\hline MOD14 & Anomalias termais, fogo e queima de biomassa \\
\hline MOD15 & $\begin{array}{l}\text { Índice de área foliar e fração de radiação } \\
\text { fotossinteticamente ativa }\end{array}$ \\
\hline MOD16 & Evapotranspiração \\
\hline MOD17 & Fotossíntese líquida e produtividade primária \\
\hline MOD43 & $\begin{array}{l}\text { BRDF - Função de distribuição de reflectância } \\
\text { bidirecional/ albedo }\end{array}$ \\
\hline MOD44 & Mudança de cobertura vegetal \\
\hline \multicolumn{2}{|r|}{ Relativos à criosfera } \\
\hline MOD10 & Extensão da cobertura de neve \\
\hline MOD29 & Extensão de gelo na superfície do mar \\
\hline \multicolumn{2}{|r|}{ Relativos ao oceano } \\
\hline MOD18 & Radiância normalizada proveniente de corpos d'água \\
\hline MOD19 & Concentração de pigmentos \\
\hline MOD20 & Fluorescência da clorofila \\
\hline MOD21 & Concentração de pigmento de clorofila alfa \\
\hline MOD22 & PAR - Radiação fotossinteticamente ativa \\
\hline MOD23 & Concentração de partículas \\
\hline MOD24 & Concentração de matéria orgânica \\
\hline MOD25 & Concentração de plâncton calcário \\
\hline MOD26 & Coeficiente de atenuação da água do mar \\
\hline MOD27 & Produtividade primária do oceano \\
\hline MOD28 & Temperatura da superfície do mar \\
\hline
\end{tabular}




\begin{tabular}{c|l}
\hline MOD31 & Concentração de pigmentos de algas vermelhas \\
\hline MOD36 & Coeficiente de absorção total \\
\hline MOD37 & Propriedades de aerossol oceânico \\
\hline MOD39 & Grau de pureza de águas claras \\
\hline
\end{tabular}

Fonte: Latorre et al. (2007).

Para este estudo, utilizou-se o produto MOD13. Ele é composto por um conjunto de 12 imagens, do qual fazem parte os índices de vegetação EVI e NDVI e também a imagem pixel reliability QA, que fornece as informações acerca da qualidade radiométrica dos pixels contidos nos índices de vegetação.

\section{2 Índices de vegetação}

Índices de vegetação têm sido empregados em diversas aplicações para detectar mudanças no uso da terra e para estimar parâmetros biofísicos relacionados ao estado da vegetação (biomassa, índice de área foliar - IAF, \% cobertura verde, produtividade primária líquida - NPP, dentre outros), a qual desempenha papel importante para o equilíbrio da biota (JENSEN, 2009; TUNDISI e TUNDISI, 2010). Portanto, o conhecimento do comportamento da vegetação e de seus padrões de distribuições permite inferir sobre as características climáticas, edáficas, geológicas e fisiográficas de uma região (WEIERS et al., 2004). São necessárias, contudo, técnicas e métodos de processamento de dados de sensoriamento remoto da vegetação à disposição da comunidade científica para observação dos ecossistemas terrestres.

Estudos nesse sentido demandam, em sua grande maioria, o conhecimento acerca dos parâmetros biofísicos da vegetação como, por exemplo, biomassa e IAF, conforme mencionado anteriormente. Índices de vegetação são razões matemáticas da reflectância, realizadas a fim de que as propriedades espectrais da vegetação, especialmente nas regiões do vermelho e do infravermelho próximo do espectro eletromagnético sejam evidenciadas (WIEGAND et al., 1991), pois é nessas regiões do espectro eletromagnético que a energia refletida encontra-se relacionada à atividade fotossintética da vegetação e à sua estrutura (FERREIRA et al., 2008; SOLANO et al., 2010).

Conforme destacou Liu (2007), a utilização de índices de vegetação no monitoramento da superfície terrestre apresenta várias vantagens, sendo as principais relacionadas ao fato de, por serem relativos, os valores calculados compensam a variação da intensidade de radiação, e também pelo fato de que ocorre uma parcial correção de efeitos atmosféricos e das variações dos ângulos de visada de sensores e dos ângulos solares. 
Existe uma gama muito variada de índices de vegetação. Os mais utilizados são o NDVI (Normalized Difference Vegetation Index; ROUSE et al., 1973) e o EVI (Enhanced Vegetation Index; HUETE et al., 1997). Outros índices que também têm sido utilizados em estudos da vegetação são o EVI2 (Enhanced Vegetation Index 2; JIANG et al., 2008), SAVI (Soil Adjusted Vegetation Index; HUETE, 1988), ARVI (Atmospherically Resistant Vegetation Index; KAUFMAN e TANRE, 1992) e PVI (Perpendicular Vegetation Index; RICHARDSON e WIEGAND, 1977).

De acordo com Moreira (2000), um dos índices de vegetação mais comumente aplicado é o NDVI. Trata-se de uma medida radiométrica adimensional calculada a partir da razão normalizada entre as bandas do infravermelho próximo e a banda do vermelho, variando entre -1 e 1 . Sua fórmula é apresentada a seguir:

$$
N D V I=\frac{\rho_{N I R}-\rho_{R E D}}{\rho_{N I R}+\rho_{R E D}}
$$

onde $\rho_{N I R}$ e $\rho_{R E D}$ são os fatores de reflectância bidirecional de superfície para as bandas do infravermelho próximo (NIR) e do vermelho (Red), respectivamente.

A despeito da capacidade que o NDVI possui de obter informações sobre parâmetros biofísicos da vegetação, como mudanças sazonais e interanuais do estado da vegetação (MOREIRA, 2011; PONZONI et al., 2012), esse índice apresenta sensibilidade à resposta do solo e também quanto à saturação nos casos em que há valores elevados de biomassa. Assim, quando a vegetação é muito densa, o NDVI não mais responde por conta justamente dessa saturação (HUETE et al., 2002; MUTANGA e SKIDMORE et al., 2004). O índice deixa de se mostrar eficiente especialmente se os valores superarem 0,8 (FERREIRA et al., 2008). A fim de contornar essa dificuldade, Huete et al. (1997) desenvolveram um índice que minimiza a saturação, o qual denominaram Índice de Vegetação Realçado (EVI), mais sensível às variações na estrutura do dossel (GAO et al., 2000). O EVI é outro índice de vegetação que também tem sido utilizado frequentemente em estudos sobre vegetação. Seu cálculo é dado pela fórmula:

$$
E V I=G \frac{\rho_{N I R}-\rho_{R E D}}{\rho_{N I R}+C_{1} * \rho_{R E D}-C_{2} * \rho_{B L U E}+L}
$$

onde $L$ é um fator de ajuste do solo; $G$ é fator de ganho; e $C_{1}$ e $C_{2}$ são coeficientes de ajuste para o efeito atmosférico. Os valores definidos empiricamente pelo autor no cálculo do EVI são: $G=2,5 ; C_{1}=6 ; C_{2}=7,5$; e L = 1 (HUETE et al., 1997; JUSTICE et al., 1998). 
Com o uso de banda situada no comprimento de onda do azul do espectro eletromagnético, é possível minimizar interferências atmosféricas, diminuindo as variações de fundo do dossel, ao mesmo tempo em que torna possível uma melhor discriminação e quantificação das áreas que contenham vegetações mais densas (DIDAN e HUETE, 2006) (Figura 2.2).
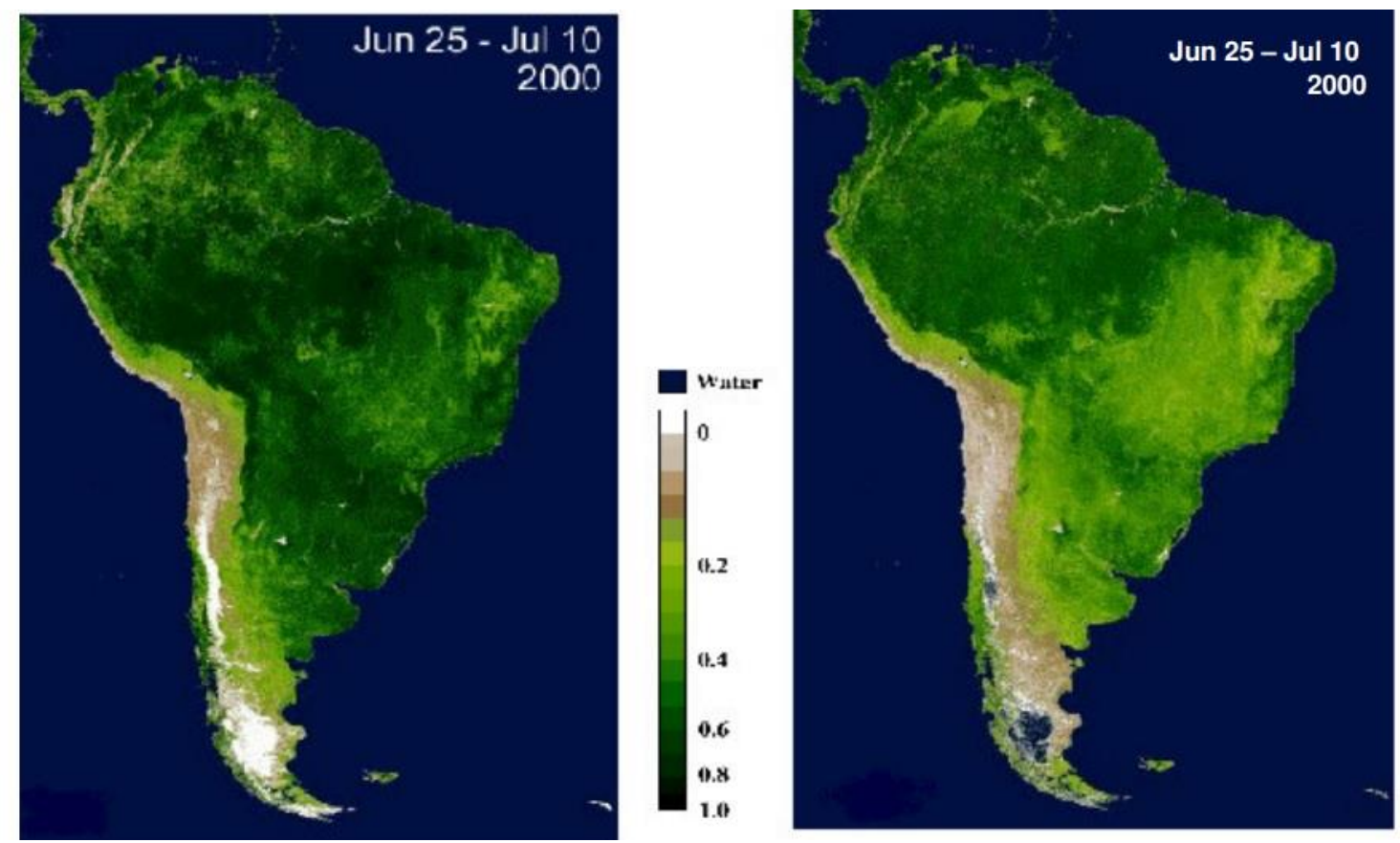

Figura 2.2 - Produto MOD 13: NDVI (à esquerda) e EVI, abrangendo a América do Sul. Fonte: Soares et al. (2007).

Para fins deste trabalho, foram considerados os índices de vegetação derivados do sensor MODIS, desenhados com o objetivo de propiciar consistentes comparações espaciais e temporais das condições da vegetação global, as quais podem ser utilizadas para monitorar a atividade fotossintética (RUNNING et al., 1994; JUSTICE et al., 1998). Os índices de vegetação propiciam a realização de estudos multitemporais, graças ao histórico de dados acumulados desde 2000 (satélite TERRA; satélite AQUA a partir de 2002). Outra vantagem é sua utilização em escala regional e global, o que confere uma aplicabilidade mais ampla de uso na avaliação e monitoramento de grande parte da superfície terrestre (JUSTICE et al., 1998).

Muitos estudos se utilizam de índices de vegetação NDVI e EVI do sensor MODIS como forma de se avaliar os ecossistemas terrestres, seja para detecção de alteração ou desmatamento, seja para monitoramento de áreas, estimativas de estádios fenológicos de cultivares ou mesmo avaliação multitemporal (ANDERSON et al., 2005; BECK et al., 2006; LUNETTA et al., 2006; FERREIRA et.al., 2007; ROSEMBACK et al., 2007; JACQUIN et al., 2010; COUTO JÚNIOR et al., 2012). 
Os dois índices de vegetação do MODIS são disponibilizados globalmente em resoluções espaciais de 1km, 500 m e 250 m, a partir de composições de 16 dias. O produto utilizado nesta dissertação - MOD13Q1 - apresenta resolução espacial de $250 \mathrm{~m}$.

\subsection{Séries temporais}

Define-se série temporal como qualquer conjunto de observações ordenadas no tempo, sendo classificadas em contínuas ou discretas (MORETTIN e TOLOI, 2006). Em sensoriamento remoto, uma série temporal contínua pode ser amostrada em uma série temporal discreta, por meio de observações que são realizadas a intervalos de tempo definidos. No caso das séries temporais de EVI e de NDVI do sensor MODIS, faz-se o processamento dos valores de reflectância de superfície coletados a cada 16 dias, de forma que somente os melhores pixels são selecionados para comporem somente um índice de vegetação daquele intervalo de tempo. Dessa maneira, dados de séries temporais de sensoriamento remoto são uma ferramenta útil para identificar e caracterizar as dinâmicas dos ecossistemas terrestres, em escala temporal (LHERMITTE et al., 2011; ZHANG et al., 2013).

Segundo Verbesselt et al. (2010), a análise de mudanças na cobertura terrestre por meio de componentes de tendência e de sazonalidade de séries temporais permite detectar diferentes tipos de alterações, sejam aquelas ocorridas no âmbito da tendência da série temporal - as quais podem indicar ocorrência de distúrbios, causados por fatores naturais ou antrópicos, como, por exemplo, fogo e ataque de insetos -, sejam as que ocorrem no componente sazonal, as quais, por sua vez, indicariam mudanças fenológicas - associadas à mudança no tipo de cobertura da terra, por exemplo, um tipo de cultivo sendo substituído por outro ou mesmo por colheita (BRADLEY et al., 2007; SINHA e KUMAR, 2013).

Vários estudos em sensoriamento remoto da vegetação em todo o mundo, especialmente na área de agricultura, utilizam séries temporais, tanto para estimativas de estádios fenológicos de cultivares, previsão de safras agrícolas, como também na avaliação temporal de uso e ocupação do solo e na quantificação das transformações ocorridas (SCHOROEDER et al., 2007; VRIELING et al., 2011; ZHANG et al., 2013; CROFT et al., 2014; HUTCHINSON et al., 2015).

No caso de estudos de ambientes naturais em ecossistemas que sofrem de estacionalidade climática - nos quais o vigor da vegetação varia de acordo com a alternância das estações chuvosa e seca ao longo do ano -, por meio de análises temporais é possível evidenciar a variabilidade espectral desses alvos, o que permite distinguir suas dinâmicas sazonais e suas fitofisionomias (CARVALHO JÚNIOR et al., 2006, 2008, 2009), e também diferenciar as áreas de pastagem e os plantios agrícolas (FERREIRA et al., 2004; RATANA 
et al., 2005; COUTO JÚNIOR et al., 2011). No Cerrado, as diferentes fitofisionomias existentes apresentam variabilidade de comportamento espectral, em função da grande heterogeneidade das formações fisionômicas. Essa variabilidade resulta da interação dos diferentes tipos vegetacionais - nos quais há diferenças em relação à composição florística, mas que mantêm similaridade estrutural -, com as variações que ocorrem nos solos, no regime de precipitação e nas variações de altitude e de latitude, assim como variações na distribuição geográfica de espécies (RATTER et al., 2000; CARVALHO, 2005; SILVA et al., 2006).

Além da variabilidade em termos fitofisionômicos e da ocorrência de diferenciados tipos de solos e de regimes de precipitação, outra característica que confere alta variabilidade em termos de comportamento espectral à vegetação do Cerrado é a marcada sazonalidade climática - caracterizada por um período de chuvas e de seca bem definidos em que a resposta fenológica da vegetação é bastante influenciada por fatores atmosféricos (precipitação e temperatura do ar).

Mudanças ocorridas em função de alterações no uso ou da cobertura da vegetação podem estar ou não relacionadas à supressão da vegetação - o que pode levar à conclusão de que determinada área pode ter sido desmatada. A incerteza na conclusão sobre a ocorrência de desmatamento existe porque outras interferências nos valores das séries históricas de EVI e de NDVI podem levar à interpretação errônea de que houve supressão da vegetação nativa. Uma dessas interferências está relacionada à ocorrência de queimadas, bastante frequentes na região do Cerrado, especialmente durante o período de estiagem. A cicatriz de queimada apresenta baixa reflectância em toda a faixa óptica (PESSOA e MENESES, 2013) e do infravermelho próximo (NIR) do espectro eletromagnético (LIBONATI et al., 2006), assemelhando-se ao comportamento da supressão da vegetação nestes mesmos comprimentos de onda.

Em geral, a análise de séries temporais requer a filtragem de seus dados para remoção de ruídos, ou seja, remoção de interferência oriunda de qualquer fonte externa ao sinal verificado (SANTOS et al., 2012). A literatura tem demonstrado que séries temporais apresentam ruídos (VANDIJK et al., 1987; VIOVY et al., 1992; ROERINK et al., 2000), causados por uma série de fatores. Conforme mencionaram Meneses e Almeida (2012), esses ruídos são distorções introduzidas nas imagens pelos sistemas sensores por conta de erros instrumentais, de interferências atmosféricas e também da geometria de imageamento. Vários estudos apontaram a necessidade de atenuação desses ruídos a fim de se reduzirem os efeitos negativos quando da caracterização e classificação de uso do solo (CHEN et al., 2004; SAKAMOTO et al., 2005; GALFORD et al., 2008; COUTO JÚNIOR et al., 2011), pois a existência de valores atípicos em um conjunto de dados a serem 
analisados estatisticamente pode interferir nos resultados apurados, o que pode não condizer com a realidade estudada.

Oliveira et al. (2014) e Doraiswamy et al. (2006) ressaltaram que mesmo os produtos MODIS utilizados nas análises multitemporais sendo mosaicos compostos pelos melhores pixels adquiridos por um determinado período de tempo, não é incomum encontrar pixels de baixa qualidade radiométrica que afetam as análises de séries temporais. Para tanto, há necessidade de filtragem que podem ser realizadas em âmbito espacial (que consideram a localização do pixel no espaço) ou temporal (posição ao longo da série temporal).

No intuito de contornar esse problema, é necessário o emprego de métodos de suavização dos dados, por meio de filtros ou de transformações, para eliminar os ruídos dessas imagens de modo a resultar numa imagem cuja resposta esteja baseada num sinal sem interferências. Essas técnicas de suavização são realizadas no âmbito do domínio espacial, isto é, os valores digitais dos pixels originais são trabalhados por meio de funções matemáticas com a utilização dos valores digitais dos pixels vizinhos a eles. Nesta dissertação, aplicou-se o método de filtragem por logística dupla, baseada em uma função harmônica polinomial (JÖNSSON et al., 2004). 


\section{CAPÍTULO 3}

\section{MATERIAIS E MÉTODOS}

Na Figura 3.1 é mostrado o fluxograma metodológico deste estudo, o qual evidencia as principais atividades desenvolvidas.

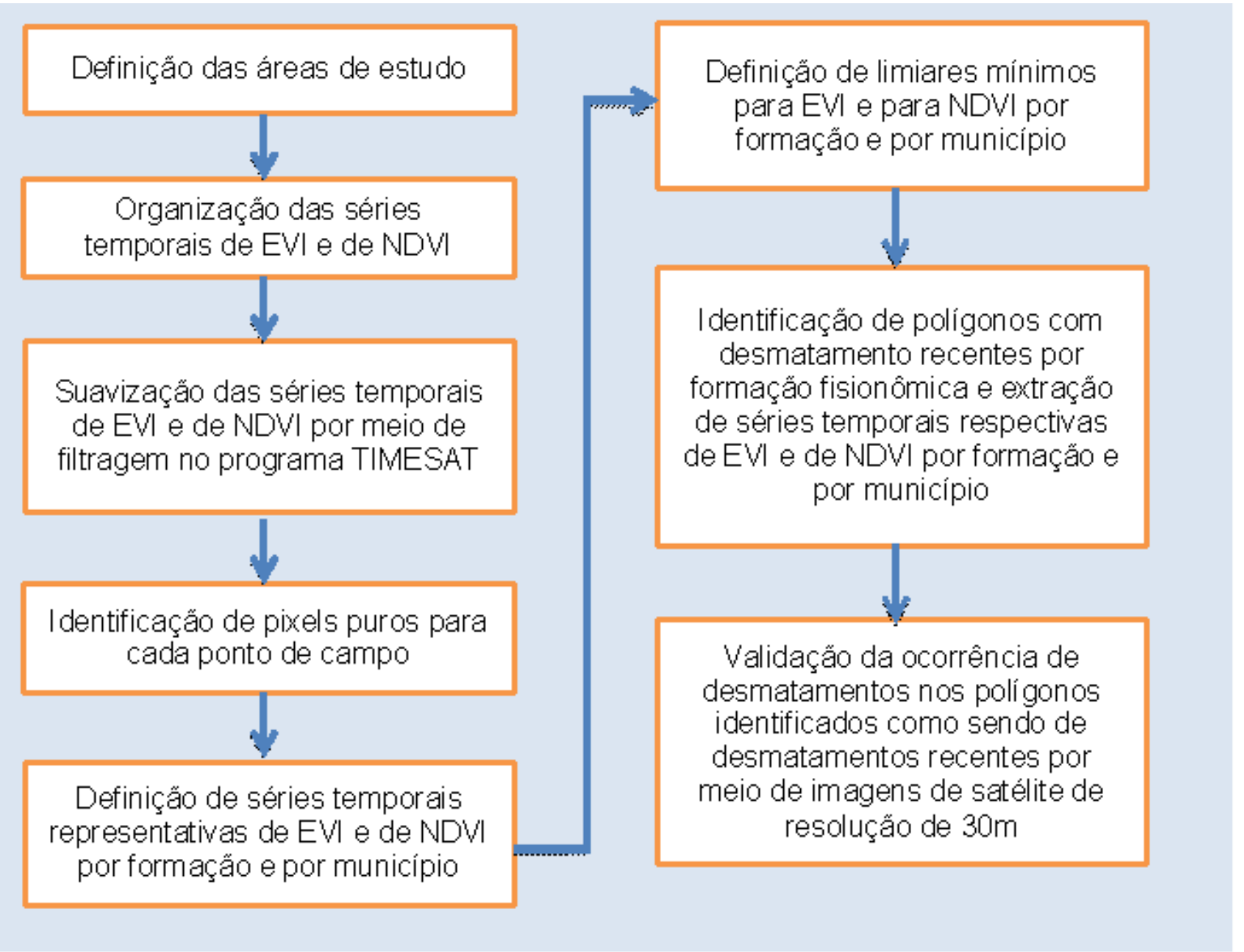

Figura 3.1 - Fluxograma metodológico das principais etapas de trabalho.

\section{1 Área de estudo}

Para o desenvolvimento desse estudo, foram selecionadas quatro áreas-teste, correspondentes aos municípios de Jataí/GO, Mateiros/TO, Luís Eduardo Magalhães/BA e São Miguel do Araguaia/GO (Figura 3.2). Os municípios foram selecionados por se constituírem em regiões do Cerrado representativas em termos de produção de grãos e energia (etanol) com elevada produtividade e tecnologia, de manutenção de extensas áreas de remanescentes de cobertura vegetal do Cerrado, de fronteira agrícola e de pecuária extensiva, respectivamente. 


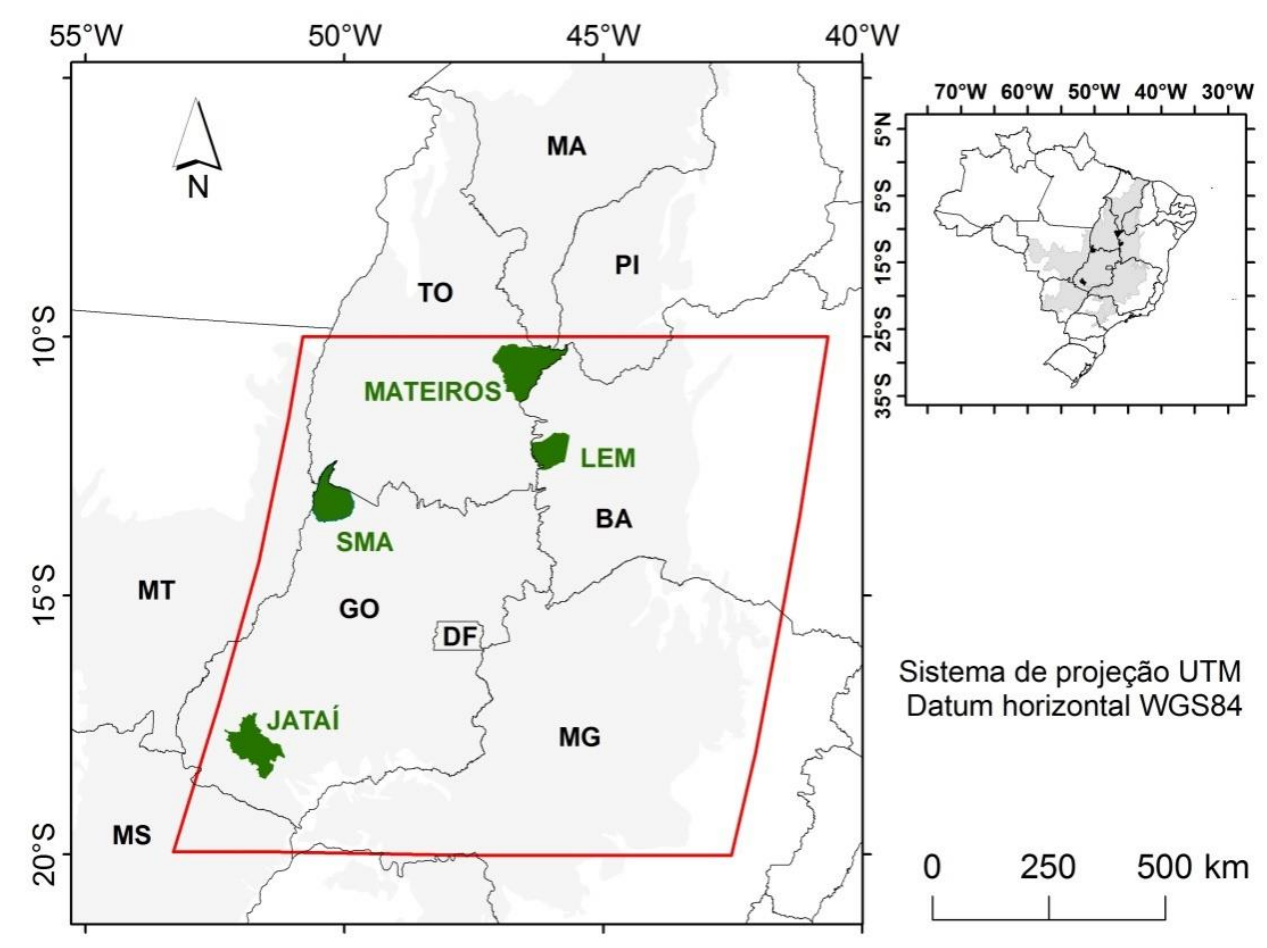

Figura 3.2- Mapa de localização das áreas de estudo no bioma Cerrado (municípios de Jataí/GO, Luís Eduardo Magalhães/BA, Mateiros/TO e São Miguel do Araguaia/GO) e localização do tile h13v10.

O município de Jataí situa-se na porção sudoeste do estado de Goiás. De acordo com dados do IBGE (2013), o município destaca-se pela produção de milho e soja. Em 2011, o referido município foi o maior produtor de milho do estado de Goiás e o sétimo do País. Mais de $70 \%$ da área municipal é utilizada para agropecuária. A pecuária intensiva, voltada para produção de leite, também é destaque no município. Em 2011, Jataí foi o terceiro maior produtor de leite do País, com 141,4 milhões de litros de leite (SEGPLAN, 2013). Por causa dos solos predominantemente férteis, as áreas naturais também são ocupadas predominantemente por formações florestais.

O município de Luís Eduardo Magalhães, que faz parte da mesorregião do Extremo Oeste Baiano, é parte integrante de uma das principais áreas de expansão do agronegócio brasileiro. As principais commodities são a soja, o algodão, o milho e o café e são produzidos com alto grau de mecanização (BATISTELLA et al., 2002). No começo de 2006, essa mesorregião apresentava mais de 2 milhões de hectares de áreas agrícolas (aproximadamente $22 \%$ do Cerrado baiano) (BARRERO, 2008). A área média das propriedades rurais frequentemente ultrapassa os 1.000 hectares. Nas áreas com cobertura vegetal natural, predominam as formações savânicas (Campo Sujo e Cerrado Ralo; RIBEIRO e WALTER, 2008). 
No município de Mateiros, ainda podem ser encontradas extensas e contínuas áreas preservadas de Cerrado. Nessa região, há uma concentração de um número relativamente grande de unidades de conservação federais e estaduais: a Estação Ecológica Serra Geral de Tocantins, o Parque Nacional Nascentes do Rio Parnaíba, o Parque Estadual do Jalapão e as Áreas de Proteção Ambiental (APA) da Serra das Mangabeiras, Serra da Tabatinga e Jalapão (ICMBio, 2013). A região é caracterizada pela agricultura de subsistência e pelo uso da biodiversidade por populações tradicionais, notadamente o extrativismo de capim dourado (Syngonanthus nitens (Bong.) Ruhland) para artesanato (SCHMIDT et al., 2008). Por ser uma das últimas fronteiras ainda não convertidas, a pressão sobre tais áreas vem crescendo ao longo dos últimos anos, principalmente devido à expansão da agricultura modernizada de soja nos chapadões a leste da região, onde estão localizados os municípios com as mais altas taxas de desmatamento do bioma. As principais fitofisionomias presentes na região são as formações savânicas (Campo Sujo) e campestres (Campo Limpo).

O município de São Miguel do Araguaia situa-se na porção noroeste de Goiás, na bacia hidrográfica do Tocantins-Araguaia e é bastante conhecido por causa da economia da região que é baseada na produção de carne bovina. Esse município possui o segundo maior rebanho bovino do estado de Goiás, com 572 mil cabeças (SEGPLAN, 2013). As áreas naturais são ocupadas principalmente por formações florestais e savânicas.

\subsection{Materiais}

O material básico desse estudo foram as séries temporais do produto MOD13Q1, coleção 5 (versão 4), tile h13v10 do período compreendido entre fevereiro de 2000 a dezembro de 2013 (total de 319 séries temporais). Cada série anual é composta de 23 imagens, com exceção do ano de 2000, que é composto por 20 imagens, uma vez que esse produto começou a ser disponibilizado a partir de 18 de fevereiro de 2000. Essas séries são disponibilizadas com resolução espacial de 250 metros e periodicidade de 16 dias (HUETE et al., 2002) e podem ser obtidas da página eletrônica da Agência Espacial Norte-Americana (NASA) (http://reverb.echo.nasa.gov). Os dados, obtidos pela plataforma Terra/MODIS e originalmente disponibilizados na projeção senoidal e formato Hierarchical Data Format (HDF), foram convertidos para o sistema de projeção UTM (Universal Transversa de Mercator), datum horizontal WGS84 e gravadas em formato TIFF (Tagged Image File Format) por meio do programa MODIS Reprojection Tool (MRT).

O MOD13Q1 disponibiliza um conjunto de 12 produtos ready-to-use (prontos para serem utilizados) (LPDAAC, 2014). Nesse estudo, foram considerados os dois índices de vegetação disponibilizados no referido produto, o EVI e o NDVI (equações e detalhes apresentados no capítulo anterior). A partir desses dois índices de vegetação, foram 
elaborados dois cubos temporais, um para cada índice de vegetação, conforme ilustrado na Figura 3.3. Nesse cubo, as imagens são ordenadas em três dimensões, de modo que os eixos $\mathrm{X}$ e $\mathrm{Y}$ representam as coordenadas geográficas e o eixo $\mathrm{Z}$, os valores do espectro temporal dos índices de vegetação (CARVALHO JÚNIOR et al., 2009).

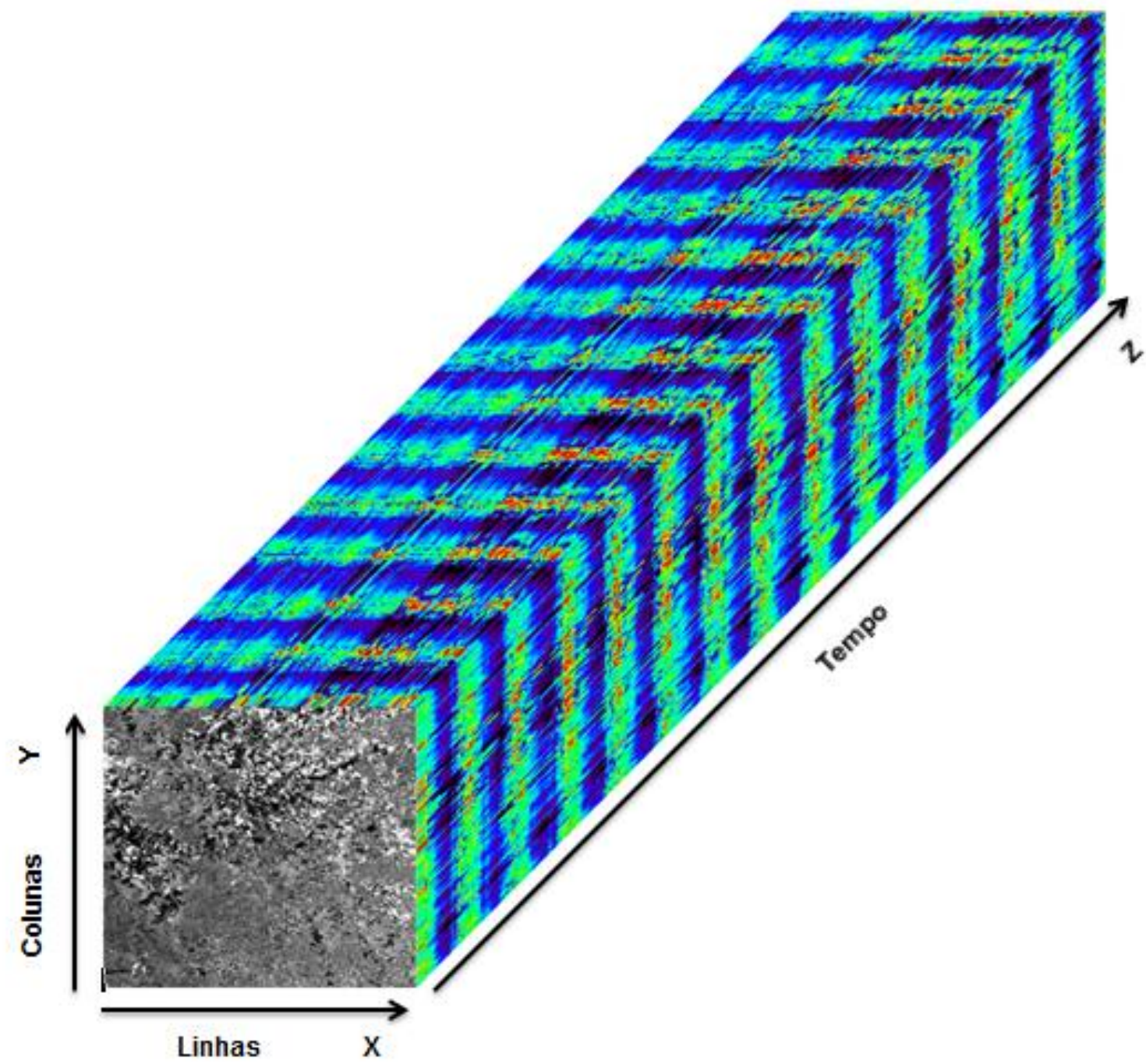

Figura 3.3 - Cubo temporal 3D das imagens MODIS.

\subsection{Campanhas de campo}

Entre outubro de 2013 e março de 2014, foram realizadas quatro campanhas de campo para a caracterização dos tipos de cobertura vegetal natural e antrópica representativos de cada município. Foram visitados 126 pontos nos quatro municípios (Figura 3.4): 32 em Jataí e São Miguel do Araguaia; e 31 em Luís Eduardo Magalhães e Mateiros. Desse total de pontos, 12 correspondeu à formação florestal; 41 à formação savânica; 13 à formação campestre; 34 às culturas agrícolas; e 26 às pastagens cultivadas 
(Tabela 3.2). Os seguintes registros foram obtidos em cada ponto: coordenadas GPS; fotografias digitais panorâmicas; identificação da classe de cobertura vegetal predominante; e amostragem de solo no horizonte superficial para caracterização de cor.

Tabela 3.1 - Dados referentes às campanhas de campo realizadas nos quatro municípios considerados nesse estudo (total de pontos visitados no campo: 126). FLO = Formação florestal; SAV = Formação savânica; CAM = Formação campestre; CA = Cultura agrícola; e $\mathrm{PC}=$ Pastagem cultivada.

\begin{tabular}{cccccccc}
\hline Município & $\begin{array}{c}\text { Data da } \\
\text { campanha }\end{array}$ & \multicolumn{5}{c}{ Número de pontos visitados } \\
\cline { 3 - 7 } & & FLO & SAV & CAM & CA & PC & TOTAL \\
\hline Jataí & $26-28 / 10 / 2013$ & 5 & 1 & - & 15 & 11 & 32 \\
$\begin{array}{c}\text { Luís } \\
\text { Eduardo } \\
\text { Magalhães }\end{array}$ & $07-09 / 03 / 2014$ & - & 15 & - & 16 & - & 31 \\
Mateiros & $15-18 / 03 / 2014$ & - & 15 & 13 & 3 & - & 31 \\
$\begin{array}{c}\text { São Miguel } \\
\text { do }\end{array}$ & $22-24 / 02 / 2014$ & 7 & 10 & - & - & 15 & 32 \\
Araguaia & & & & & & & \\
\hline
\end{tabular}


JATAÍ-GO
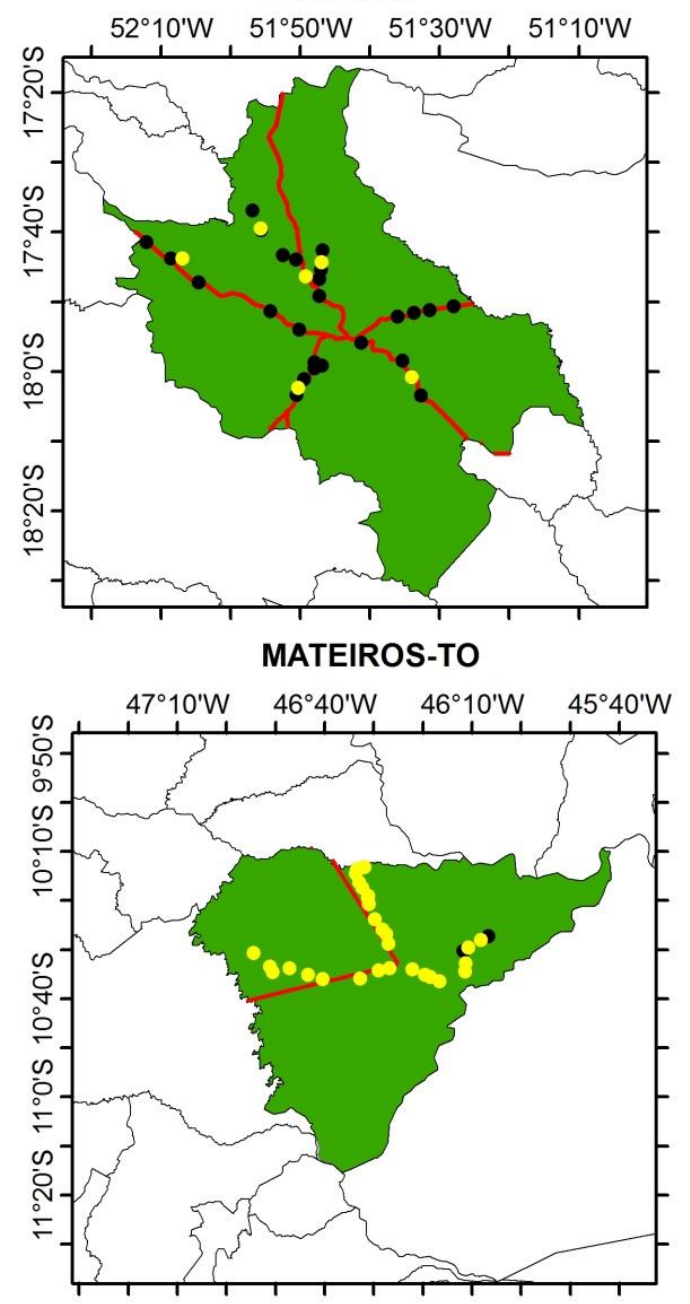

LUÍS EDUARDO MAGALHÃES-BA

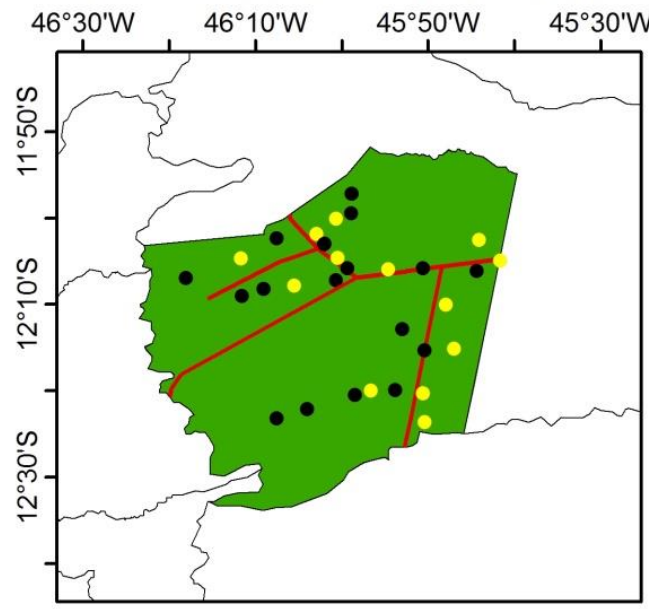

SÃO MIGUEL DO ARAGUAIA-GO

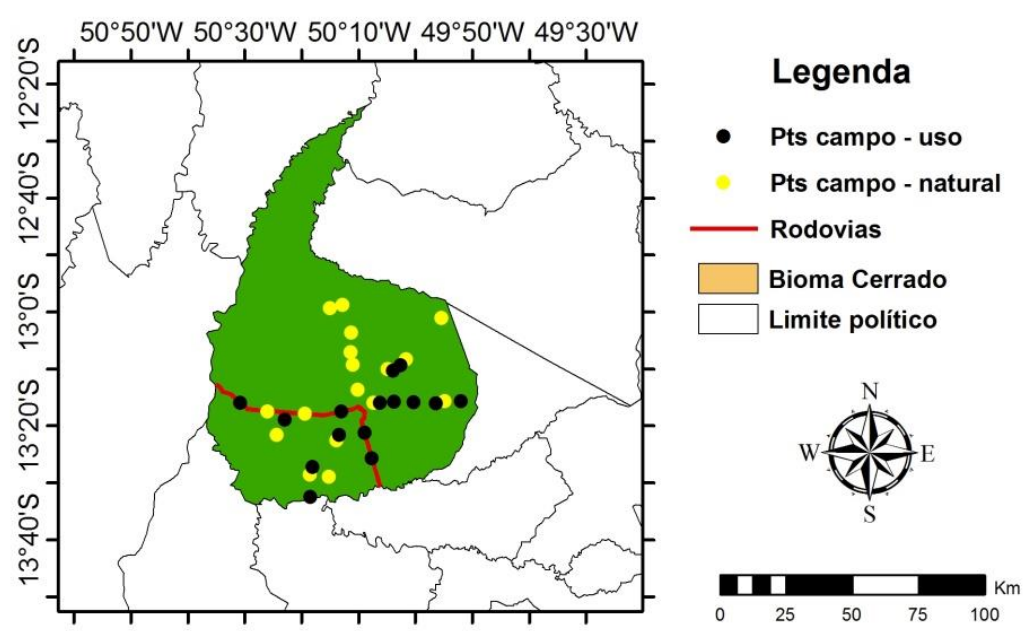

Figura 3.4 - Localização dos pontos de visita de campo nos municípios de Jataí/GO, Luís Eduardo Magalhães/BA, Mateiros/TO e São Miguel do Araguaia/GO. 
A título de ilustração, a Figura 3.5 ilustra as classes de cobertura vegetal natural ou antrópica representativas de cada município considerado nesse estudo: cultura agrícola em Jataí; formação savânica em Luís Eduardo Magalhães; formação campestre em Mateiros; e pastagem cultivada em São Miguel do Araguaia.

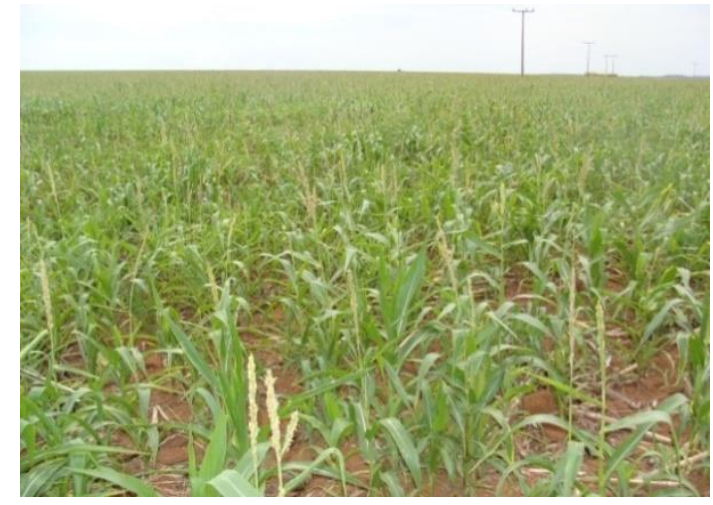

(a)

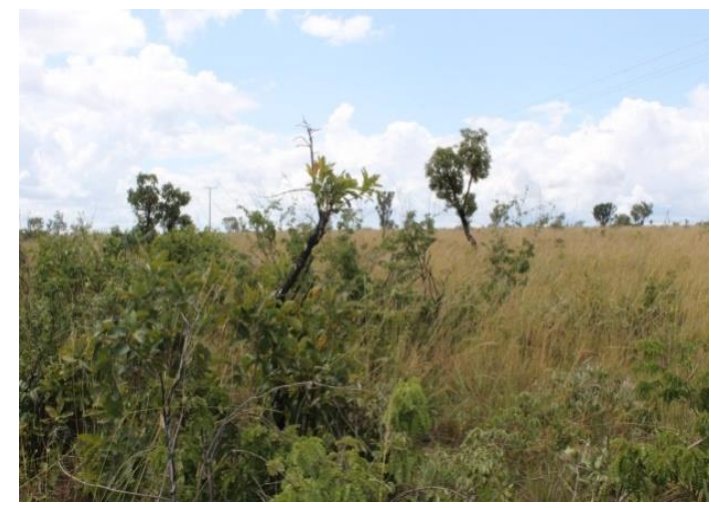

(c)

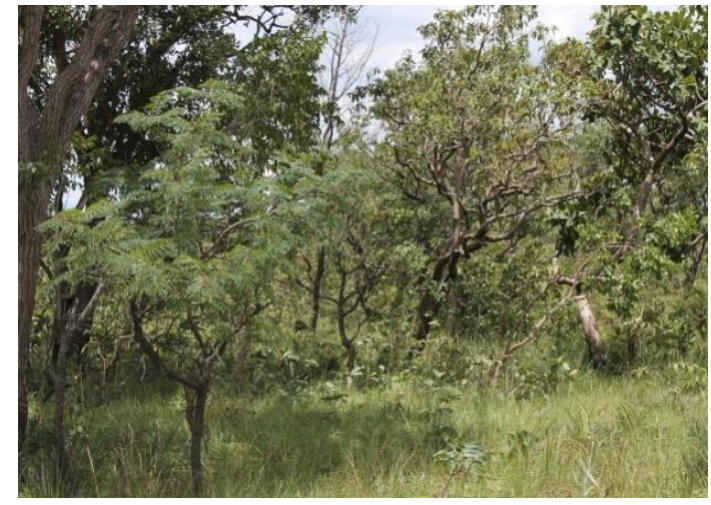

(b)

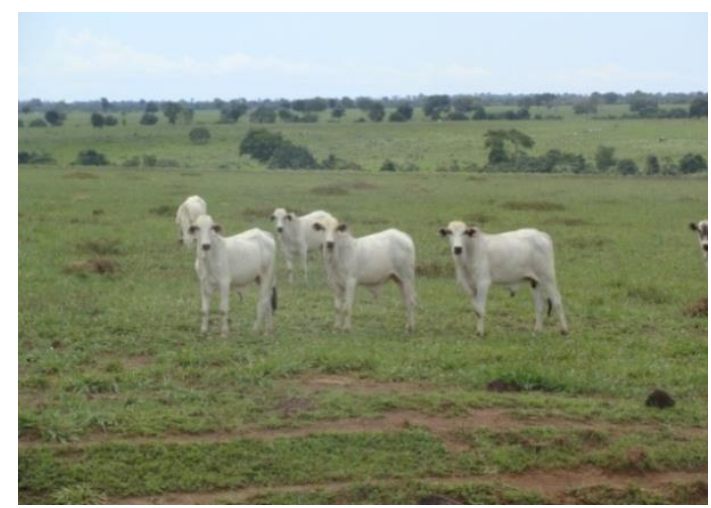

(d)

Figura 3.5 - Fotografias panorâmicas de campo ilustrando plantio de milho em Jataí (a), formação savânica em Luís Eduardo Magalhães (b), formação campestre em Mateiros (c) e pastagem cultivada com Brachiaria em São Miguel do Araguaia (d).

\subsection{Assinaturas temporais do MODIS EVI e NDVI representativas de cada formação vegetacional}

A partir dos dados de campo, foram extraídas assinaturas temporais representativas das formações florestais, savânicas e campestres. Para assegurar que a extração dessas assinaturas espectrais seria realizada com base em pixels puros do MODIS, isto é, com nível mínimo de mistura espectral, as coordenadas GPS de campo foram sobrepostas nas imagens ortorretificadas do Landsat- 8 e também em uma grade de células de 250 metros $x$ 250 metros, coincidente com os pixels do MODIS (Figura 3.6). O software utilizado foi ArcGIS 10.1. Procurou-se selecionar ao menos quatro pixels para cada ponto amostral, os 
quais foram convertidos para um único valor por meio de média aritmética simples. Entretanto, em alguns casos, em função do tamanho da área visitada em campo, somente foi possível a seleção de um pixel puro. A extração de séries temporais de NDVI e EVI dos pixels selecionados foi feita por meio do software ENVI 4.8 .

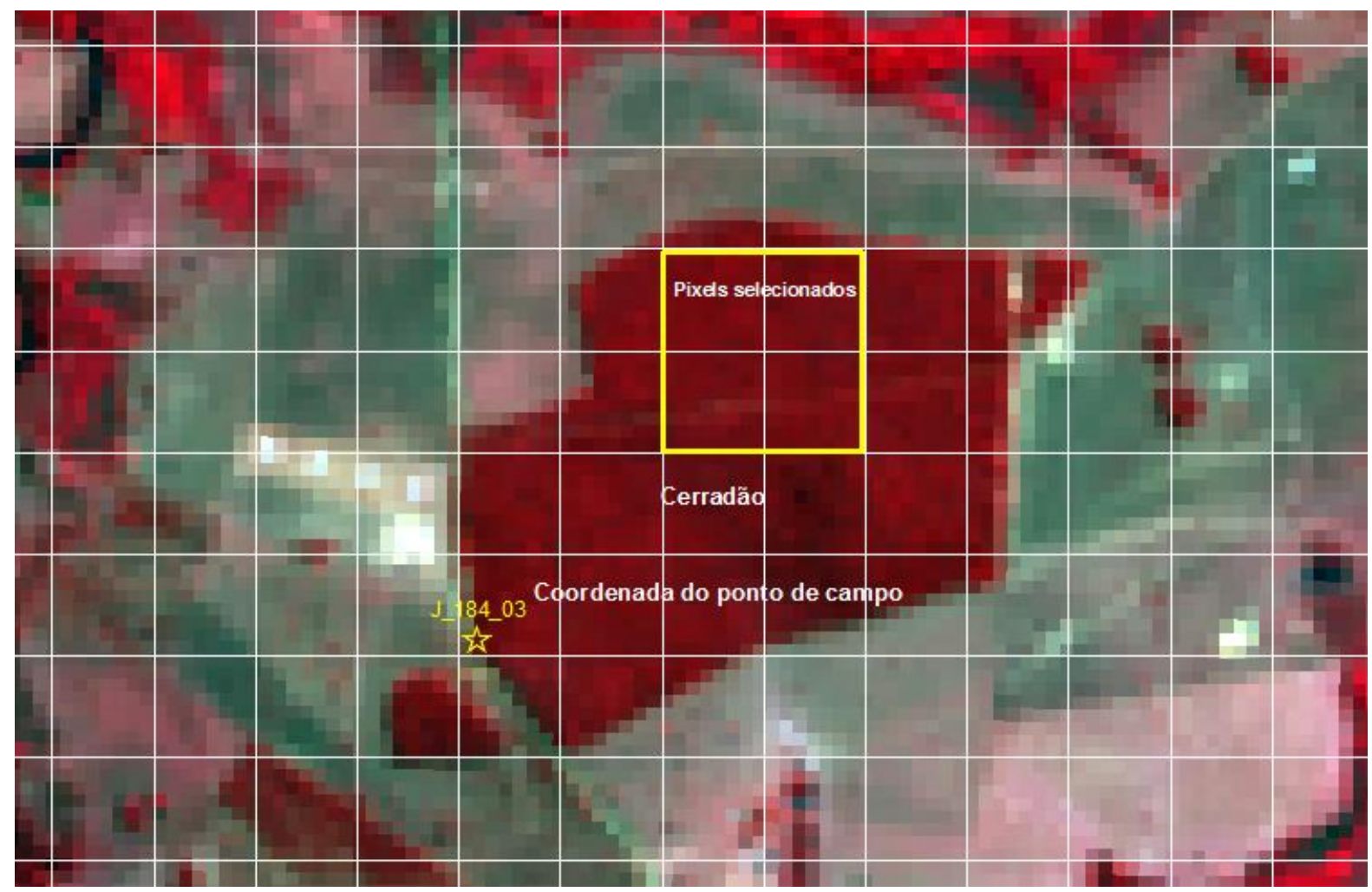

Figura 3.6 - Recorte de imagem Landsat-8 de Jataí/GO (composição colorida RGB/564) mostrando uma coordenada GPS de campo correspondente à formação florestal (Cerradão). A grade regular dessa figura corresponde à grade de pixels do sensor MODIS. O quadrado amarelo corresponde aos quatro pixels da série temporal do MODIS que foram considerados na extração de assinatura temporal representativa de formação florestal no município.

As séries temporais de EVI e de NDVI de cada um dos 66 pontos de campo correspondentes às três formações vegetais naturais do Cerrado (Tabela 3.1) foram então convertidas em séries representativas por formação e por município. Assim, foram obtidas séries temporais de formação florestal de Jataí e São Miguel do Araguaia, formação savânica de todos os quatro municípios e formação campestre de Mateiros.

Essas séries temporais, por apresentarem ruídos causados, por exemplo, pela presença de nuvens durante a passagem do satélite, foram suavizadas pelo filtro denominado logística dupla, disponível no programa TIMESAT (JÖNSSON e EKLUNDH, 2002, 2004). Esse software, de domínio público, disponibiliza três métodos de suavização: logística dupla, Savitzky-Golay e gaussiano assimétrico. Testes intensivos realizados por 
Borges et al. (2014) indicaram melhor desempenho da logística dupla para dados do MODIS EVI do Cerrado, mais especificamente, do oeste da Bahia. A logística dupla corresponde a uma função harmônica e polinomial. Sua formulação matemática é dada pela Eq. 3.1, onde o parâmetro $x_{1}$ determina a posição do ponto de inflexão esquerdo, enquanto $x_{2}$ determina a taxa de variação. $O$ parâmetro $x_{3}$ determina a posição do ponto de inflexão do lado direito, enquanto $x_{4}$ fornece a taxa de variação nesse ponto. De acordo com Jönsson et al. (2004), esse filtro garante uma forma suave às séries temporais.

$$
g\left(t ; \mathrm{x}_{1}, \ldots, \mathrm{x}_{4}\right)=\frac{1}{1+\exp \left(\frac{\mathrm{x}_{1}-\mathrm{t}}{\mathrm{x}_{2}}\right)}-\frac{1}{1+\exp \left(\frac{\mathrm{x}_{3}-\mathrm{t}}{\mathrm{x}_{4}}\right)}
$$

O programa TIMESAT oferece a possibilidade de filtragem de dados de séries temporais a partir de imagens ou de arquivos em formato ASCII (sigla em inglês para American Standard Code for Information Interchange). Esse padrão permite que códigos de textos sejam reconhecidos por programas de computadores. Assim, os valores médios representativos foram salvos em arquivos TXT, os quais, por sua vez, foram lidos pelo programa. O resultado foi a suavização dos valores médios originais de EVI e de NDVI para cada formação por município pelo filtro de logística dupla. Os parâmetros de configuração utilizados na filtragem dos dados foram: amplitude cutoff =0; spike method = 3; spike value $=2$; season parameter $=0$; number of envelope iterations $=3$; adaptation strength $=3$; fitting method $=1$; weight update method $=1$; season start/stop method $=1$; season start/stop values $=0,5 / 0,5$. Em função de uma necessidade operacional do programa TIMESAT, utilizado para suavização das séries temporais, três granules tiveram que ser replicados para perfazerem 23 cenas no ano de 2000, tendo em vista que as séries temporais MODIS do satélite TERRA só passaram a ser disponibilizadas em 18 de fevereiro de 2000, e, portanto, somente 20 granules existiam para o ano 2000. Diante dessa peculiaridade, no total, foram processados 322 granules, tanto para EVI quanto para NDVI.

Teste não-paramétrico de Kruskal-Wallis, disponível no pacote estatístico de domínio público denominado Action® 2.7, foi conduzido para verificar se as séries temporais de uma mesma formação vegetacional, porém, de municípios diferentes, eram estatisticamente iguais ou diferentes. O teste de Kruskal-Wallis é um teste não paramétrico empregado para comparação de três ou mais populações. É um teste análogo à análise de variância (ANOVA) com um fator. Assim, da mesma forma como é realizado na ANOVA, ao se rejeitar a hipótese nula, não se sabe quais populações são diferentes umas das outras. A fim de se conhecer essa diferença, comparações múltiplas são efetuadas (Zar, 1999), A opção por esse teste foi decorrente dos resultados do teste de normalidade pelo método de Shapiro- 
Wilk, aplicado às séries temporais consideradas nesse estudo. O intuito do teste de KruskalWallis era definir se haveria uma única assinatura temporal por formação vegetal ou se haveria assinaturas temporais distintas para cada município. Pelo fato de a formação campestre ter sido amostrada somente em Mateiros-TO, não foi testada a igualdade das séries temporais para essa formação.

Assim, foi estabelecida hipótese nula $\left(\mathrm{H}_{0}\right)$ de igualdade entre as séries temporais de EVI e de NDVI de cada formação entre os municípios estudados, a um nível de significância de $5 \%$. É um teste bastante útil para testar a hipótese nula de que todas as amostras independentes são provenientes de populações que possuem funções de distribuição iguais. Assim, para este teste, a afirmação para a hipótese nula foi a de que as populações (séries temporais representativas por formação), comparadas duas a duas, possuem funções de distribuição iguais.

\subsection{Limiares de desmatamento}

Essa etapa consistiu na definição de limiares de desmatamento para cada formação vegetaional considerada (florestal, savânica e campestre). Por limiar de desmatamento, entendem-se como sendo aqueles valores de NDVI e EVI abaixo dos quais podem ser considerados como desmatamento. Por causa da elevada sazonalidade climática do Cerrado, as séries temporais do NDVI e EVI de áreas naturais possuem padrão tipicamente senoidal; os seus valores mais baixos coincidem aproximadamente com o pico da estação seca, enquanto os seus valores mais altos coincidem aproximadamente com o pico da estação chuvosa. Analisando as séries temporais desses dois índices de vegetação para as três formações vegetacionais naturais, podem-se definir os correspondentes valores mínimos de NDVI e de EVI para as formações florestais, savânicas e campestres, os quais foram denominados nesse estudo como limiares de desmatamento. Quando uma área natural é desmatada, os índices de vegetação das passagens subseqüentes do sensor MODIS tendem a apresentar valores menores do que os limiares de desmatamento.

O desempenho dos limiares foi verificado a partir do arquivo em formato shapefile contendo polígonos de desmatamento do bioma Cerrado do ano de 2011, identificados pelo Centro de Sensoriamento Remoto do IBAMA por meio de análise de imagens do satélite Landsat TM (dados não-publicados). Foram selecionados ao menos um polígono de desmatamento por formação vegetacional e por município (total de 8 pontos). Assinaturas temporais desses polígonos de desmatamento foram então comparadas com as assinaturas temporais das formações vegetacionais naturais por meio de diagramas de dispersão $X Y$, onde $\mathrm{X}=$ data; e $\mathrm{Y}=$ índice de vegetação. 
Em seguida, foram identificadas visualmente, nos diagramas de dispersão, datas prováveis de desmatamento, as quais foram inferidas a partir de quedas acentuadas e continuadas nos valores de índices de vegetação, abaixo do limiar pré-definido. A presença ou não dessas áreas desmatadas foram confirmadas por meio de análise de duas cenas do satélite Landsat ou Resourcesat, anterior e posterior à data provável de desmatamento (Tabela 3.2).

Tabela 3.2 - Datas das imagens dos satélites Landsat e ResourceSat utilizadas para analisar o desempenho dos limiares de desmatamento relativos a séries temporais do MODIS EVI e NDVI.

\begin{tabular}{lrr} 
Município & \multicolumn{1}{c}{ Satélite } & \multicolumn{1}{c}{ Datas das Imagens } \\
\hline Jataí/GO & Landsat-5 TM & 01 de agosto de 2009 \\
& & 22 de julho de 2010 \\
& & 12 de julho de 2011 \\
\hline Luís Eduardo Magalhães/BA & Landsat-7 ETM+ 2010 \\
& & 03 de setembro de 2011 \\
\hline Mateiros/TO & Landsat-7 ETM+ de setembro de 2013 \\
& & 14 de agosto de 2010 \\
& & 15 de setembro de 2013 \\
& ResourceSat-2 LISS3 & 02 de setembro de 2011 \\
& & 10 de julho de 2012 \\
\hline São Miguel do Araguaia/GO & Landsat-7 ETM+ & 29 de julho de 2013 \\
\hline & & 01 de agosto de 2009 \\
& & 01 de agosto de 2012 \\
& & 12 de agosto de 2013 \\
\hline
\end{tabular}




\section{CAPÍTULO 4}

\section{RESULTADOS E DISCUSSÃO}

$\mathrm{Na}$ Tabela 4.1, são mostrados os resultados da análise da qualidade radiométrica dos pixels do MOD13Q1 dos quatro municípios. Na média, $76 \%$ dos pixels foram classificados como bons, $14 \%$ como marginais e $10 \%$ como cobertos por nuvens. A qualidade desses dados está ligeiramente inferior em relação aos dados do oeste da Bahia do período de 2000 a 2010 que foram analisados por Borges et al. (2014). Segundo esses autores, $83 \%$ dos pixels do Oeste da Bahia foram considerados bons, $12 \%$ foram considerados marginais e $5 \%$ apresentaram problemas de cobertura de nuvens.

Tabela 4.1 - Avaliação da qualidade dos pixels utilizados na composição das médias representativas das formações fisionômicas por município. $0=$ dado bom; $1=$ dado marginal; 3 = dado com influência de cobertura de nuvens. A categoria 2 (neve/gelo) não ocorre nos quatro municípios em questão.

\begin{tabular}{lccc}
\hline \multicolumn{1}{c}{ Município } & Categoria & Frequência & $\begin{array}{c}\text { Porcentagem } \\
(\%)\end{array}$ \\
\hline Jataí & 0 & 22.594 & 77,96 \\
& 1 & 4.043 & 13,95 \\
Luís Eduardo Magalhães & 3 & 2.343 & 8,08 \\
& 0 & 26.541 & 78,50 \\
& 1 & 5.059 & 14,96 \\
Mateiros & 3 & 2.210 & 6,54 \\
& 0 & 29.248 & 74,45 \\
& 1 & 5.807 & 14,78 \\
São Miguel do Araguaia & 3 & 4.229 & 10,77 \\
& 0 & & \\
& 1 & 19.299 & 72,21 \\
& 3 & 3.389 & 12,68 \\
& & 4.038 & 15,11 \\
\hline
\end{tabular}

A título de ilustração, na Figura 4.1 são mostradas as séries temporais de formações florestais, savânicas e campestres de São Miguel do Araguaia, Luís Eduardo Magalhães e Mateiros, respectivamente. As três assinaturas espectrais mostram nítida interferência da sazonalidade climática. Regra geral, valores mais altos de EVI representam pico da estação chuvosa (meados de fevereiro) e valores mais baixos próximos aos picos da estação seca (meados de setembro), indicando uma relação direta do padrão sazonal da precipitação com a sazonalidade da vegetação (BECERRA et al., 2009). Outro aspecto relevante mostrado nessa figura é a presença de ruídos nos valores originais de EVI, indicando a necessidade de suavizar as séries temporais do MOD13Q1. A figura ilustra ainda os resultados da 
suavização pelo método da logística dupla. Pode-se observar que, de uma maneira geral, o filtro conseguiu reduzir com sucesso, os valores anômalos excessivamente altos e baixos das séries temporais. As séries suavizadas são bastante similares aos perfis apresentados em estudos anteriores (e.g., CHEN et al., 2004; MA e VEROUSTRAETE, 2006; JULIEN e SOBRINO, 2010; ATKINSON et al., 2012). Resultados similares ao EVI foram obtidos na suavização dos dados do NDVI (Figura 4.2) e também para outras formações vegetacionais de outros municípios. 


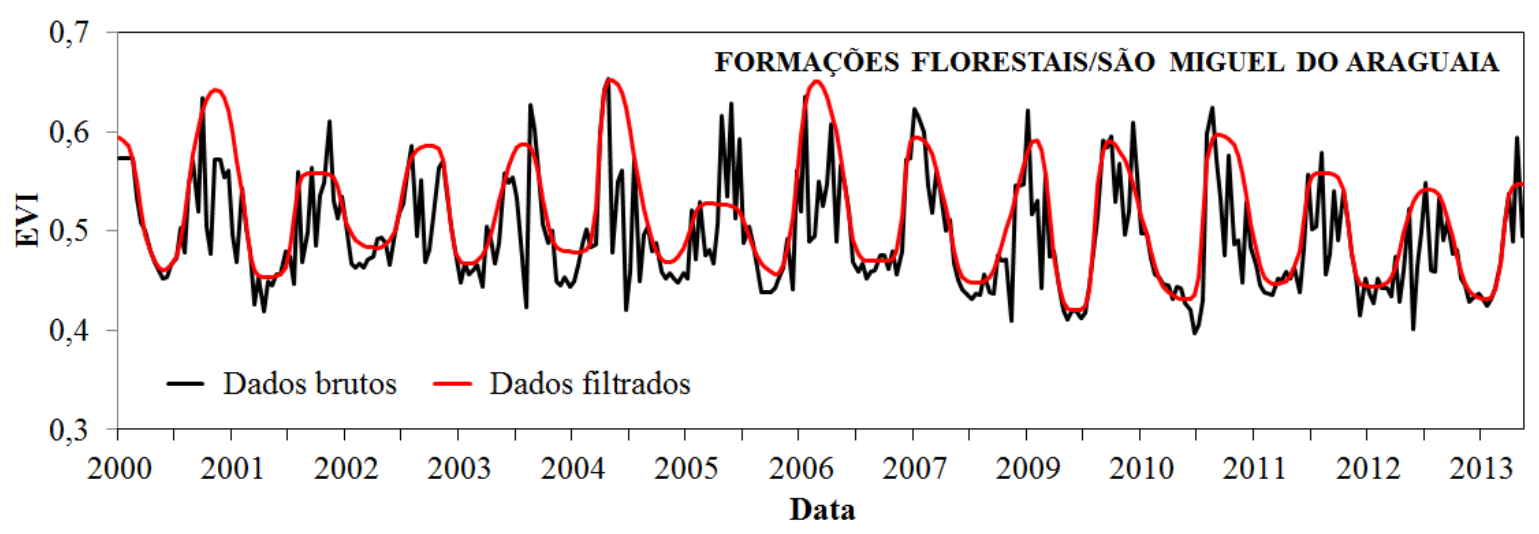

(a)

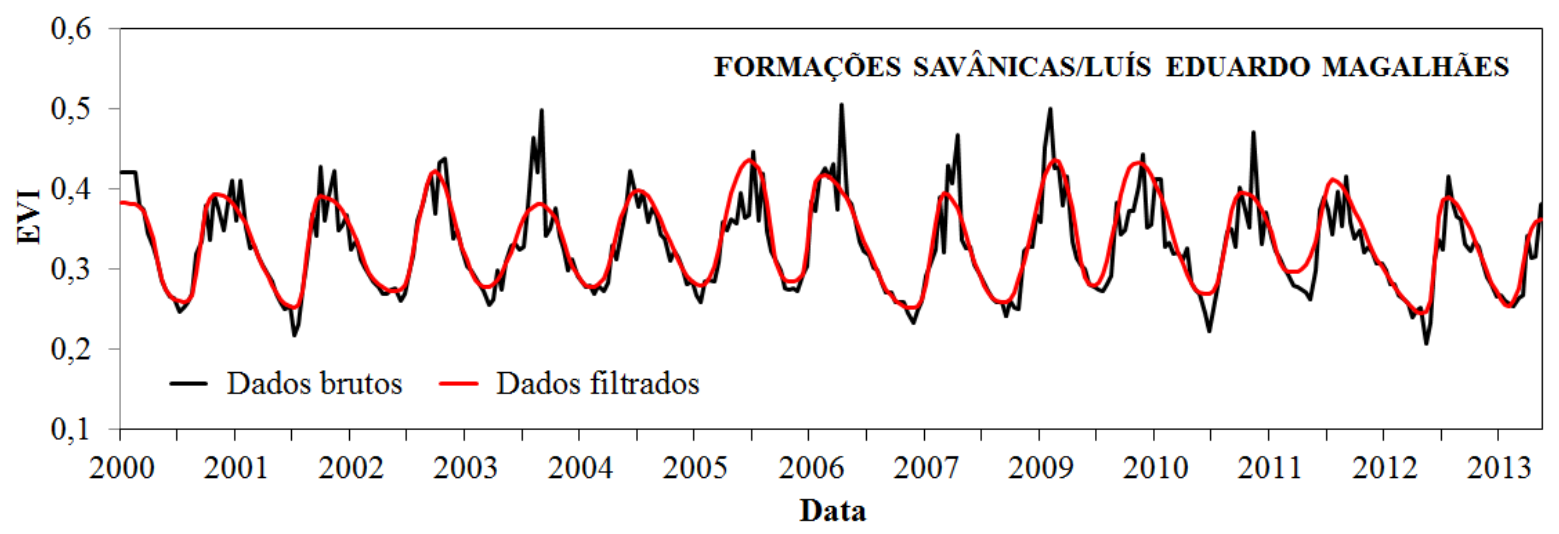

(b)

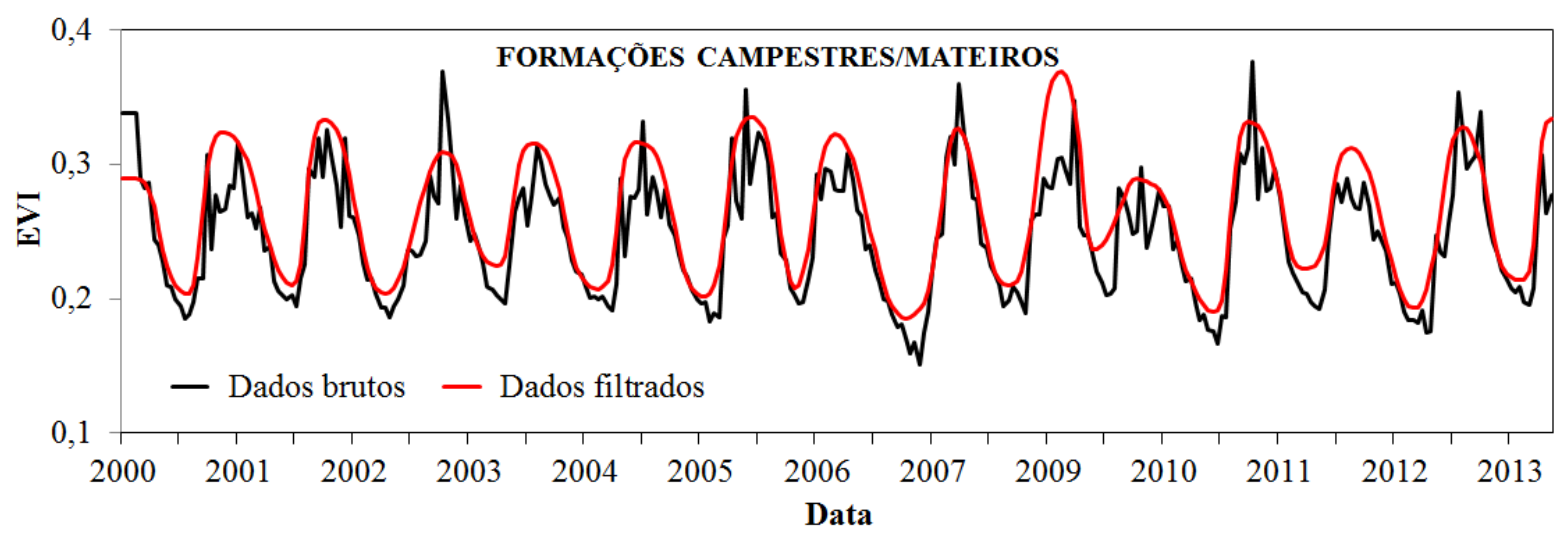

(c)

Figura 4.1 - Dados originais e filtrados de séries temporais de EVI de formações florestais de São Miguel do Araguaia (a), formações savânicas de Luís Eduardo Magalhães (b) e formações campestres de Mateiros (c). 


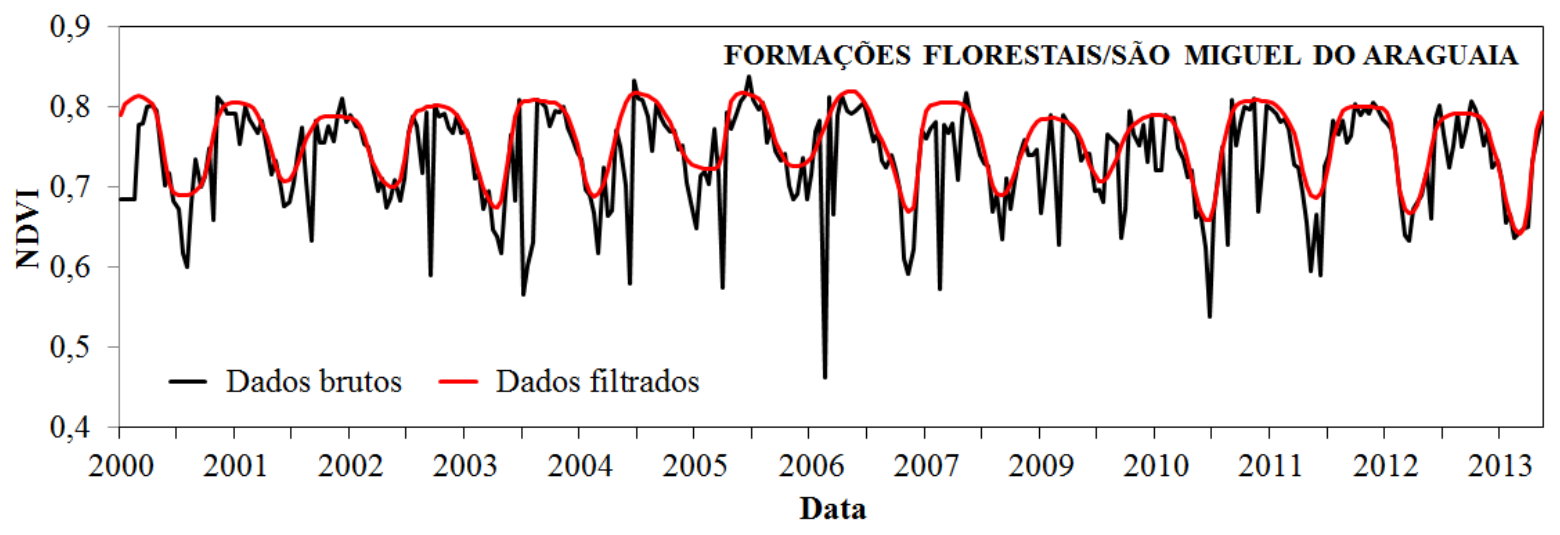

(a)

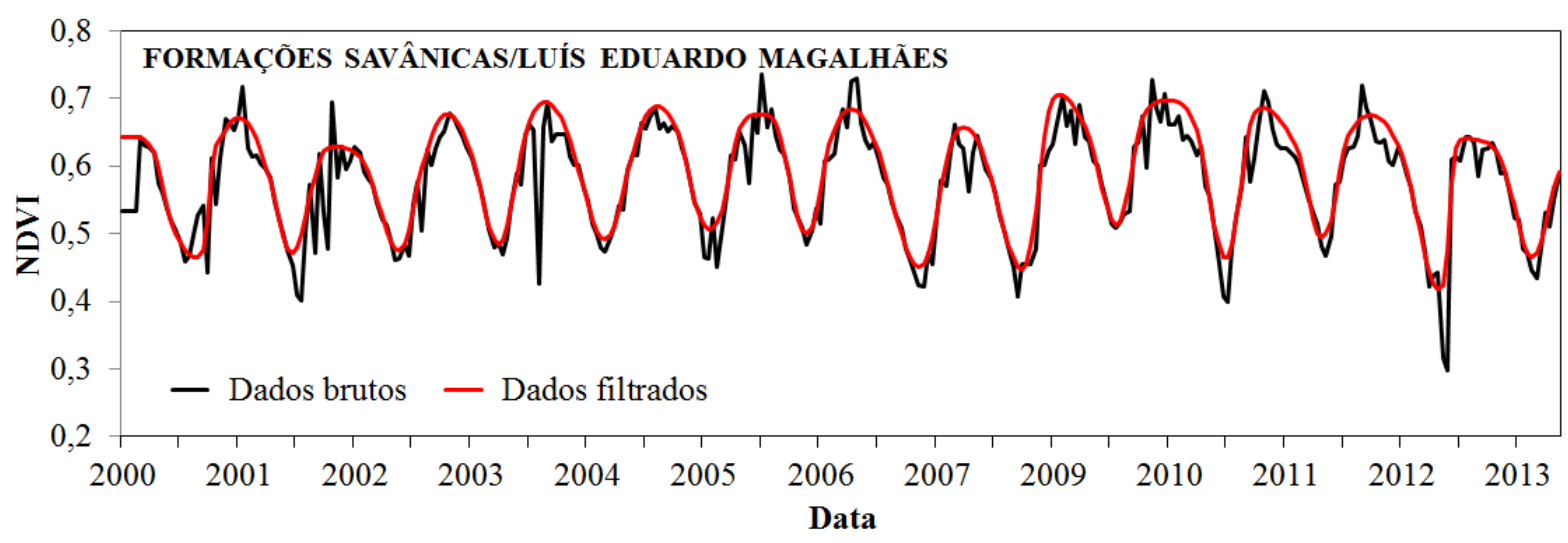

(b)

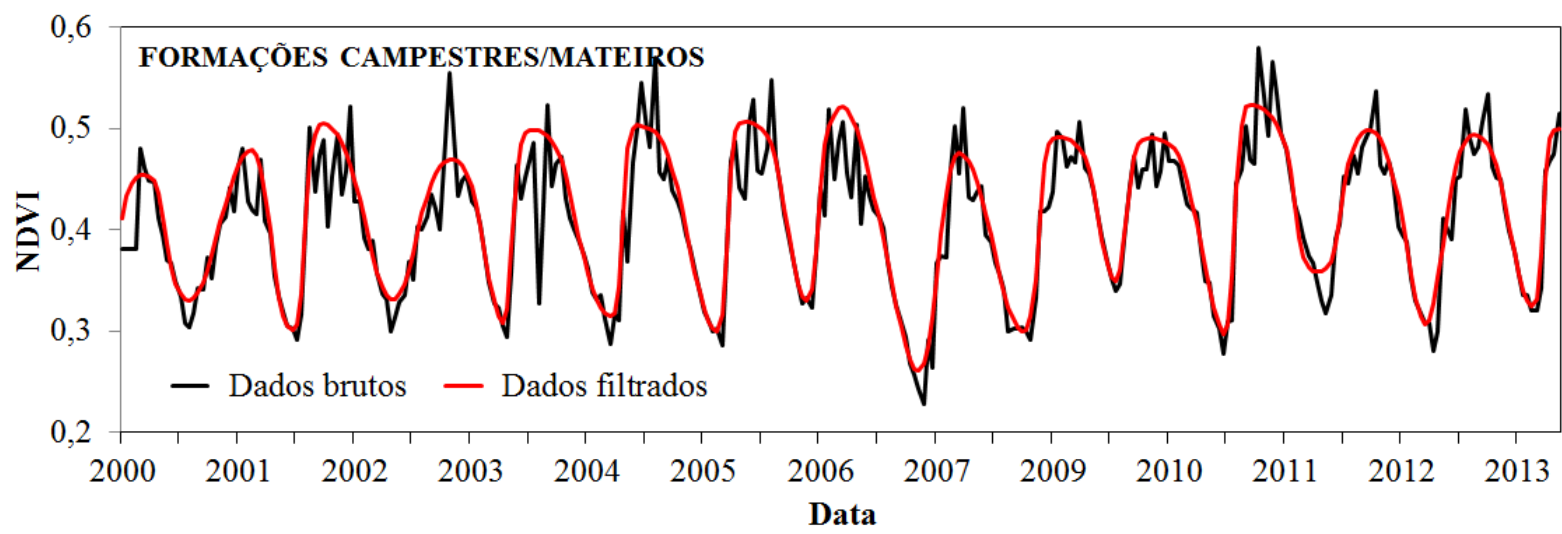

(c)

Figura 4.2 - Dados originais e filtrados de séries temporais de NDVI de formações florestais de São Miguel do Araguaia (a), formações savânicas de Luís Eduardo Magalhães (b) e formações campestres de Mateiros (c).

Na Figura 4.4, são mostradas as séries temporais de EVI correspondentes às formações florestais, savânicas e campestres encontradas nos quatro municípios considerados nesse estudo, filtradas pelo método de logística dupla. Essas séries estão de acordo com os encontrados por Borges et al. (2014) : valores médios de EVI do oeste da Bahia variando de 
0,26 a 0,38 para formações savânicas e de 0,24 para formações campestres. Apenas o valor médio de EVI para formações florestais $(0,24$, oeste da Bahia), ficou abaixo dos encontrados nesse presente estudo. Esse fato pode ser explicado pela densidade da cobertura florestal, mais densa em Jataí e São Miguel do Araguaia do que no oeste da Bahia, principalmente decorrente da precipitação média anual que é maior em Jataí e São Miguel do Araguaia do que no oeste da Bahia. Nota-se a presença de dois padrões nas séries temporais de formações savânicas: o grupo formado pelos municípios de LEM e Mateiros, com valores de EVI mais baixos e o grupo formado pelos municípios de Jataí e SMA, com valores de EVI mais altos. Este fato pode estar novamente relacionado com o regime distinto de chuvas: menor para os municípios de LEM e Mateiros (zona de transição com o bioma Caatinga) e maior para os municípios de Jataí e SMA (Figura 4.3).

Outro fator que pode estar relacionado com a similaridade entre as séries temporais dos munícípios que se situam na parte mais a oeste do bioma (Jataí e SMA) e dos dois outros situados na porção leste (Mateiros e LEM) é a similaridade florística existente entre eles, o que pode influenciar na resposta espectral diferenciada entre essas áreas. A análise da composição florística de 376 áreas de cerrado e de savana amazônica, conduzida por Ratter et al. (2003), resultaram em oito regiões com forte padrão fitogeográfico na distribuição do Cerrado. Considerando as áreas estudadas nessa dissertação, pode-se inferir que os municípios de Jatai e SMA pertencem à província Centro-Oeste e os municípios de Mateiros e LEM, à província Norte-Nordeste.

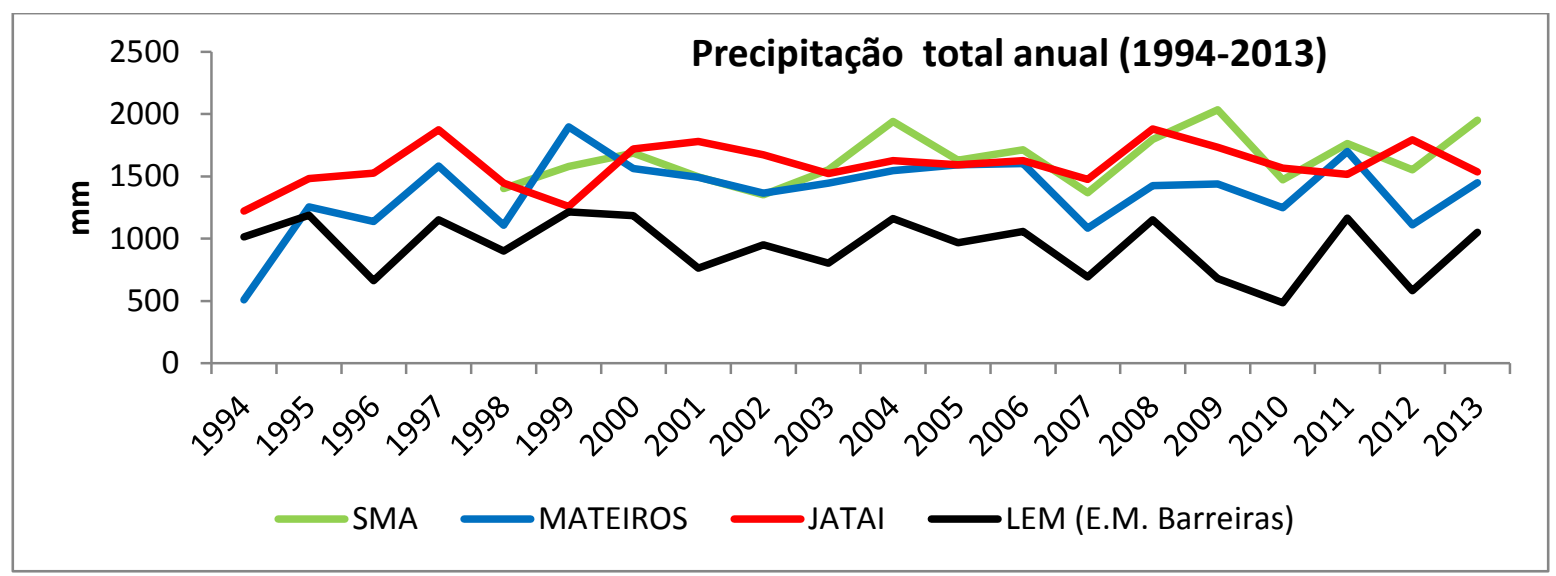

Figura 4.3 - Precipitação total anual dos municípios estudados (os dados para Mateiros e SMA foram obtidos por meio de interpolação). Fonte: INMET (2015).

Nota-se ainda que a transição, em termos de valores de EVI, entre as formações florestais, savânicas e campestres é gradativa e com sobreposição em mais de uma situação (por exemplo, EVI médio de formações florestais e savânicas de Jataí = 0,48 e 0,49 , respectivamente). Este fato é reflexo da própria transição gradual entre as diferentes fitofisionomias do Cerrado: Campo Limpo, Campo Sujo, Cerrado Ralo, Cerrado Típico, 
Cerrado Denso e Cerradão, da menor para a maior densidade de biomassa do dossel. Por causa dessa passagem gradual, a identificação da fitofisionomia correta não é tarefa simples, mesmo em nível de campo.

Variações médias entre os valores máximo e mínimo de EVI foram de 0,12 para formações florestais, 0,12 para formações savânicas e 0,09 para formações campestres (dados não mostrados na Figura 4.3). Essas variações também estão de acordo com as obtidas por Ratana et al. (2005) que analisaram séries temporais de quatro anos do MODIS EVI e MODIS NDVI de formações naturais do Cerrado do Distrito Federal e do município de Planaltina de Goiás. Percebe-se que não há diferença significativa nas variações de valores mínimo e máximo de EVI entre as três formações, indicando que os efeitos da sazonalidade climática típica do Cerrado aparecem com magnitudes similares nas séries temporais do EVI.

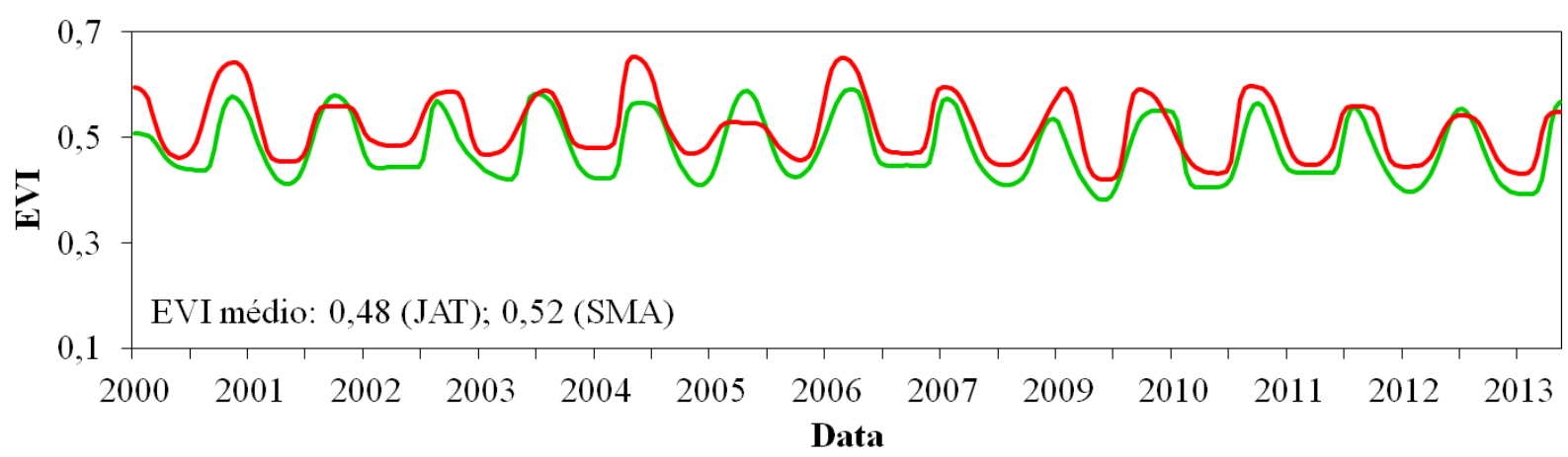

- EVI/Jataí - EVI/São Miguel do Araguaia

(a)

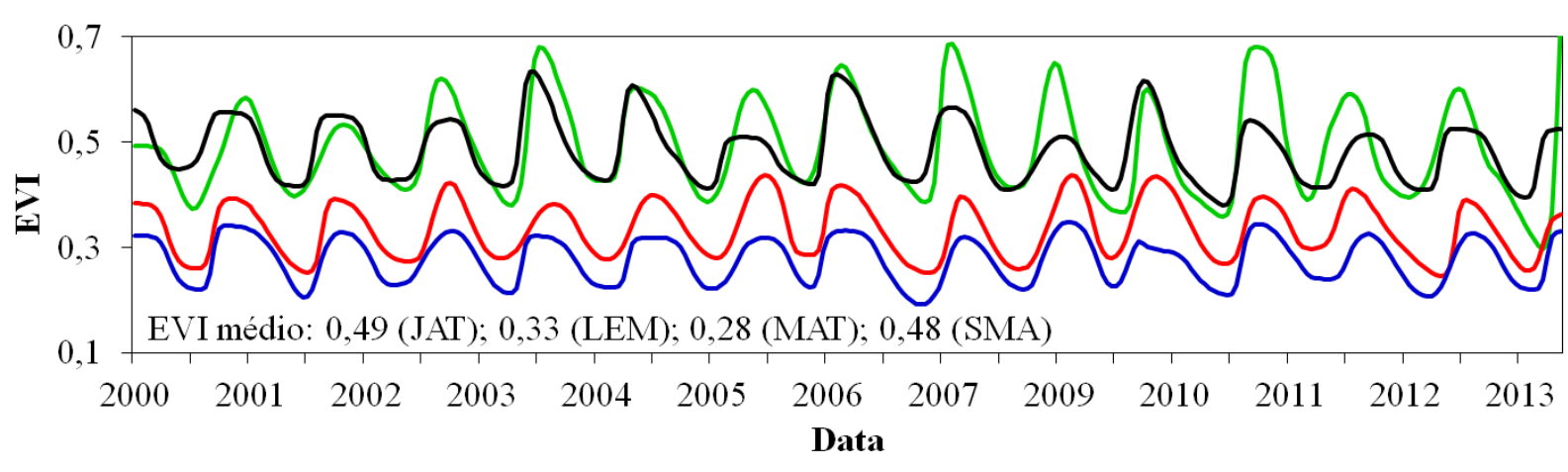

- EVI/Jataí - EVI/Luís Eduardo Magalhães - EVI/Mateiros - EVI/São Miguel do Araguaia

(b) 


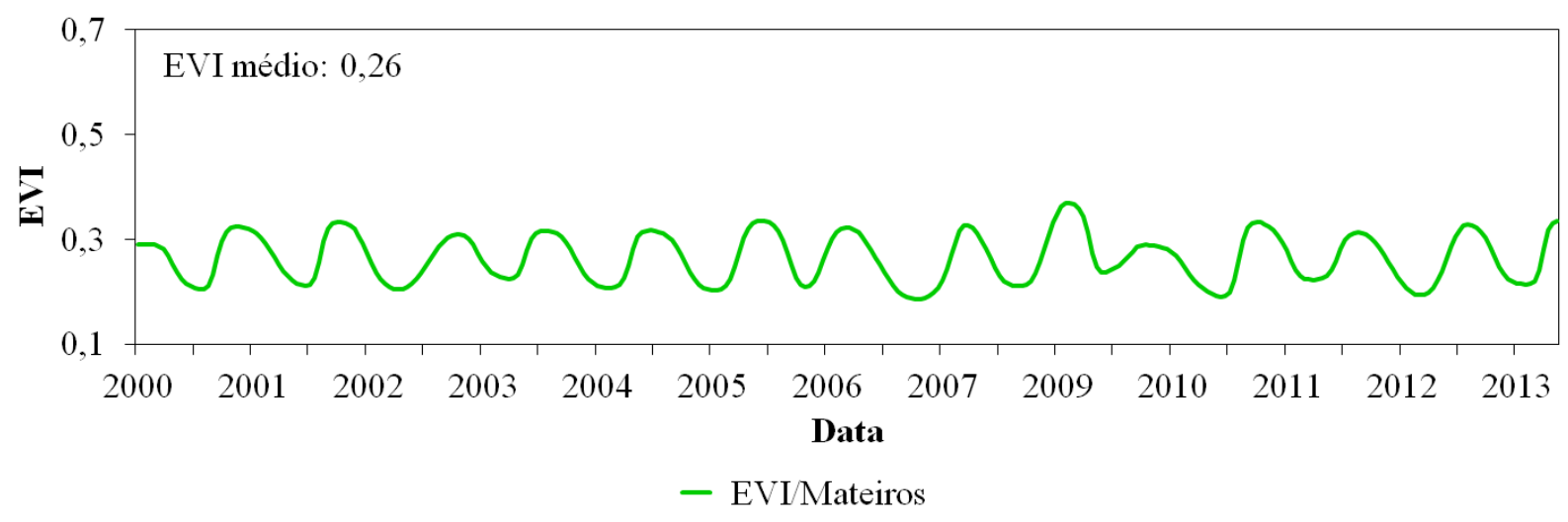

(c)

Figura 4.4 - Séries temporais de EVI para as formações florestais (a), savânicas (b) e campestres (c), encontrados nos municípios de Jataí/GO, Luís Eduardo Magalhães/BA, Mateiros/TO e São Miguel do Araguaia/GO, filtrados pelo método de logística dupla, disponível no programa TIMESAT. Dados baseados nas coordenadas GPS de campo e nos valores médios de EVI por formação vegetacional. JAT = Jataí; LEM = Luís Eduardo Magalhães; MAT = Mateiros; SMA = São Miguel do Araguaia.

As séries temporais filtradas de NDVI para as três formações vegetacionais (Figura 4.5) mostram que os padrões temporais das formações savânicas de Jataí e de SMA apresentaram valores de NDVI muito mais próximas do que os de EVI. Já as amplitudes médias de variação nos valores de NDVI praticamente foram as mesmas do EVI $(0,13$ e 0,12 , respectivamente; dados não mostrados nas figuras). De uma maneira geral, as assinaturas temporais de NDVI foram similares aos obtidos para o EVI, porém, com valores mais altos. Por exemplo, para a formação florestal de Jataí, o valor de índice de vegetação aumentou de 0,48 para 0,76 . Esse aumento foi verificado para todas as formações vegetacionais e em todos os municípios. Essa variação de 0,2 a 0,3 nos dois índices também já foram observados por outros autores como Liesenberg et al. (2007). De fato, todos os 2.254 valores de NDVI (23 valores por ano x 14 anos x 7 médias de índices de vegetação) foram maiores do que os seus correspondentes valores de EVI (Figura 4.6). Esta última figura mostra ainda a presença de tendência de saturação dos pixels de NDVI para valores relativamente altos (NDVI > 0,75) e que, no terreno, correspondem a áreas com altos índices de biomassa, conforme mencionado por Huete et al. (2002). 


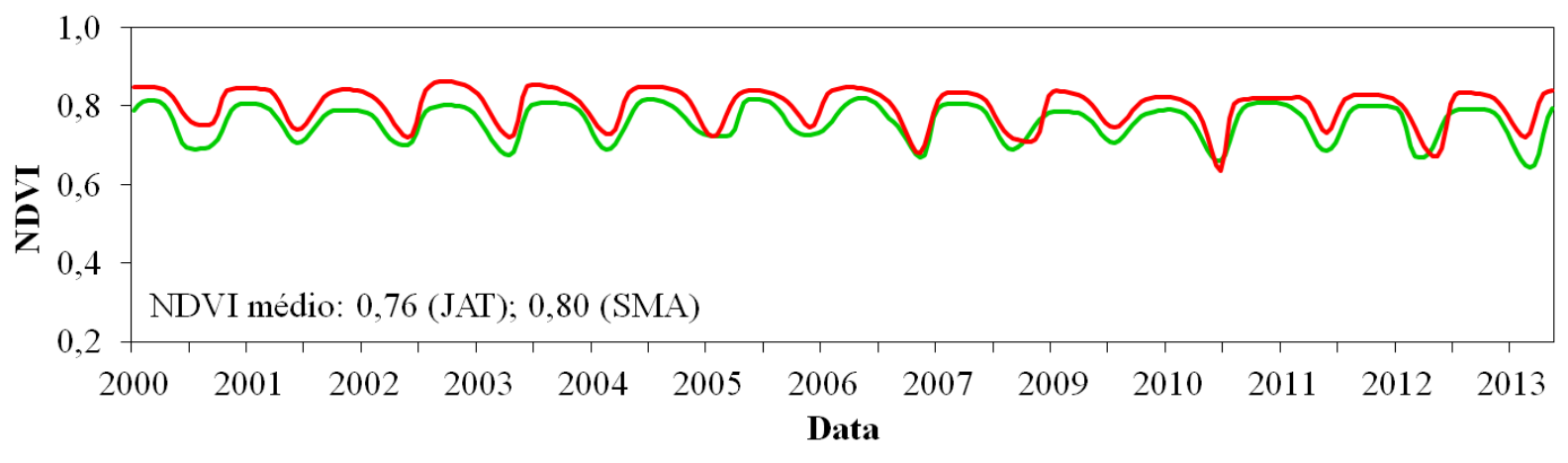

- NDVI/Jataí - NDVI/São Miguel do Araguaia

(a)

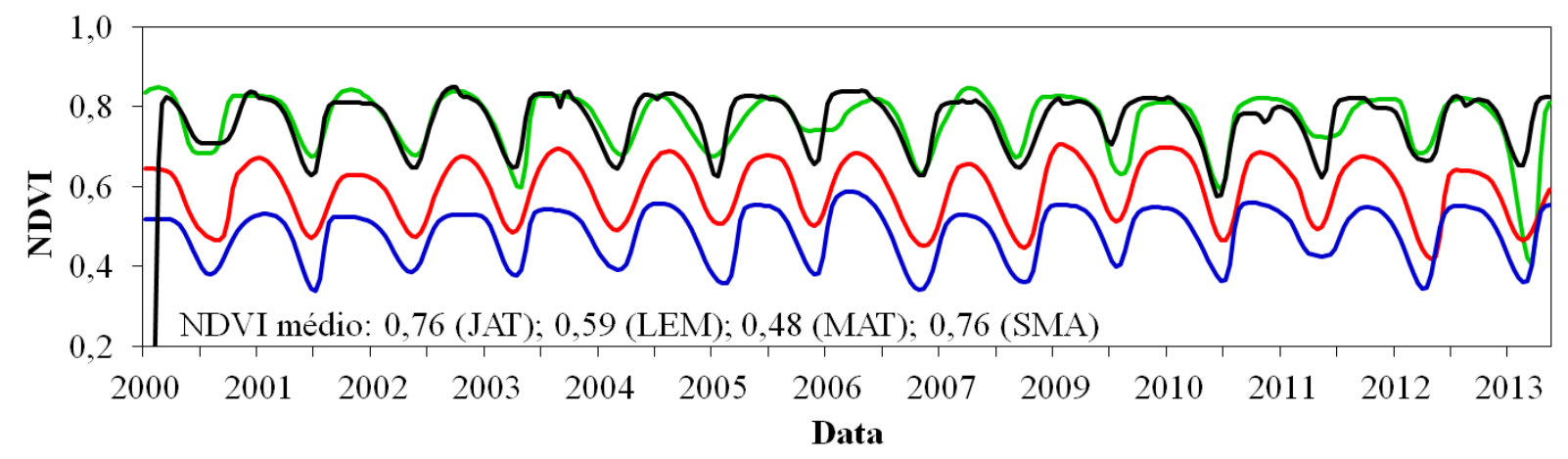

- NDVI/Jataí - NDVI/Luís Eduardo Magalhães - NDVI/Mateiros - NDVI/São Miguel do Araguaia

(b)

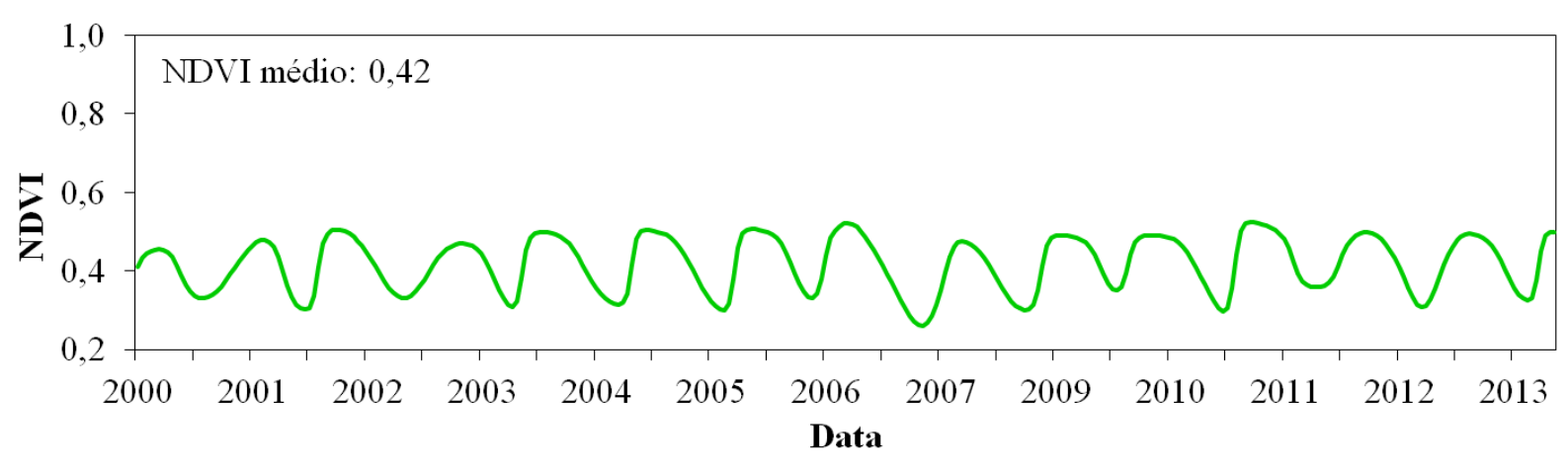

- NDVI/Mateiros

(c)

Figura 4.5 - Séries temporais de NDVI para as formações florestais (a), savânicas (b) e campestres (c), encontrados nos municípios de Jataí/GO, Luís Eduardo Magalhães/BA, Mateiros/TO e São Miguel do Araguaia/GO, filtrados pelo método de logística dupla, disponível no programa TIMESAT. Dados baseados nas coordenadas GPS de campo e nos valores médios de EVI por formação vegetacional. JAT = Jataí; LEM = Luís Eduardo Magalhães; MAT = Mateiros; SMA = São Miguel do Araguaia. 


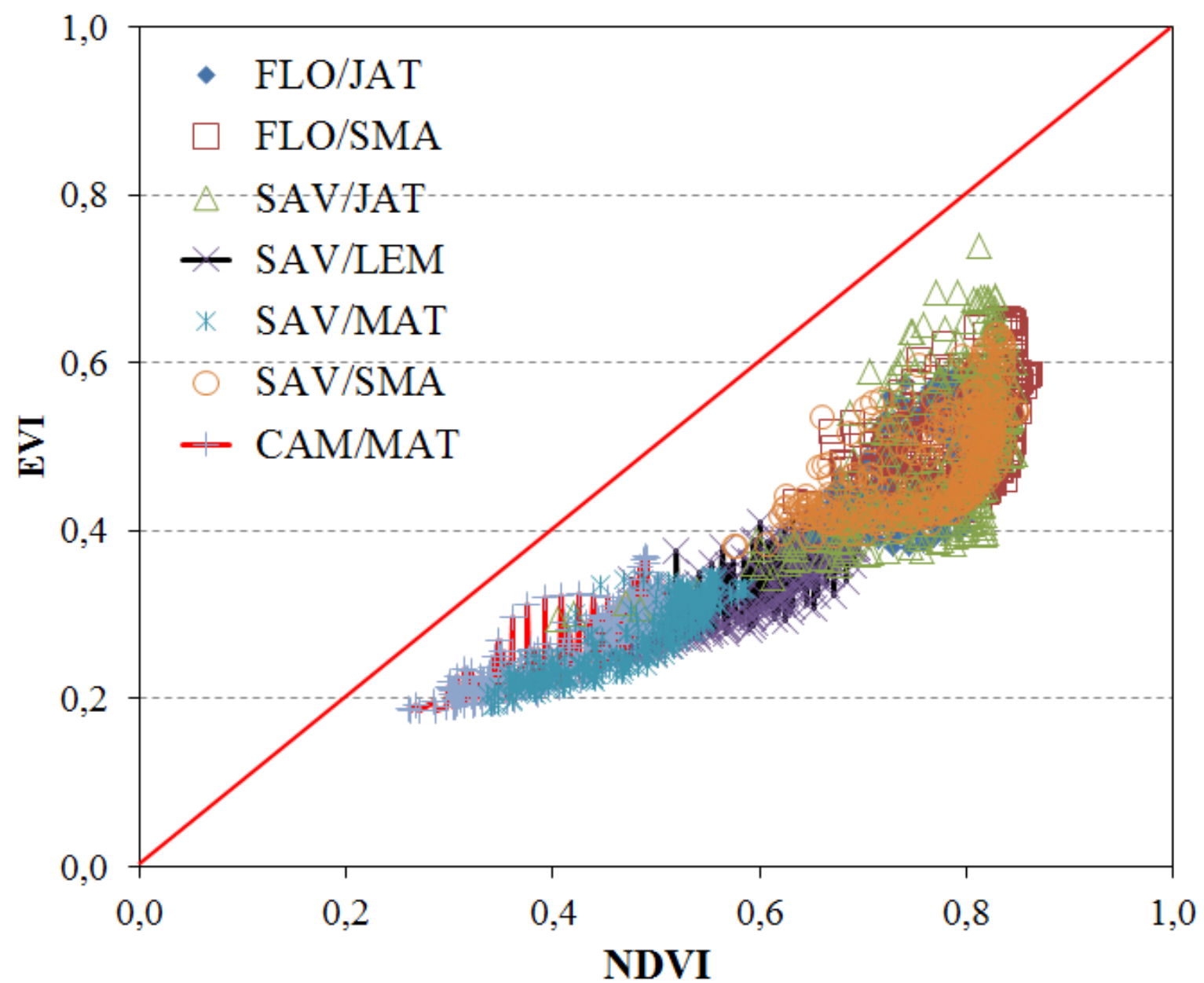

Figura 4.6 - Relação entre NDVI e EVI referente às séries temporais (período: 2000-2013) das formações vegetacionais naturais dos municípios de Jataí (JAT), Luís Eduardo Magalhães (LEM), Mateiros (MAT) e São Miguel do Araguaia (SMA). FLO = formações florestais; $S A V$ = formações savânicas; $C A M=$ formações campestres.

A Tabela 4.2 exibe os valores mínimos e máximos encontrados nas séries temporais representativas de EVI e de NDVI dos municípios estudados, bem como os valores de média e de desvio padrão.

Tabela 4.2 - Estatística básica das séries temporais representativas dos municípios estudados. JAT = Jataí; LEM = Luís Eduardo Magalhães; MAT = Mateiros; SMA = São Miguel do Araguaia; FLO = formações florestais; $S A V=$ formações savânicas; $C A M=$ formações campestres.

\begin{tabular}{ccccccccc}
\cline { 2 - 9 } & \multicolumn{4}{c}{ EVI } & \multicolumn{5}{c}{ NDVI } \\
\hline $\begin{array}{c}\text { Munic./Form. } \\
\mathrm{N}=322\end{array}$ & $\begin{array}{c}\text { Valor } \\
\text { mínimo }\end{array}$ & $\begin{array}{c}\text { Valor } \\
\text { máximo }\end{array}$ & Média & DP & $\begin{array}{c}\text { Valor } \\
\text { mínimo }\end{array}$ & $\begin{array}{c}\text { Valor } \\
\text { máximo }\end{array}$ & Média & DP \\
\hline JAT-FLO & 0,38 & 0,59 & 0,48 & 0,058 & 0,64 & 0,82 & 0,76 & 0,044 \\
\hline
\end{tabular}




\begin{tabular}{ccccccccc}
\hline JAT-SAV & 0,30 & 0,74 & 0,49 & 0,089 & 0,40 & 0,84 & 0,76 & 0,071 \\
\hline LEM-SAV & 0,24 & 0,44 & 0,33 & 0,053 & 0,42 & 0,70 & 0,59 & 0,075 \\
\hline MAT-SAV & 0,20 & 0,35 & 0,28 & 0,043 & 0,34 & 0,59 & 0,48 & 0,065 \\
\hline MAT-CAM & 0,19 & 0,37 & 0,26 & 0,046 & 0,26 & 0,52 & 0,42 & 0,069 \\
\hline SMA-FLO & 0,42 & 0,65 & 0,52 & 0,058 & 0,64 & 0,86 & 0,78 & 0,047 \\
\hline SMA-SAV & 0,38 & 0,63 & 0,48 & 0,059 & 0,58 & 0,85 & 0,76 & 0.064 \\
\hline
\end{tabular}

Testes Shapiro-Wilk de normalidade das séries temporais de EVI e NDVI das três formações vegetacionais encontradas nos quatro municípios indicaram que a distribuição não é normal para nenhuma das séries analisadas, conforme comportamento nãogaussiano evidenciado pelos gráficos (Figuras 4.7 e 4.8). De acordo com Prof. Lúcio Vivaldi (informação verbal), professor de Estatística da Universidade de Brasília e pesquisador aposentado da Embrapa Cerrados, curvas com padrão senoidal sequencial típico, que é o caso das séries temporais de EVI e NDVI do Cerrado, dificilmente apresentam distribuição normal.

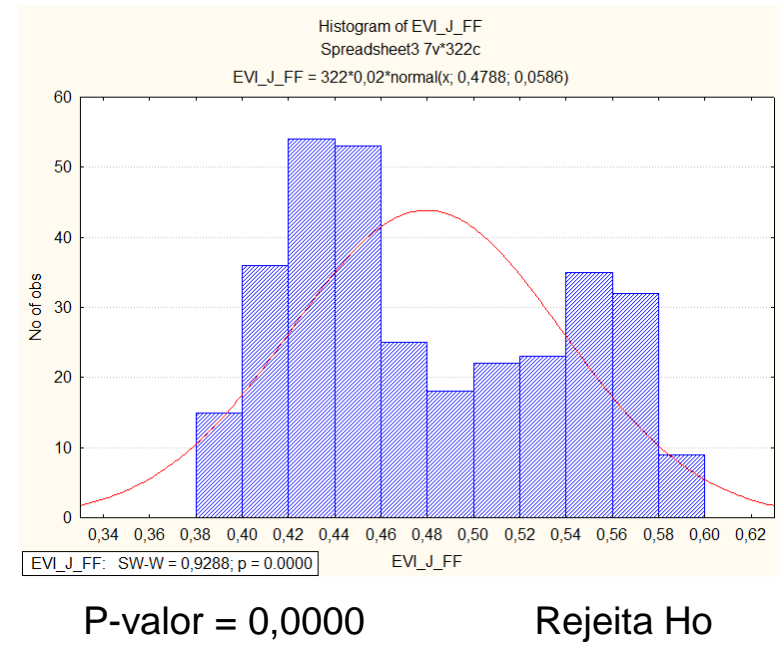

(a)

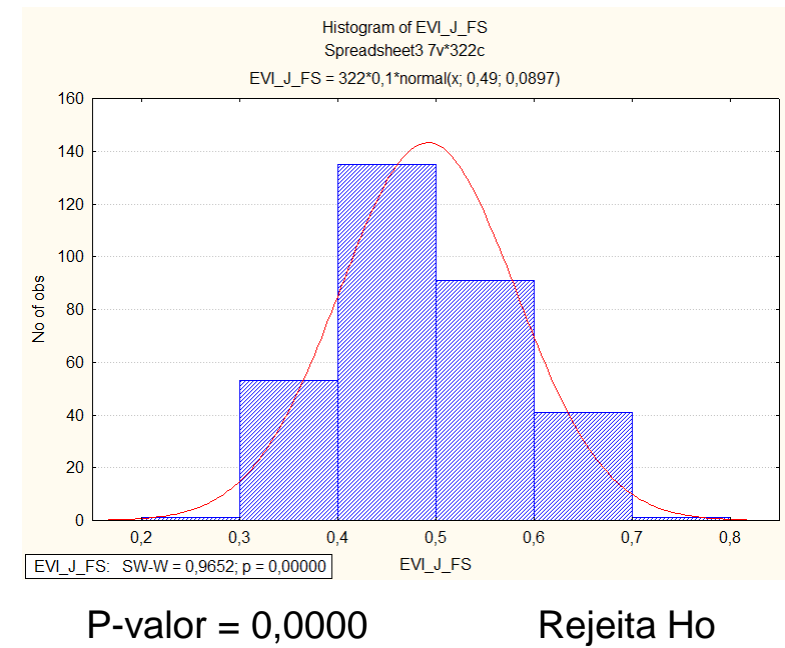

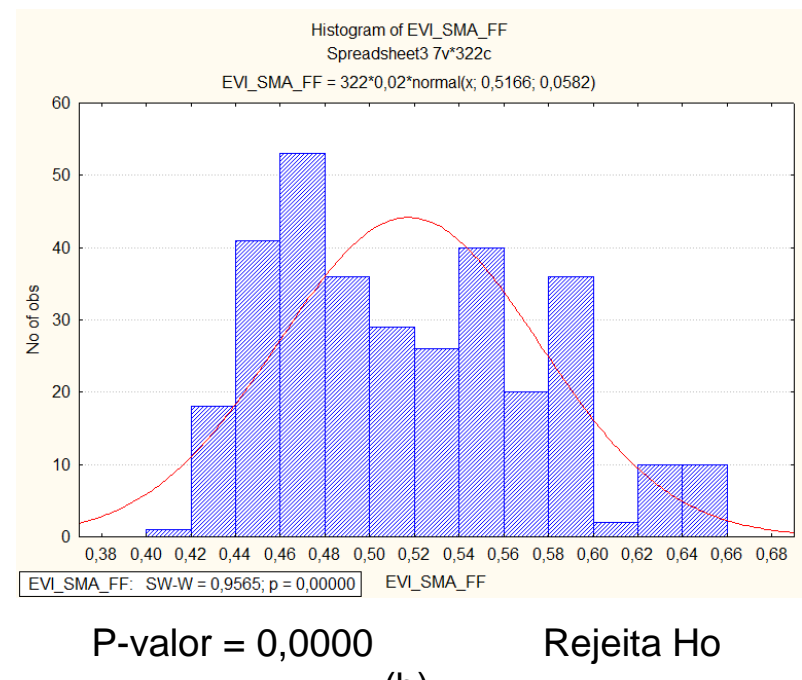

(b)

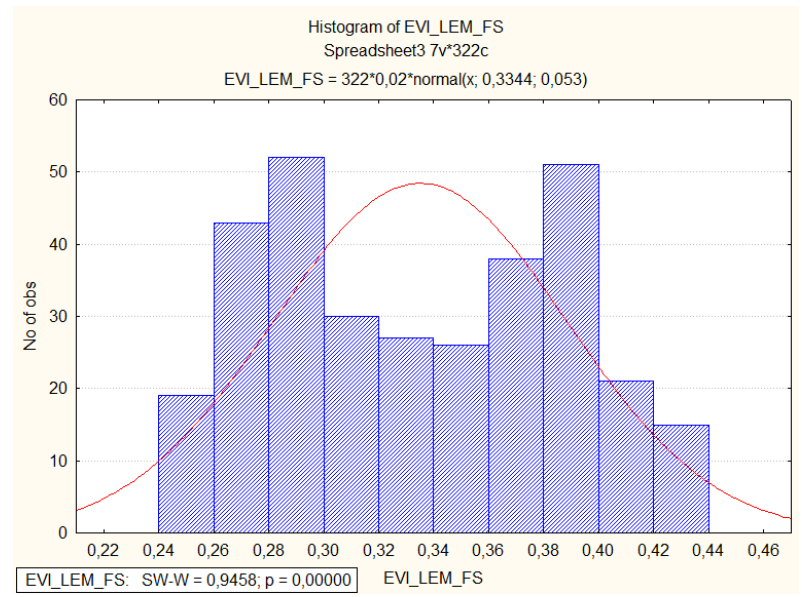


(c)

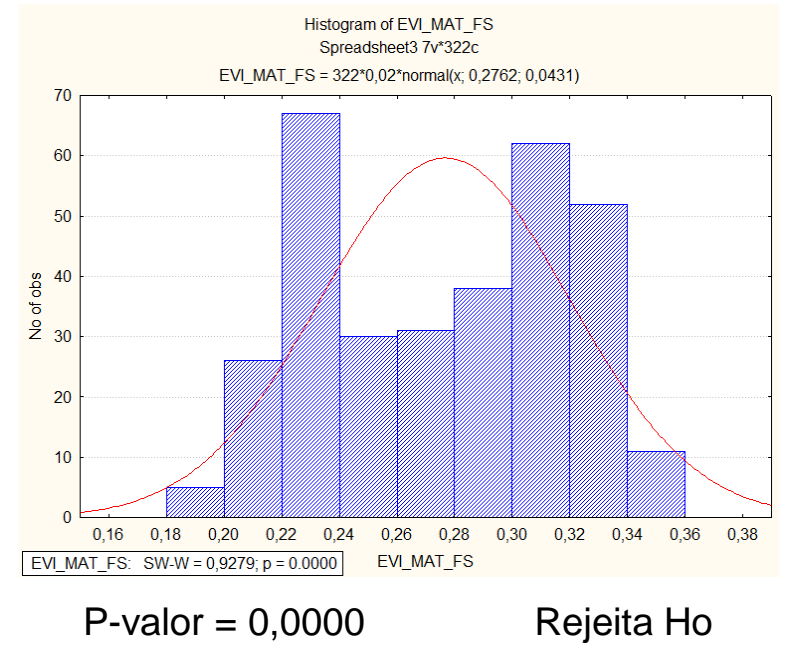

(e)

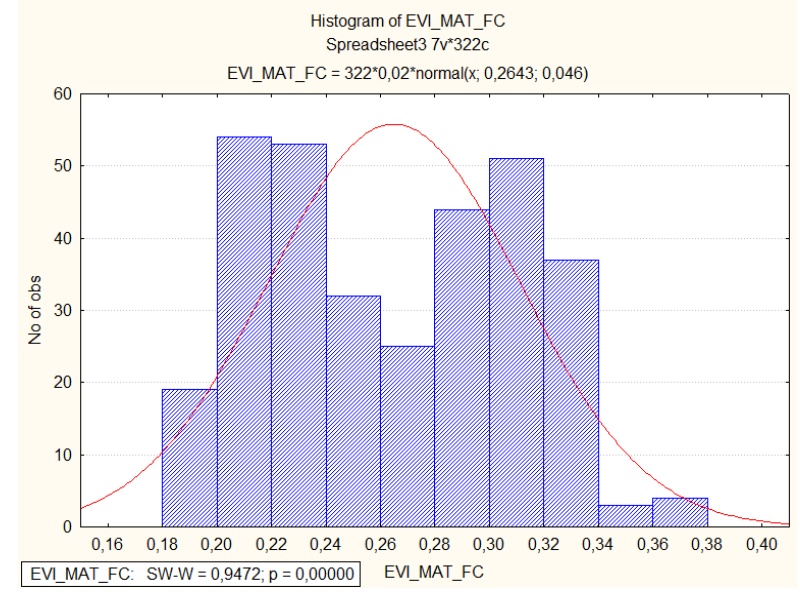

P-valor $=0,0000$

(g)

$$
\text { P-valor }=0,0000
$$

(d)

Rejeita Ho

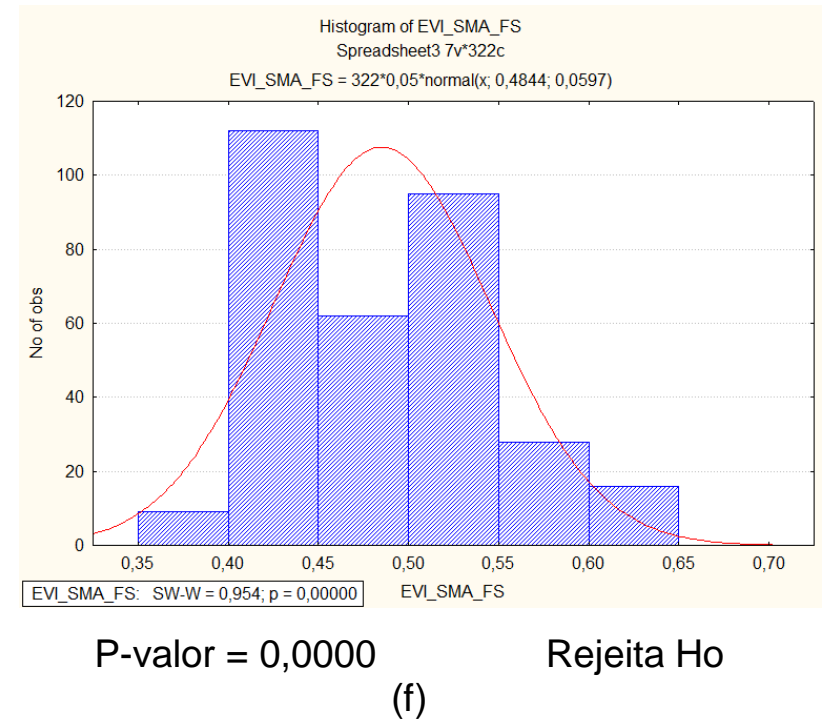

Figura 4.7 - Teste de Shapiro-Wilk para verificação da normalidade dos valores de EVI das formações florestais dos municípios de Jataí (a) e São Miguel do Araguaia (b), das formações savânicas dos municípios de Jataí (c), Luís Eduardo Magalhães (d), Mateiros (e) e São Miguel do Araguaia (f) e das formações campestres de Mateiros (g). Ho: série temporal possui distribuição normal.

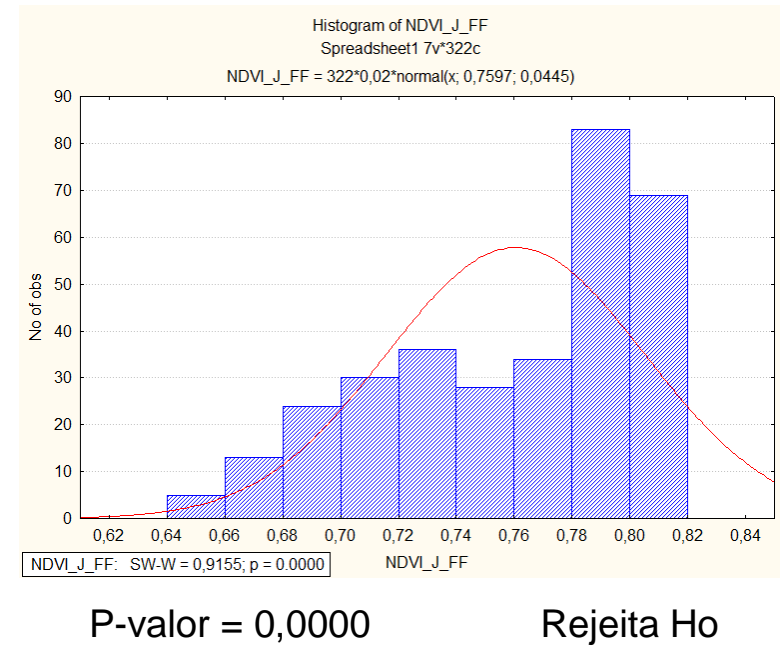

(a)

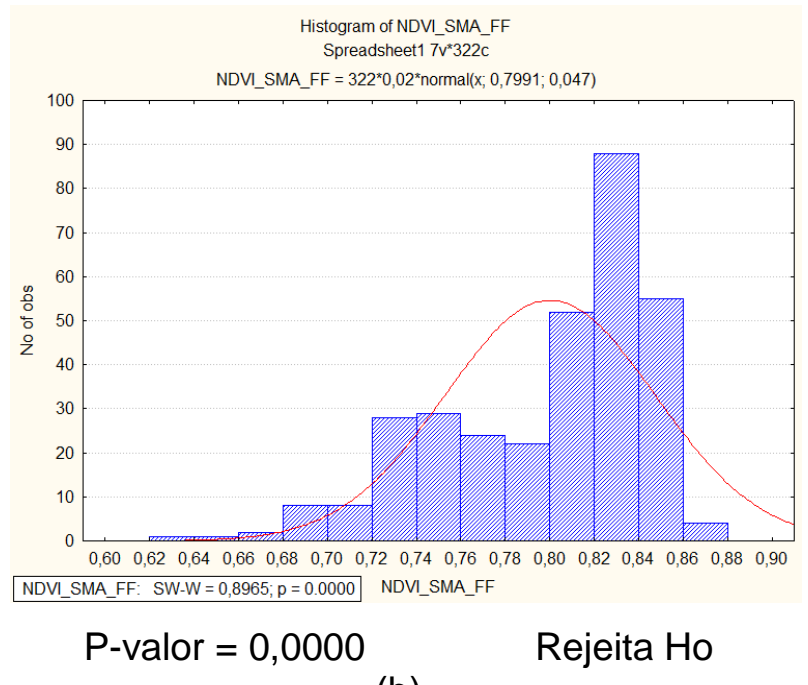

(b) 


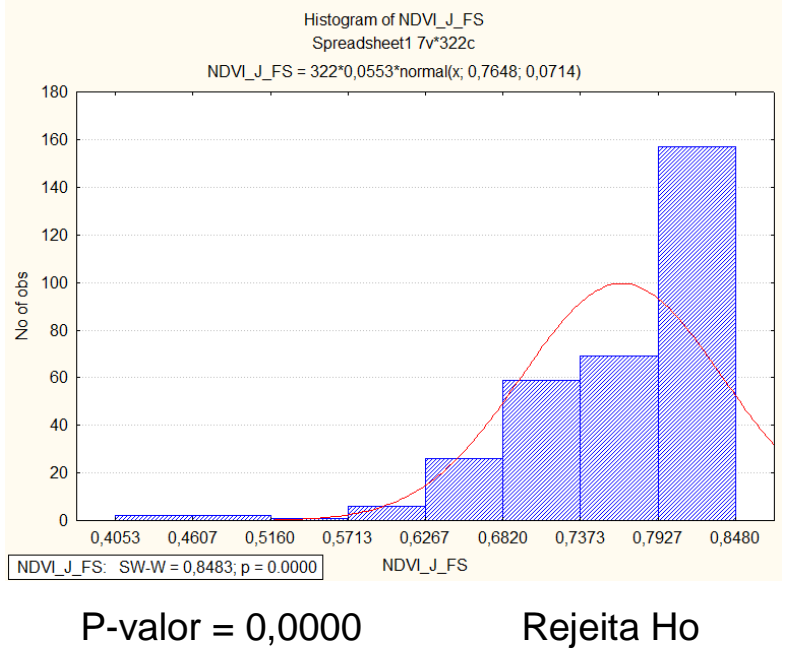

(c)

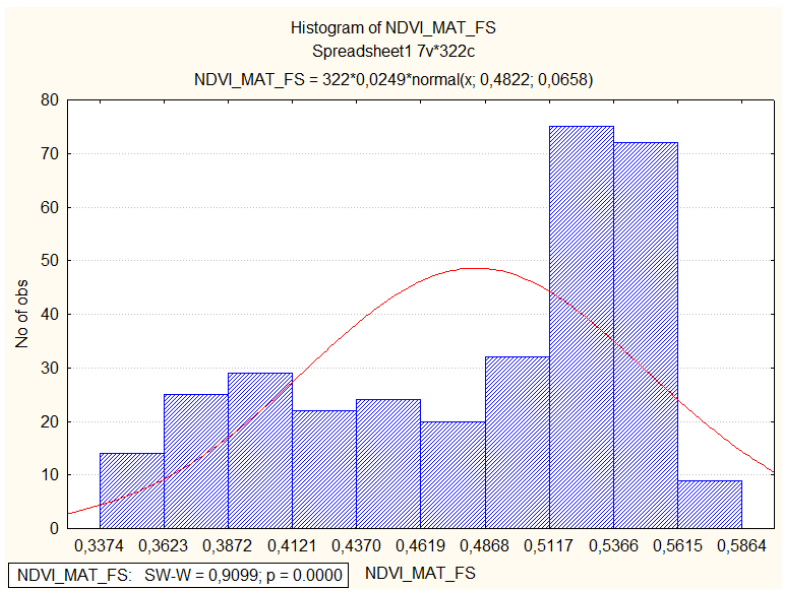

$\mathrm{P}$-valor $=0,0000$

(e)

Rejeita Ho

Histogram of NDVI_MAT_FC

Spreadsheet $17 \mathrm{v}^{*} 322 \mathrm{c}$

NDVI_MAT_FC $=322^{*} 0,0263^{*}$ normal $(x ; 0,4186 ; 0,069)$

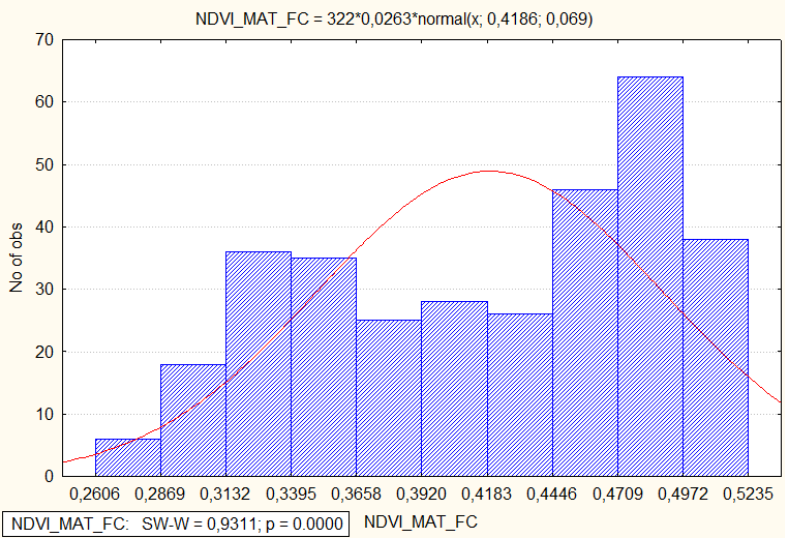

P-valor $=0,0000$

(g)

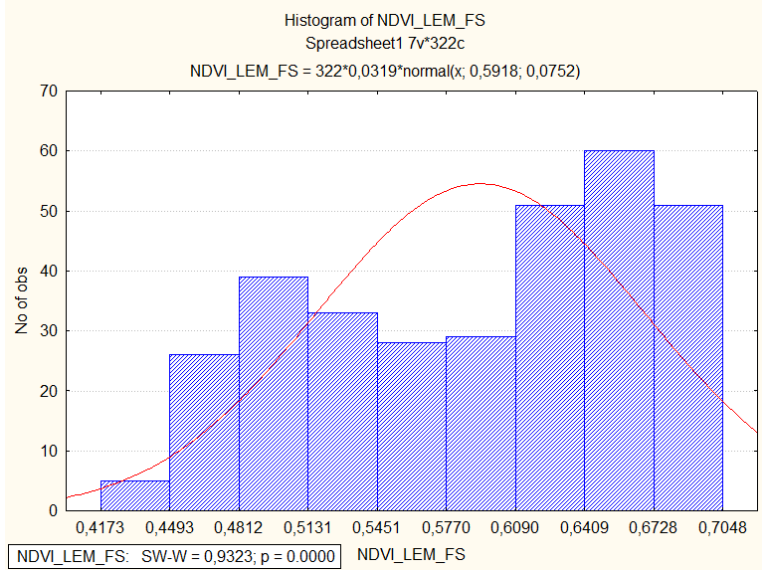

$\mathrm{P}$-valor $=0,0000$

Rejeita Ho

(d)

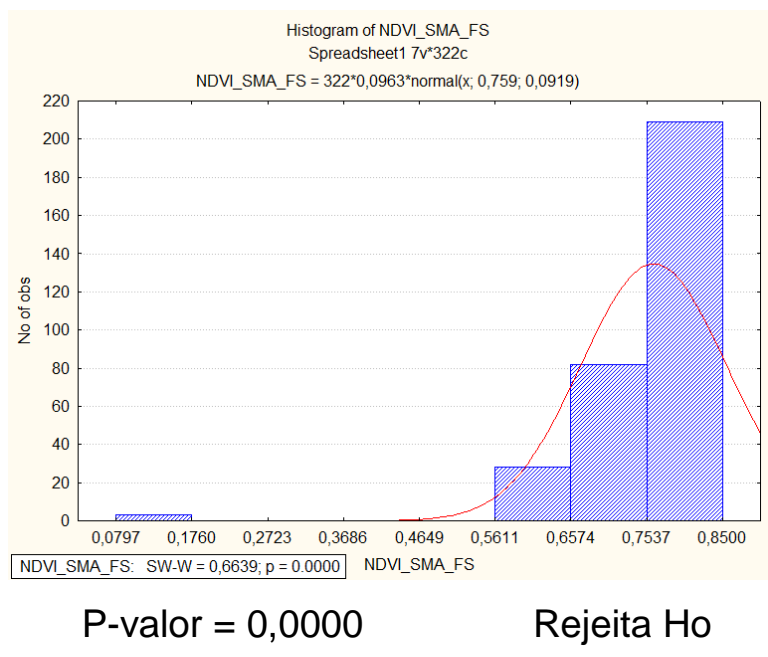

(f)

Figura 4.8 - Teste de Shapiro-Wilk para verificação da normalidade dos valores de NDVI das formações florestais dos municípios de Jataí (a) e São Miguel do Araguaia (b), das formações savânicas dos municípios de Jataí (c), Luís Eduardo Magalhães (d), Mateiros (e) e São Miguel do Araguaia (f) e das formações campestres de Mateiros (g). Ho: série temporal possui distribuição normal.

Testes não-paramétricos de Kruskal-Wallis envolvendo valores de EVI e NDVI (Tabelas 4.3 e 4.4) indicaram que as séries temporais de EVI das formações florestais de Jataí e São Miguel do Araguaia são estatisticamente diferentes. Já as formações savânicas 
de Jataí e São Miguel do Araguaia e de Luís Eduardo Magalhães e Mateiros demonstraram ser estatisticamente iguais, porém, entre todos os outros municípios foram diferentes. Conclusões similares foram encontradas para NDVI. Esses resultados indicam que os limiares de desmatamento de cada formação vegetacional não podem ser únicos para todo o Cerrado, uma vez que as séries temporais são estatisticamente diferentes, dependendo da região em que se encontra dentro do bioma. Não foi possível efetuar a análise para as formações campestres, uma vez que essa formação só foi encontrada no município de Mateiros.

Tabela 4.3 - Teste Kruskal-Wallis de igualdade de médias de valores de EVI (série temporal de 2000 a 2013) para a mesma formação vegetacional e diferentes municípios. JAT = Jataí; LEM = Luís Eduardo Magalhães; MAT = Mateiros; e SMA = São Miguel do Araguaia. Ho = séries temporais são estatisticamente iguais.

\begin{tabular}{lcccccc}
\hline Formação & Municípios & $\begin{array}{c}\text { Valor de P } \\
(\mathrm{P} \text {-value })\end{array}$ & $\begin{array}{c}\text { Grau de } \\
\text { liberdade } \\
(\mathrm{GL})\end{array}$ & $\begin{array}{c}\text { Valor } \\
\text { Observado } \\
\left(\mathrm{H}_{\mathrm{obs}}\right)\end{array}$ & $\begin{array}{c}\text { Valor } \\
\text { Crítico } \\
\left(\mathrm{Q}_{0,95}\right)\end{array}$ & $\begin{array}{c}\text { Hipótese } \\
\text { Nula (Ho) }\end{array}$ \\
\hline Florestal & JAT x SMA & 0,0126 & 1 & 9,86 & 7,76 & Rejeita \\
Savânica & JAT x LEM & 0,0000 & 3 & 38,83 & 20,77 & Rejeita \\
Savânica & JAT X MAT & 0,0000 & 3 & 52,52 & 20,77 & Rejeita \\
Savânica & JAT X SMA & 0,0000 & 3 & 0,48 & 20,77 & Aceita \\
Savânica & LEM X MAT & 0,0000 & 3 & 13,70 & 20,77 & Aceita \\
Savânica & LEM X SMA & 0,0000 & 3 & 39,30 & 20,77 & Rejeita \\
Savânica & MAT X SMA & 0,0000 & 3 & 53,00 & 20,77 & Rejeita \\
\hline
\end{tabular}

Tabela 4.4 - Teste Kruskal-Wallis de igualdade de médias de valores de NDVI (série temporal de 2000 a 2013) para a mesma formação vegetacional e diferentes municípios. JAT = Jataí; LEM = Luís Eduardo Magalhães; MAT = Mateiros; e SMA = São Miguel do Araguaia. Ho = séries temporais são estatisticamente iguais.

\begin{tabular}{lcccccc}
\hline Formação & Municípios & $\begin{array}{c}\text { Valor de } \mathrm{P} \\
(\mathrm{P} \text {-value })\end{array}$ & $\begin{array}{c}\text { Grau de } \\
\text { liberdade } \\
(\mathrm{GL})\end{array}$ & $\begin{array}{c}\text { Valor } \\
\text { Observado } \\
\left(\mathrm{H}_{\text {obs }}\right)\end{array}$ & $\begin{array}{c}\text { Valor } \\
\text { Crítico } \\
\left(\mathrm{Q}_{0,95}\right)\end{array}$ & $\begin{array}{c}\text { Hipótese } \\
\text { Nula (Ho) }\end{array}$ \\
\hline Florestal & JAT x SMA & 0,0126 & 1 & 11,96 & 7,76 & Rejeita \\
Savânica & JAT x LEM & 0,0000 & 3 & 37,57 & 20,77 & Rejeita \\
Savânica & JAT X MAT & 0,0000 & 3 & 54,78 & 20,77 & Rejeita \\
Savânica & JAT X SMA & 0,0000 & 3 & 3,39 & 20,77 & Aceita
\end{tabular}




\begin{tabular}{lllllll} 
Savânica & LEM X MAT & 0,0000 & 3 & 17,22 & 20,77 & Aceita \\
Savânica & LEM X SMA & 0,0000 & 3 & 34,17 & 20,77 & Rejeita \\
Savânica & MAT X SMA & 0,0000 & 3 & 51,39 & 20,77 & Rejeita \\
\hline
\end{tabular}

Dessa forma, foram obtidos dois limiares de desmatamento para as formações florestais. Conforme definido no Capítulo 3, limiar de desmatamento corresponde ao valor mínimo de EVI ou NDVI, abaixo do qual é considerado, nesse estudo, como início de um evento de desmatamento. Para as formações savânicas, também foram definidos dois limiares, um para os municípios de Jataí e São Miguel do Araguaia e outro para os municípios de Luís Eduardo Magalhães e Mateiros. Nesse caso, foi considerada a média aritmética simples dos limiares correspondentes aos pares de municípios envolvidos. Para as formações campestres, foi considerado o limiar obtido em Mateiros. Os limiares de desmatamento de EVI e de NDVI encontram-se na Tabela 4.5. Limiares de desmatamento para NDVI foram sempre maiores que os de EVI.

Tabela 4.5 - Valores mínimos de EVI e de NDVI para as formações fisionômicas das áreas estudadas.

Formações Vegetacionais

\begin{tabular}{|c|c|c|c|c|c|c|}
\hline \multirow[t]{2}{*}{ Município } & \multicolumn{2}{|c|}{ Florestal } & \multicolumn{2}{|c|}{ Savânica } & \multicolumn{2}{|c|}{ Campestre } \\
\hline & $\begin{array}{c}\text { EVI } \\
\text { Mínimo }\end{array}$ & $\begin{array}{c}\text { NDVI } \\
\text { Mínimo }\end{array}$ & $\begin{array}{c}\text { EVI } \\
\text { Mínimo }\end{array}$ & $\begin{array}{c}\text { NDVI } \\
\text { Mínimo }\end{array}$ & $\begin{array}{c}\text { EVI } \\
\text { Mínimo }\end{array}$ & $\begin{array}{l}\text { NDVI } \\
\text { Mínimo }\end{array}$ \\
\hline Jataí & 0,38 & 0,64 & \multirow{2}{*}{0,34} & \multirow{2}{*}{0,49} & - & - \\
\hline $\begin{array}{l}\text { São Miguel do } \\
\text { Araguaia }\end{array}$ & 0,42 & 0,64 & & & - & - \\
\hline $\begin{array}{l}\text { Luís Eduardo } \\
\text { Magalhães }\end{array}$ & - & - & \multirow{2}{*}{0,22} & \multirow{2}{*}{0,38} & - & - \\
\hline Mateiros & - & - & & & 0,19 & 0,26 \\
\hline
\end{tabular}

A seguir, são apresentados alguns casos que demonstram o bom funcionamento desses limiares para identificar desmatamento a partir de séries temporais do MODIS EVI e MODIS NDVI. Na Figura 4.9, são mostradas as séries temporais de EVI e NDVI de uma área desmatada em Jataí, com os respectivos limiares de desmatamento. Nota-se que a assinatura espectral corta os limiares de desmatamento em meados de 2010. O desmatamento nesse período pôde ser confirmado pelas análises de três sequências de imagens do satélite Landsat de 01 de agosto de 2009 (área natural), 03 de julho de 2010 (área natural) e 22 de julho de 2011 (área desmatada). Análises similares são apresentadas nas Figuras 4.9 (desmatamento de formação florestal em São Miguel do Araguaia), 4.10 
(desmatamento em formação savânica de Jataí), 4.11 e 4.12 (desmatamento em formação savânica de Jataí), 4.13 (desmatamento em formação savânica de São Miguel do Araguaia), 4.14 (desmatamento em formação savânica de Mateiros) e 4.15 (desmatamento em formação campestre de Mateiros). Eventos de desmatamentos foram nitidamente identificados em todos os exemplos ilustrados nessas figuras, à exceção do caso de formação campestre de Mateiros. 


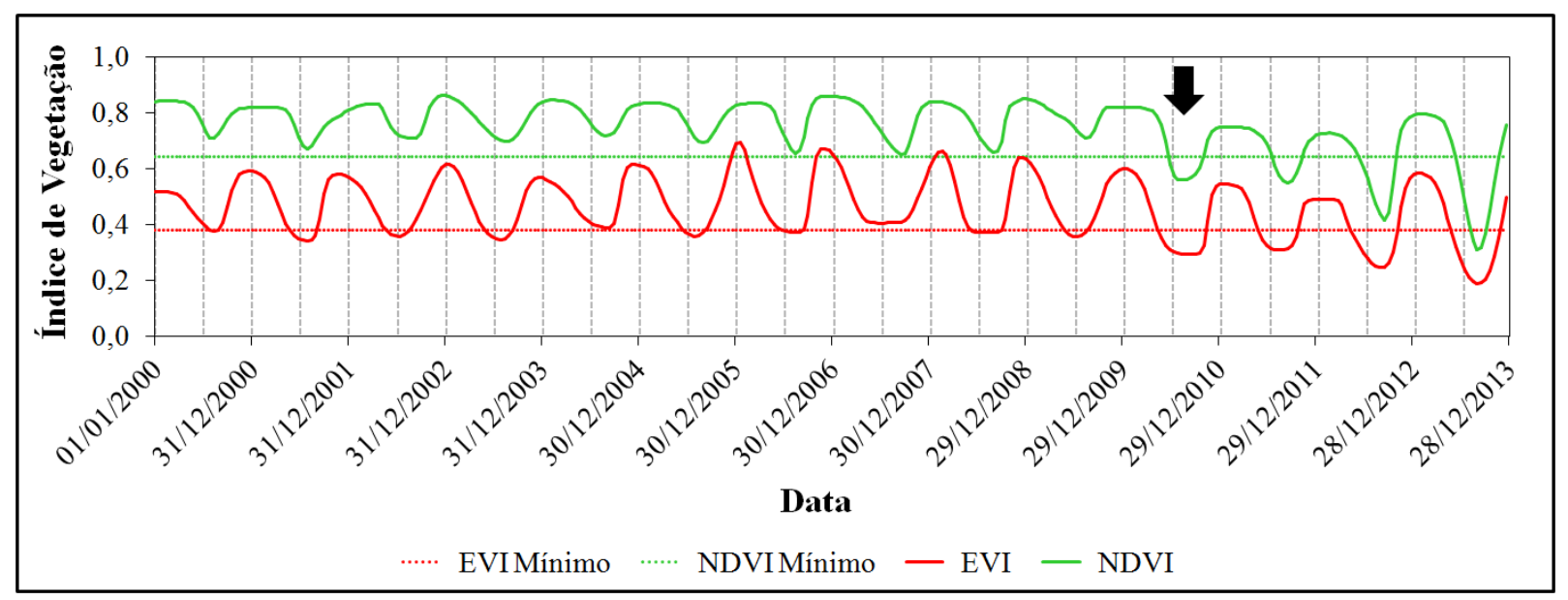

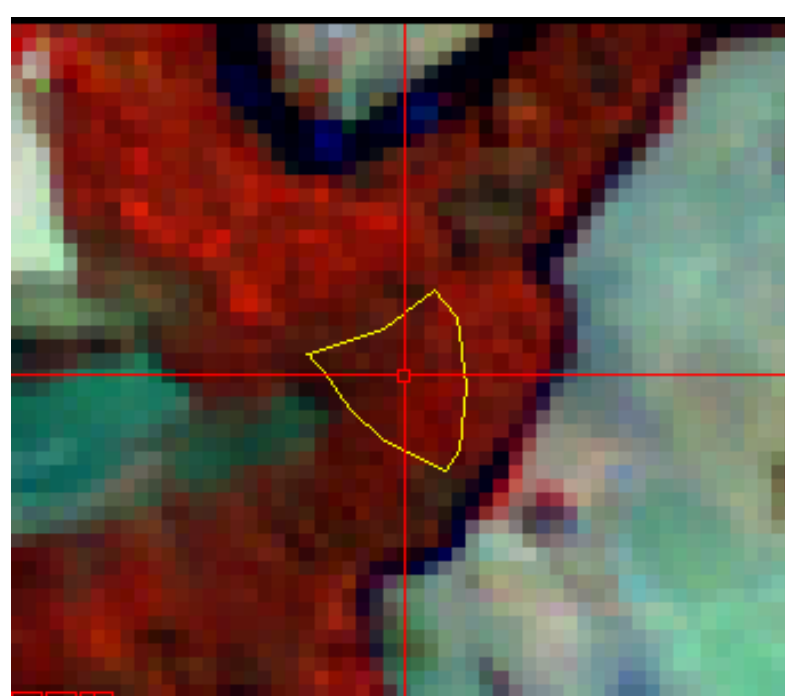

(a)

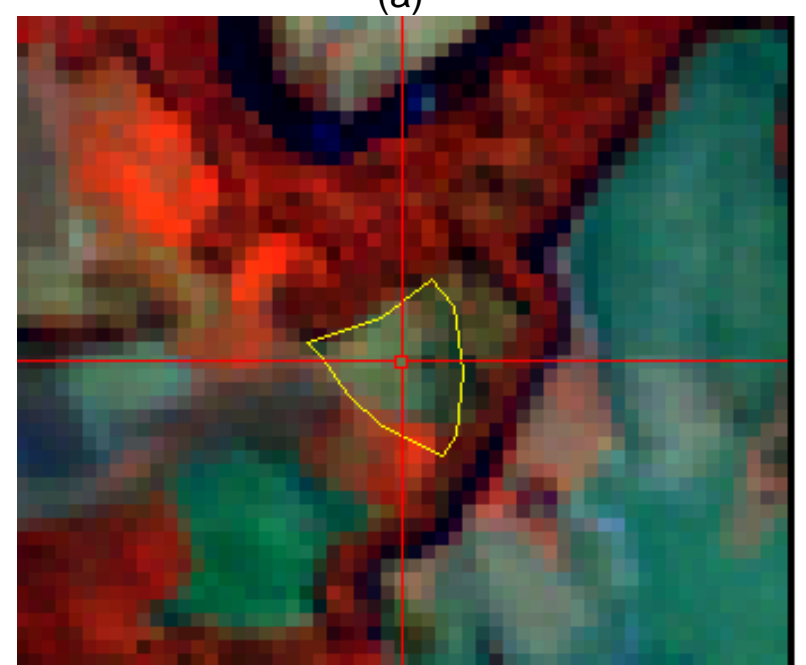

(c)

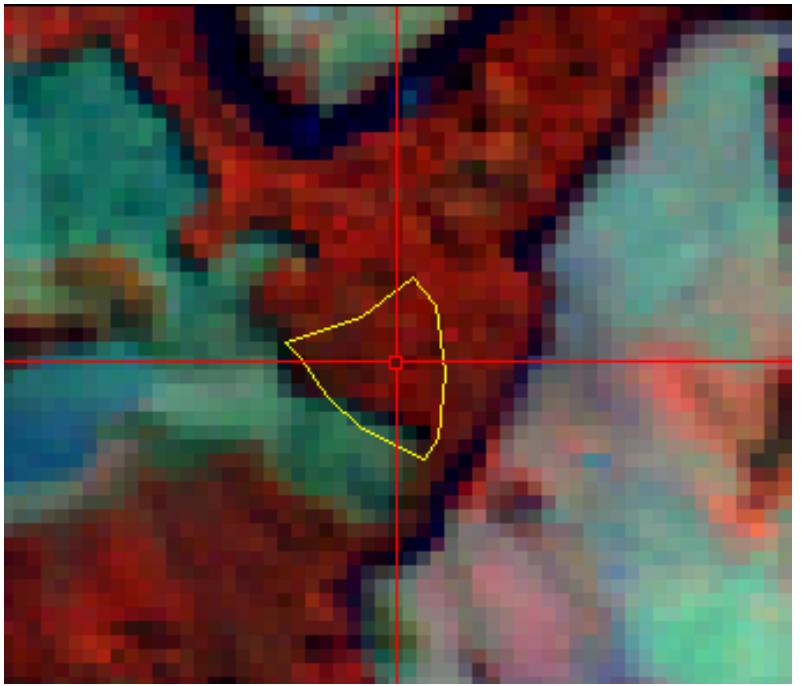

(b)

Figura 4.9 - Séries temporais de EVI e de NDVI de um ponto em Jataí (latitude: S 1758 54,79; longitude: W 5141 37,54) com correspondentes limiares de desmatamento de uma formação florestal. Em meados de 2010, as séries temporais cruzam os limiares de desmatamento (seta preta). O desmatamento nesse período pode ser confirmado pelos recortes de cenas do satélite Landsat de 01 de agosto de 2009 (não desmatado) (a), 03 de julho de 2010 (desmatamento nas adjacências do polígono) (b) e 22 de julho de 2011 (desmatado) (c). 


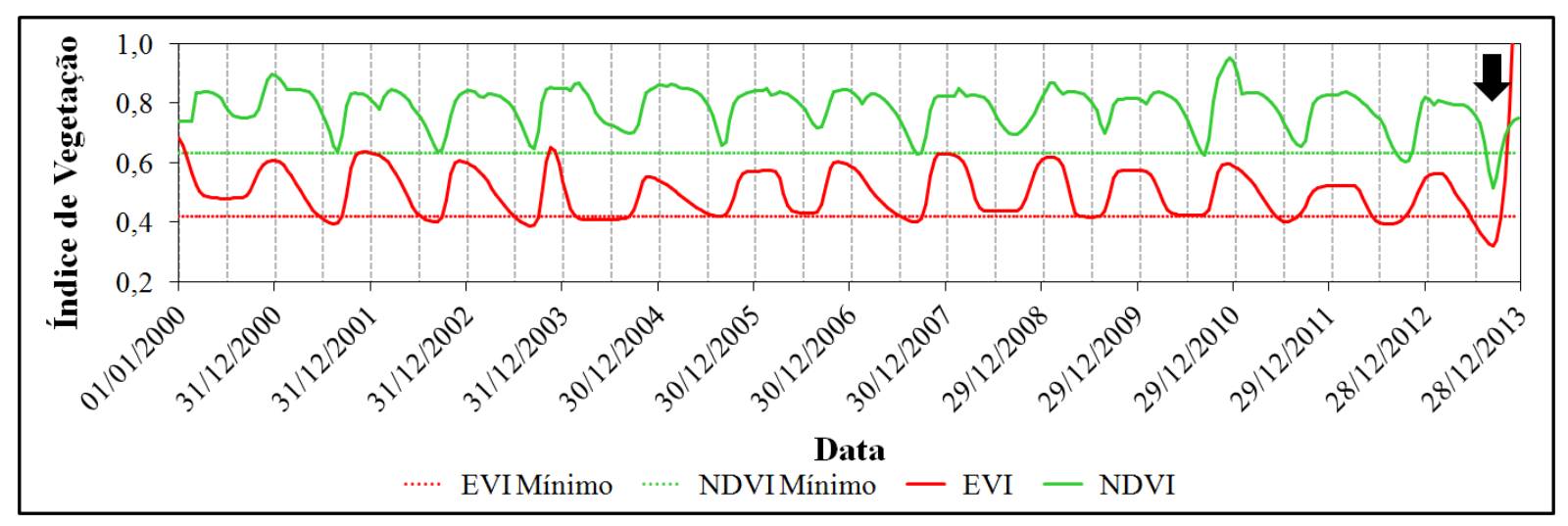

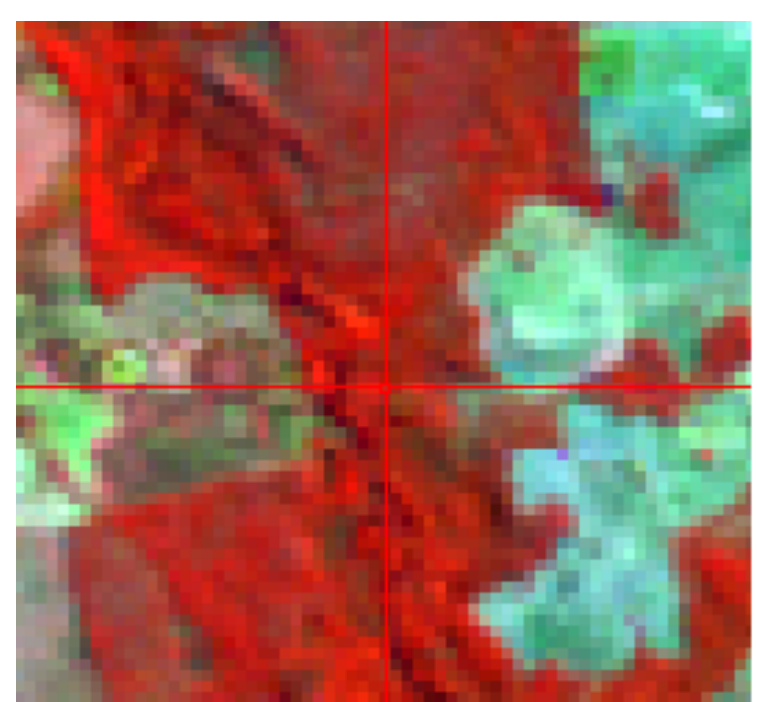

(a)

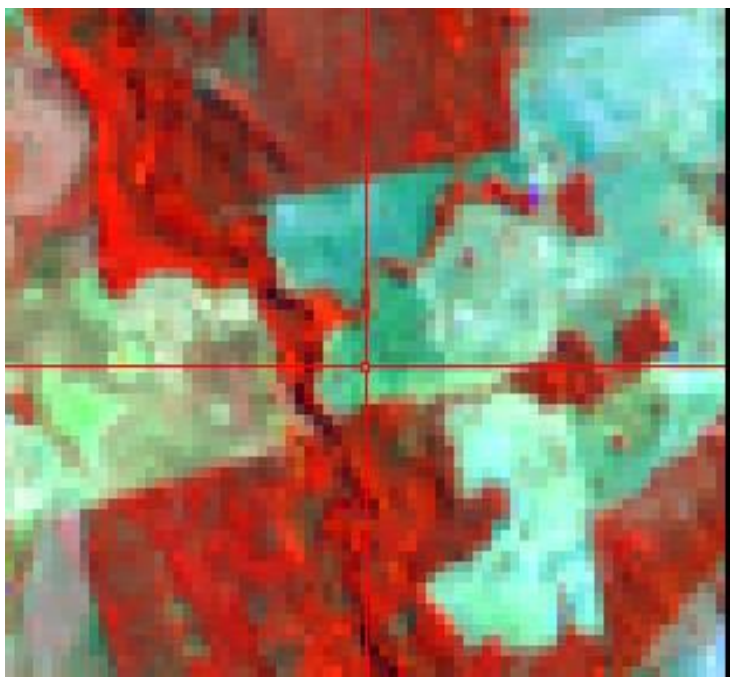

(b)

Figura 4.10 - Séries temporais de EVI e de NDVI de um ponto em São Miguel do Araguaia (latitude: S 1320 42,46; longitude: W 4958 52,29) com correspondentes limiares de desmatamento de uma formação florestal. Em meados de 2013, as séries temporais cruzam os limiares de desmatamento (seta preta). O desmatamento nesse período pode ser confirmado pelos recortes de cenas do satélite Landsat de 01 de agosto de 2012 (não desmatado) (a) e 12 agosto de 2013 (desmatado) (b). 


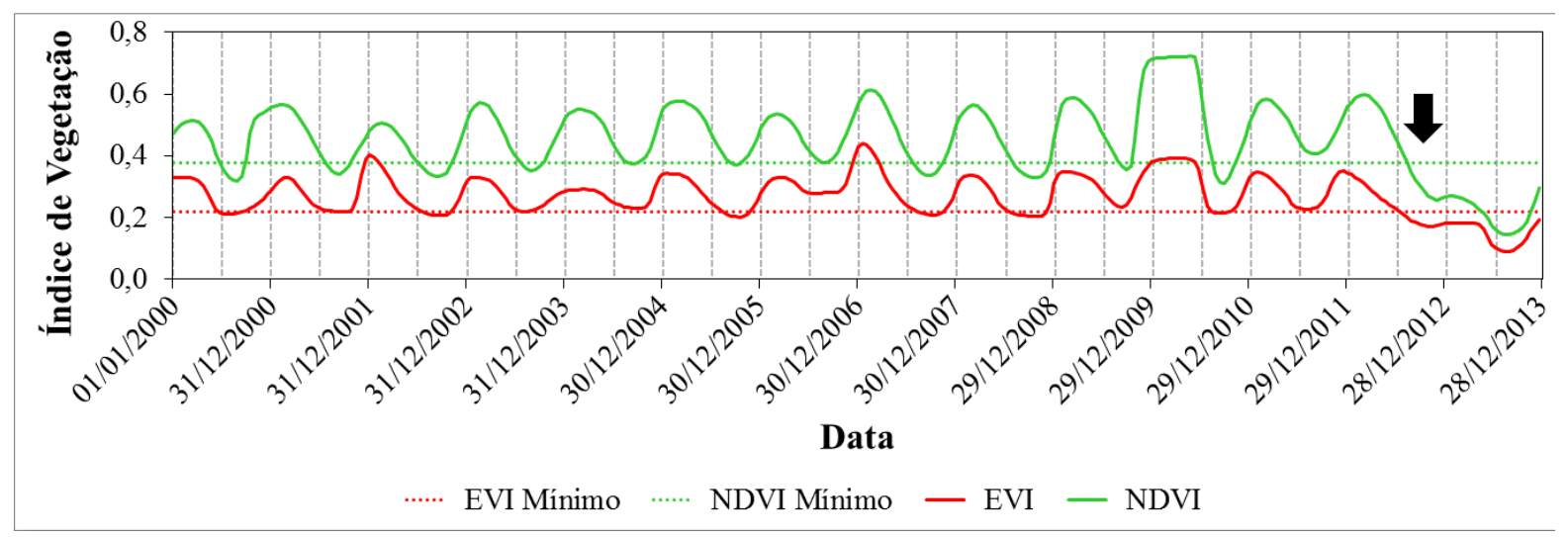

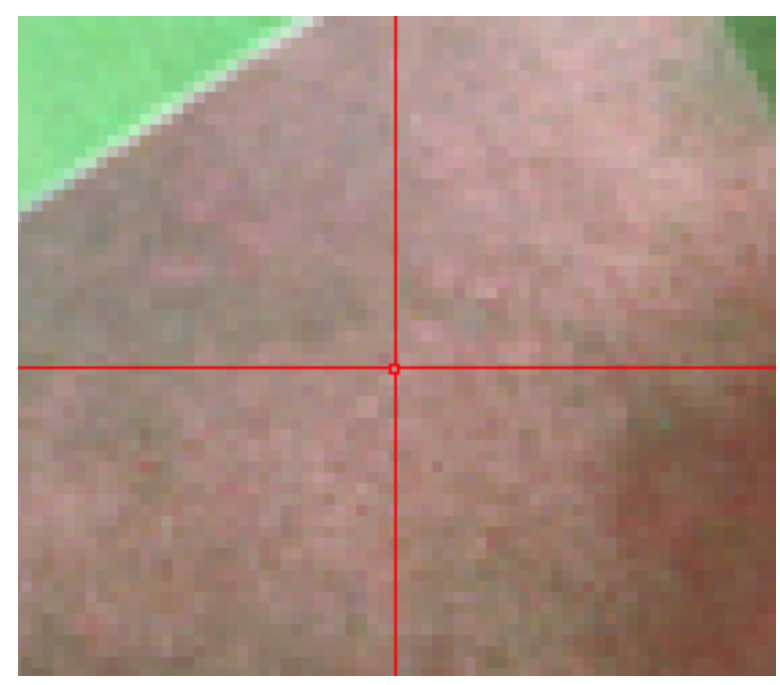

(a)

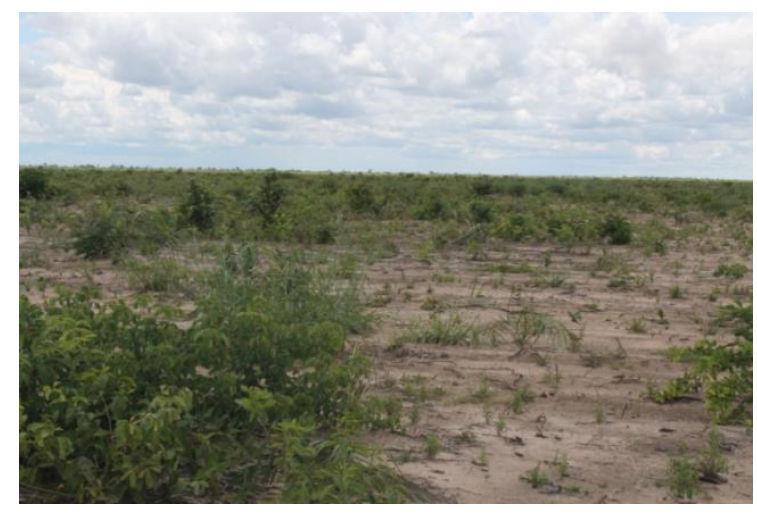

(c)

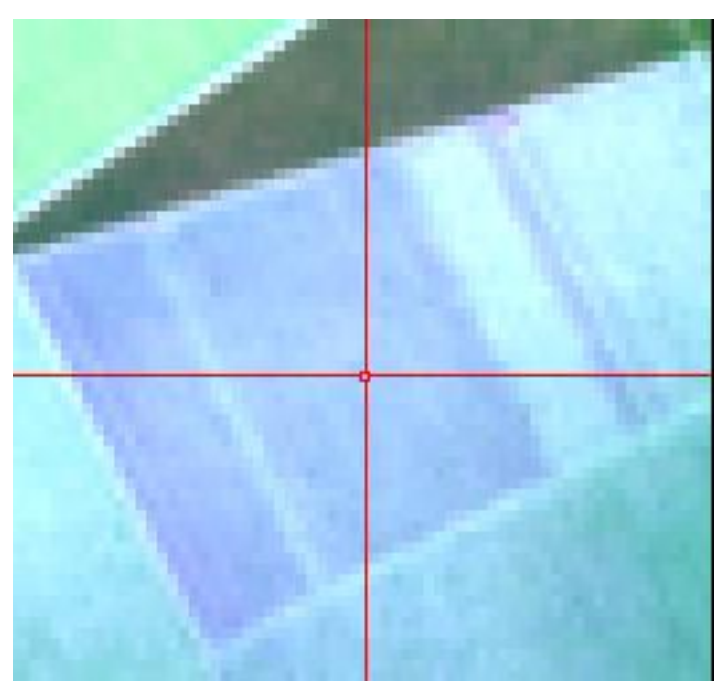

(b)

Figura 4.11 - Séries temporais de EVI e de NDVI de um ponto em Luís Eduardo Magalhães (latitude: S $11 \quad 59$ 27,50; longitude: W 4558 48,16) com correspondentes limiares de desmatamento de uma formação savânica. Em meados de 2012, as séries temporais cruzam os limiares de desmatamento (seta preta). O desmatamento nesse período pode ser confirmado pelos recortes de cenas do satélite Landsat de 03 de setembro de 2011 (a) e 08 de setembro de 2013 (b). Fotografia de campo obtida em fevereiro de 2014 (c) também indica que a área foi desmatada. Foto: R. Trevizam. 


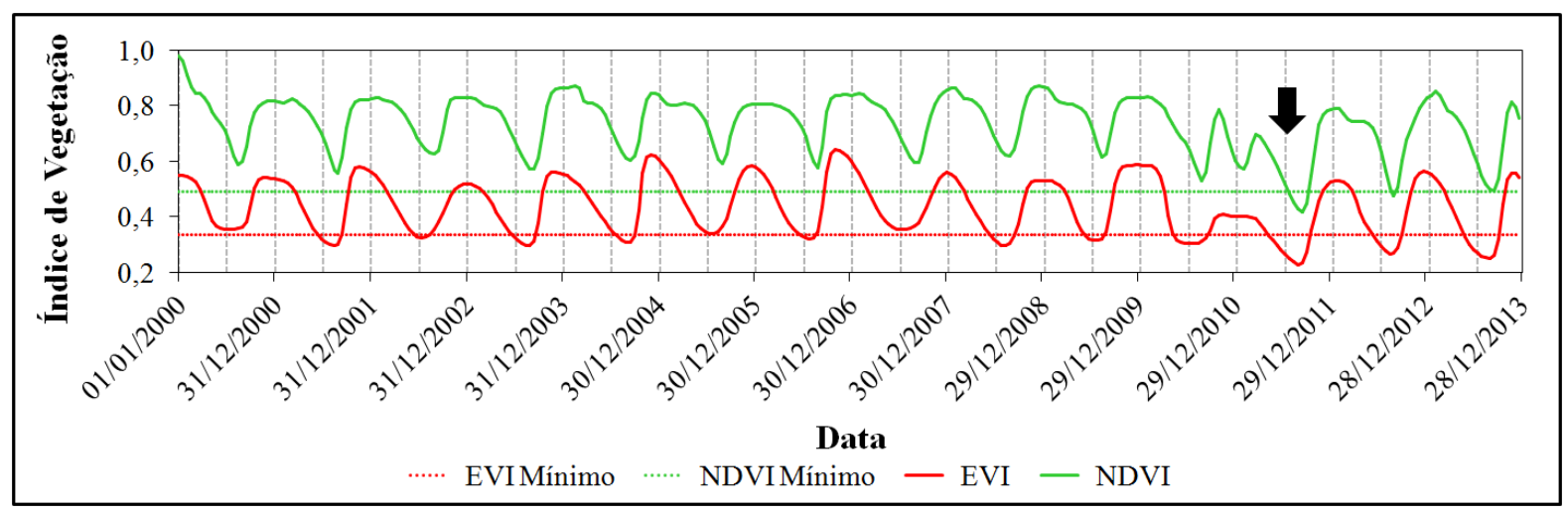

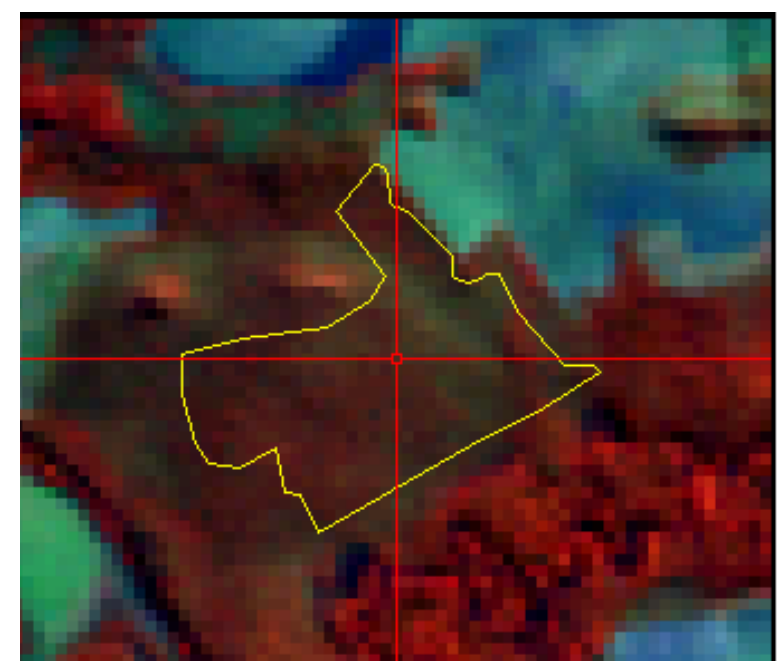

(a)

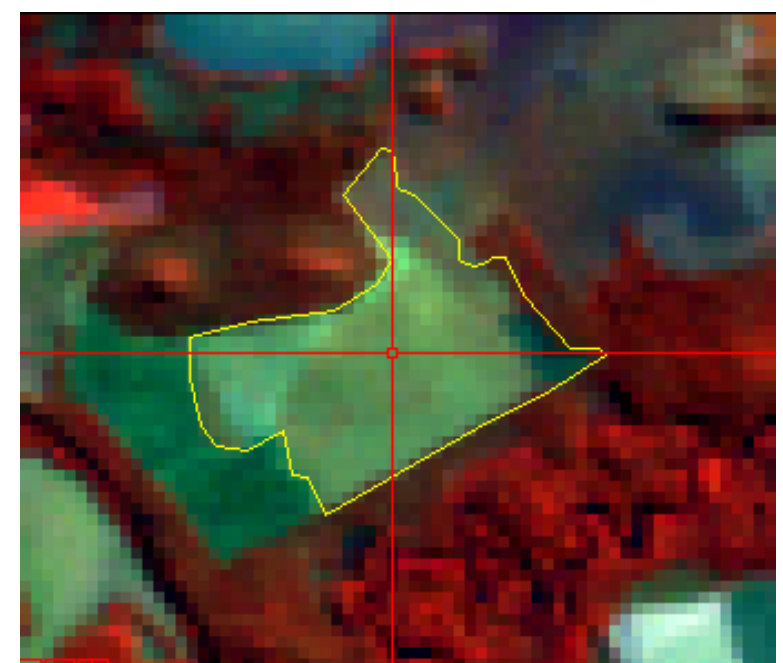

(b)

Figura 4.12 - Séries temporais de EVI e de NDVI de um ponto em Jataí (latitude: S 1759 7,84; longitude: W 5142 39,07) com correspondentes limiares de desmatamento de uma formação savânica. Em meados de 2011, as séries temporais cruzam os limiares de desmatamento (seta preta). O desmatamento nesse período pode ser confirmado pelos recortes de cenas do satélite Landsat de 03 de julho de 2010 (não desmatado) (a) e 21 de julho de 2011 (desmatado) (b). 


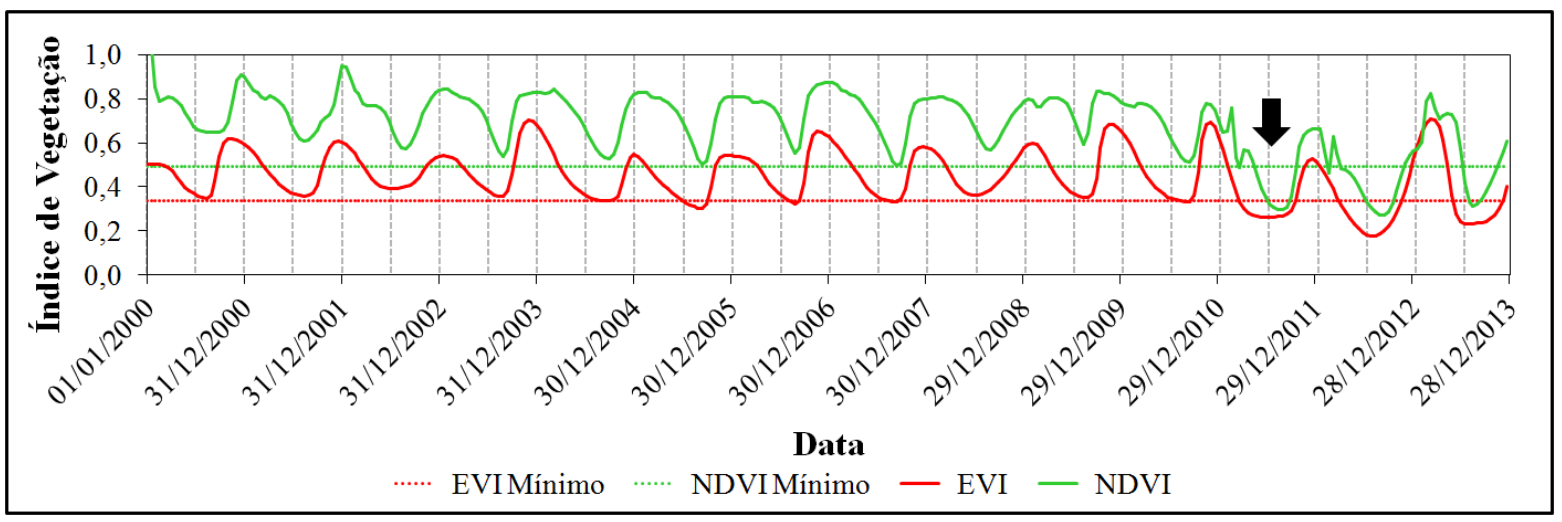

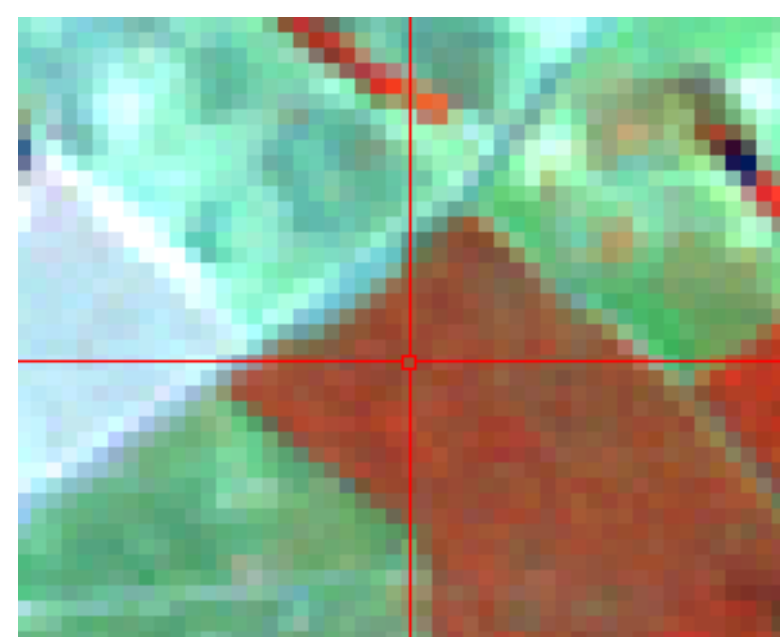

(a)

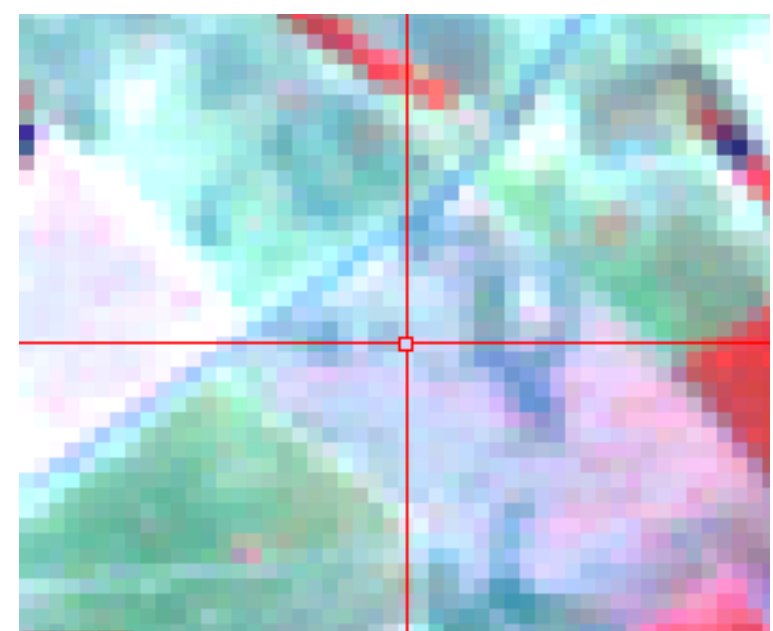

(b)

Figura 4.13 - Séries temporais de EVI e de NDVI de um ponto em São Miguel do Araguaia (latitude: S 139 15,89; longitude: W 502 8,34) com correspondentes limiares de desmatamento de uma formação savânica. Em meados de 2011, as séries temporais cruzam os limiares de desmatamento (seta preta). O desmatamento nesse período pode ser confirmado pelos recortes de cenas do satélite Landsat de 01 de agosto de 2011 (não desmatado) (a) e 07 de setembro de 2011 (desmatado) (b). 


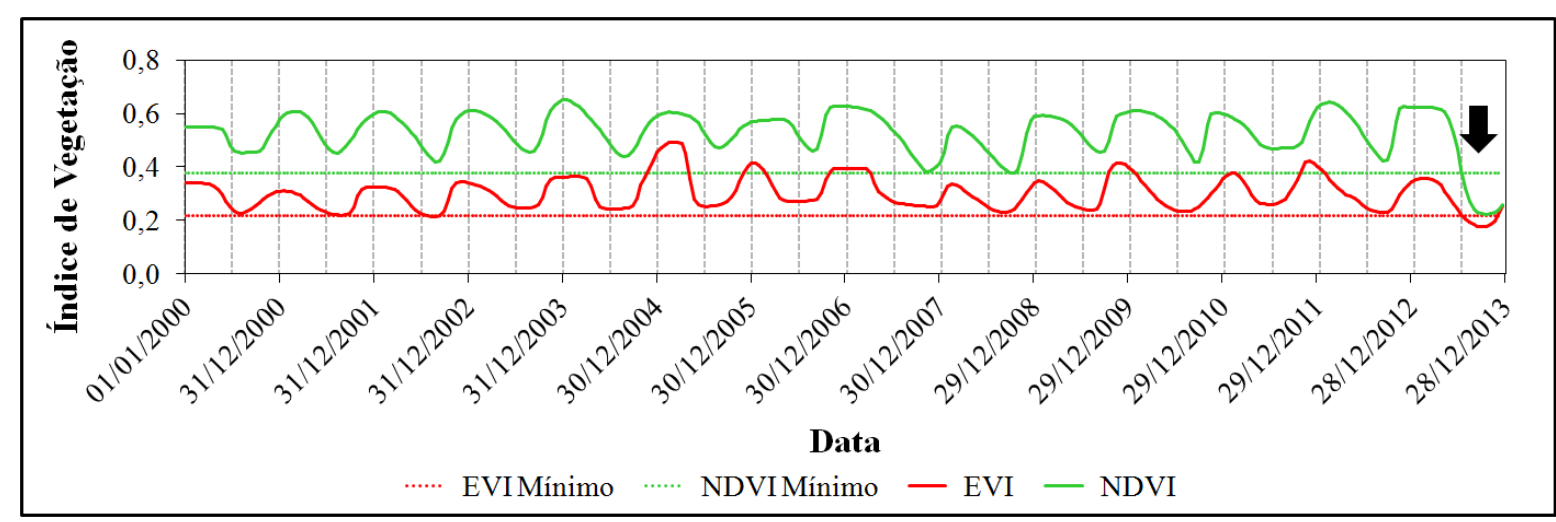

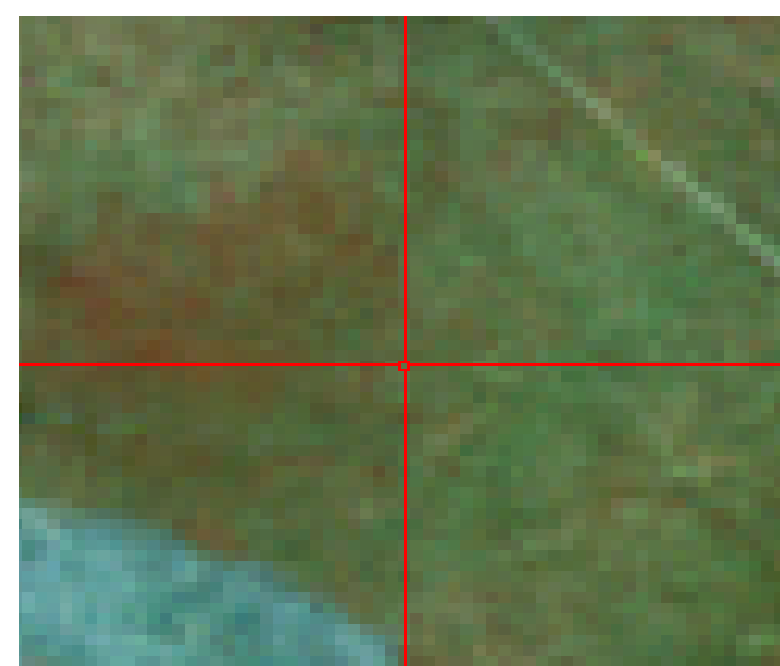

(a)

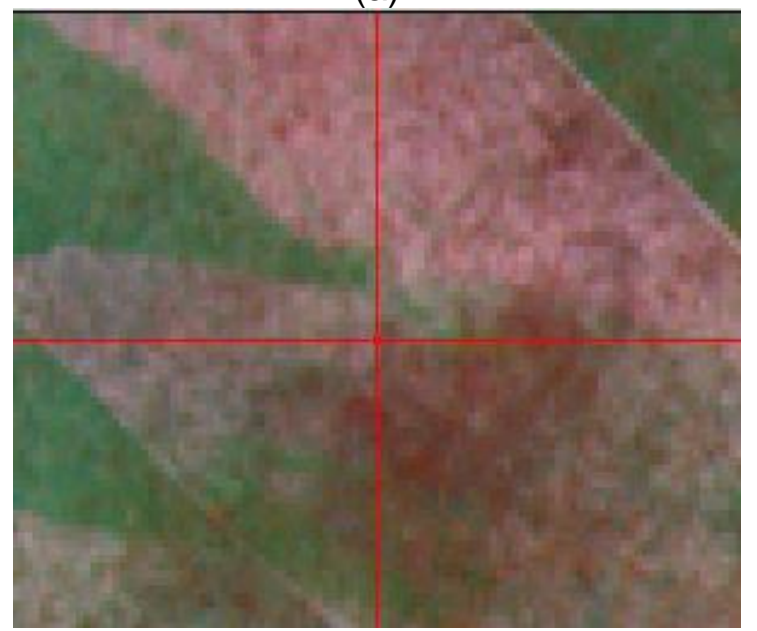

(c)

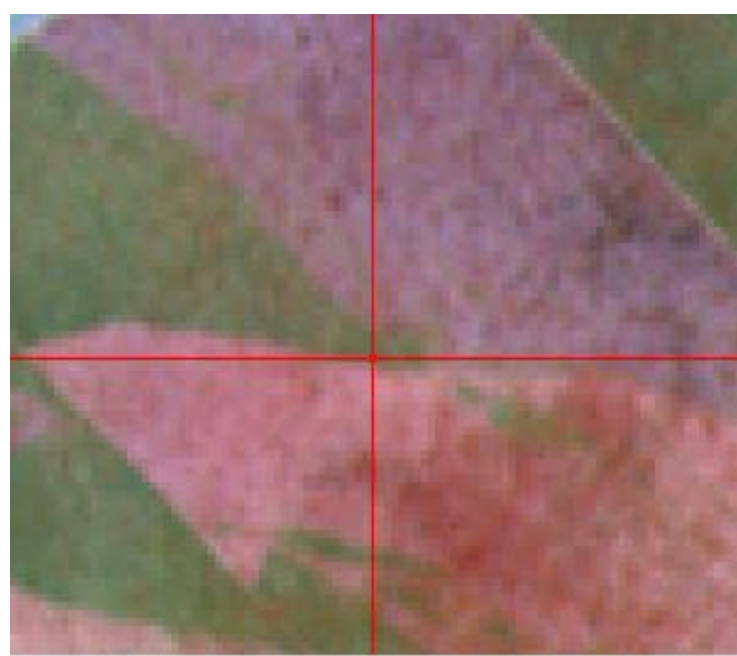

(b)

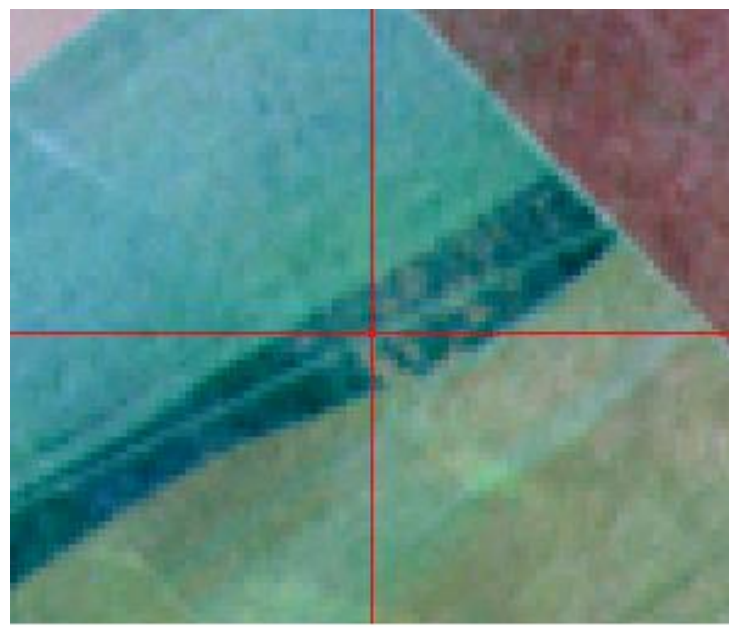

(d)

Figura 4.14 - Séries temporais de EVI e de NDVI de um ponto em Mateiros (latitude: S 1027 21,11; longitude: W 462 47,75) com correspondentes limiares de desmatamento de uma formação savânica. Em meados de 2013, as séries temporais cruzam os limiares de desmatamento (seta preta). O desmatamento nesse período pode ser confirmado pelos recortes de cena do satélite Landsat de 14 de agosto de 2010 (não desmatado) (a), recorte de cenas do Resourcesat LISS 3 de 02 de setembro de 2011 (não desmatado) (b) e 10 de julho de 2012 (não desmatado) (c) e recorte de cena do satélite Landsat de 29 de julho de 2013 (desmatado) (d). 


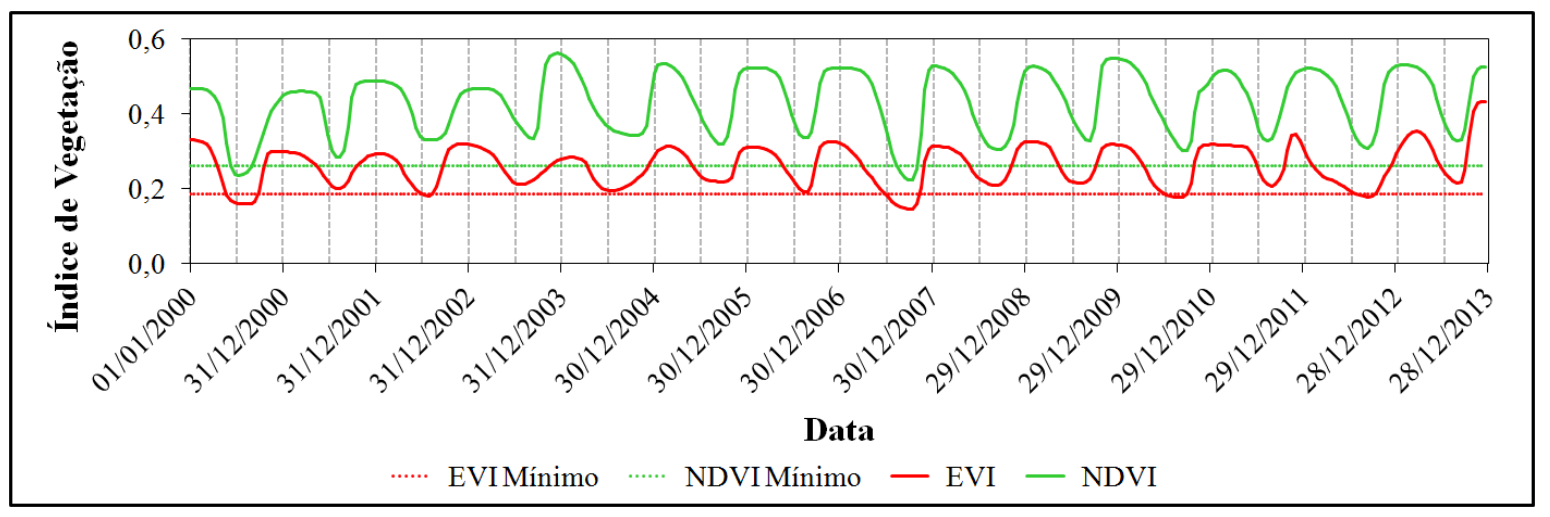

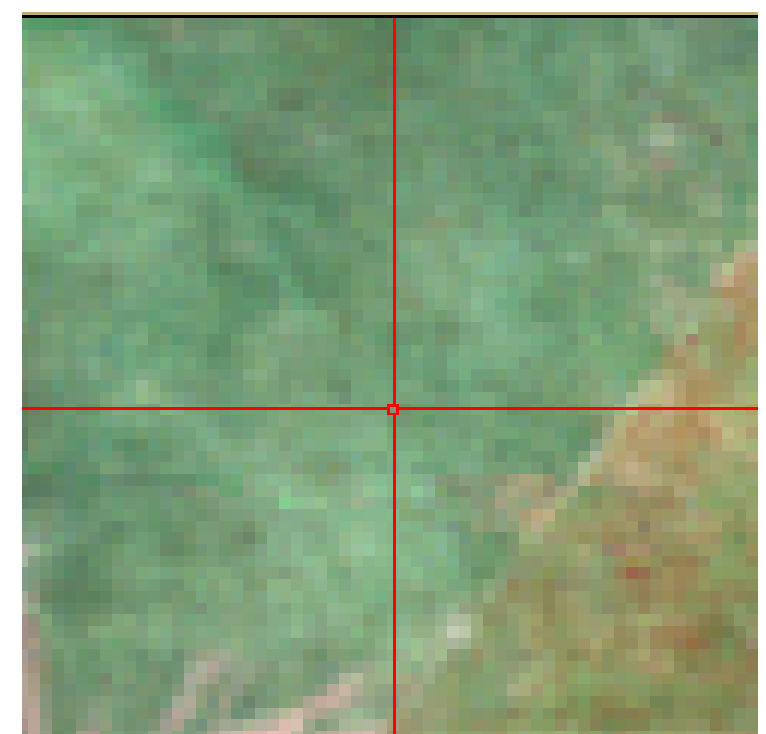

(a)

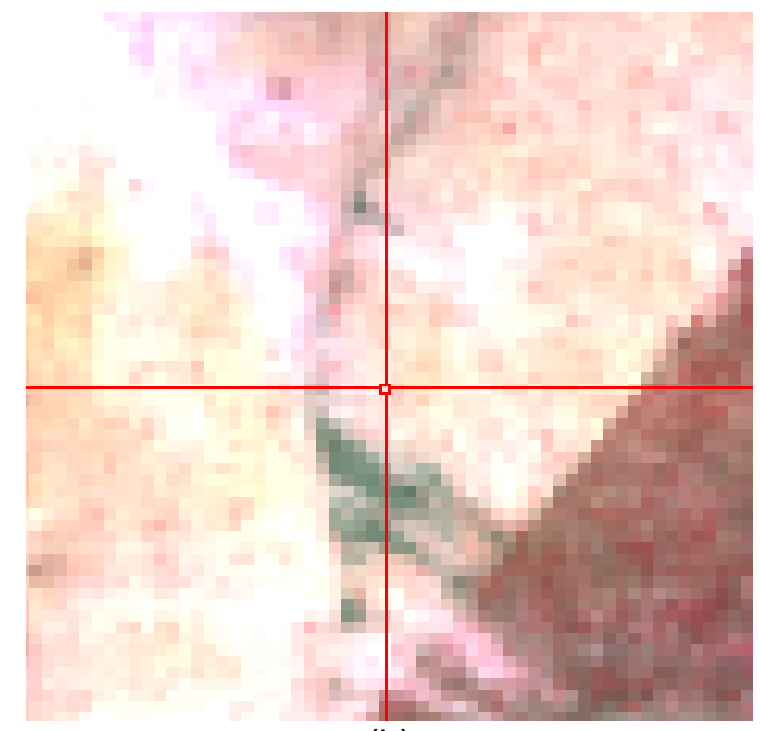

(b)

Figura 4.15 - Séries temporais de EVI e de NDVI de um ponto em Mateiros (latitude: S 1019 41,44; longitude: W 470 59,99) com correspondentes limiares de desmatamento de uma formação campestre. Os recortes de cenas do satélite Landsat de 14 de agosto de 2010 mostram, respectivamente, área não desmatada em 14 de agosto de 2010 (a), e área desmatada em 15 de setembro de 2013 (b). Esse desmatamento que ocorreu em algum momento no período de 2010 a 2013 não foi detectado pelas séries temporais. 


\section{CONSIDERAÇÕES FINAIS}

A análise de séries temporais do sensor MODIS convertidos para dois índices de vegetação (EVI e NDVI) de quatro municípios do Cerrado (Jataí/GO, Luís Eduardo Magalhães/BA, Mateiros/TO e São Miguel do Araguaia/GO) demonstrou que é possível utilizar essas assinaturas temporais para detecção de desmatamentos no bioma Cerrado. Todos os três objetivos específicos estabelecidos nesse estudo foram alcançados:

Estruturação de um banco de dados contendo séries temporais (período 20002013) do MODIS EVI e NDVI de quatro municípios do Cerrado: séries temporais do produto MOD13Q1 foram obtidos da página eletrônica da NASA, reprojetados para o sistema de projeção UTM, datum WGS 84 e fuso 23, e convertidos para o formato geotiff.

Definição de assinaturas temporais representativas de classes de cobertura vegetal natural encontradas nos quatro municípios: foram definidas assinaturas temporais representativas de formações florestais para os municípios de Jataí e São Miguel do Araguaia, de formações savânicas para os quatro municípios e de formações campestres para o município de Mateiros.

Definição de limiares de desmatamento por formação vegetacional: foram definidos limiares de desmatamento para as formações florestais e savânicas. Não foi possível definir um limiar de desmatamento confiável para a formação campestre.

Outras informações relevantes geradas nesse estudo foram:

Não é possível gerar um limiar único de desmatamento para cada formação vegetacional do Cerrado. Por exemplo, existe uma forte similaridade nas assinaturas temporais de formações savânicas de Luís Eduardo Magalhães e Mateiros ou de Jataí e São Miguel do Araguaia, mas não se pode afirmar o mesmo para os quatro municípios juntos.

Apesar de diversos estudos afirmarem que o desempenho do EVI é superior ao do NDVI, por exemplo, por causa de menor interferência de efeitos do solo e atmosfera no EVI, nesse estudo, o desempenho dos dois índices foi similar.

Recomenda-se, como continuação desse estudo, avaliar a possibilidade de utilizar as séries temporais de EVI e NDVI para detecção de desmatamentos em tempo quase real. Para isso, é necessário implementar um algoritmo (plug-in) para detectar os pixels de uma cena do MODIS EVI ou MODIS NDVI que estão abaixo dos limiares de desmatamento. Nos locais onde houver uma concentração maior de pixels detectados como desmatamento, recomenda-se realizar uma validação no campo ou com imagens 
do satélite RapidEye que possui uma resolução espacial de 5 metros e periodicidade de um dia. Outra recomendação é o de estender esse estudo para um maior número de municípios, notadamente naqueles localizados na parte setentrional, central e meridional do Cerrado. Essa recomendação se justifica por causa da possível influência da composição florística nas séries temporais de índices de vegetação, além da existência de outros possíveis fatores de influência como solos, altitude e regime de pluviosidade. 


\section{REFERÊNCIAS}

AB' SÁBER, A. N. Os domínios da natureza do Brasil: potencialidades paisagísticas. São Paulo: Ateliê Editorial. 160p. 1987.

ANDERSON, L. O.; LATORRE, M. L.; SHIMABUKURO, Y. E.; ARAI, E.; CARVALHO JÚNIOR, O. A. Sensor MODIS: Uma abordagem geral. São José dos Campos: INPE, 2003.

ANDERSON, L. O.; ARAGÃO, L. E. O. C.; LIMA, A.; SHIMABUKURO, Y. E. Detecção de cicatrizes de áreas queimadas baseada no modelo linear de mistura espectral e imagens índice de vegetação utilizando dados multitemporais do sensor MODIS/TERRA no estado do Mato Grosso, Amazônia brasileira. Acta Amazonica, v. 35(4), p. 445-456, 2005.

ANJOS, V. S.; SANO, E. E.; BEZERRA, H. S.; ROSA, R. Caracterização espectro-temporal de pastagens do Triângulo Mineiro utilizando dados MODIS EVI2 (2000-2010). Sociedade \& Natureza, v. 25(1), p. 205-215, 2013.-

ATKINSON, P. M. JEGANATHAN, C. DASH, J. ATZBERGER, C. Inter-comparison of four models for smoothing satellite sensor timeseries data to estimate vegetation phenology. Remote Sensing of Environment. v. 123, p. 400-417, 2012.

BARRERO, F. M. C. Plano de recuperação e prevenção das ocupações em área de preservação permanente da sub-bacia do Rio de Ondas. Relatório de consultoria. Instituto de Gestão das Águas e Clima. Salvador, 2008.

BATISTELLA, M.: GUIMARÃES, M.; MIRANDA, E.E.; VIEIRA, H.R.; VALLADARES, G.S.; MANGABEIRA, J.A.C.; ASSIS, M.C. Monitoramento da expansão agropecuária na região oeste da Bahia. Campinas, SP: Embrapa Monitoramento por Satélite (Série Documentos, 20), 39 p., 2002.

BECERRA, J. A. B.; SHIMABUKURO, Y. E.; ALVALÁ, R. C. S. Relação do padrão sazonal da vegetação com a precipitação na região de Cerrado da Amazônia Legal, usando índices espectrais de vegetação. Revista Brasileira de Meteorologia, v. 24 (2), p. 125134, 2009.

BECK, P. S. A.; ATZBERGER, C.; HØGDA, K. A.; JOHANSEN, B.; SKIDMORE, A. K. Improved monitoring of vegetation dynamics at very high latitudes: A new method using MODIS NDVI. Remote Sensing of Environment, v. 100, p. 321-334, 2006.

BORGES, E. F.; SANO, E. E.; MEDRADO, E. Radiometric quality and performance of TIMESAT for smoothing moderate resolution imaging spectroradiometer enhanced vegetation index time series from western Bahia State, Brazil. Journal of Applied Remote Sensing. 083580-1-21 v. 8, 2014.

BRADLEY, B. A.; JACOB, R. W.; HERMANCE, J. F.; MUSTARD, J. F. A curve fitting procedure to derive inter-annual phonologies from time series of noisy satellite NDVI data. Remote Sensing of Environment, v. 106, n.2, p. 137-145, 2007.

BUREAU, POPULATION REFERENCE (Org.). World Population Data Sheet 2014. 2014. Cálculo percentual população mundial elaborado por Adriana P. Bayma. Disponível em: $<$ http://www.prb.org/Publications/Datasheets/2014/2014-world-population-datasheet.aspx>. Acesso em: 17 nov, 2014.

CARVALHO, A. P. F. Estudo de características foliares de espécies lenhosas de Cerrado e sua relação com os espectros de refletância. Dissertação de mestrado, Departamento de Ecologia, Universidade de Brasília, Brasília, 126p. 2005. 
CARVALHO Jr., O. A.; HERMUCHE, P. M.; GUIMARÃES, R. F. Identificação regional da floresta estacional decidual na bacia do Rio Paranã a partir da análise multitemporal de imagens MODIS. Revista Brasileira de Geofísica, v. 24(3), p. 319-332, 2006.

CARVALHO Jr., O. A.; SAMPAIO, C. S.; SILVA, N. C.; COUTO JÚNIOR, A. F.; GOMES, R. A. T.; CARVALHO, A. P. F.; SHMABUKURO, Y. E. Classificação de padrões de savana usando assinaturas temporais NDVI do sensor MODIS no Parque Nacional da Chapada dos Veadeiros. Revista Brasileira de Geofísica. v.26 (4), p.505-517, 2008.

CARVALHO Jr., O. A.; COUTO JÚNIOR, A. F.; SILVA, N. C.; MARTINS, E. S.; CARVALHO, A. P. F.; GOMES, R. A. T. Avaliação dos classificadores espectrais de mínima distância euclidiana e spectral correlation mapper em séries temporais NDVI-MODIS no campo de instrução militar de Formosa (GO). Revista Brasileira de Cartografia, v. 61, p. 399412, 2009.

CHEN, J. JÖNSSON, P.; TAMURA, M.; GU, Z.; MATSUSHITA, B.; EKLUNDH, L. A simple method for reconstructing a high-quality NDVI time-series data set based on the Savitzky-Golay filter. Remote Sensing of Environment. 91(3-4), p. 332-344, 2004.

CORREIA, A. H.; FORMAGGIO, A. R.; SHIMABUKURO, Y. E.; DUARTE, V. Avaliação de índices de vegetação MODIS para detecção de desmatamentos na Amazônia. Revista Ambiente \& Água - An interdisciplinar Journal of Applied Science. p. 52-64. Ano 1 (2). Universidade de Taubaté, Taubaté - SP, 2006.

COUTO Jr, A. F.; CARVALHO Jr, O. A.; MARTINS, E. S.; SANTANA, O. A.; SOUZA, V. V.; ENCINAS, J. I. Tratamento de ruídos e caracterização de fisionomias do Cerrado utilizando séries temporais do sensor MODIS. Revista Árvore, v. 35, p. 699-705, 2011.

COUTO Jr., A. F.; CARVALHO Jr., O. A.; MARTINS, E. S. Séries temporais MODIS aplicadas em sucessão de culturas de soja (Glycine max (L.) Merrill) e milho (Zea mays L.) em sistema de plantio direto. Revista Brasileira de Cartografia, v. 64, p. 405-418, 2012.

CROFT, H.; CHEN, J. M.; NOLAND, T. L. Stand age effects on Boreal forest physiology using a long time-series of satellite data. Forest Ecology and Management, v. 328, p. 202-208, 2014.

DIAS, B. F. S. Cerrados: uma caracterização. IN: DIAS, B. F. S. (Org.). Alternativas de desenvolvimento dos Cerrados: manejo e conservação dos recursos naturais renováveis. Brasília: Fundação Pró-Natureza, p. 11-25, 1992.

DIAS, B. F. S. A conservação da natureza. IN: PINTO, M. N. (org.). Cerrado: caracterização, ocupação e perspectivas. Brasília: Editora Universidade de Brasília, p. 607-663, 1994.

DIDAN, K.; HUETE, A. Modis vegetation index product series collection 5 change summary. Arizona: The University of Arizona, 2006. 17 p. Disponível em: <http://landqa2.nascom.nasa.gov/QA_WWW/forPage/MOD13_VI_C5_Changes_Docum ent_06_28_06.pdf>. Acesso em: 10 out 2013.

DORAISWAMY, P. C.; BAKHYT, A.; STERN, A. J. Improved Techniques for Crop Classification using MODIS Imagery. IEEE International Conference on Geoscience and Remote Sensing Symposium, IGARSS, 2006, Denver, CO. p.2084 - 2087, 2006.

EITEN, G. Vegetação do Cerrado. IN: PINTO, M. N. (org.). Cerrado: caracterização, ocupação e perspectivas. Brasília: Editora Universidade de Brasília, p. 17-73, 1993.

EVA, H. D.; BELWARD, A. S.; MIRANDA, E. E.; DI BELLA, C. M.; GOND, V.; HUBER, O.; JONES, S.; SGRENZAROLI, M.; FRITZ, S. A land cover map of South America. Global Change Biology, v. 10. p. 731-744, 2004. 
FERREIRA, L. G.; SILVA, A. A.; JESUS, E. T.; SANO, E. E.; SHIMABUKURO, Y. E. Monitoramento sistemático da cobertura vegetal no bioma Cerrado através dos índices de vegetação MODIS. In: Simpósio Brasileiro de Sensoriamento Remoto, 11, Belo Horizonte, MG. Anais... p. 2729-2736, 2003.

FERREIRA, L. G.; HUETE, A. R. Assessing the seasonal dynamics of the Brazilian Cerrado vegetation through the use of spectral vegetation indices. International Journal of Remote Sensing. v. 25(10), p. 1837-1860, 2004.

FERREIRA, L. G.; FERREIRA, N. C.; FERREIRA, M. E. Sensoriamento remoto da vegetação: evolução e estado-da-arte. Acta Scientiarum Biological Sciences, v. 30, n. 4, p. 379-390, 2008.

FERREIRA, M. E.; FERREIRA, L. G.; FERREIRA, N. C.; ROCHA, G. F.; NEMAYER, M. Desmatamentos no bioma Cerrado: uma análise temporal (2001-2005) com base nos dados MODIS - MOD13Q1 In: Simpósio Brasileiro de Sensoriamento Remoto, 13, Florianópolis, SC. Anais...São José dos Campos: INPE, 2007, p.3877-3883.

GAO, X.; HUETE, A. R.; NI, W.; MIURA, T. Optical-biophysical relationships of vegetation spectra without background contamination. Remote Sensing of Environment, v. 74, p. 609-620, 2000.

GALFORD, G. L.; MUSTARD, J. F.; MELILLO, J.; GENDRIN, A.; CERRI, C. C.; CERRI, C. E. P. Wavelet analysis of MODIS time series to detect expansion and intensification of row-crop agriculture in Brazil. Remote Sensing of Environment, v. 112, p. 576-587, 2008.

GINCIENE, B. R.; BITENCOURT, M. D. Utilização do EVI (Enhanced Vegetation Index) para maior sensibilidade na detecção de mudanças temporais em fragmentos de floresta estacional semidecidual. In: Simpósio Brasileiro de Sensoriamento Remoto, 15, Curitiba, PR. Anais.... p. 1620-1627, 2011.

HUETE, A. R. A soil-adjusted vegetation index (SAVI). Remote Sensing of Environment, v. 25, p. 295-309, 1988.

HUETE, A. R.; DIDAN, K.; MIURA, T.; RODRIGUEZ, E. P.; GAO, X.; FERREIRA, L. G. Overview of the radiometric and biophysical performance of the MODIS vegetation indices. Remote Sensing of Environment, v. 83(1-2), p. 195-213, 2002.

HUTCHINSON, J. M. S.; JACQUIN, A.; HUTCHINSON, S. L.; VERBESSELT, J. Monitoring vegetation change and dynamics on U.S. Army training lands using satellite image time series analysis. Journal of Environmental Management, v. 150, p. 355-366, 2015.

IBAMA. Instituto Brasileiro do Meio Ambiente e dos Recursos Naturais Renováveis. Monitoramento do Bioma Cerrado 2010. Monitoramento do Desmatamento dos Biomas Brasileiros por Satélite. Relatório. Disponível em: http://siscom.ibama.gov.br/monitorabiomas/cerrado/RELATORIO\%20FINAL_CERRADO 2010.pdf. Acessado em: 10 jul. 2013.

IBGE. Instituto Brasileiro de Geografia e Estatística. Mapa de Biomas do Brasil. 2004. Disponível em: http://www.ibge.gov.br/home/presidencia/noticias/ 21052004 biomashtml.shtm. Acesso em: 26 dez. 2014.

ICMBio. Instituto Chico Mendes de Conservação da Biodiversidade. Atlas do Corredor Ecológico da Região do Jalapão. Atlas. Versão digital. Disponível em: http://www.icmbio.gov.br/portal/images/stories/comunicacao/downloads/atlasjalapao.pdf. Acessado em: 10 jul. 2013.

INMET. Insituto Nacional de Meteorologia. BDMEP - Banco de Dados Meteorológicos para Ensino e Pesquisa. Disponível em: http://www.inmet.gov.br/portal/index.php?r=bdmep/bdmep. Acessado em: 13 de fevereiro de 2015. 
JACQUIN, A.; SHEEREN, D.; LACOMBE, J. P. Vegetation cover degradation assessment in Madagascar savanna based on trend analysis of MODIS NDVI time series. International Journal of Applied Earth Observation and Geoinformation, v. 125, p. S3-S10, 2010.

JENSEN, J. R. Sensoriamento Remoto do Ambiente: Uma perspectiva em recursos terrestres. São José dos Campos: Parêntese, $2^{\mathrm{a}}$ ed., 598 p., 2009.

JIANG, Z.; HUETE, A. R.; DIDAN, K.; MIURA, T. Development of a two-band enhanced vegetation index without a blue band. Remote Sensing of Environment, v.112, p.38333845, 2008.

JÖNSSON, P.; EKLUNDH, L. Seasonality extraction by function fitting to time-series of satellite sensor data. IEEE Transactions on Geoscience and Remote Sensing, v. 40(8), p. 1824-1832, 2002.

JÖNSSON, P.; EKLUNDH, L. TIMESAT: a program for analyzing time-series of satellite sensor data. Computers \& Geosciences, v. 30(1), p. 833-845, 2004.

JULIEN, Y.; SOBRINO, J. A. Comparison of cloud-reconstruction methods for time series of composite NDVI data. Remote Sensing of Environment. 114(3), p. 618-625, 2010.

JUSTICE, C. O. VERMOTE, E.; TOWNSHEND, J. R. G.; DEFRIES, R.; ROY, D.P. ; HALL, D.K. ; SALOMONSON, V.V. ; PRIVETTE, J.L. ; RIGGS, G. ; STRAHLER, A. ; LUCHT, W. ; MYNENI, R.B. ; KNYAZIKHIN, Y. ; RUNNING, S.W. ; NEMANI, R.R. ; ZHENGMING WAN ; HUETE, A.R. ; VAN LEEUWEN, W. ; WOLFE, R.E. ; GIGLIO, L. ; MULLER, J.-P. ; LEWIS, P. ; BARNSLEY, M.J. The moderate resolution imaging spectroradiometer (MODIS): land remote sensing for global change research. IEEE Transactions on Geoscience and Remote Sensing, v. 36, p. 1228-1249, 1998.

JUSTICE, C. O.; TOWNSHEND, J. R. G. Special issue on the moderate resolution imaging spectroradiometer (MODIS): a new generation of land surface monitoring. Remote Sensing of Environment, v. 83, n. 1-2, p. 1-2, 2002.

JUSTICE, C. O.; TOWNSHEND, J. R. G.; VERMOTE, E. F.; MASUOKA, E.; WOLFE, R. E.; SALEOUS, N.; ROY, D. P.; MORISETTE, J. T. An overview of MODIS Land data processing and product status. Remote Sensing of Environment, v.83, p. 3-15, 2002.

KAUFMAN, Y. J.; TANRE, D. Atmospherically Resistant Vegetation Index (ARVI) for EOSMODIS. IEEE Transactions on Geosciences and Remote Sensing. v. 30 (2), p. 261270, 1992.

KLINK, C. A.; MACHADO, R. B. Conservation of Brazilian Cerrado. Conservation Biology, v. 19, p.707-713, 2005.

KRONKA, F. J. N.; NALON, M. A.; MATSUKUMA, C. K.; YWANE, M. S. S.; LIMA, L. M. P. R.; GUILLAUMON, J. R.; BARRADAS, A. M. F.; PAVÃO, M.; MANETTI, L. A.; BORGO, S. C. Monitoramento da vegetação natural e do reflorestamento no estado de São Paulo. In: Simpósio Brasieiro de Sensoriamento Remoto, 12, Goiânia, GO. Anais... São José dos Campos: INPE, p. 1569-1576, 2005.

LATORRE, M. L. ANDERSON, L. O.; SHIMABUKURO, Y. E.; CARVALHO JUNIOR, O. A. Sensor MODIS: características gerais e aplicações. Espaço e Geografia, v. 6 (1), p. 91 121, 2003.

LATORRE, M. L.; SHIMABUKURO, Y. E.; ANDERSON, L. O. Produtos para ecossistemas terrestres - MODLAND. IN: RUDORFF, B. F. T.; SHIMABUKURO, Y. E.; CEBALLOS, J. C. (Org.). O Sensor Modis e suas Aplicações Ambientais no Brasil. São José dos Campos: Parêntese, p. 23-35, 2007. 
LEWINSOHN, T. M.; PRADO, P. I. How many species are there in Brazil? Conservation Biology, v. 19, p.619-624, 2005.

LHERMITTE, S.; VERBESSELT, J.; VERSTRAETEN, W.W.; COPPIN, P. A comparison of time series similarity measures for classification and change detection of ecosystem dynamics. Remote Sensing of Environment. v. 115. p. 3129-3152, 2011.

LIBONATI, R.; MORELLI, F.; SETZER, A.; CAMARA, C.; PEREIRA, J. M. C. Análise da assinatura espectral no visível e infra-vermelho próximo de áreas queimadas em produtos MODIS. In: Simposio Latinoamericano sobre Percepción remota y sistemas de información espacial, 12, Cartagena, Colômbia, Anais...24-29 de setembro de 2006.

LIESENBERG, V.; PONZONI, F. J.; GALVÃO, L. S. Análise da dinâmica sazonal e separabilidade espectral de algumas fitofisionomias do Cerrado com índices de vegetação dos sensores MODIS/TERRA e AQUA1. Revista Árvore, v.31(2), p.295-305, 2007.

LIMA, J. E. F. W.; SILVA, E. M. Estimativa da contribuição hídrica superficial do Cerrado para as grandes regiões hidrográficas brasileiras. In: Simpósio Brasileiro de Recursos Hídricos, São Paulo, SP, 17, Anais... ABRH, 2007. Disponível em: <http://www.abrh.org.br/sgcv3/index.php?PUB=3\&ID=19\&PAG=8>. Acessado em: 10 jan 2015.

LOPES, A. S.; GUILHERME, L. R. G. Solos sob cerrado: manejo da fertilidade para a produção agropecuária. São Paulo, Associação Nacional para Difusão de Adubos e Corretivos Agrícolas: ANDA, São Paulo. 2ª Ed. 62p. Boletim técnico. n. 5, 1994.

LPDAAC. Land Processes Distributed Active Archive Center. Vegetation Indices 16-Day L3 Global 250m - MOD13Q1. Disponível em: https://lpdaac.usgs.gov/products/modis_products_table/mod13q1. Acessado em: $19 \mathrm{de}$ dezembro de 2014.

LIU, W. T. H. Aplicações de Sensoriamento Remoto. Ed. UNIDERP. 881 p, 2007.

LUNETTA, R. S.; KNIGHT, J. F.; EDIRIWICKREMA, J.; LYON, J. G.; WORTHY, L. D. Land cover detection using multi-temporal MODIS NDVI data. Remote Sensing of Environment, v.105, p. 142-154, 2006.

MA, M.; VEROUSTRAETE, F. Reconstructing pathfinder AVHRR land NDVI time series data for the northwest of China. Advances in Space Research. 37(4), 835-840, 2006.

MACHADO, R. B.; RAMOS NETO, M. B.; PEREIRA, P. G. P.; CALDAS, E. F.; GONÇALVES, D. A.; SANTOS, N. S.; TABOR, K.; STEININGER, M. Estimativas de perda da área do Cerrado brasileiro. Relatório técnico (não publicado). Brasília: Conservação Internacional, 23 p., 2004.

MANTOVANI, J. E.; PEREIRA, A. Estimativa da integridade da cobertura vegetal de Cerrado através de dados TM/Landsat. In: Simpósio Brasileiro de Sensoriamento Remoto, 9, Santos, SP. Anais... 1998.

MENDONÇA, R., J. FELFILI, B. WALTER, J.C. SILVA JÚNIOR., A. REZENDE, T. FILGUEIRAS; P. NOGUEIRA. Flora vascular do Cerrado. IN: SANO, S. M.; ALMEIDA, S. P. (eds.). Cerrado. Ambiente e flora. p. 288-556. Empresa Brasileira de Pesquisa Agropecuária - Embrapa Cerrados, Planaltina, Brasil, 1998.

MENESES, P. R.; ALMEIDA, T. (Org.) Introdução ao processamento de imagens de sensoriamento remoto. Brasília: CNPq, 2012.

MITTERMEIER, R. A.; MYERS, N.; MITTERMEIER, C. G.; MYERS, N.; FORD, H. Hotspots: Earth's Biologically Richest and Most Endangered Terrestrial Ecoregions. Cidade do México: CEMEX- Conservation International, 430p., 1999. 
MOREIRA, M. A. Fundamentos de Sensoriamento Remoto e Metodologias de Aplicação. 4. ed. Viçosa: Ed. UFV, 2011.

MOREIRA, R. C. Influência do posicionamento e da largura de bandas de sensores remotos e dos efeitos atmosféricos na determinação de índices de vegetação. São José dos Campos, INPE, 2000. Dissertação de Mestrado em Sensoriamento Remoto, 181 p., 2000.

MORETTIN, P. A.; TOLOI, C. M. C. Análise de séries temporais. São Paulo: Edgard Blucher, $2^{a}$ ed., 544 p, 2006.

MUTANGA, O.; SKIDMORE, A. K. Narrow band vegetation indices overcome the saturation problem in biomass estimation. International Journal of Remote Sensing, v. 25 (19), p. 3999-4014, 2004.

MYERS, N.; MITTERMEIER, R. A.; MITTERMEIER, C. G.; FONSECA, G. A. B.; KENT, J. Biodiversity hotspots for conservation priorities. Nature, n. 403, p. 853-858, 2000.

NSIDC. 2004. MODIS Sinusoidal Grid. Boulder, Colorado USA: National Snow and Ice Data Center. http://http://nsidc.org/data/docs/daac/mod10_modis_snow/landgrid.html. Acesso em: 09 out 2013.

OLIVEIRA, J. C.; EPIPHANIO, J. C. N.; RENNÓ, C. D. Window regression: a spatialtemporal analysis to estimate pixels classified as low-quality in MODIS NDVI time series. Remote Sensing, n. 6, p. 3123-3142, 2014.

PESSOA, O. A. A.; MENESES, P. R. Evolução do comportamento espectral de cicatrizes de incêndio florestal no Cerrado. In: Simpósio Brasileiro de Sensoriamento Remoto, 16, Foz do Iguaçu, PR. Anais... 2013.

PONZONI, F. J.; SHIMABUKURO, Y. E.; KUPLICH, T. M. Sensoriamento Remoto da vegetação. 2. Ed. Atualizada e ampliada. São Paulo: Oficina de Textos, 2012.

RATANA, P.; HUETE, A.; FERREIRA, L. G. Analysis of Cerrado physiognomies and conversion in the MODIS seasonal-temporal domain. Earth Interactions, v. 9, Paper no. 3, 22 p., 2005.

RATTER, J. A. BRIDGEWATER, S.; RIBEIRO, J. F.; DIAS, T. A. B. Estudo preliminar da distribuição das espécies lenhosas da fitofisionomia cerrado sentido restrito nos estados compreendidos pelo bioma Cerrado. Boletim do Herbário Esechias Paulo Heringer, v. 5. p.5-43, 2000.

RATTER, J. A.; BRIDGEWATER, S.; RIBEIRO, J. F. Analysis of the floristic composition of the Brazilian Cerrado vegetation. III: Comparison of the woody vegetation of 376 areas. Edinburgh Journal of Botany. 60 (1): 57-109, 2003.

RIBEIRO, J. F.; WALTER, B. M. T. Fitofisionomias do bioma Cerrado. IN: SANO, S. M.; ALMEIDA, S. P. Cerrado: Ambiente e Flora. Planaltina: Embrapa-CPAC, p. 89-166, 1998.

RICHARDSON, A. J.,; WIEGAND, C. L. Distinguishing vegetation from soil background information, Photogrammetric Engineering and Remote Sensing, v. 43(2), p. 15411552, 1977.

ROERINK, G.; MENENTI, M.; VERHOEF, W. Reconstructing cloud free NDVI composites using Fourier analysis of time series. International Journal of Remote Sensing, 21, n. 9, p. 1911-1917, 2000.

ROSEMBACK, R.; CONFORTE, J. C.; SHIMABUKURO, Y. E.; FERREIRA, N. J. Análise da variabilidade temporal do NDVI/MODIS na região sul do Brasil. IN: Anais do XIII Simpósio Brasileiro de Sensoriamento Remoto, Florianópolis, SC, Brasil. p.1823-1829, 2007. 
ROUSE, J. W.; HAAS, R. H.; SCHELL, J. A.; DEERING, D. W. Monitoring vegetation systems in the Great Plains with ERTS. Proceedings of the Third ERTS Symposium, NASA SP-351, NASA, Washington, DC, v. 1, p. 309-317, 1973.

RUDORFF, F. T.; SHIMABUKURO, Y. E.; CEBALLOS, J. C. (Orgs.). O sensor Modis e suas aplicações ambientais no Brasil. São José dos Campos: Parêntese, 2007.

RUNNING, S. W.; JUSTICE, C. O.; SALOMONSON, V.; HALL, D.; BARKER, J.; KAUFMANN, Y. J.; STRAHLER, A. H.; HUETE, A. R.; MULLER, J. P.; VANDERBILT, V.; WAN, Z. M.; TEILLET, P.; CARNEGGIE, D. Terrestrial remote sensing science and slgorithms planned for EOS/MODIS. International Journal of Remote Sensing, v. 15 (17), p. 3587-3620, 1994.

SAKAMOTO, T.; YOKOZAWA, M.; TORITANI, H.; SHIBAYAMA, M.; ISHITSUKA, N.; OHNO, $\mathrm{H}$. A crop phenology detection method using time-series MODIS data. Remote Sensing of Environment, v. 96, p. 366-374, 2005.

SANO, E. E.; FERREIRA, L. G.; ASNER, G. P.; STEINKE, E. T. Spatial and temporal probabilities of obtaining cloud-free Landsat images over the Brazilian tropical savanna. International Journal of Remote Sensing, v. 28 (12), p. 2739-2752, 2007.

SANO, E. E.; ROSA, R.; BRITO, J. L. S.; FERREIRA, L. G. Mapeamento semi-detalhado do uso da terra do Bioma Cerrado. Pesquisa Agropecuária Brasileira, v. 43(1), p. 153156, 2008.

SANO, E. E.; ROSA, R.; BRITO, J. L. S.; FERREIRA, L. G. Land cover mapping of the tropical savanna region in Brazil. Environmental Monitoring and Assessment, v. 166, p. 113-124, 2010.

SANTOS, L.; CASTRO, J. J. B.; MACAU, E. E. N.; GODOY, M. F. Uso de um filtro adaptativo para pré-análise de séries temporais. In: Workshop de Computação Aplicada, WORCAP 2012, São José dos Campos, SP, 12. Anais... 2012.

SCHMIDT, I. B.; FIGUEIREDO, I. B.; BORGHETTI, F.; SCARIOT, A. Produção e germinação de sementes de "capim dourado", Syngonanthusnitens (Bong.) Ruhland (Eriocaulaceae): implicações para o manejo. Acta Botanica Brasilica. v.22 (1), p. 3742, 2008.

SCHOROEDER, T. A.; COHEN, W. B.; YANG, Z. Patterns of forest regrowth following clearcutting in western Oregon as determined from a Landsat time-series. Forest Ecology and Management, v. 243, p. 259-273, 2007.

SCOLFORO, J. R.; CARVALHO, L. M. T. Mapeamento e inventário da flora nativa e dos reflorestamentos de Minas Gerais. Lavras: UFLA, 288p., 2006.

SEGPLAN. Secretaria de Estado de Gestão e Planejamento do Estado de Goiás. Perfil socioeconômico dos municípios goianos. Disponível em: http://www.seplan.go.gov.br/sepin/perfilweb/perfil_bde.asp. Acessado em: 10 jul. 2013.

SILVA, J. F.; FARIÑAS, M. R.; FELFILI, J.M.; KLINK, C. A. Spatial heterogeneity, land use and conservation in the cerrado region of Brazil. Journal of Biogeography, v. 33, p. 536548, 2006.

SINHA, P.; KUMAR, L. Independent two-step thresholding of binary images in inter-annual land cover change/no-change identification. ISPRS Journal of Photogrammetry and Remote Sensing. v. 81. p. 31-43, 2013.

SOARES, J. V.; BATISTA, G. T.; SHIMABUKURO, Y. E. Histórico e descrição. IN: RUDORFF, B. F. T.; SHIMABUKURO, Y. E.; CEBALLOS, J. C. (Org.). O Sensor Modis e suas Aplicações Ambientais no Brasil. São José dos Campos: Parêntese, 2007. 
SOLANO, R.; DIDAN, K.; JACOBSON, A.; HUETE, A. MODIS Vegetation Index User'sGuide (MOD13 Series) Version 2.0, Vegetation Index and Phenology Lab., Universidade do Arizona, 38p., 2010.

TUNDISI, J. G.; MATSUMURA-TUNDISI, T. M. Impactos potenciais das alterações do Código Florestal nos recursos hídricos. Biota Neotropical, v. 10(4), p. 67-76, 2010.

VANDIJK, A.; CALLIS, S. L; SAKAMOTO, C. M.; DECKER, W. L. Smoothing vegetation index profiles: an alternative method for reducing radometric disturbance in NOAA/AVHRR data. Photogrammetric Engineering and Remote Sensing, v. 53(8), p. 1059-1067, 1987.

VERBESSELT, J.; HYNDMAN, R.; NEWNHAM, G.; CULVENOR, D. Detecting trend and seasonal changes in satellite image time series. Remote Sensing of Environment, v. 114. p. 106-115. 2010.

VERBESSELT. J.; ZEILEIS, A.; HEROLD, M. Near real-time disturbance detection using satellite image time-series. Remote Sensing of Environment, v. 123, p. 98-108, 2012.

VIOVY, N.; ARINO, O.; BELWARD, A. S. The best index slope extraction (BISE): A method for reducing noise in NDVI time series. International Journal of Remote Sensing, $v$. 13, p. 1585- 1590, 1992.

VRIELING, A.; BEURS, K. M.; BROWN, M. E. Variability of African farming systems from phenological analysis of NDVI time series. Climatic Change, v. 109, p. 455-477, 2011.

WEIERS, S.; BOCK, M.; WISSEN, M.; ROSSNER, G. Mapping and indicator approaches for the assessment of habitats at different scales using remote sensing and GIS methods. Landscape and Urban Planning, v. 67, p. 43-65, 2004.

WIEGAND, C. L.; RICHARDSON, A. J.; ESCOBAR, D. E.; GERBERMANN, A. H. Vegetation indices in crop assessments. Remote Sensing of Environment, v. 35, p. 105-119, 1991.

ZAR, J. H. Bioestatistical Analysis. 4ª ed. New Jersey: Prentice Hall.

ZHANG M-Q.; GUO H-Q.; XIE X.; ZHANG T-T.; OUYANG Z-T.; ZHAO, B. Identification of Land-Cover Characteristics Using MODIS Time Series Data: An Application in the Yangtze River Estuary. PLoS ONE v. 8 (7), 2013. 


\begin{abstract}
ANEXO
Relatório fotográfico das expedições de campo, realizadas nos municípios Jataí/GO, Luís Eduardo Magalhães/BA, Mateiros/TO e São Miguel do Araguaia/GO.
\end{abstract}

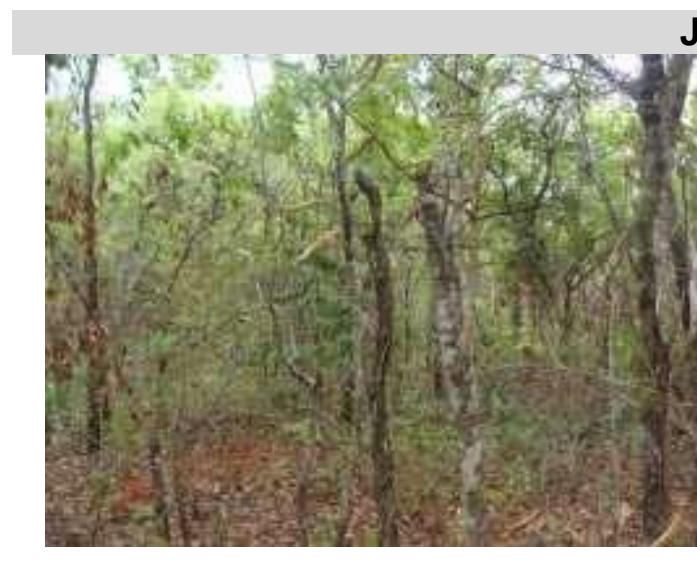

Ponto 01

Fitofisionomia: Cerrado Típico Latitude: S $18^{\circ} 00^{\prime} 45.6^{\prime \prime}$

Longitude: W $51^{\circ} 33^{\prime}$ 53.2" Cor do solo: 7,5 YR $3 / 4$

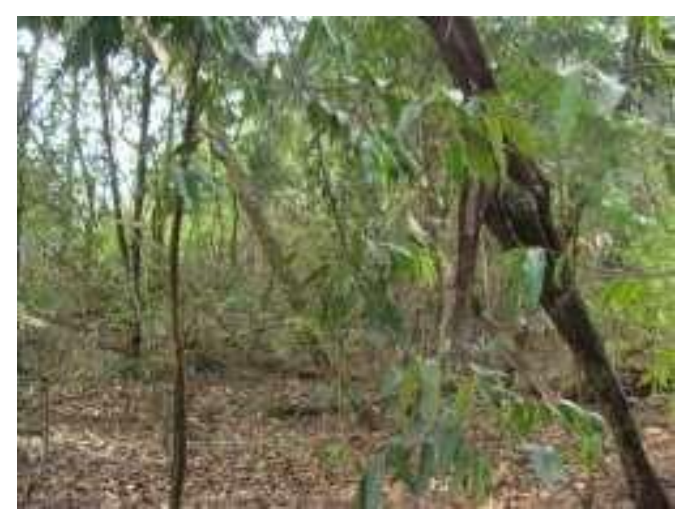

Ponto 03

Fitofisionomia: Cerradão Latitude: S $17^{\circ} 39^{\prime} 29.2^{\prime \prime}$

Longitude: W $51^{\circ} 55^{\prime} 36.9^{\prime \prime}$

Cor do solo: 5 YR 5/4

\section{Jataí-GO}

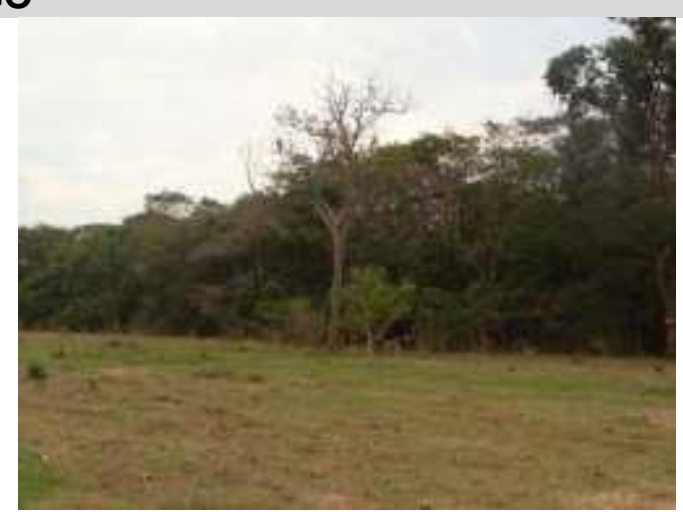

Ponto 02

Fitofisionomia: Cerradão

Latitude: S 17046' 21.7"

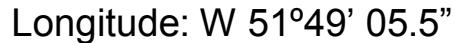

Cor do solo: 5 YR 5/4

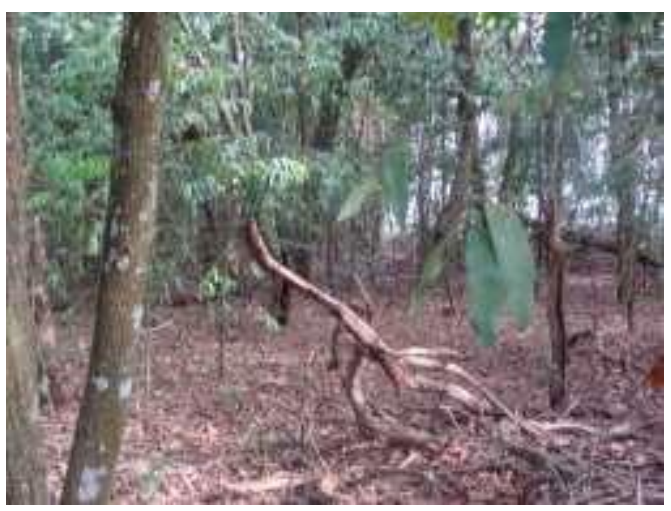

Ponto 04

Fitofisionomia: Cerradão

Latitude: S $18^{\circ} 02^{\prime} 22.7^{\prime \prime}$

Longitude: W 51 $50^{\circ}$ ' 12.4"

Cor do solo: 2,5 YR 3/6 


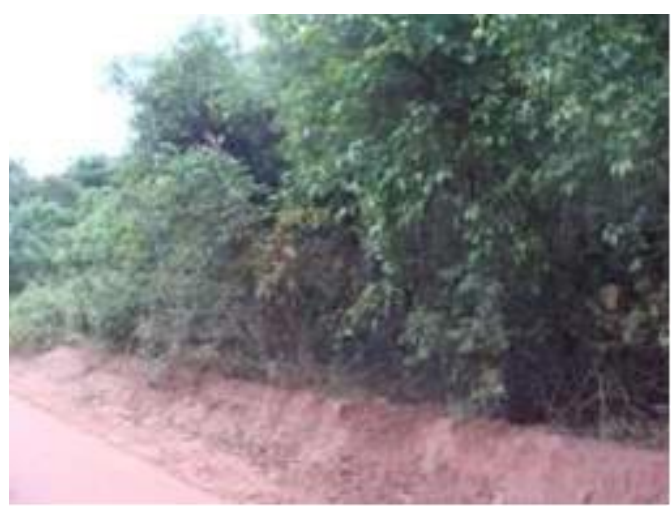

Ponto 05

Fitofisionomia: Cerradão Latitude: S $17^{\circ} 44^{\prime} 17.9^{\prime \prime}$ Longitude: W 51 ${ }^{\circ} 46^{\prime} 50.3^{\prime \prime}$ Cor do solo: 7,5 YR 4/4

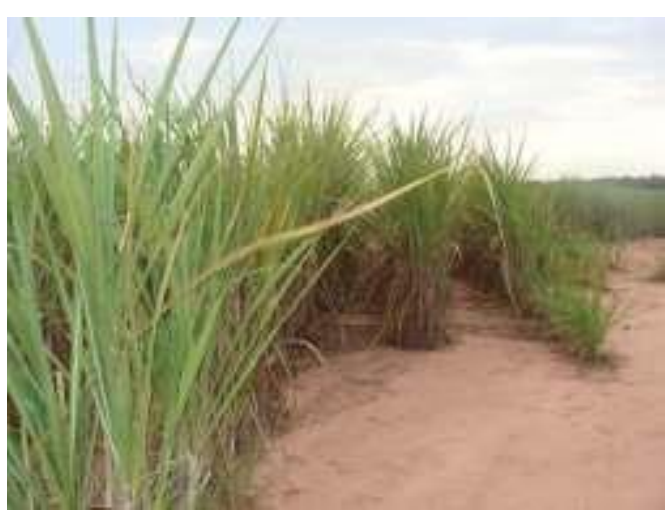

Ponto 07

Uso do solo: Cana de açúcar Latitude: S $17^{\circ} 43^{\prime} 16.3^{\prime \prime}$ Longitude: W 51 ${ }^{\circ} 52^{\prime} 22.9$ Cor do solo: 5 YR 4/4

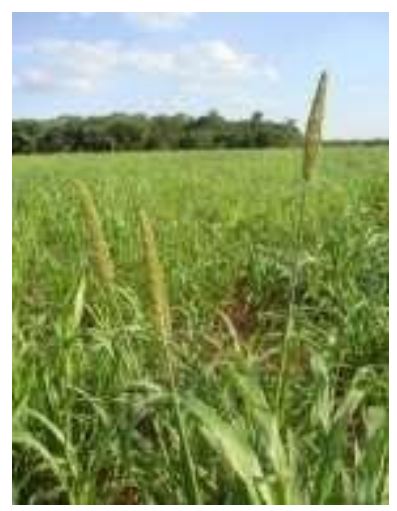

Ponto 09 Uso do solo: Milheto Latitude: S $17^{\circ} 51^{\prime} 11.1^{\prime \prime}$ Longitude: W $51^{\circ} 31^{\prime} 21.9^{\prime \prime}$ Cor do solo: 7,5 YR 4/4

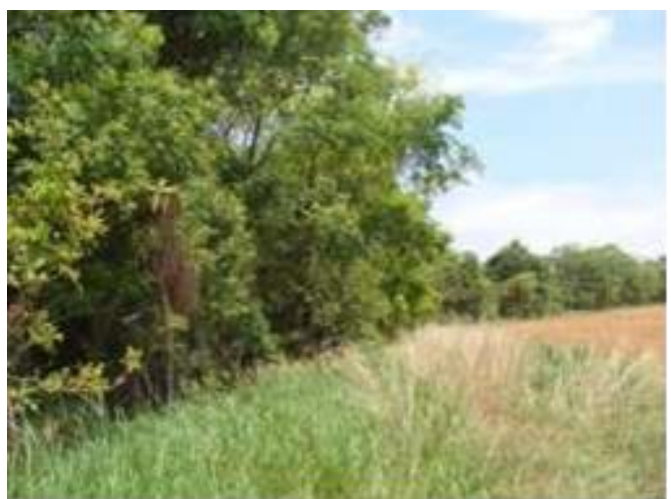

Ponto 06

Fitofisionomia: Cerradão Latitude: S $17^{\circ} 43^{\prime \prime} 46.4^{\prime \prime}$ Longitude: W $52^{\circ} 06^{\prime} 52.6^{\prime \prime}$ Cor do solo: 5 YR 4/3

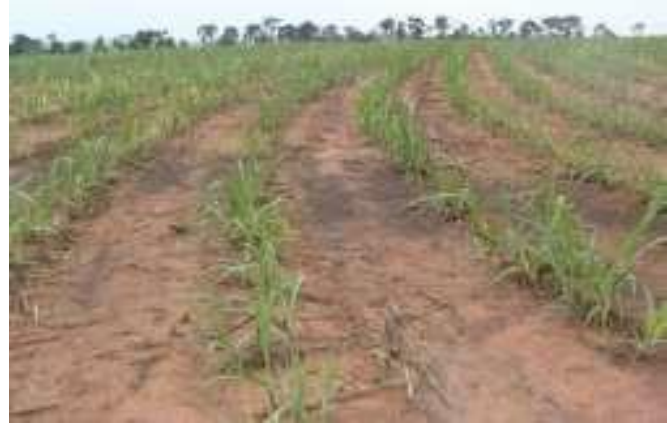

Ponto 08

Uso do solo: Cana de açúcar Latitude: S $18^{\circ} 00^{\prime} 43.0^{\prime \prime}$ Longitude: W $51^{\circ} 33^{\prime} 54.5^{\prime \prime}$ Cor do solo: 7,5 YR $3 / 3$

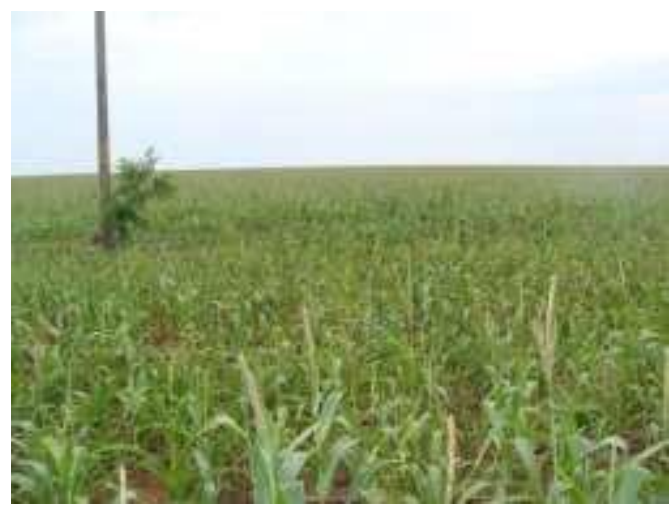

Ponto 10

Uso do solo: Milho Latitude: S $17^{\circ} 58^{\prime} 24.4^{\prime \prime}$ Longitude: W $51^{\circ} 35^{\prime} 14.6^{\prime \prime}$ Cor do solo: 5 YR 3/3 


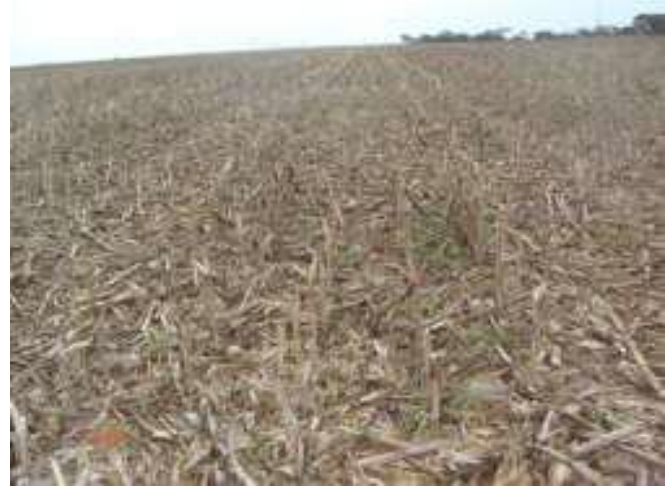

Ponto 11

Uso do solo: Milho

Latitude: S $17^{\circ} 47^{\prime} 09.6^{\prime \prime}$

Longitude: W $52^{\circ}$ 04' 32.3"

Cor do solo: 2,5 YR 4/3

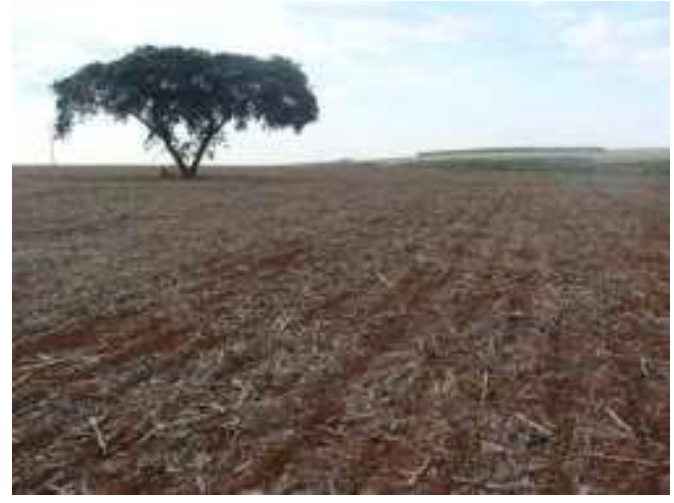

Ponto 13

Uso do solo: Soja

Latitude: S $17^{\circ} 51^{\prime} 34.3^{\prime \prime}$

Longitude: W 51 $33^{\prime} 36.9^{\prime \prime}$

Cor do solo: 2,5 YR 3/4

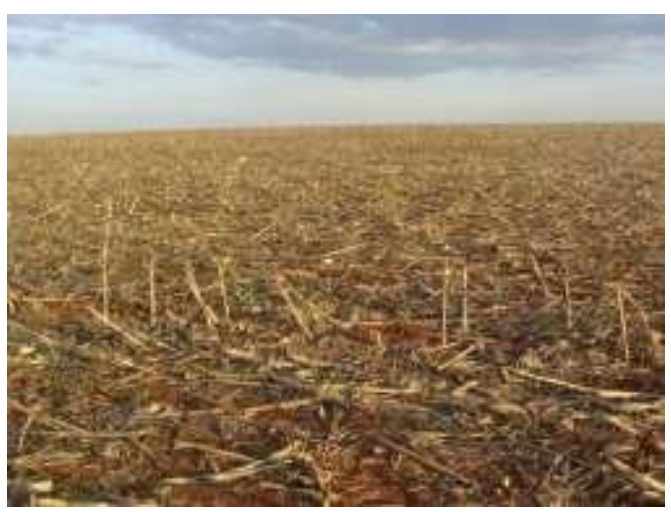

Ponto 15

Uso do solo: Soja

Latitude: S $17^{\circ} 59^{\prime} 10.6^{\prime \prime}$

Longitude: W 51 $46^{\prime}$ '46.9"

Cor do solo: 2,5 YR $3 / 4$

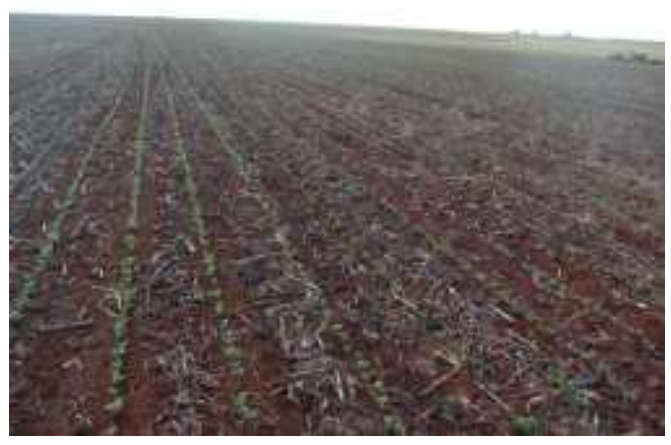

Ponto 12

Uso do solo: Soja

Latitude: S $17^{\circ} 50^{\prime} 37.1^{\prime \prime}$

Longitude: W $51^{\circ} 27^{\prime} 54.8^{\prime \prime}$

Cor do solo: 2,5 YR 3/4

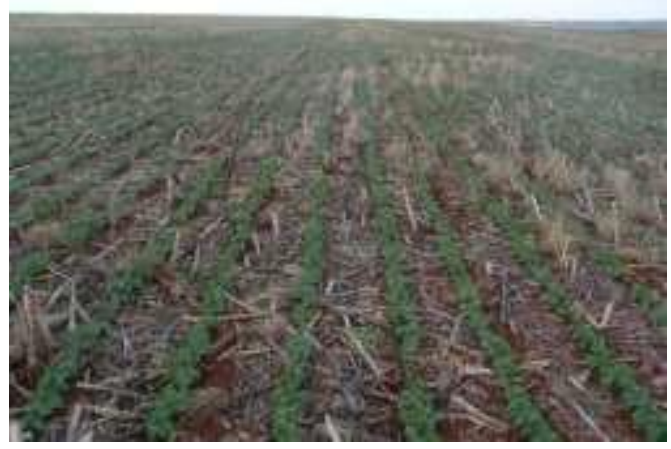

Ponto 14

Uso do solo: Soja

Latitude: S $17^{\circ} 52^{\prime} 06.8^{\prime \prime}$

Longitude: W $51^{\circ} 35^{\prime} 57.4^{\prime \prime}$

Cor do solo: 2,5 YR 3/6

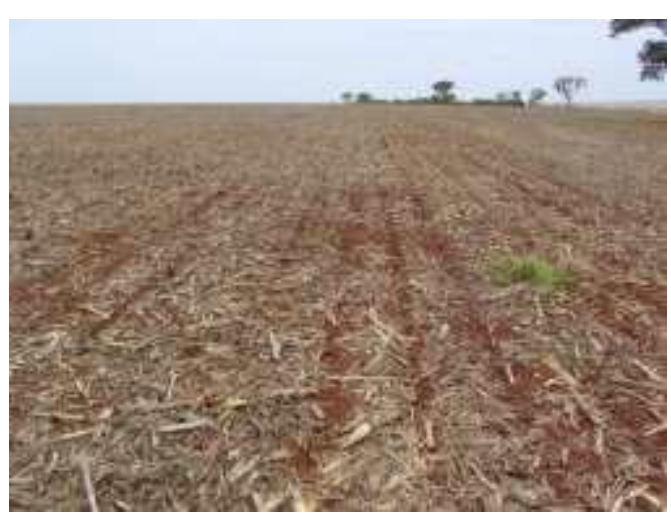

Ponto 16

Uso do solo: Soja

Latitude: S $17^{\circ} 53^{\prime} 58.0^{\prime \prime}$

Longitude: W $51^{\circ} 50^{\prime} 06.0^{\prime \prime}$

Cor do solo: 2,5 YR 3/3 


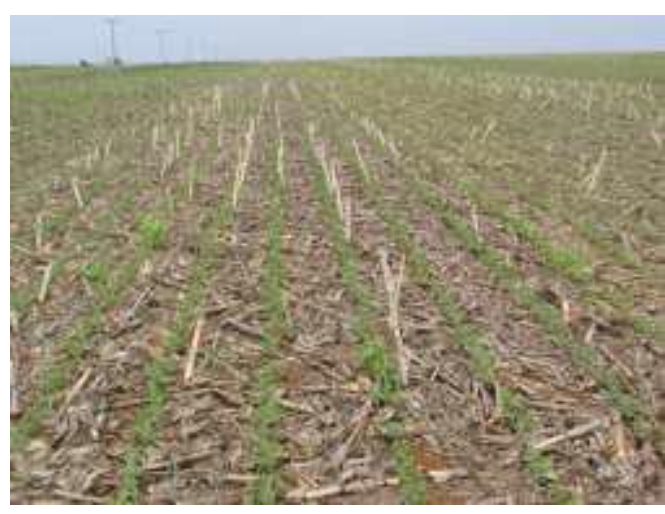

Ponto 17

Uso do solo: Soja

Latitude: S $17^{\circ} 51^{\prime} 22.5^{\prime \prime}$

Longitude: W 51ํ $54^{\prime} 10.6^{\prime \prime}$

Cor do solo: 2,5 YR 4/3

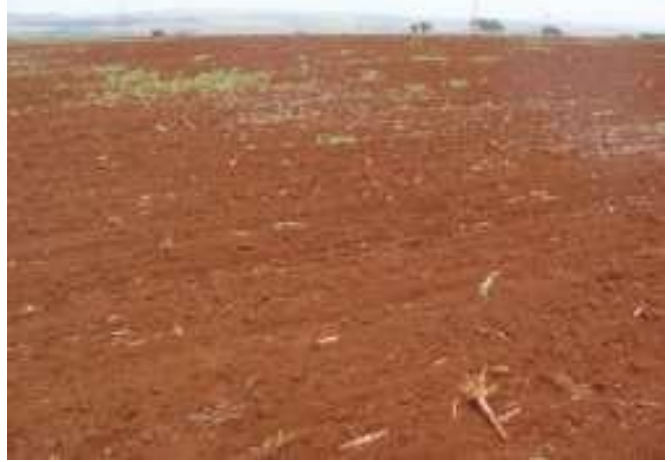

Ponto 19

Uso do solo: Solo exposto

Latitude: S $17^{\circ} 55^{\prime} 51.5^{\prime \prime}$

Longitude: W 51 41'09.5"

Cor do solo: 2,5 YR 3/4

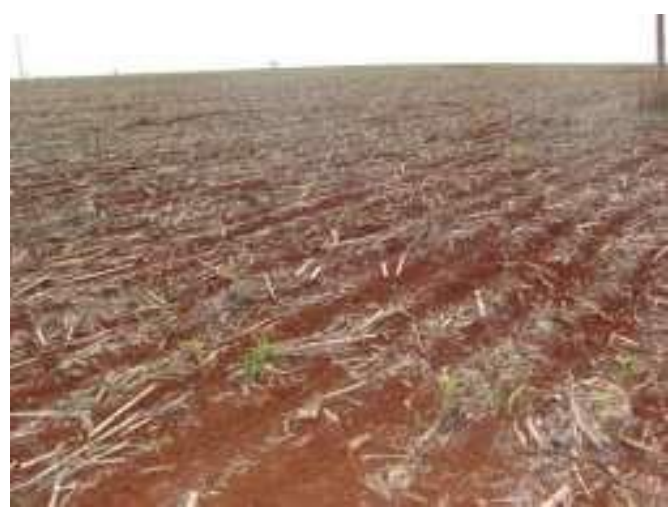

Ponto 21

Uso do solo: Solo exposto Latitude: S $18^{\circ} 01^{\prime} 04.9^{\prime \prime}$

Longitude: W 51 49' 22.7"

Cor do solo: 2,5 YR 3/4

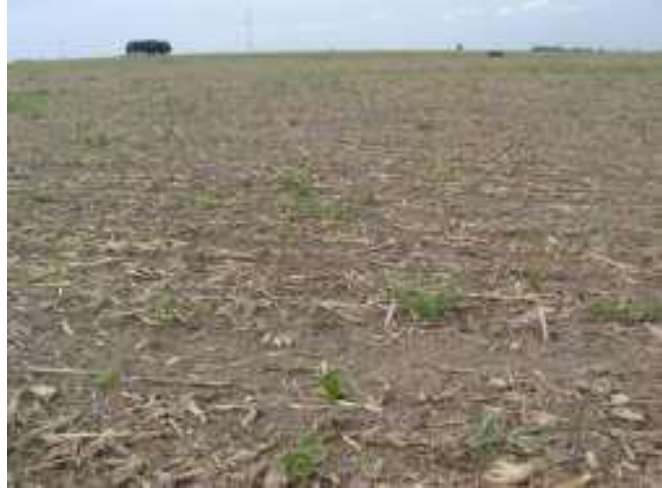

Ponto 18

Uso do solo: Soja

Latitude: S $17^{\circ} 43^{\prime} 46.9^{\prime \prime}$

Longitude: W 520 08' 29.2"

Cor do solo: 7,5 YR 5/1

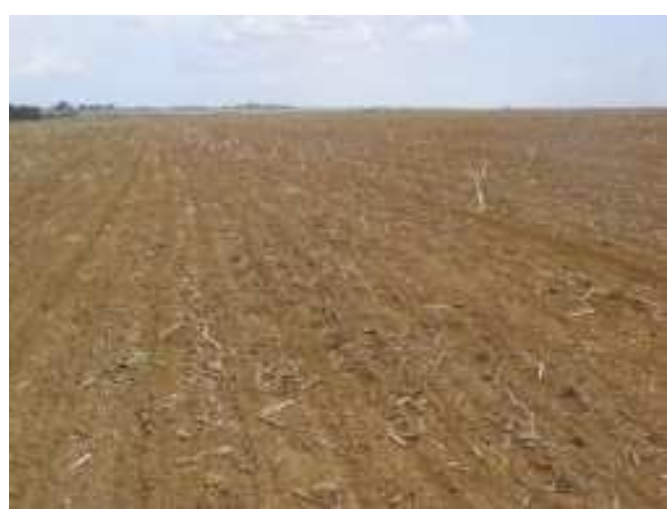

Ponto 20

Uso do solo: Solo exposto com palhada de milho

Latitude: S $17^{\circ} 41^{\prime} 24.8^{\prime \prime}$

Longitude: W $52^{\circ} 12^{\prime} 00.0^{\prime \prime}$

Cor do solo: 2,5 YR 4/4

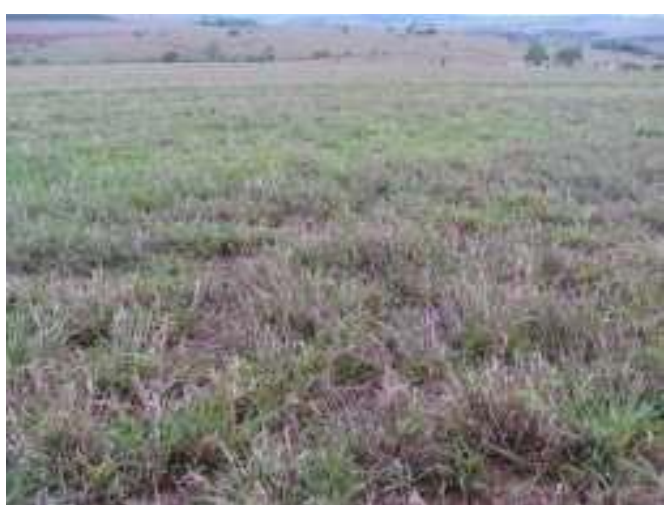

Ponto 22

Uso do solo: Pastagem

Latitude: S $17^{\circ} 58^{\prime} 38.5^{\prime \prime}$

Longitude: W $51^{\circ} 47^{\prime} 52.1^{\prime \prime}$

Cor do solo: 2,5 YR 3/4 


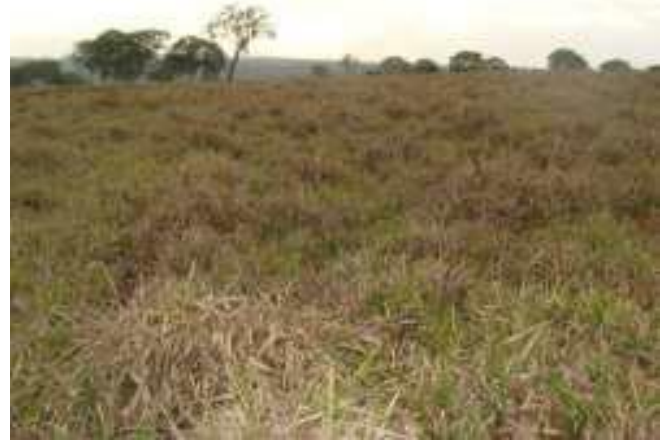

Ponto 23

Uso do solo: Pastagem Latitude: S $17^{\circ} 49^{\prime} 08.5^{\prime \prime}$

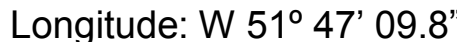

Cor do solo: 2,5 YR 3/4

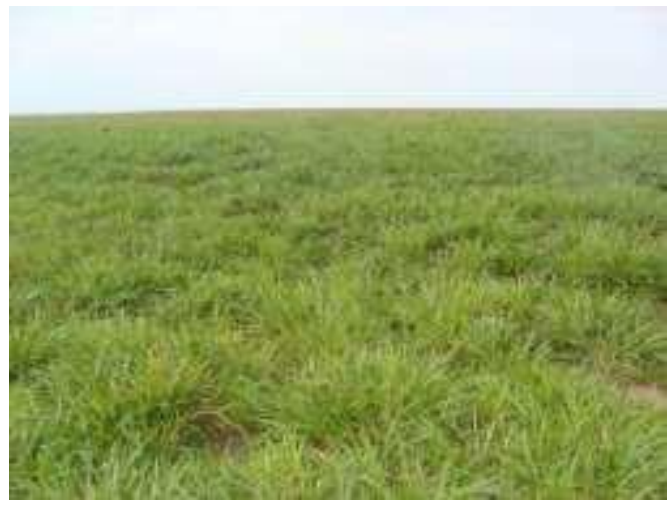

Ponto 25

Uso do solo: Pastagem

Latitude: S $17^{\circ} 39^{\prime} 40.2^{\prime \prime}$

Longitude: W 51 ${ }^{\circ} 55^{\prime} 33.5^{\prime \prime}$

Cor do solo: 5 YR 5/2

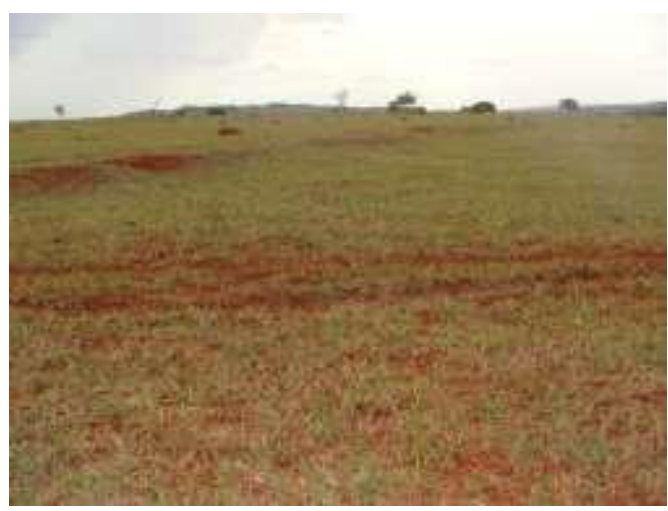

Ponto 27

Uso do solo: Pastagem

Latitude: S $17^{\circ} 59^{\prime} 33.2^{\prime \prime}$

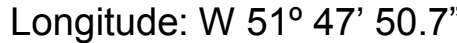

Cor do solo: 2,5 YR 3/3

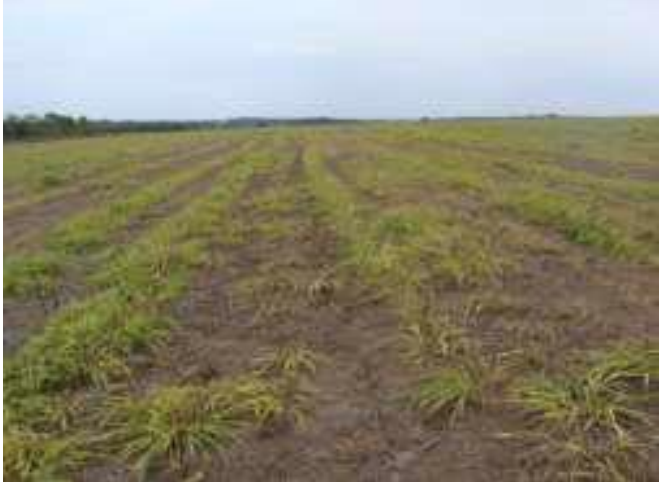

Ponto 24

Uso do solo: Pastagem

Latitude: S $17^{\circ} 43^{\prime} 54.5^{\prime \prime}$

Longitude: W 51ํ 50' 29.7"

Cor do solo: 5 YR 4/2

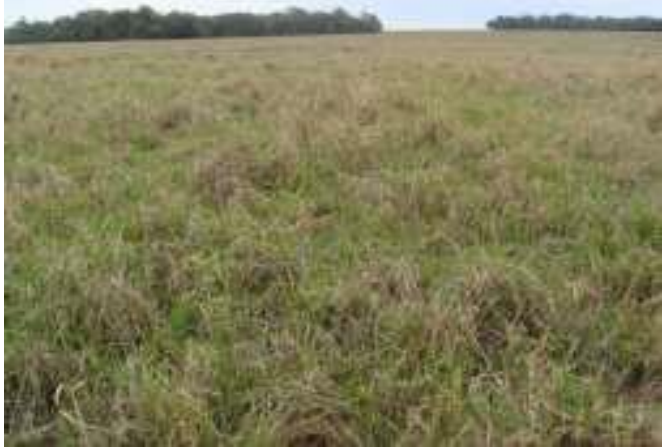

Ponto26

Uso do solo: Pastagem

Latitude: S $18^{\circ} 03^{\prime} 26.7^{\prime \prime}$

Longitude: W $51^{\circ} 32^{\prime} 34.7^{\prime \prime}$

Cor do solo: 5 YR 4/3

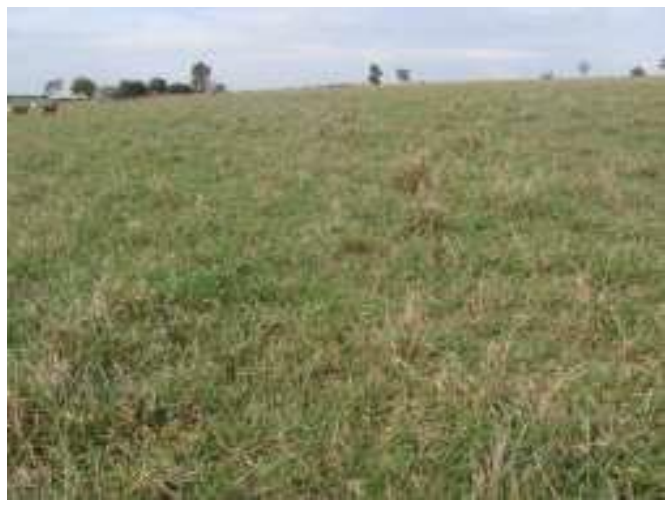

Ponto 28

Uso do solo: Pastagem

Latitude: S $18^{\circ} 03^{\prime} 23.9^{\prime \prime}$

Longitude: W 51 50 ' 28.2"

Cor do solo: 2,5 YR 3/4 


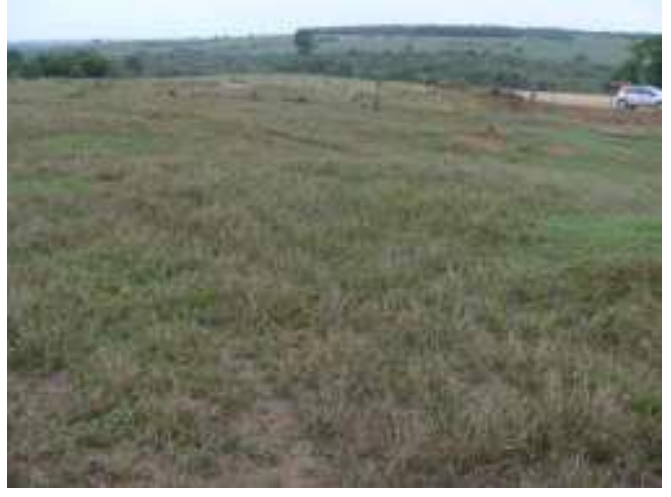

Ponto 29

Uso do solo: Pastagem Latitude: S $17^{\circ} 46^{\prime} 42.2^{\prime \prime}$

Longitude: W $51^{\circ} 47^{\prime}$ 08.6"

Cor do solo: 7,5 YR 4/3

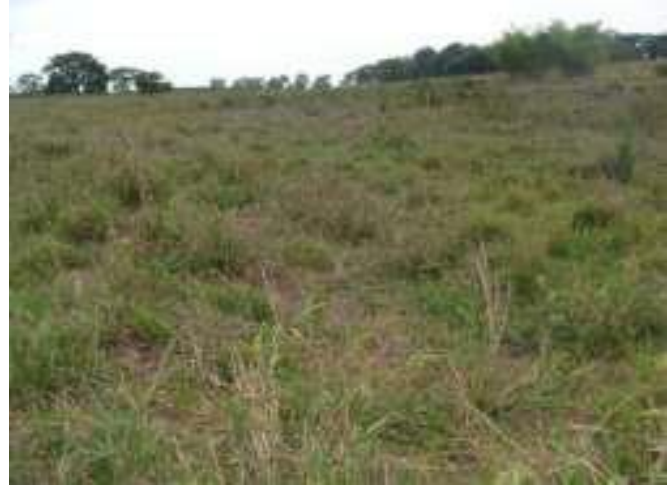

Ponto 31

Uso do solo: Pastagem

Latitude: S $17^{\circ} 45^{\prime} 24.2^{\prime \prime}$

Longitude: W 51 46' 55.9"

Cor do solo: 7,5 YR 4/2

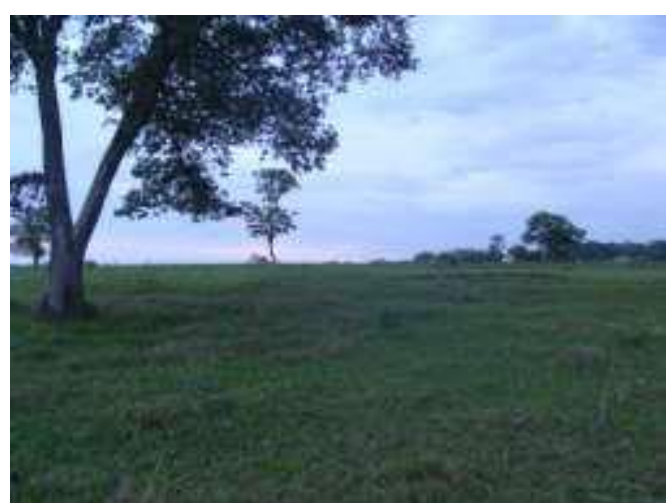

Ponto 30

Uso do solo: Pastagem

Latitude: S $17^{\circ} 42^{\prime} 35.4^{\prime \prime}$

Longitude: W 51 46' 43.2"

Cor do solo: 5 YR 4/3

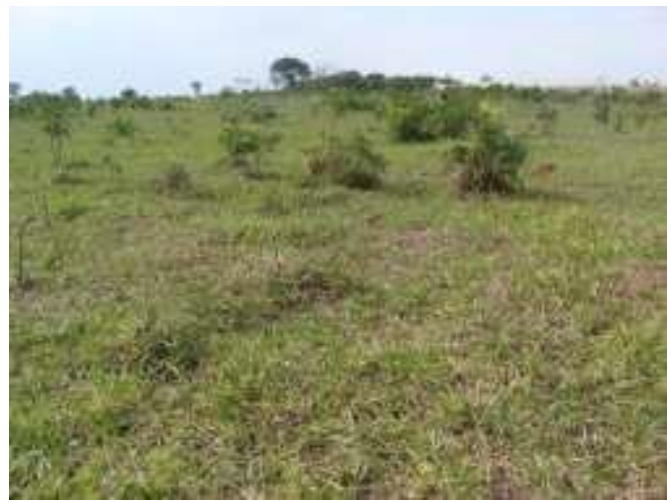

Ponto 32

Uso do solo: Pastagem

Latitude: S $17^{\circ} 36^{\prime} 54.1^{\prime \prime}$

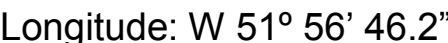

Cor do solo: 5 YR 4/3

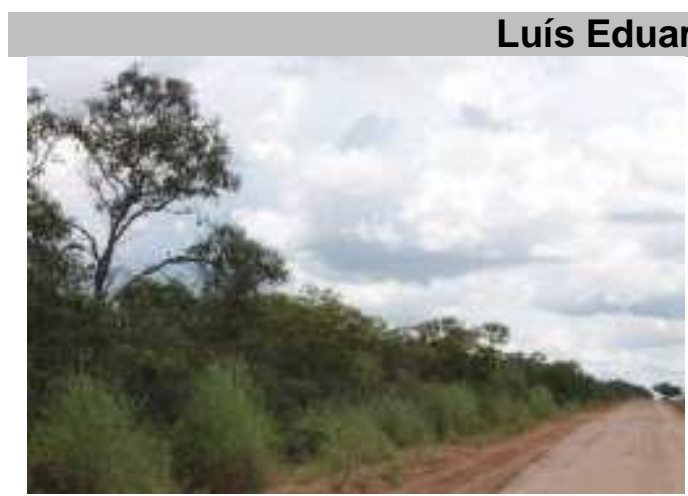

Ponto 33

Fitofisionomia: Cerrado stricto sensu Latitude: S $12^{\circ} 7^{\prime} 47.8^{\prime \prime}$

Longitude: W 46 $6^{\circ}$ ' 26.0"

Cor do solo: 10 YR 4/3

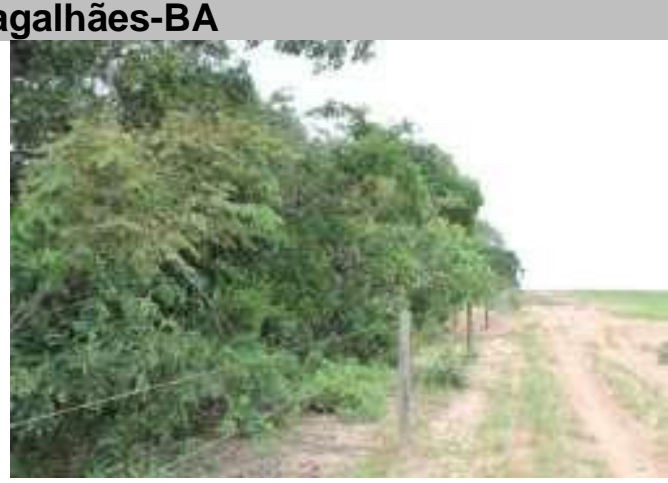

Ponto 34

Fitofisionomia: Cerrado stricto sensu Latitude: S $12^{\circ} 20^{\prime} 18.5^{\prime \prime}$

Longitude: W $45^{\circ} 50^{\prime} 31.0^{\prime \prime}$

Cor do solo: 10 YR 4/4 


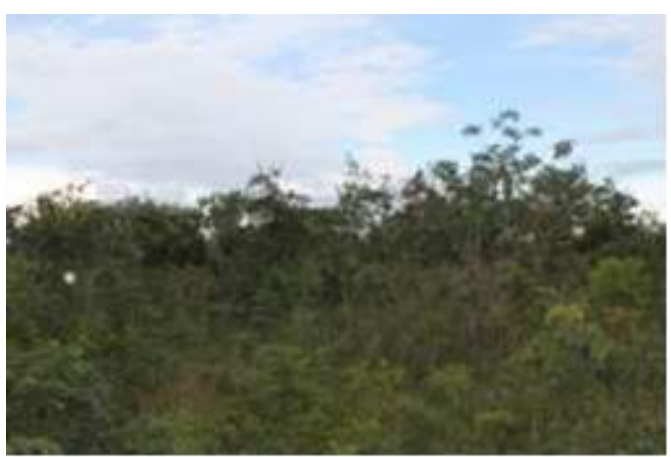

Ponto 35

Fitofisionomia: Cerrado stricto sensu Latitude: S $12^{\circ} 2^{\prime} 32.0^{\prime}$

Longitude: W $45^{\circ} 44^{\prime} 1.0^{\prime \prime}$

Cor do solo: 10 YR 4/2

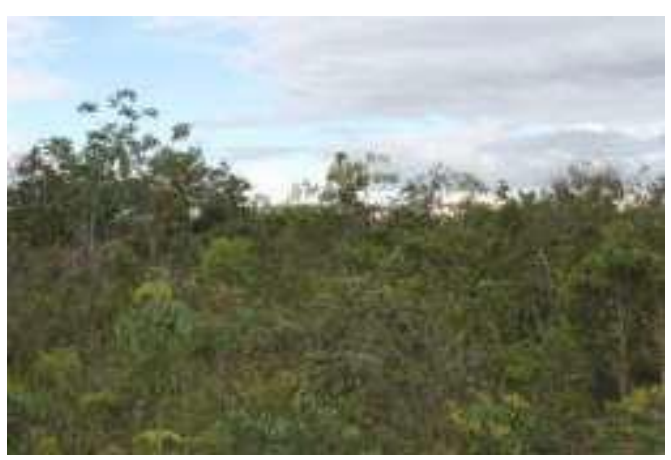

Ponto 37

Fitofisionomia: Cerrado stricto sensu Latitude: S $12^{\circ} 15^{\prime} 5.9^{\prime \prime}$

Longitude: W $45^{\circ} 46^{\prime}$ 57.3"

Cor do solo: 10 YR 4/1

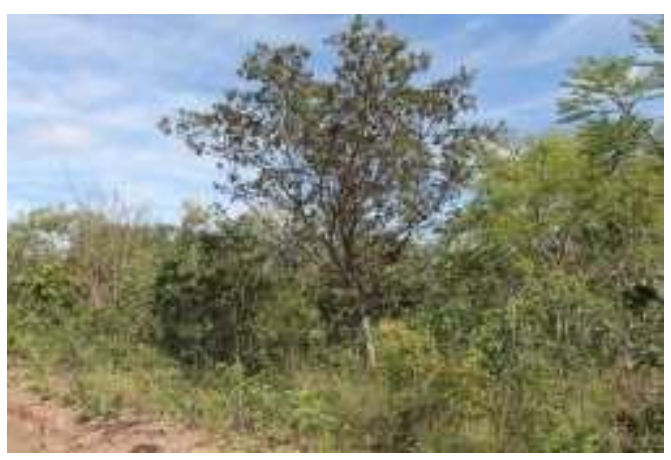

Ponto 39

Fitofisionomia: Cerrado stricto sensu Latitude: S $12^{\circ} 4^{\prime} 41.4^{\prime \prime}$

Longitude: W $46^{\circ} 11^{\prime} 38.7^{\prime \prime}$

Cor do solo: 10 YR $3 / 3$

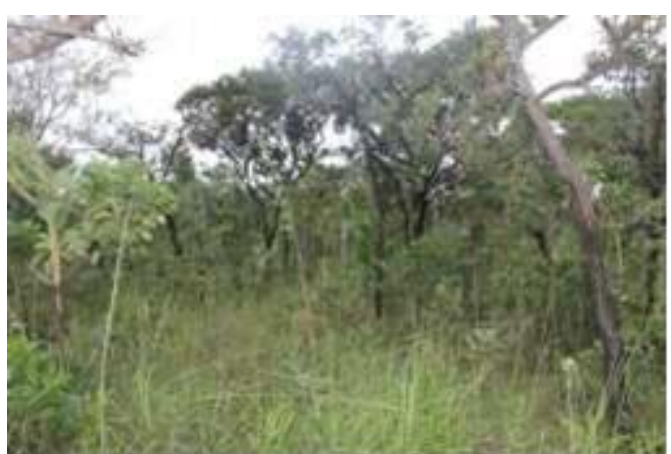

\section{Ponto 36}

Fitofisionomia: Cerrado stricto sensu Latitude: S $12^{\circ} 4^{\prime} 54.8^{\prime}$

Longitude: W $45^{\circ} 41^{\prime} 34.4^{\prime \prime}$

Cor do solo: 10 YR 4/4

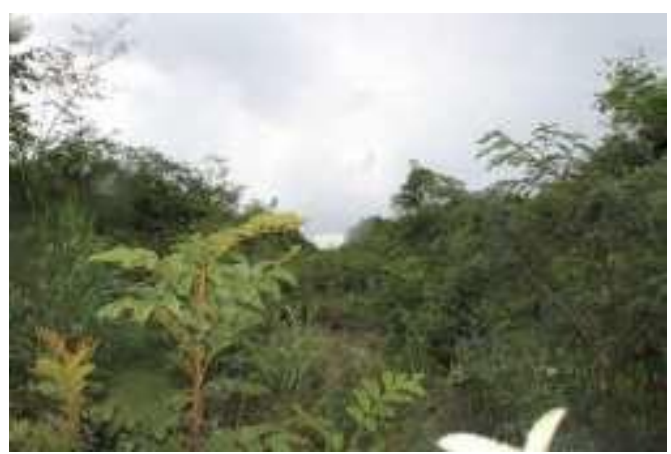

Ponto 38

Fitofisionomia: Cerrado stricto sensu Latitude: S $12^{\circ} 19^{\prime} 58.8^{\prime \prime}$

Longitude: W $45^{\circ} 56^{\prime} 32.1^{\prime \prime}$

Cor do solo: 10 YR $3 / 3$

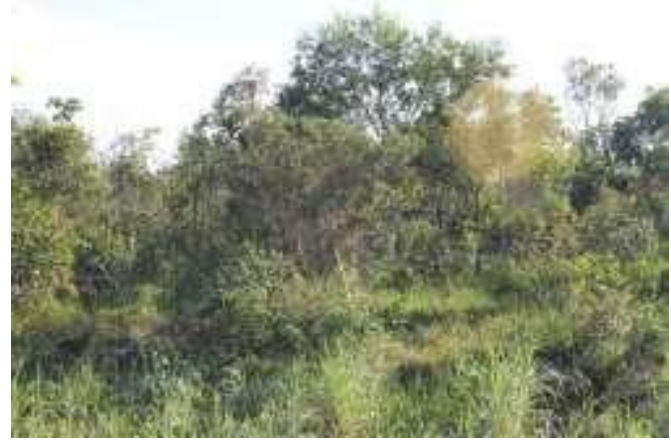

Ponto 40

Fitofisionomia: Cerrado stricto sensu Latitude: S $12^{\circ} 4^{\prime} 35.7^{\prime \prime}$

Longitude: W $46^{\circ}$ 0' $22.7^{\prime \prime}$

Cor do solo: 10 YR 4/3 


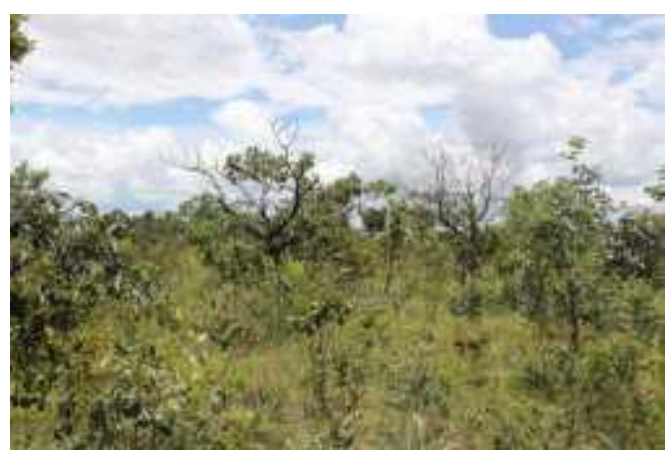

Ponto 41

Fitofisionomia: Cerrado stricto sensu Latitude: S $12^{\circ} 0^{\prime} 2.2^{\prime \prime}$ Longitude: W $46^{\circ} 0^{\prime} 37.2^{\prime}$ Cor do solo: 10 YR 5/2

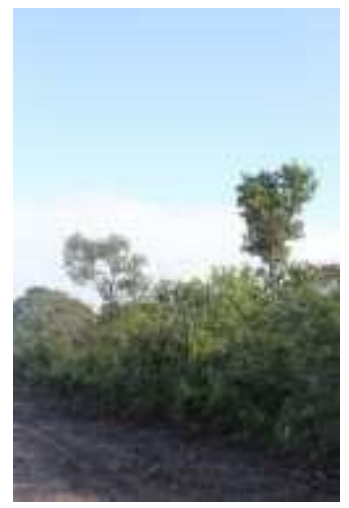

Ponto 43

Fitofisionomia:Cerrado stricto sensu Latitude: S $12^{\circ} 5^{\prime}$ 57.2"

Longitude: W $45^{\circ} 54^{\prime} 32.7^{\prime \prime}$

Cor do solo: 10 YR 4/2

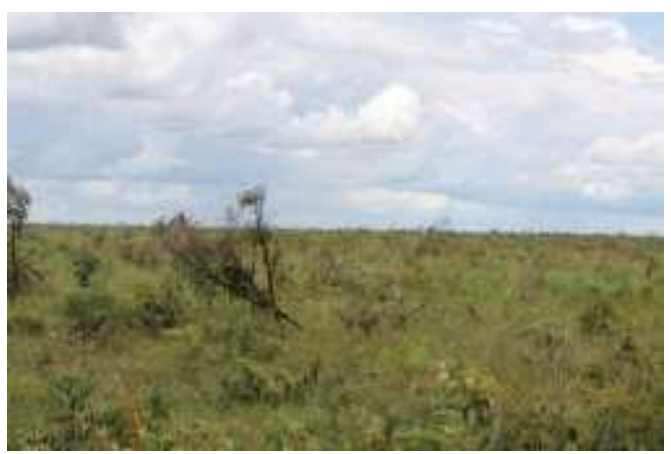

Ponto 45

Fitofisionomia: Cerrado desmatado Latitude: S $12^{\circ} 7^{\prime} 12.1^{\prime}$

Longitude: W $46^{\circ} 0$ ' $34.0^{\prime \prime}$

Cor do solo: 10 YR 4/4

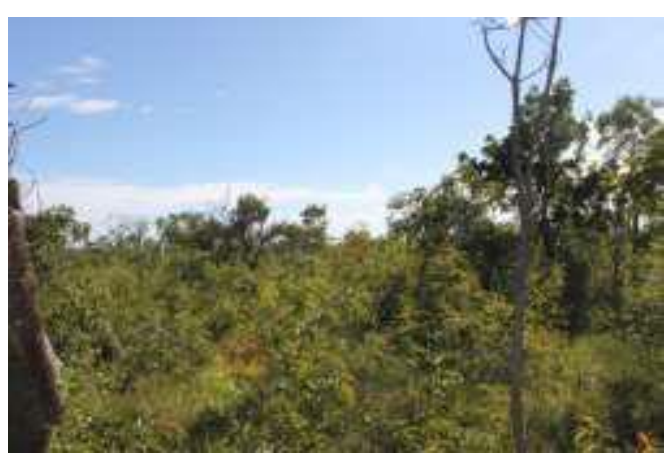

Ponto 42

Fitofisionomia: Cerrado stricto sensu Latitude: S $12^{\circ} 1^{\prime}$ '50.5" Longitude: $W 6^{\circ} 2^{\prime} 52.7^{\prime}$ Cor do solo: 10 YR $4 / 3$

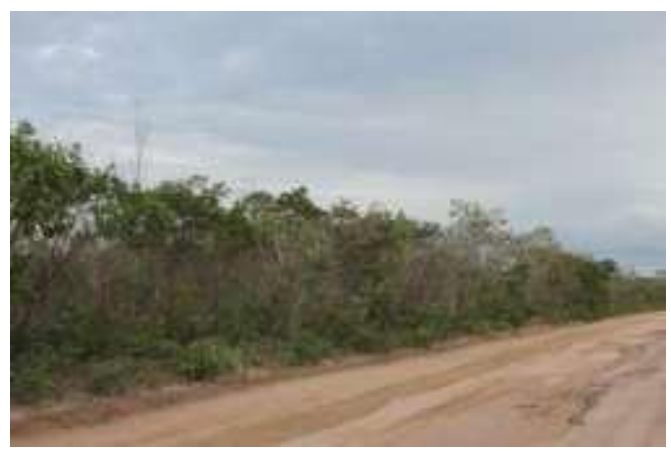

\section{Ponto 44}

Fitofisionomia: Cerrado stricto sensu Latitude: S $12^{\circ} 10^{\prime} 0.0^{\prime \prime}$

Longitude: W $45^{\circ} 47^{\prime} 52.0^{\prime \prime}$

Cor do solo: 10 YR 4/2

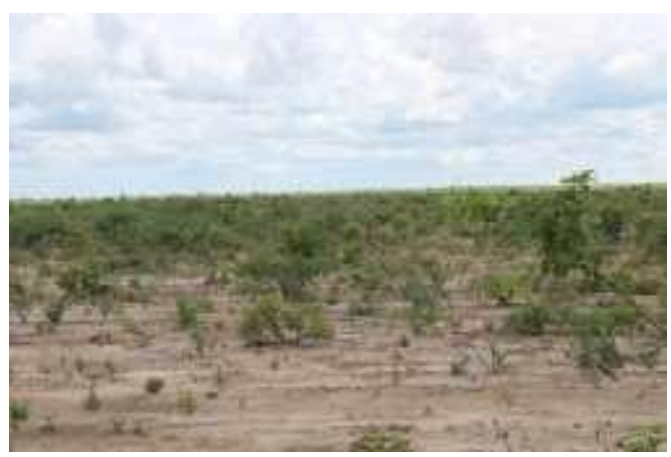

Ponto 46

Fitofisionomia: Cerrado desmatado Latitude: S $11^{\circ} 59^{\prime} 27.5^{\prime \prime}$

Longitude: W $45^{\circ} 58^{\prime} 48.1^{\prime \prime}$ Cor do solo: 10 YR 5/2 


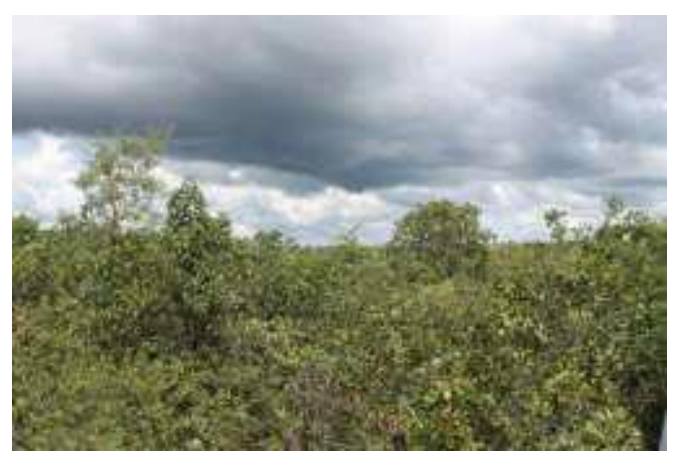

Ponto 47

Fitofisionomia: Cerrado stricto sensu Latitude: S $12^{\circ} 23^{\prime} 36.5^{\prime \prime}$

Longitude: W $45^{\circ} 50^{\prime} 19.3^{\prime \prime}$

Cor do solo: 7,5 YR 4/2

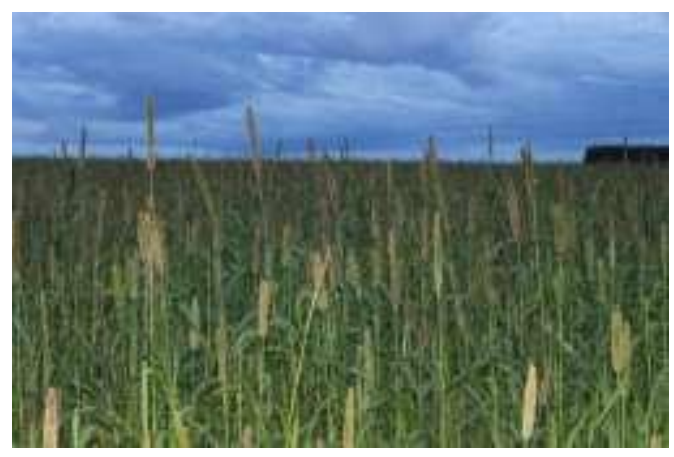

Ponto 49

Uso do solo: Milheto

Latitude: S $12^{\circ} 15^{\prime} 20.6^{\prime}$

Longitude: W 45 $50^{\prime}$ ' 18.2"

Cor do solo: 10 YR 4/3

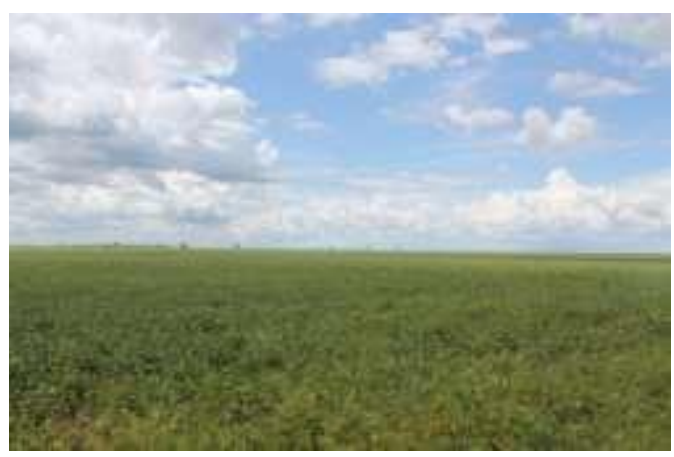

Ponto 51

Uso do solo: Soja

Latitude: S $12^{\circ} 8^{\prime} 13.4^{\prime \prime}$

Longitude: W $46^{\circ} 8^{\prime} 58.58^{\prime \prime}$

Cor do solo: 10 YR 4/3

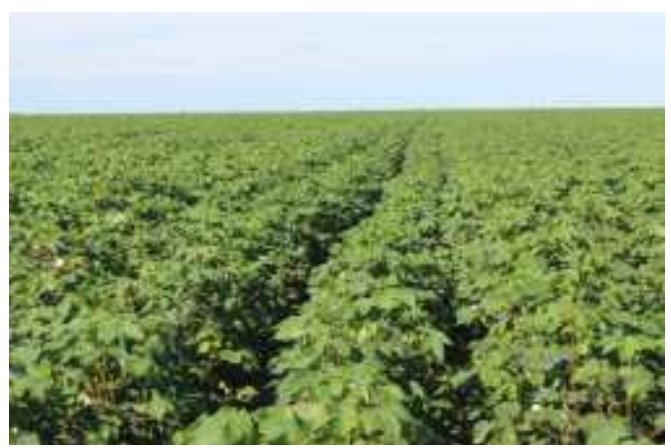

Ponto 48

Uso do Solo: Algodão

Latitude: S $12^{\circ} 2^{\prime}$ 59.8"

Longitude: W $46^{\circ} 1^{\prime}$ '58.0"

Cor do solo: nd

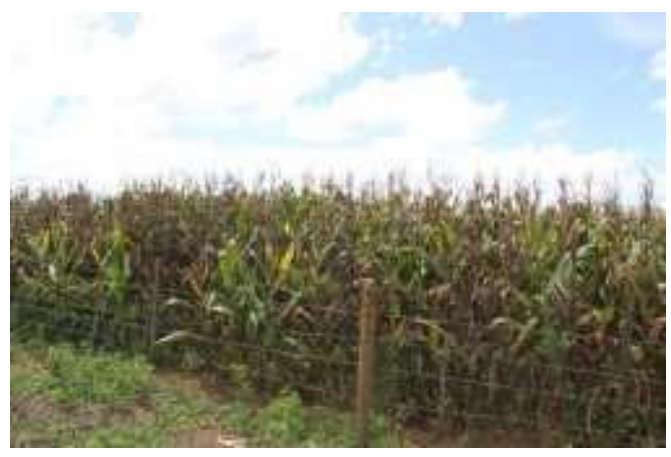

Ponto 50

Uso do Solo: Milho

Latitude: S $12^{\circ} 6^{\prime} 57.3^{\prime \prime}$

Longitude: W 46 17' 59.1"

Cor do solo: 7,5 YR 4/3

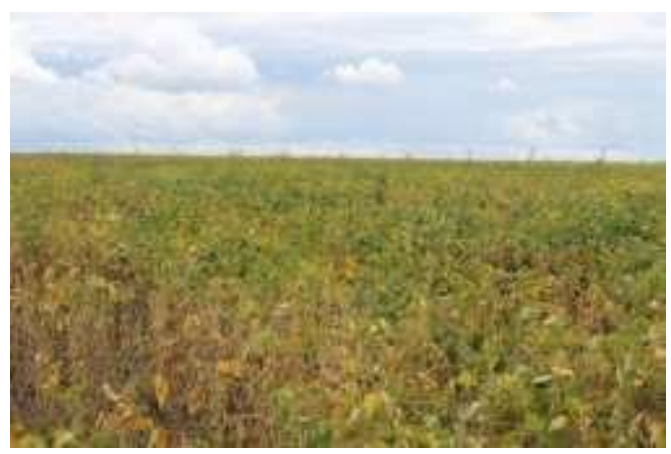

Ponto 52

Uso do solo: Soja

Latitude: S $12^{\circ} 8^{\prime}$ 59.6"

Longitude: W 46 $16^{\circ} 30.8^{\prime \prime}$

Cor do solo: 10 YR 4/4 


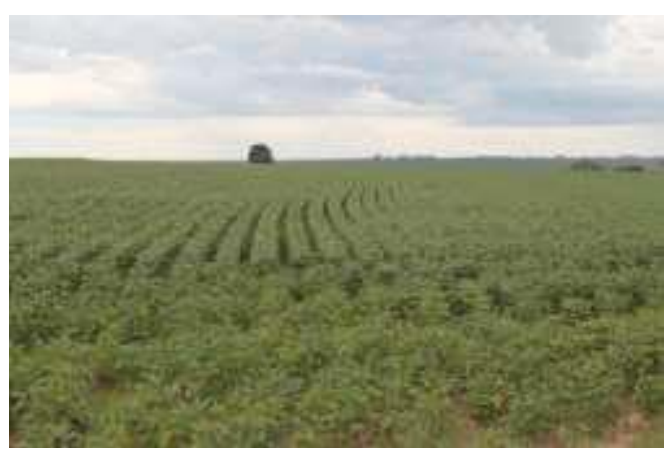

Ponto 53

Uso do solo: Soja

Latitude: S $12^{\circ} 6^{\prime} 5.0^{\prime \prime}$

Longitude: W $45^{\circ} 44^{\prime} 18.7$ "

Cor do solo: 10 YR 4/4

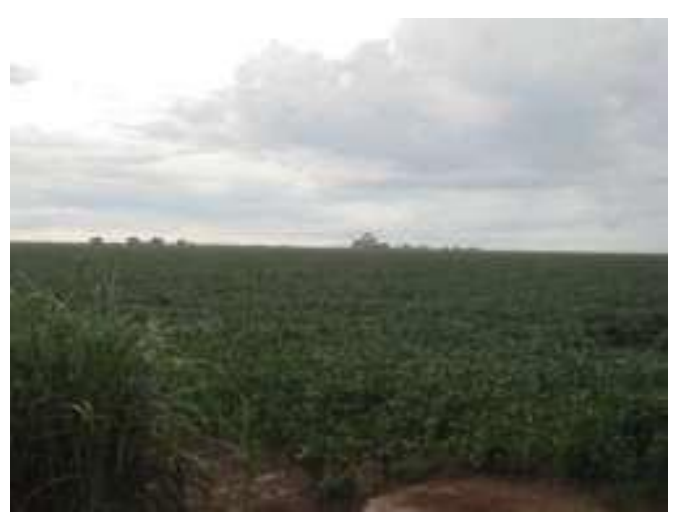

Ponto 55

Uso do solo: Soja

Latitude: S $12^{\circ} 13^{\prime} 11.4^{\prime \prime}$

Longitude: W $46^{\circ} 7^{\prime} 26.0^{\prime \prime}$

Cor do solo: 7,5 YR 5/3

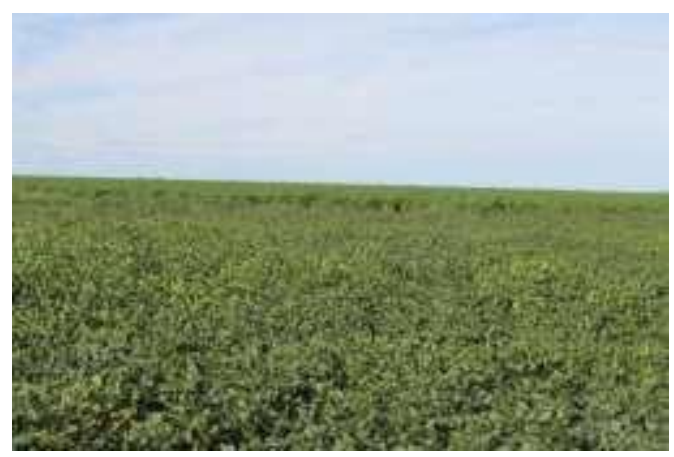

Ponto 57

Uso do solo: Soja

Latitude: S $12^{\circ} 2^{\prime}$ 58.6"

Longitude: W $46^{\circ} 1^{\prime}$ '56.4"

Cor do solo: 10 YR 5/2

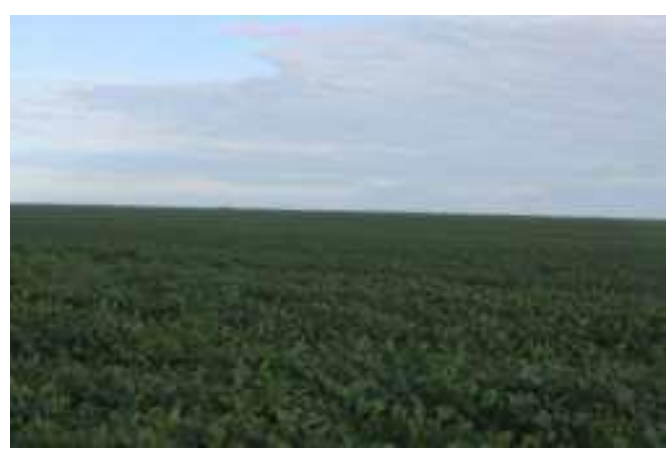

Ponto 54

Uso do solo: Soja Latitude: S $12^{\circ} 5^{\prime} 49.7^{\prime}$

Longitude: W $45^{\circ} 50^{\prime} 30.3^{\prime \prime}$

Cor do solo: 10 YR 5/2

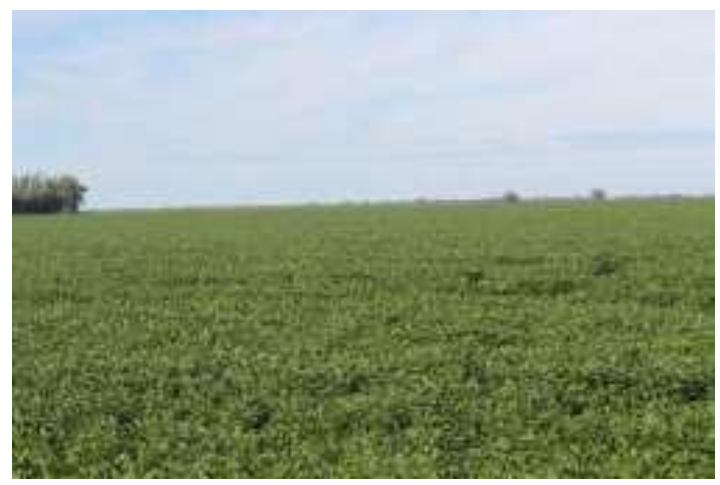

Ponto 56

Uso do solo: Soja

Latitude: S $12^{\circ} 5^{\prime} 47.7^{\prime \prime}$

Longitude: W $45^{\circ} 59^{\prime} 17.4^{\prime \prime}$

Cor do solo: 2,5 Y $5 / 3$

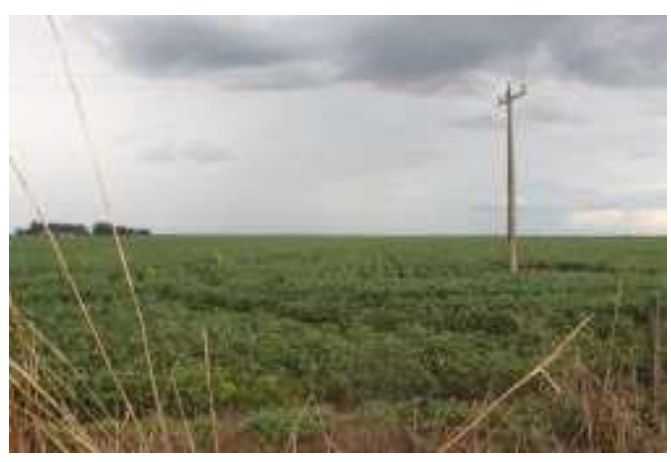

Ponto 58

Uso do solo: Soja

Latitude: S $12^{\circ} 22^{\prime} 7.4^{\prime \prime}$

Longitude: W $46^{\circ} 3^{\prime} 56.2^{\prime \prime}$

Cor do solo: 7,5 YR 5/4 


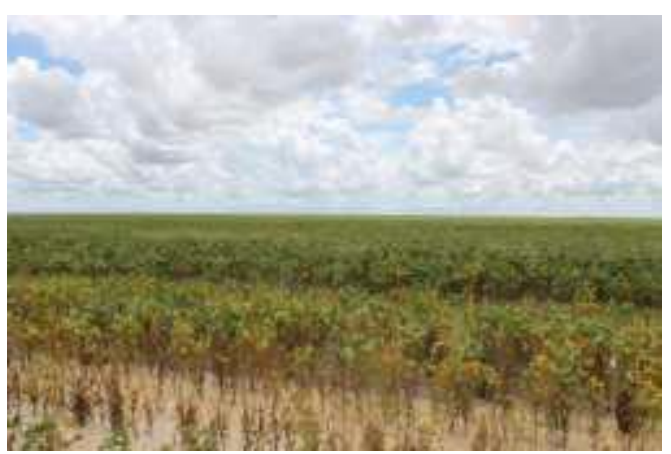

Ponto 59

Uso do solo: Soja

Latitude: S $11^{\circ} 57^{\prime} 10.1^{\prime \prime}$

Longitude: W $45^{\circ} 58^{\prime} 45.0^{\prime \prime}$

Cor do solo: 10 YR 4/2

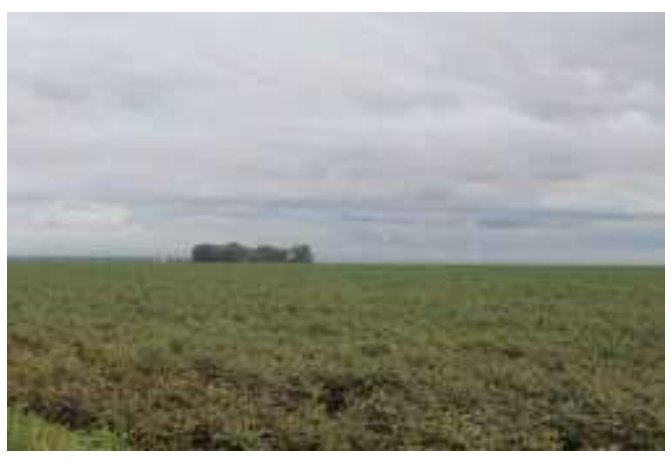

Ponto 61

Uso do solo: Soja

Latitude: S $12^{\circ} 12^{\prime} 51.4^{\prime \prime}$

Longitude: W $45^{\circ} 52^{\prime}$ 56.3"

Cor do solo: 7,5 YR 4/3

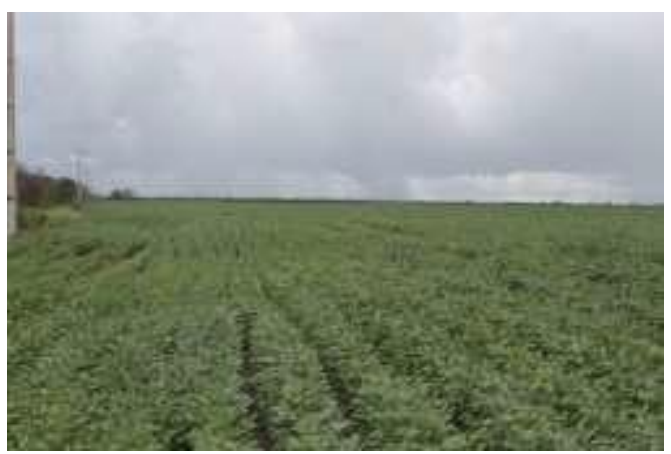

Ponto 63

Uso do solo: Soja

Latitude: S $12^{\circ} 20^{\prime} 27.4^{\prime \prime}$

Longitude: W $45^{\circ} 58^{\prime} 24.7^{\prime \prime}$

Cor do solo: 10 YR 4/3

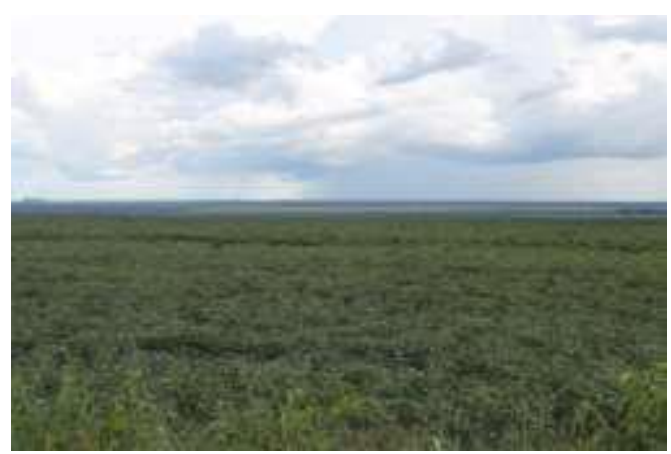

Ponto 60

Uso do solo: Soja

Latitude: S $12^{\circ} 19^{\prime} 56.2^{\prime \prime}$

Longitude: W $45^{\circ} 53^{\prime} 42.2^{\prime \prime}$

Cor do solo: 10 YR 4/3

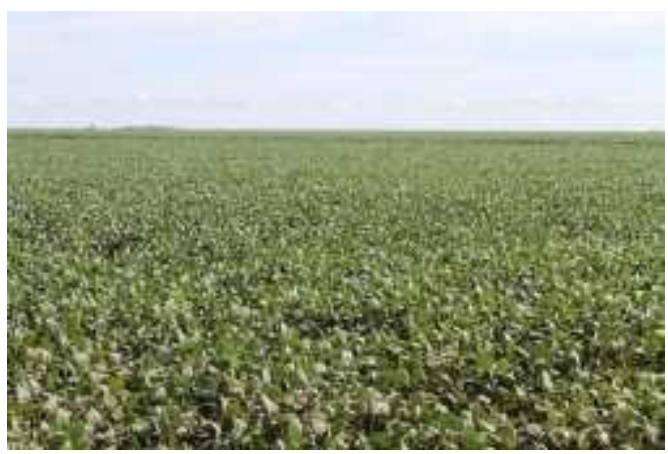

Ponto 62

Uso do solo: Soja

Latitude: S $12^{\circ}$ 2'18.6"

Longitude: W 46 $7^{\circ}$ '27.6"

Cor do solo: 5 YR 4/3 


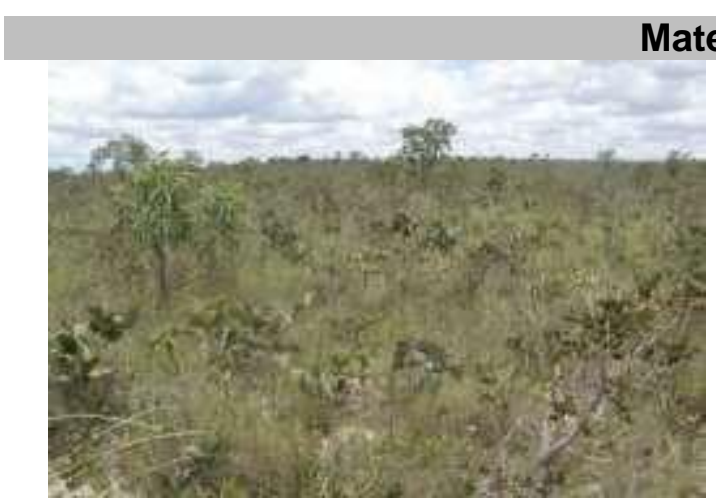

Ponto 64

Fitofisionomia: Campo sujo Latitude: $10^{\circ} 33^{\prime} 46,8^{\prime \prime}$

Longitude: $46^{\circ} 26^{\prime} 42,9^{\prime \prime}$

Cor do solo: 10 YR 6/2

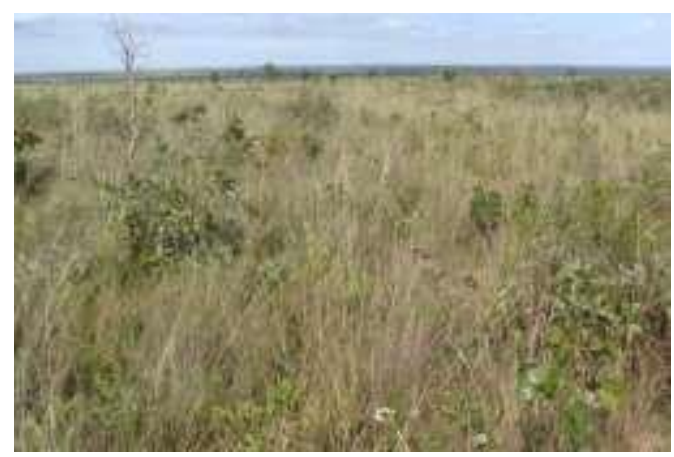

Ponto 66

Fitofisionomia: Campo sujo

Latitude: $10^{\circ} 35^{\prime} 55,1^{\prime \prime}$

Longitude: $46^{\circ} 32^{\prime} 40,8^{\prime \prime}$

Cor do solo: 7,5 YR 5/3

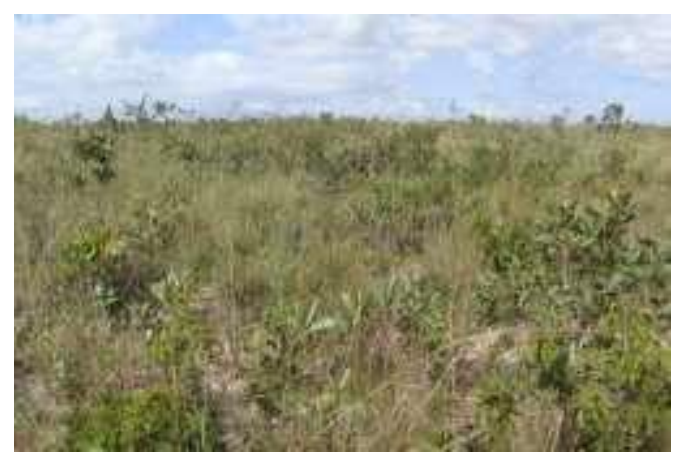

Ponto 68

Fitofisionomia: Campo sujo

Latitude: $10^{\circ} 35^{\prime} 07,6^{\prime \prime}$

Longitude: $46^{\circ} 43^{\prime} 18,9^{\prime \prime}$

Cor do solo: 10 YR 5/4

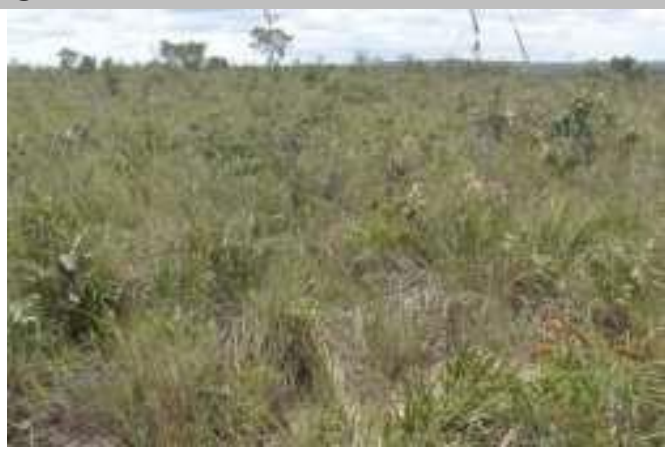

Ponto 65

Fitofisionomia: Campo sujo

Latitude: $10^{\circ} 34^{\prime} 14,9^{\prime \prime}$

Longitude: $46^{\circ} 28^{\prime} 58,0^{\prime \prime}$

Cor do solo: 10 YR 5/4

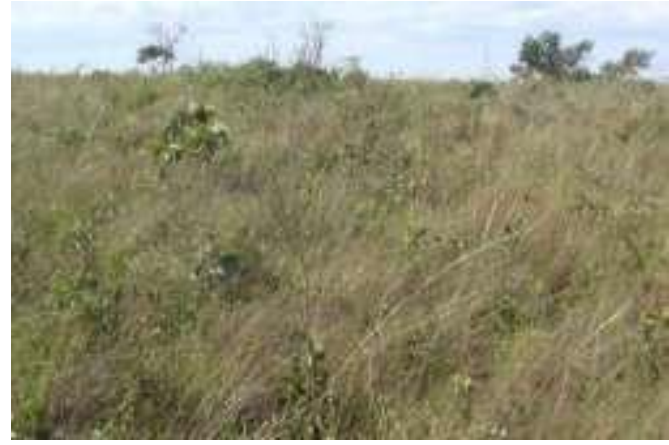

Ponto 67

Fitofisionomia:Campo sujo

Latitude: $10^{\circ} 36^{\prime} 00,3$ "

Longitude: $46^{\circ} 40^{\prime} 19,4^{\prime \prime}$

Cor do solo: 7,5 YR 5/4

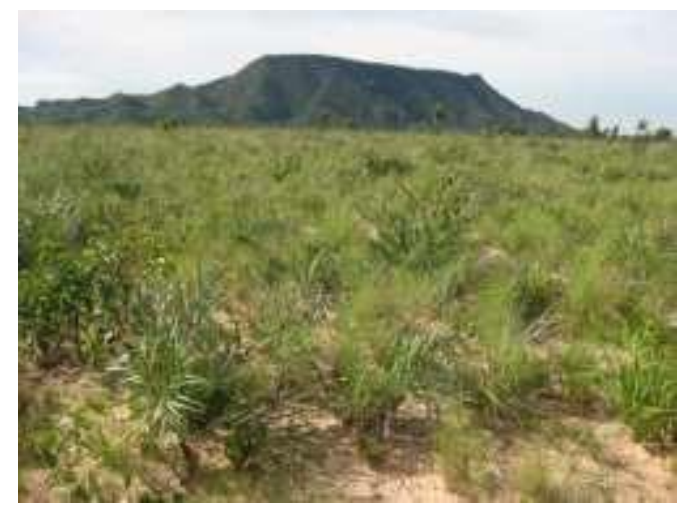

\section{Ponto 69}

Fitofisionomia: Campo sujo

Latitude: $10^{\circ} 26^{\prime} 52,5^{\prime \prime}$

Longitude: $46^{\circ} 27^{\prime} 25,8^{\prime \prime}$

Cor do solo: 10 YR 5/4 


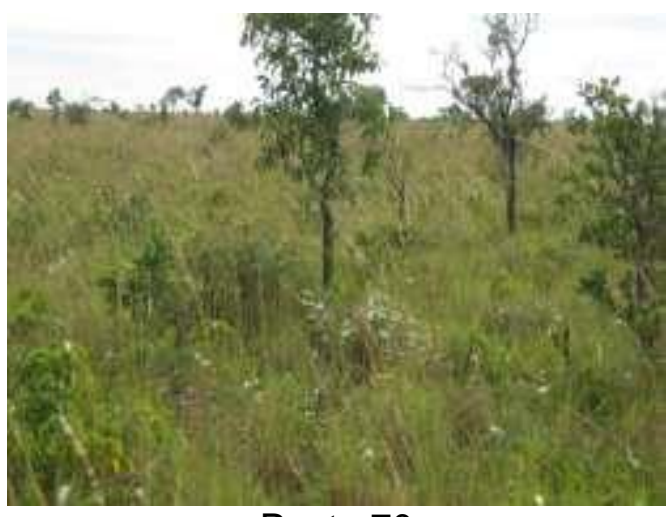

Ponto 70

Fitofisionomia: Campo sujo Latitude: $10^{\circ} 19^{\prime} 03,2$ " Longitude: $46^{\circ} 31^{\prime} 06,8^{\prime \prime}$

Cor do solo: 10 YR 6/2

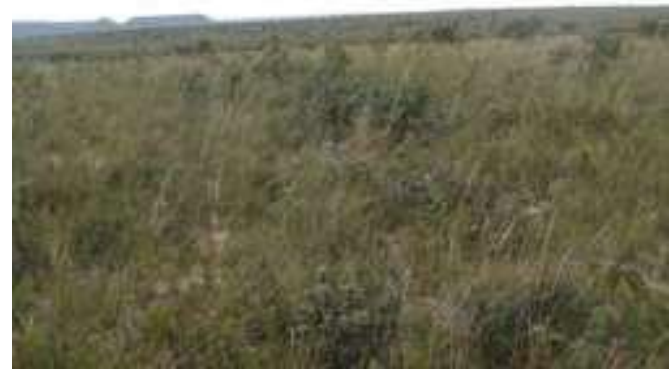

Ponto 72

Fitofisionomia: Campo sujo

Latitude: $10^{\circ} 35^{\prime} 34,0^{\prime \prime}$

Longitude: $46^{\circ} 18^{\prime} 24,4^{\prime \prime}$

Cor do solo: 7,5 YR 5/3

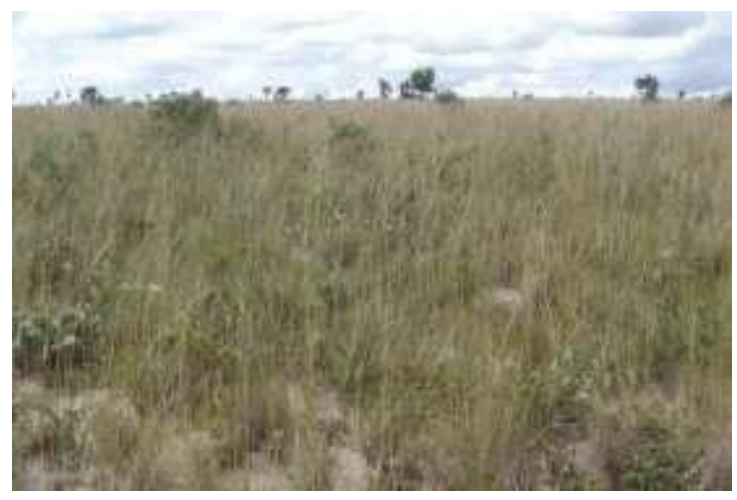

Ponto 74

Fitofisionomia: Campo sujo

Latitude: $10^{\circ} 30^{\prime} 43,5^{\prime \prime}$

Longitude: $46^{\circ} 54^{\prime} 22,5^{\prime \prime}$

Cor do solo: 10 YR 5/3

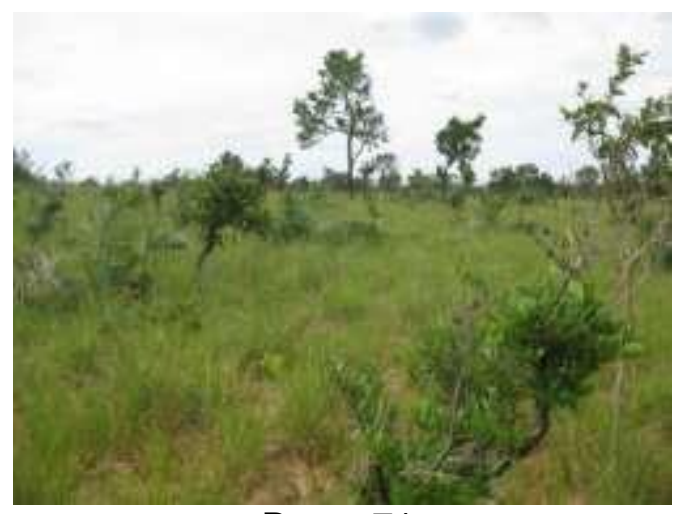

Ponto 71

Fitofisionomia: Campo sujo Latitude: $10^{\circ} 13^{\prime} 41,3$ " Longitude: $46^{\circ} 33^{\prime} 22,5^{\prime \prime}$ Cor do solo: 7,5 YR 4/6

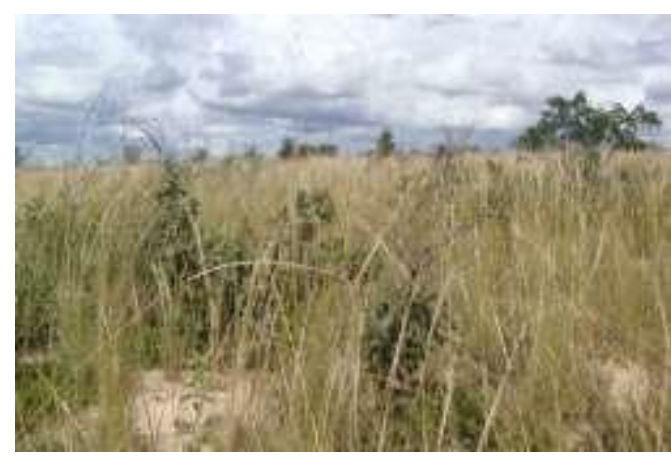

Ponto 73

Fitofisionomia: Campo sujo Latitude: $10^{\circ} 34^{\prime} 32,6^{\prime \prime}$ Longitude: $46^{\circ} 50^{\prime} 31,4^{\prime \prime}$ Cor do solo: 10 YR 5/4

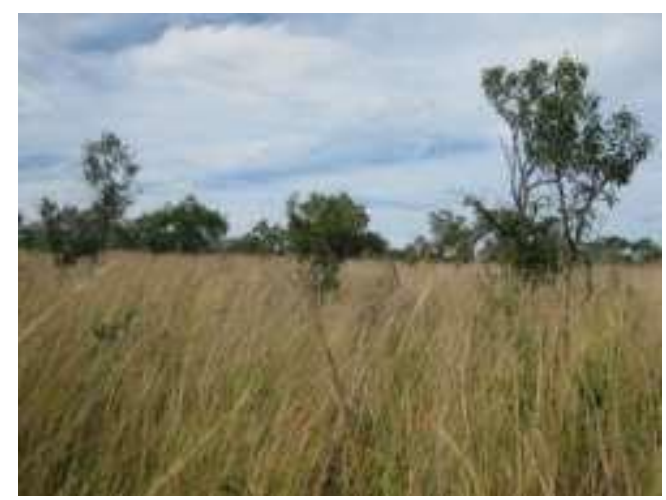

\section{Ponto 75}

Fitofisionomia: Campo sujo

Latitude: $10^{\circ} 20^{\prime} 45,7^{\prime \prime}$

Longitude: $46^{\circ} 3057,4$

Cor do solo: 7,5 YR 5/3 


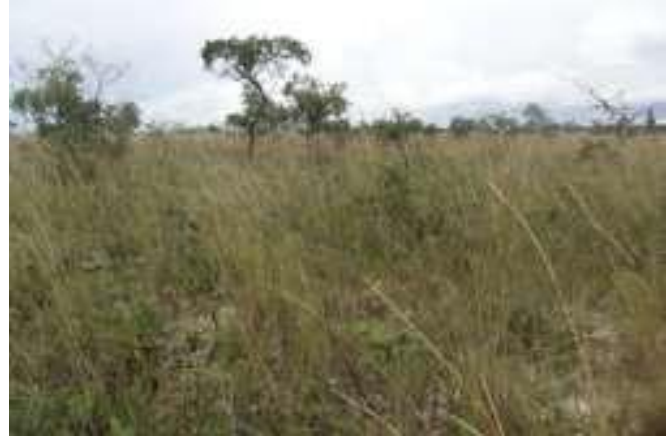

Ponto 76

Fitofisionomia: Campo sujo Latitude: $10^{\circ} 34^{\prime} 27,2^{\prime \prime}$ Longitude: $46^{\circ} 11^{\prime} 21,4^{\prime \prime}$ Cor do solo: 10 YR 5/4

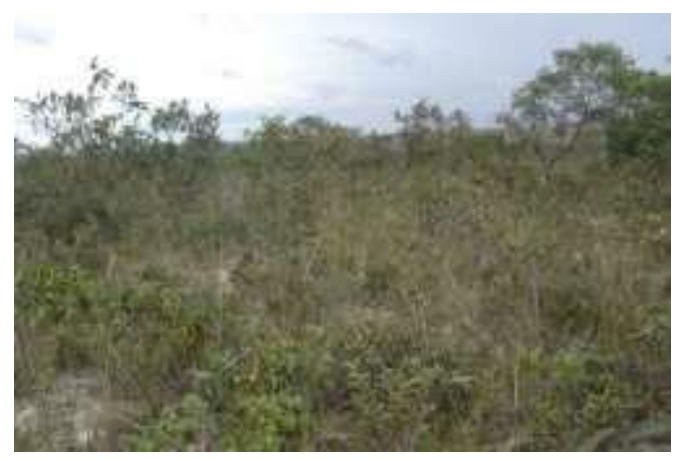

Ponto 78

Fitofisionomia: Campo sujo Latitude: $10^{\circ} 36^{\prime} 29,9$ " Longitude: $46^{\circ} 16^{\prime} 31,7^{\prime \prime}$ Cor do solo: 2,5 YR 5/3

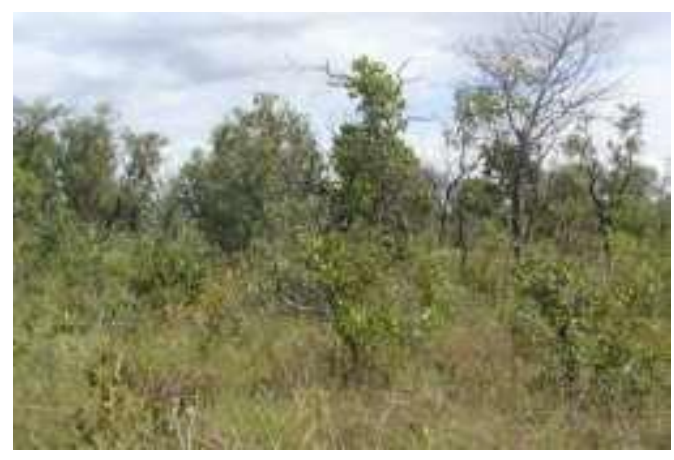

Ponto 80

Fitofisionomia: Cerrado ralo Latitude: $10^{\circ} 33^{\prime} 45,8^{\prime \prime}$ Longitude: $46^{\circ} 47^{\prime} 09,5^{\prime \prime}$ Cor do solo: 10 YR 4/4

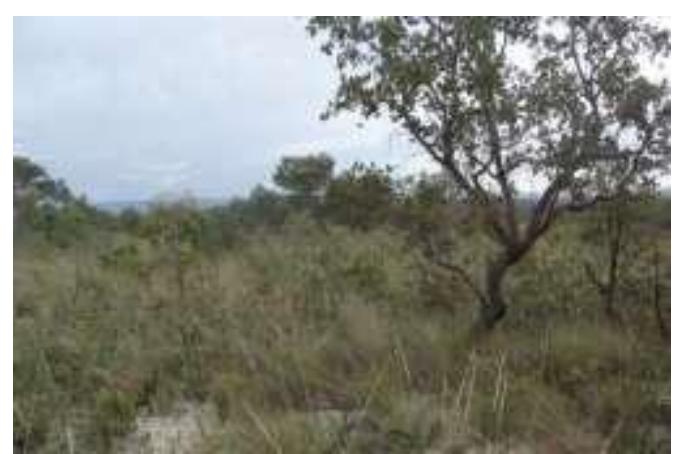

Ponto 77

Fitofisionomia: Campo sujo Latitude: $10^{\circ} 35^{\prime} 07,2^{\prime \prime}$ Longitude: $46^{\circ} 19^{\prime} 34,9^{\prime \prime}$ Cor do solo: 10 YR 6/2

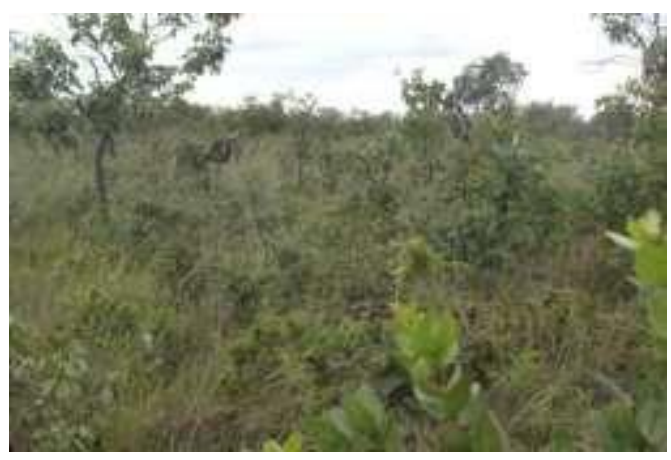

Ponto 79

Fitofisionomia: Campo sujo Latitude: $10^{\circ} 32$ ' 46,7" Longitude: $46^{\circ} 11^{\prime} 13,7^{\prime \prime}$ Cor do solo: 7,5 YR 5/4

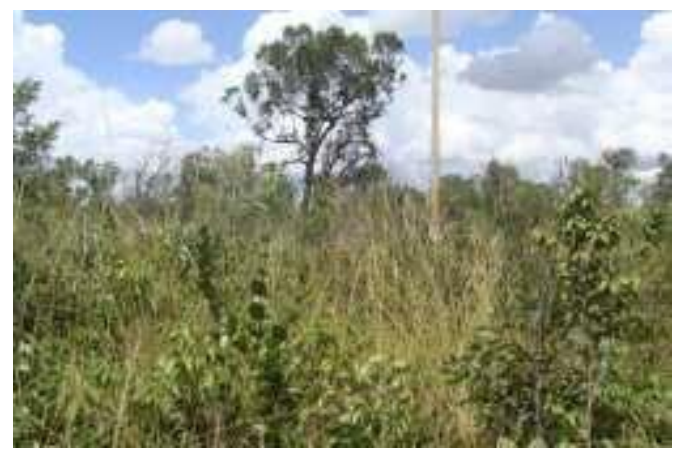

Ponto 81

Fitofisionomia: Cerrado ralo Latitude: $10^{\circ} 3326,8^{\prime \prime}$ Longitude: $46^{\circ} 5105,0^{\prime \prime}$ Cor do solo: 7,5 YR 4/3 


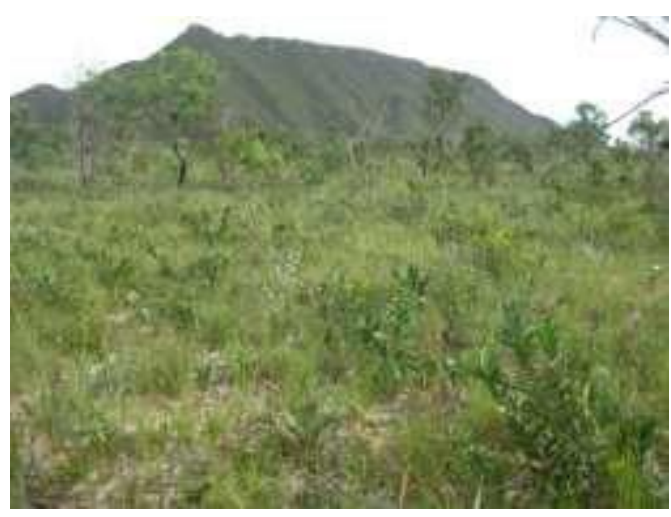

Ponto 82

Fitofisionomia: Cerrado ralo Latitude: $10^{\circ} 2848,8^{\prime \prime}$ Longitude: $46^{\circ} 2656,8^{\prime \prime}$ Cor do solo: 10 YR 6/2

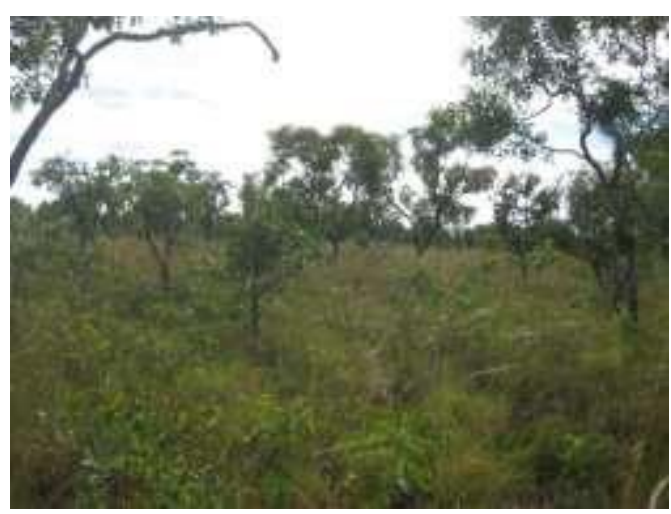

Ponto 84

Fitofisionomia: Cerrado ralo Latitude: $10^{\circ} 23^{\prime} 49,3$ " Longitude: $46^{\circ} 29^{\prime} 42,0^{\prime \prime}$ Cor do solo: 7,5 YR 5/3

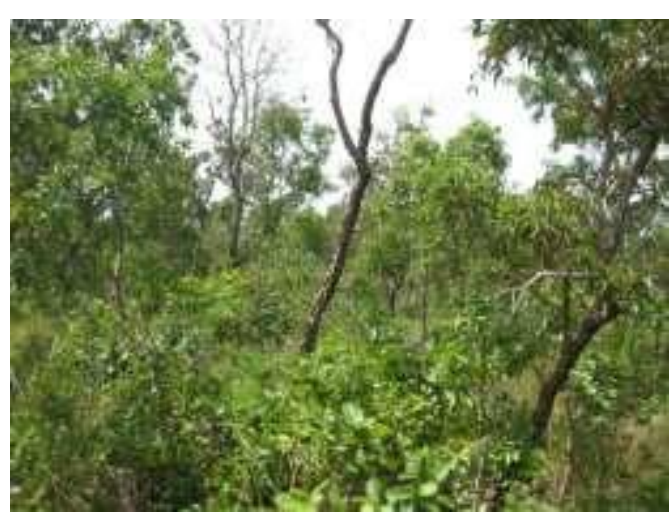

Ponto 86

Fitofisionomia: Cerrado ralo Latitude: $10^{\circ} 14^{\prime} 32,5^{\prime \prime}$ Longitude: $46^{\circ} 33^{\prime} 35,4^{\prime \prime}$ Cor do solo: 7,5 YR 4/6

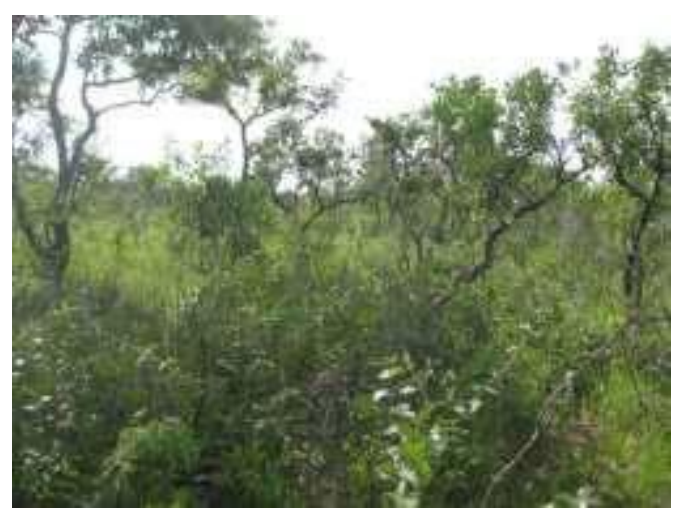

Ponto 83

Fitofisionomia: Cerrado ralo Latitude: $10^{\circ} 25^{\prime} 55,3^{\prime \prime}$ Longitude: 46 28' 12,3" Cor do solo: 10 YR 4/4

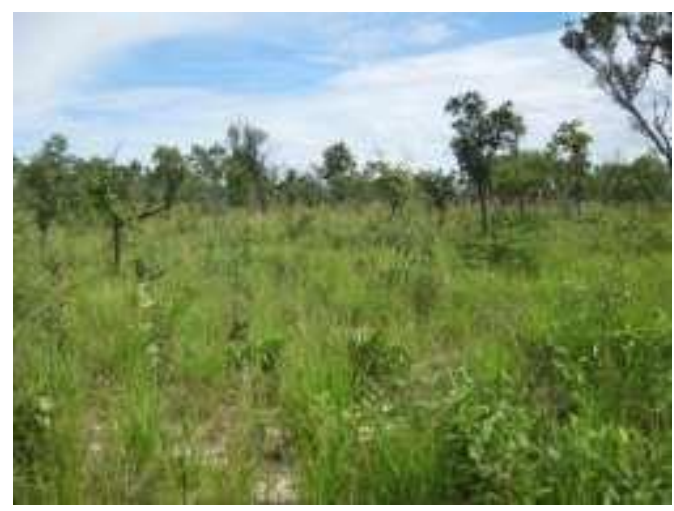

Ponto 85

Fitofisionomia: Cerrado ralo Latitude:10 19' 21,9" Longitude: $46^{\circ} 31^{\prime} 07,7^{\prime \prime}$ Cor do solo: 10 YR 5/3

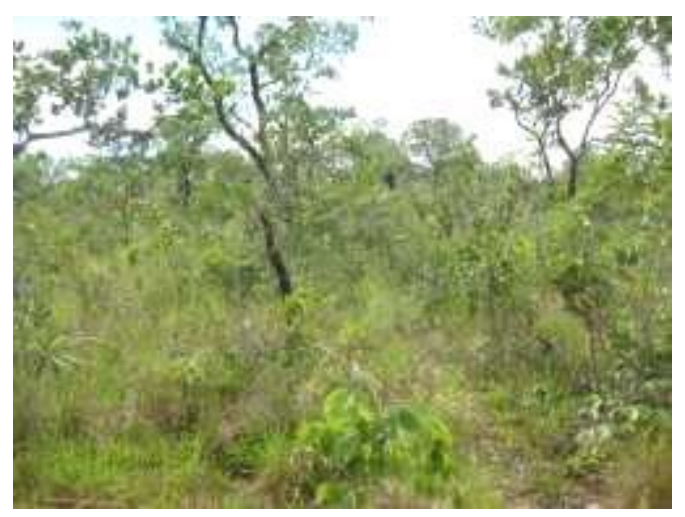

Ponto 87

Fitofisionomia: Cerrado ralo Latitude: $10^{\circ} 13^{\prime} 14,6^{\prime \prime}$ Longitude: $46^{\circ} 31^{\prime} 51,5^{\prime \prime}$ Cor do solo: 10 YR 4/4 


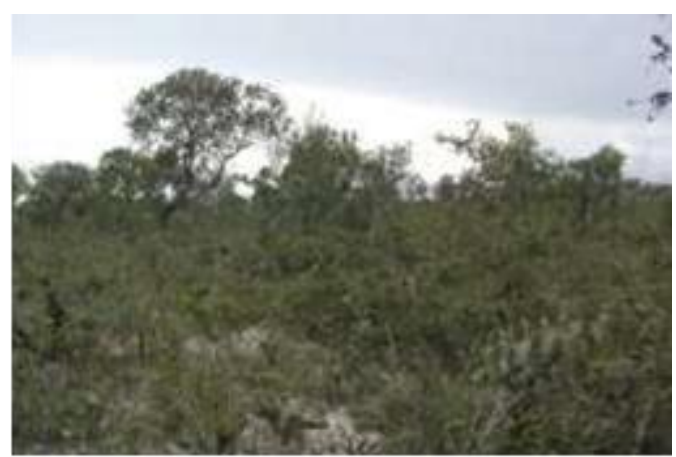

Ponto 88

Fitofisionomia: Cerrado ralo Latitude: $10^{\circ} 34^{\prime} 01,5^{\prime \prime}$ Longitude: $46^{\circ} 22^{\prime} 07,1^{\prime \prime}$ Cor do solo: 10 YR 5/2

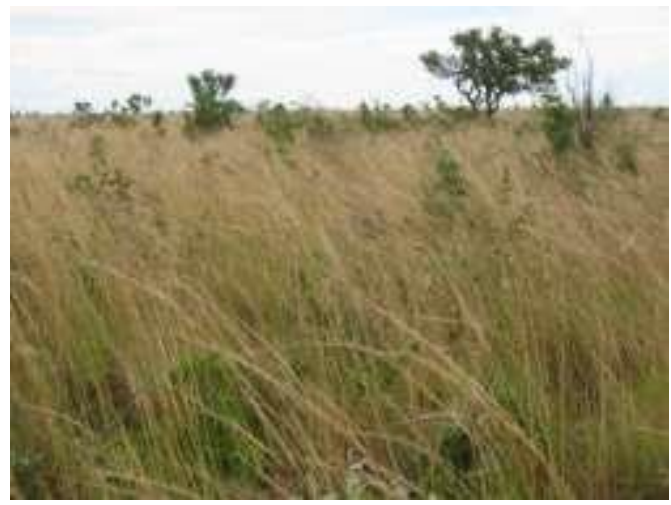

Ponto 90

Fitofisionomia: Cerrado ralo Latitude: $10^{\circ} 17^{\prime} 25,2$ ' Longitude: $46^{\circ} 32$ ' $14,9^{\prime \prime}$ Cor do solo: 10 YR 5/3

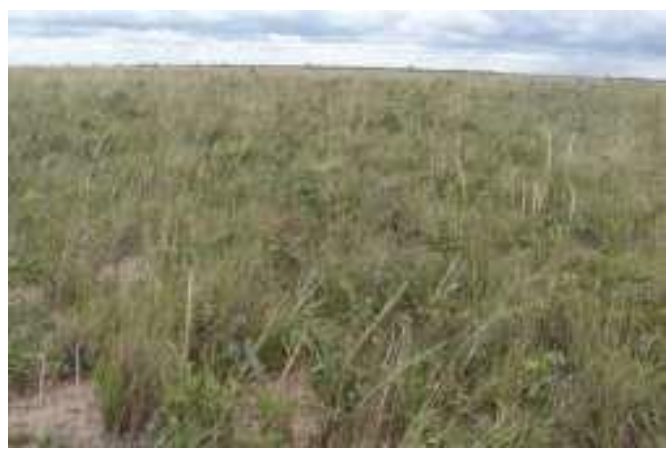

Ponto 92

Fitofisionomia: Desmate recente Latitude: $10^{\circ} 28^{\prime} 00,7^{\prime \prime}$ Longitude: $46^{\circ} 08^{\prime} 06,2^{\prime \prime}$ Cor do solo: 7,5 YR 4/4

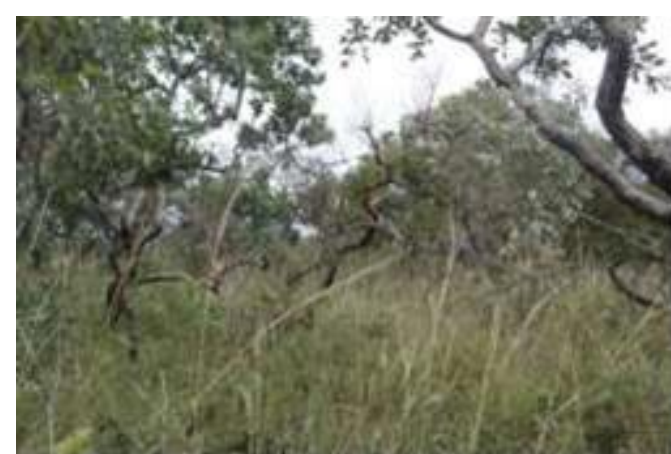

Ponto 89

Fitofisionomia: Cerrado ralo Latitude: $10^{\circ} 29^{\prime} 36,1^{\prime \prime}$

Longitude: $46^{\circ} 10^{\prime} 40,8^{\prime \prime}$

Cor do solo: 10 YR 4/4

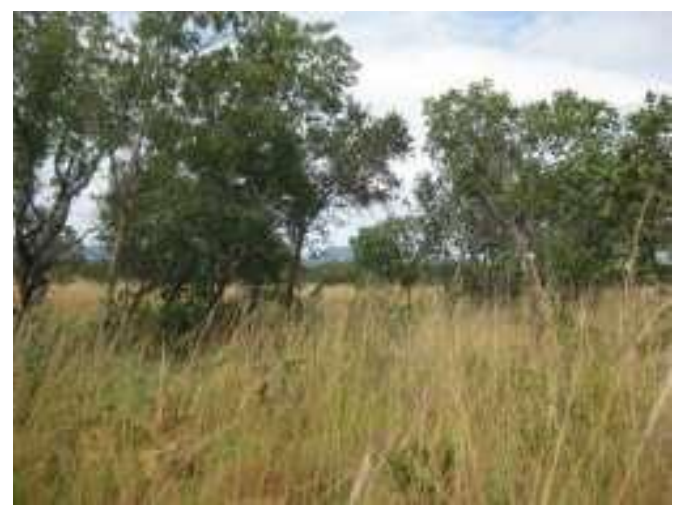

Ponto 91

Fitofisionomia: Cerrado ralo Latitude: $10^{\circ} 16^{\prime} 19,4^{\prime \prime}$ Longitude: $46^{\circ} 32^{\prime} 54,3^{\prime \prime}$ Cor do solo: 7,5 YR 4/6

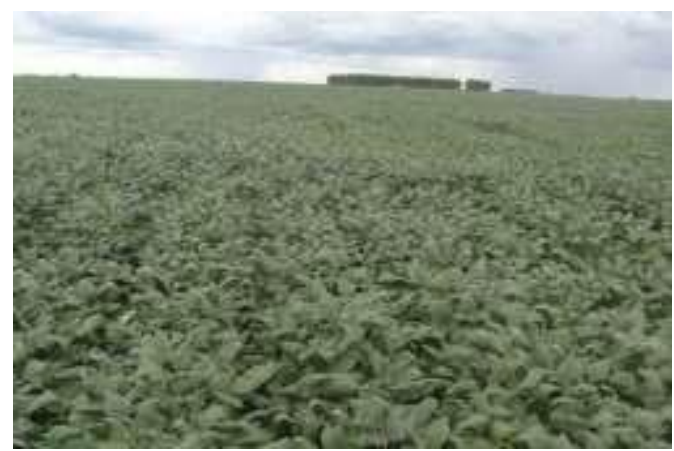

Ponto 93

Fitofisionomia: Soja Latitude: $10^{\circ} 30^{\prime} 17,0^{\prime \prime}$ Longitude: $46^{\circ} 11^{\prime} 40,5^{\prime \prime}$ Cor do solo: 7,5 YR 4/4 


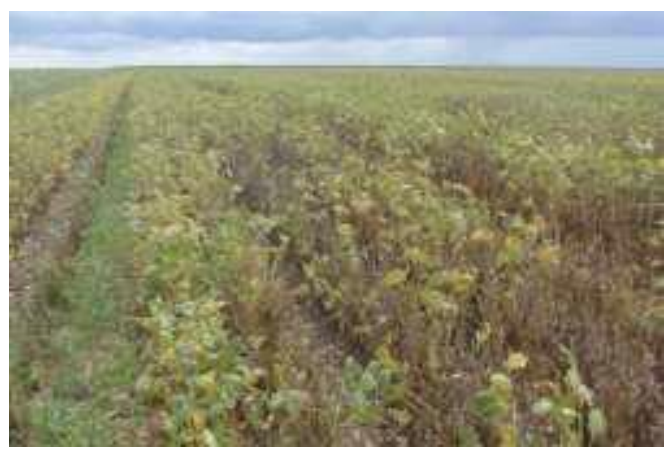

Ponto 94

Fitofisionomia: Soja

Latitude: $10^{\circ} 27^{\prime} 19,2$ "

Longitude: $46^{\circ} 06^{\prime} 37,5^{\prime \prime}$

Cor do solo: 7,5 YR 4/4

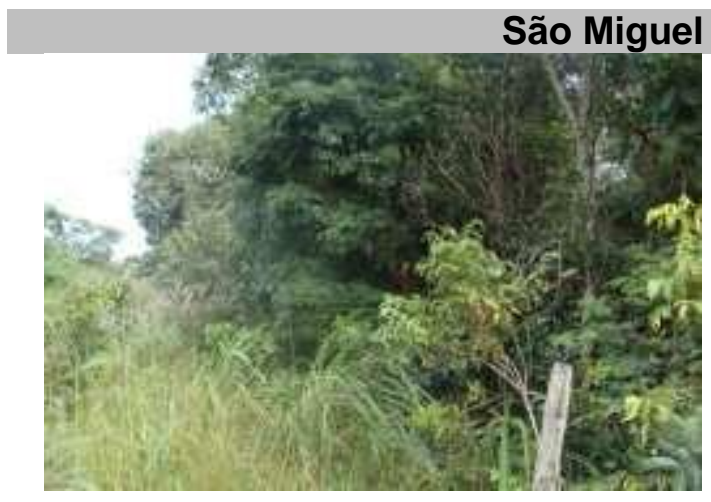

Ponto 95

Fitofisionomia: Cerrado denso

Latitude: $13^{\circ} 15^{\prime} 42,7^{\prime \prime}$

Longitude: $49^{\circ} 54^{\prime} 43,5^{\prime \prime}$

Cor do solo: 10 YR 4/4

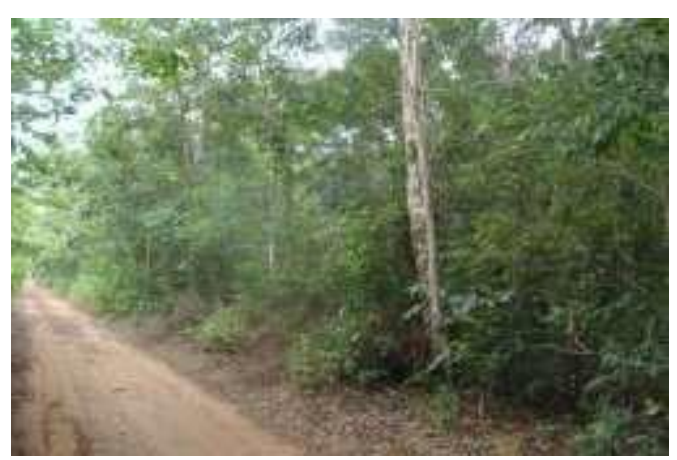

Ponto 97

Fitofisionomia: Cerrado denso

Latitude: $13^{\circ} 13^{\prime} 38,0^{\prime \prime}$

Longitude: $50^{\circ} 10^{\prime} 01,0^{\prime \prime}$

Cor do solo: 10 YR 5/4

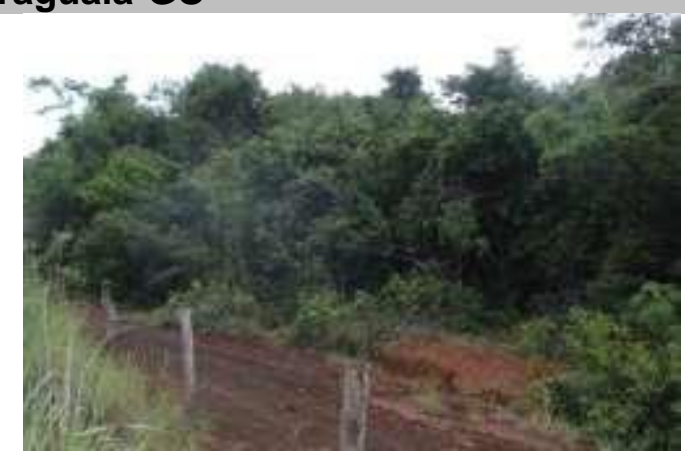

Ponto 96

Fitofisionomia: Cerrado denso

Latitude: $13^{\circ} 15^{\prime} 57,1^{\prime \prime}$

Longitude: $50^{\circ} 07^{\prime} 17,3^{\prime \prime}$

Cor do solo: 10 YR 2/2

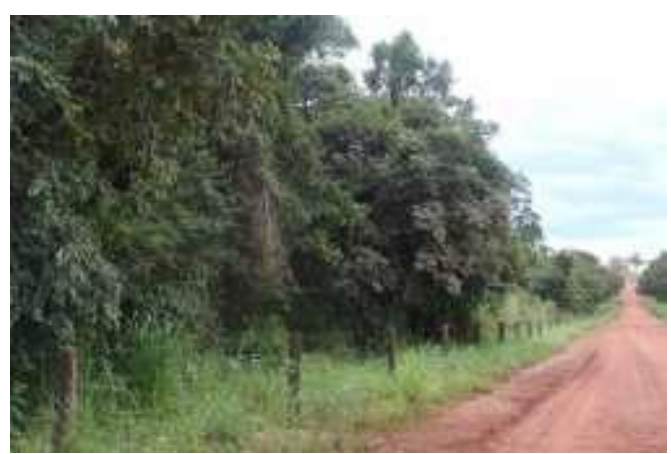

Ponto 98

Fitofisionomia: Cerrado denso

Latitude: $13^{\circ} 09^{\prime} 14,6^{\prime \prime}$

Longitude: $50^{\circ} 10^{\prime} 56,5^{\prime \prime}$

Cor do solo: 10 YR 4/2 


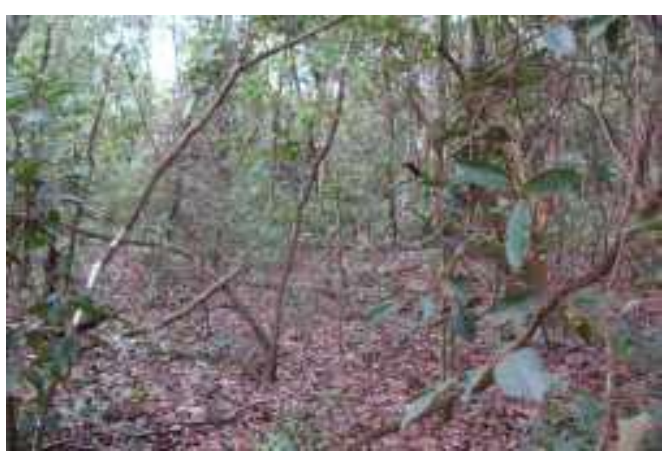

Ponto 99

Fitofisionomia: Cerrado denso Latitude: $13^{\circ} 03^{\prime} 37,7^{\prime \prime}$

Longitude: $50^{\circ} 11^{\prime} 14,6^{\prime \prime}$ Cor do solo: nd

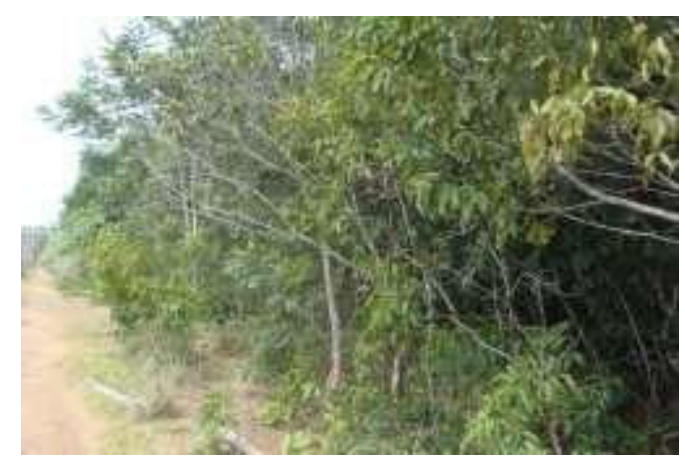

Ponto 101

Fitofisionomia: Cerrado típico Latitude: $12^{\circ} 58^{\prime} 46,0^{\prime \prime}$ Longitude: $50^{\circ} 12^{\prime} 43,3^{\prime \prime}$ Cor do solo: 10 YR $3 / 6$

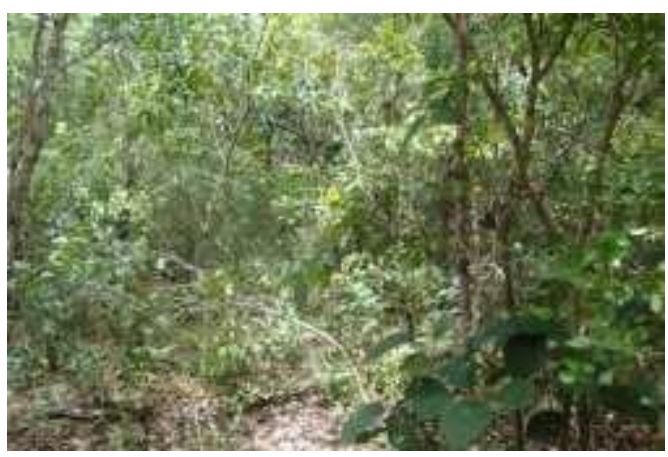

Ponto 103

Fitofisionomia: Cerrado típico Latitude: $13^{\circ} 08^{\prime} 18,8^{\prime \prime}$ Longitude: $50^{\circ} 01^{\prime} 31,2$ ' Cor do solo: nd

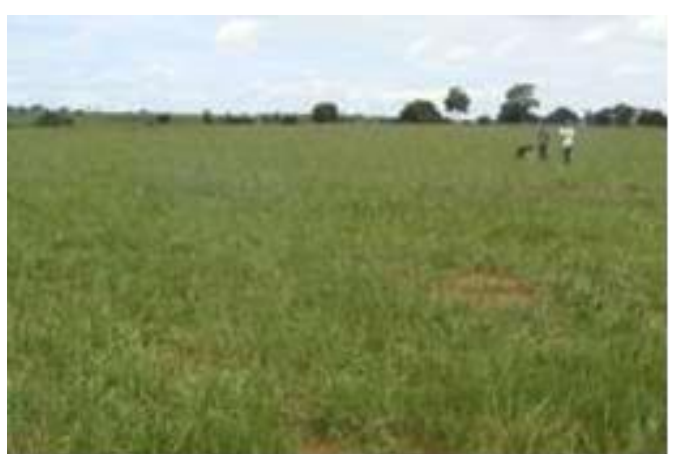

Ponto 100

Fitofisionomia: Cerrado típico Latitude: $12^{\circ} 59^{\prime} 17,9^{\prime \prime}$

Longitude: $50^{\circ} 14^{\prime} 58,2^{\prime \prime}$ Cor do solo: nd

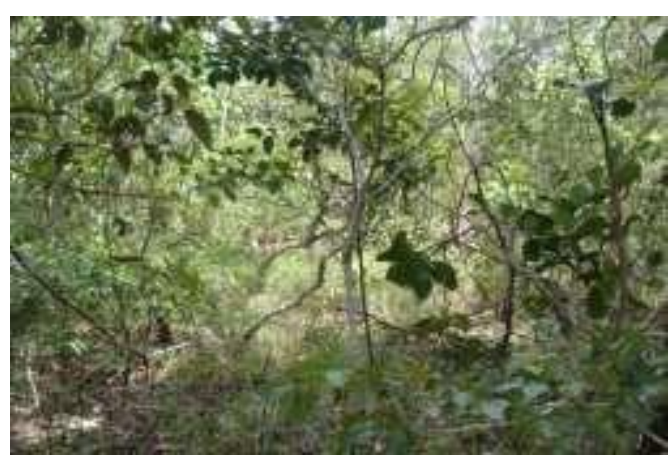

Ponto 102

Fitofisionomia: Cerrado típico Latitude: $13^{\circ} 10^{\prime} 02,5^{\prime \prime}$ Longitude: $50^{\circ} 04^{\prime} 48,0^{\prime \prime}$ Cor do solo: 7,5 YR 4/4

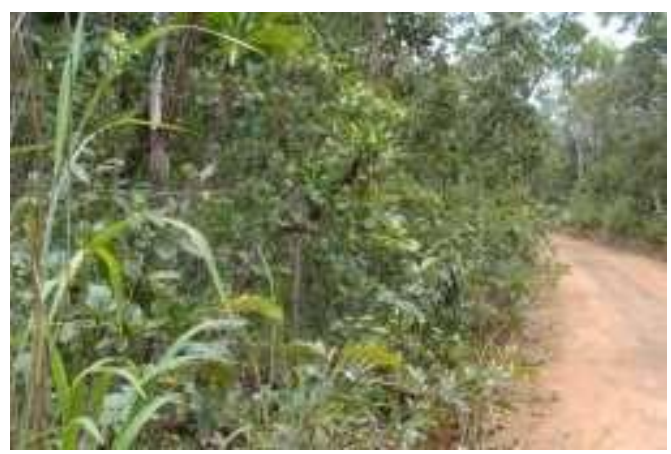

Ponto 104

Fitofisionomia: Cerrado típico

Latitude: $13^{\circ} 01^{\prime} 03,5^{\prime \prime}$ Longitude: $49^{\circ} 55^{\prime} 17,9^{\prime \prime}$ Cor do solo: 7,5 YR 4/4 


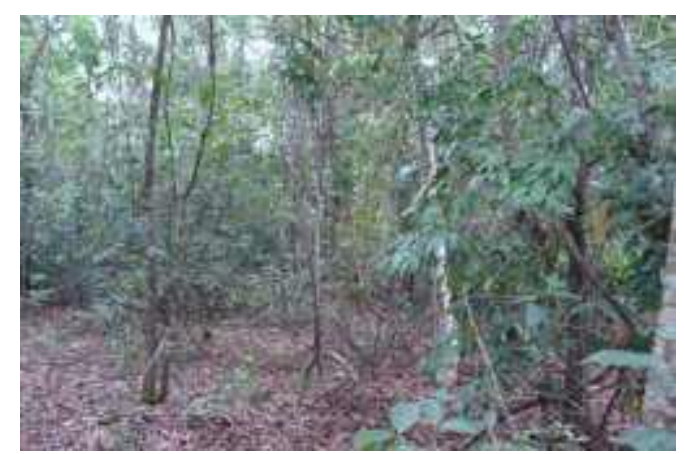

Ponto 105

Fitofisionomia: Cerradão Latitude: $13^{\circ} 22^{\prime} 31,9^{\prime \prime}$ Longitude: $50^{\circ} 13^{\prime} 46,3^{\prime \prime}$ Cor do solo: 10 YR $3 / 4$

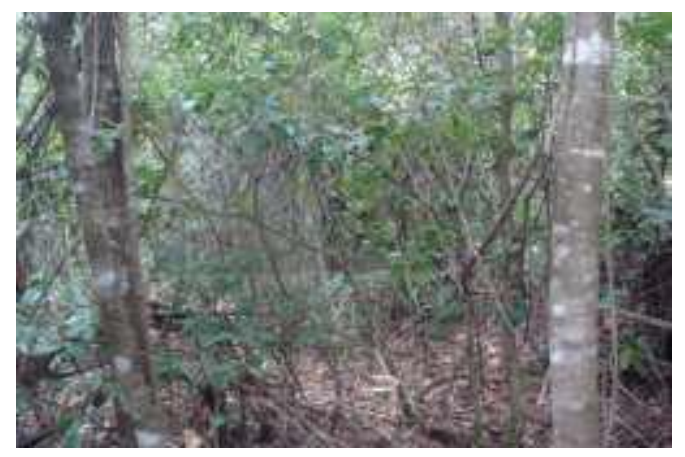

Ponto 107

Fitofisionomia: Cerradão Latitude: $13^{\circ} 17^{\prime} 53,7^{\prime \prime}$ Longitude: $50^{\circ} 19^{\prime} 22,1^{\prime \prime}$ Cor do solo: 10 YR 3/2

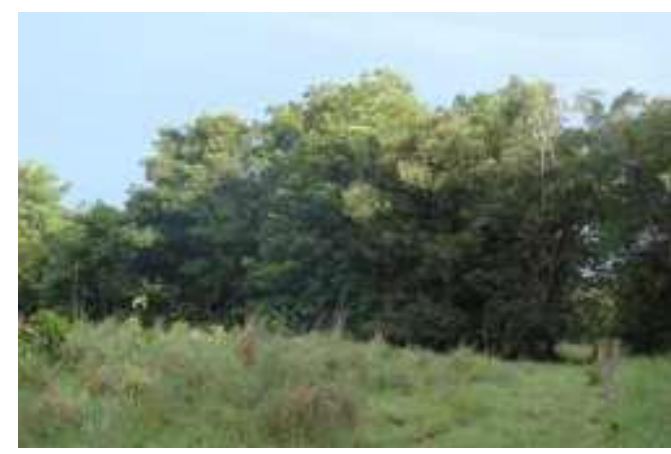

Ponto 109

Fitofisionomia: Cerradão Latitude: $13^{\circ} 17^{\prime} 28,6^{\prime \prime}$ Longitude: $50^{\circ} 25^{\prime} 54,1^{\prime \prime}$ Cor do solo: 10 YR 3/6

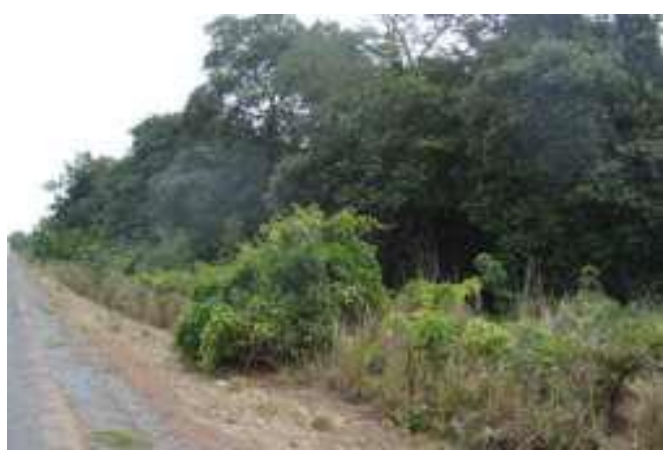

Ponto 106

Fitofisionomia: Cerradão Latitude: $13^{\circ} 28^{\prime} 34,4^{\prime \prime}$

Longitude: $50^{\circ} 18^{\prime} 27,7^{\prime \prime}$ Cor do solo: nd

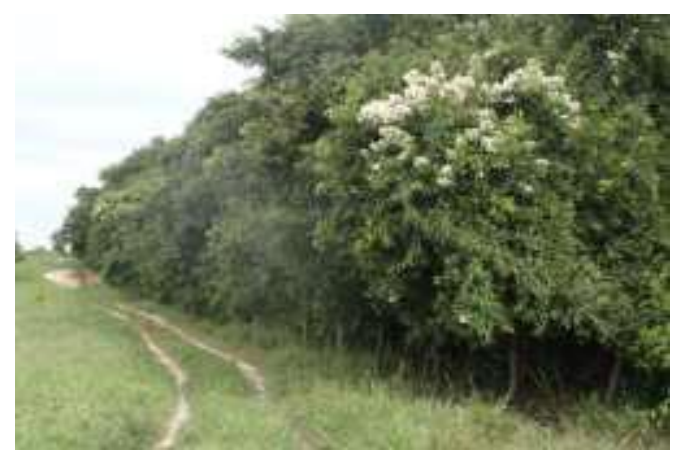

Ponto 108

Fitofisionomia: Cerradão Latitude: $13^{\circ} 21^{\prime} 35,7^{\prime \prime}$

Longitude: $50^{\circ} 24^{\prime} 16,1^{\prime \prime}$

Cor do solo: 5 YR 5/2

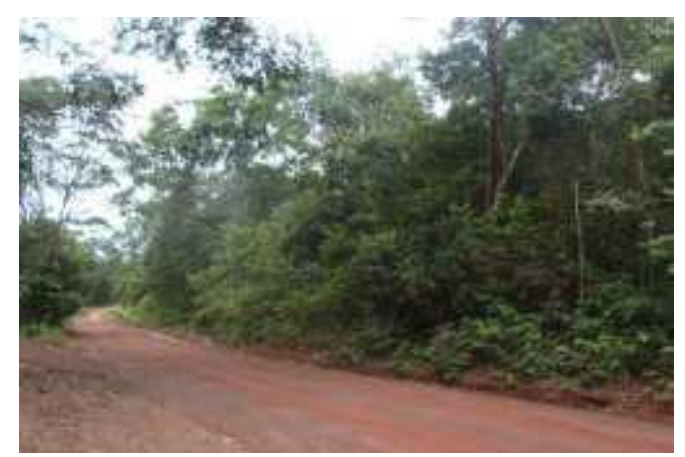

Ponto 110

Fitofisionomia: Floresta aluvial Latitude: $13^{\circ} 07^{\prime} 02,8^{\prime \prime}$ Longitude: $50^{\circ} 11^{\prime} 20,4^{\prime \prime}$ Cor do solo: 10 YR 4/4 


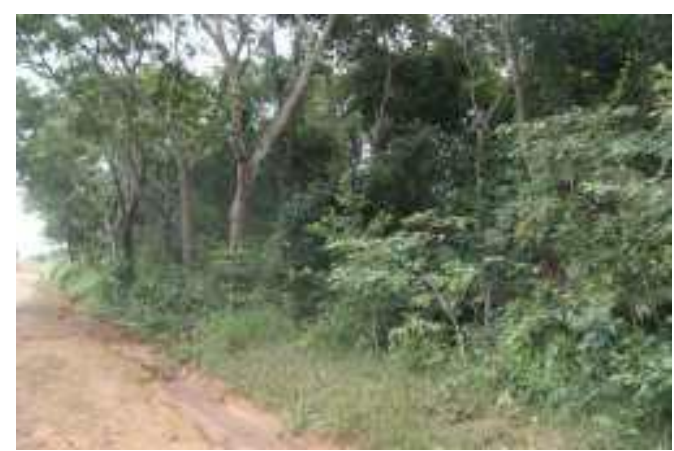

Ponto 111

Fitofisionomia: Floresta arbórea Latitude: $13^{\circ} 28^{\prime} 56,4^{\prime \prime}$ Longitude: $50^{\circ} 15^{\prime} 06,5^{\prime \prime}$ Cor do solo: 10 YR $3 / 3$

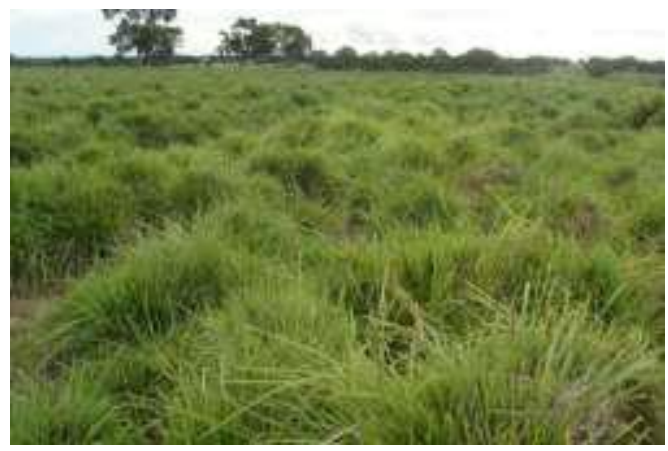

Ponto 113

Fitofisionomia: Pastagem Latitude: $13^{\circ} 15^{\prime} 46,7^{\prime \prime}$ Longitude: $50^{\circ} 03^{\prime} 38,9^{\prime \prime}$ Cor do solo: 7,5 YR 4/6

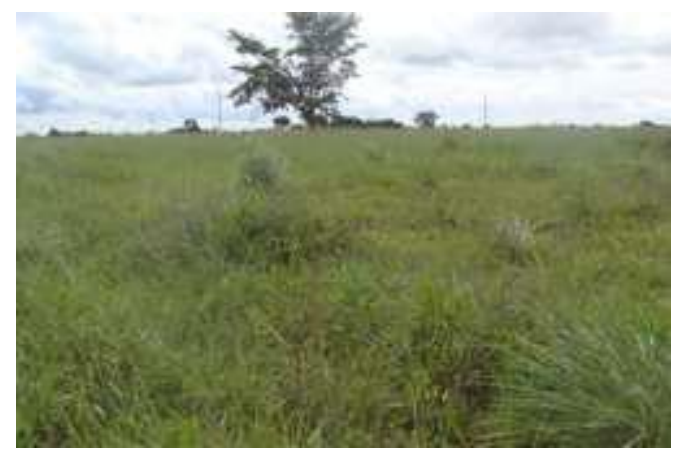

Ponto 115

Fitofisionomia: Pastagem Latitude: $13^{\circ} 15^{\prime} 40,7^{\prime \prime}$ Longitude: $49^{\circ} 51^{\prime} 53,1^{\prime \prime}$ Cor do solo: 10 YR 5/6

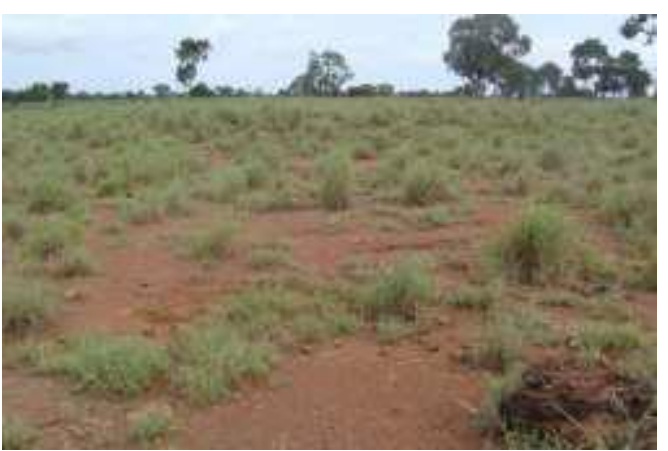

Ponto 112

Fitofisionomia: Pastagem Latitude: $13^{\circ} 16^{\prime} 01,9^{\prime \prime}$ Longitude: $49^{\circ} 56^{\prime} 20,4^{\prime \prime}$ Cor do solo: nd

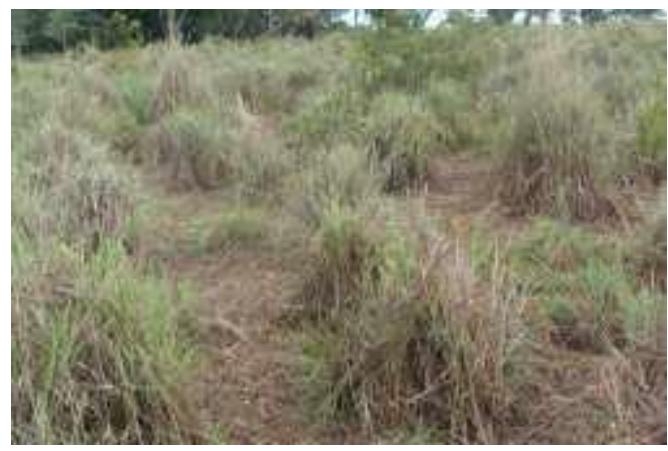

Ponto 114

Fitofisionomia: Pastagem Latitude: $13^{\circ} 15^{\prime} 58,4^{\prime \prime}$

Longitude: $50^{\circ} 30^{\prime} 44,6^{\prime \prime}$ Cor do solo: nd

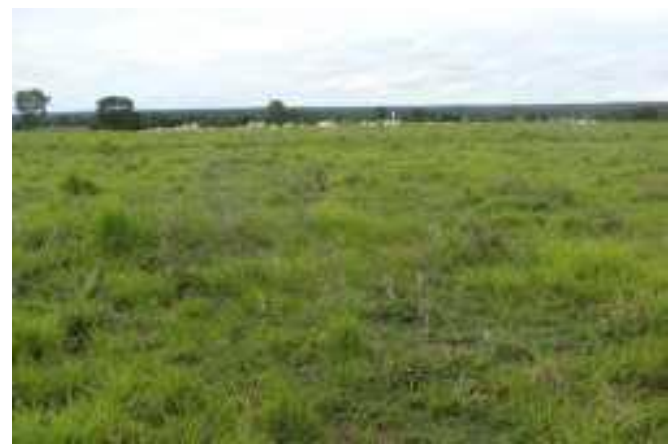

Ponto 116

Fitofisionomia: Pastagem Latitude: $13^{\circ} 15^{\prime}$ 51,9"

Longitude: $50^{\circ} 00^{\prime} 11,1$ "

Cor do solo: nd 


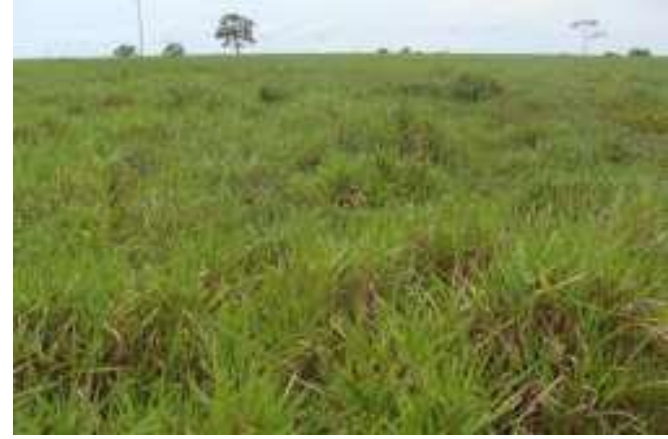

Ponto 117

Fitofisionomia: Pastagem

Latitude: $13^{\circ} 15^{\prime} 56,8^{\prime \prime}$

Longitude: $50^{\circ} 06^{\prime} 08,6^{\prime \prime}$

Cor do solo: 7,5 YR 5/4

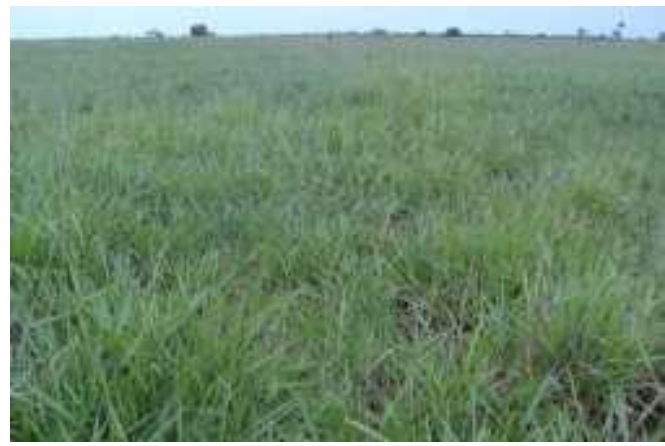

Ponto 119

Fitofisionomia: Pastagem

Latitude: $13^{\circ} 25^{\prime} 42,4^{\prime \prime}$

Longitude: $50^{\circ} 07^{\prime} 35,3^{\prime \prime}$

Cor do solo: 7,5 YR 5/4

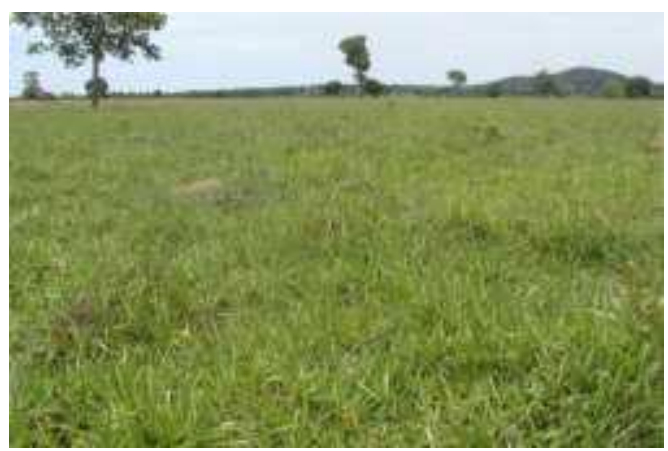

Ponto 121

Fitofisionomia: Pastagem

Latitude: $13^{\circ} 09^{\prime} 20,8^{\prime \prime}$

Longitude: $50^{\circ} 02$ ' 29,8"

Cor do solo: 10 YR 4/4

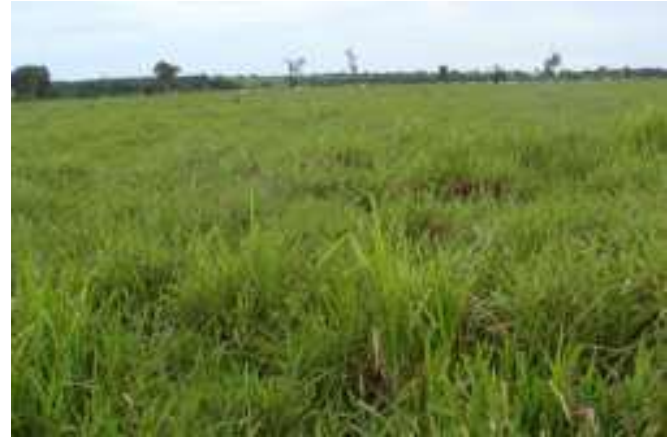

Ponto 118

Fitofisionomia: Pastagem

Latitude: $13^{\circ} 21^{\prime} 12,6^{\prime \prime}$

Longitude: $50^{\circ} 08^{\prime} 51,3^{\prime \prime}$

Cor do solo: 7,5 YR 4/4

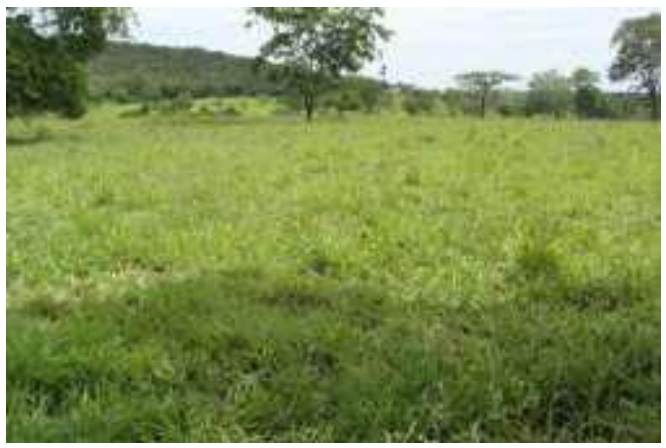

Ponto 120

Fitofisionomia: Pastagem

Latitude: $13^{\circ} 10^{\prime} 22,1^{\prime \prime}$

Longitude: $50^{\circ} 03^{\prime} 49,0^{\prime \prime}$

Cor do solo: 10 YR 3/6

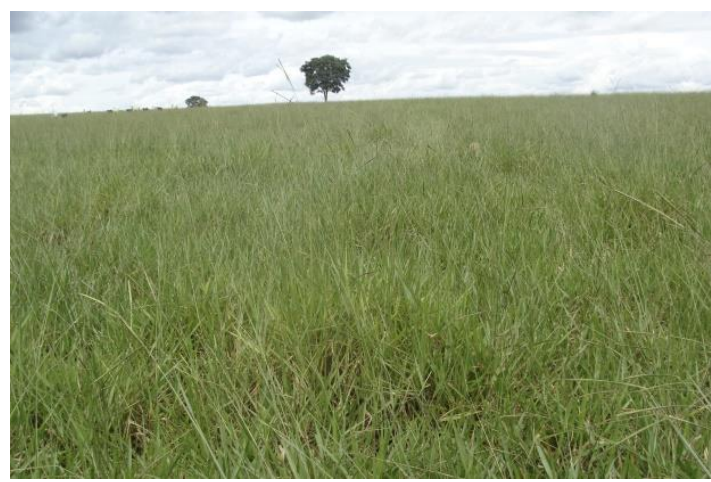

Ponto 122

Fitofisionomia: Pastagem

Latitude: $13^{\circ} 21^{\prime} 37,1^{\prime \prime}$

Longitude: $50^{\circ} 13^{\prime} 15,5^{\prime \prime}$

Cor do solo: 10 YR 4/6 


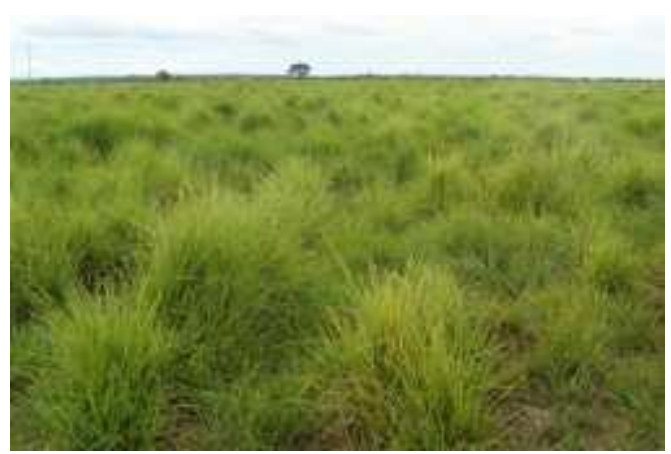

Ponto 123

Fitofisionomia: Pastagem Latitude: $13^{\circ} 27^{\prime} 16,4^{\prime \prime}$

Longitude: $50^{\circ} 17^{\prime}$ 59,8" Cor do solo: nd

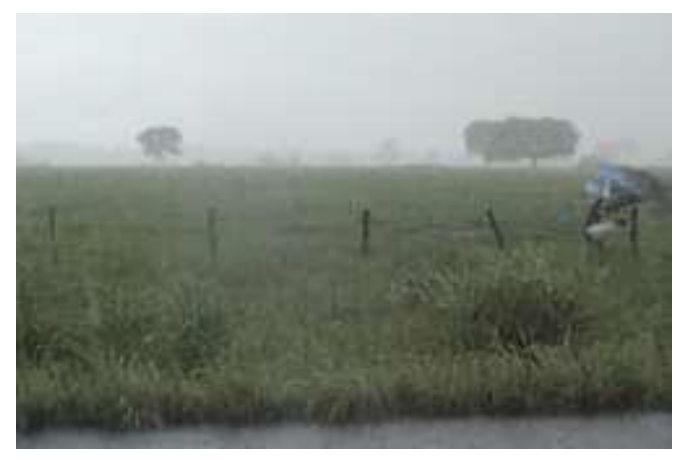

Ponto 125

Fitofisionomia: Pastagem

Latitude: $13^{\circ} 17^{\prime} 29,5^{\prime \prime}$

Longitude: $50^{\circ} 12^{\prime} 58,1^{\prime \prime}$

Cor do solo: 10 YR 5/3

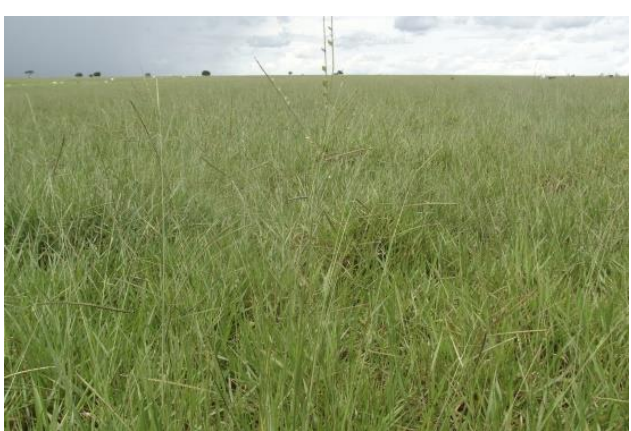

Ponto 124

Fitofisionomia: Pastagem

Latitude: $13^{\circ} 32$ ' 30,5"

Longitude: $50^{\circ} 18^{\prime} 24,4$ "

Cor do solo: 7,5 YR 4/1

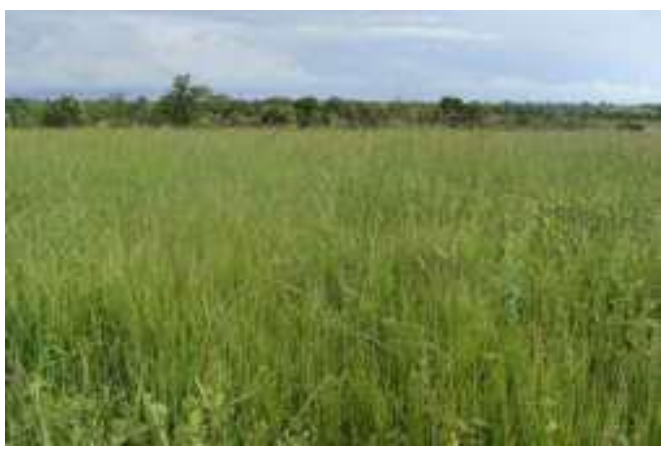

Ponto 126

Fitofisionomia: Pastagem

Latitude: $13^{\circ} 18^{\prime}$ 55,5"

Longitude: $50^{\circ} 22^{\prime} 49,2^{\prime \prime}$

Cor do solo: 10 YR 4/4

nd - não disponível 